\title{
Acreditação de Farmácias: a construção de um modelo
}

\author{
Rogério Renato Silva
}

Tese de Doutorado apresentada ao Departamento de Prática de Saúde Pública da Faculdade de Saúde Pública da Universidade de São Paulo para obtenção do grau de Doutor.

Orientador

Professor Doutor

Francisco Bernardini Tancredi

São Paulo

2003

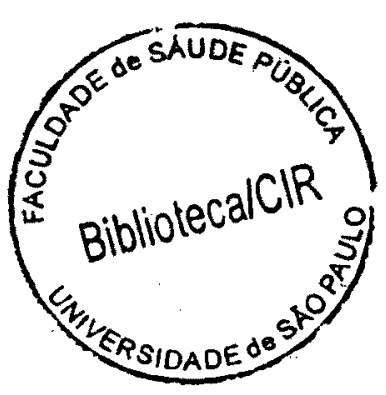


Autorizo, exclusivamente para fins acadêmicos e científicos, a reprodução total ou parcial desta tese, por processos fotocopiadores.

Maiores informações e outras mídias podem ser obtidas com o pesquisador: rogerio_rs@uol.com.br

Assinatura:

Data: 25 de setembro de 2003. 
Para

David Capistrano da Costa Filho 


\section{Agradecimentos}

- À Deise, pelo seu amor, carinho e cuidado. Pelo seu apoio e respeito a esta fase da minha vida. Pela compreensão diante de tantas horas de ausência nestes últimos meses e pelas leituras e correções da tese.

- Ao meu orientador, Professor Doutor Francisco Bernardini Tancredi, pela confiança e paciência ao longo destes quatro anos de trabalho. Pela relação especial que desenvolvemos desde os anos de mestrado e que hoje se estende a nossos caminhos profissionais.

- À Professora Doutora Ana Maria Malik, cuja companhia e ensinamentos desde nossos estudos em Michigan, em 1997, até os dias de hoje, muito me ajudaram. Também pelas oportunidades profissionais que tem me oferecido e por seu carinho.

- Ao Professor Doutor Oswaldo Yoshimi Tanaka, cuja sabedoria, paciência e habilidades de educador e de avaliador muito contribuem em meu desenvolvimento profissional. Também pelas contribuições metodológicas e pelo estímulo para terminar esta tese.

口 À Professora Doutora Fabíola Zioni, pelas excelentes contribuições a este trabalho e, sobretudo, pelo apoio a minha formação desde 1996, no curso de especialização, no mestrado e agora no doutorado.

- À Professora Doutora Nicolina Silvana Romano-Lieber, pelas contribuições a este trabalho desde a qualificação e por abrir a possibilidade de que a atenção farmacêutica encontre espaço nas linhas de pesquisa da FSP.

- Ao Professor Airton José Pétris, meu eterno Mestre, cuja cumplicidade, incentivo e apoio nestes tantos anos de graduação, especialização, mestrado e doutorado, tanta diferença fazem na minha vida.

- Aos farmacêuticos, balconistas, gerentes, sub-gerentes e proprietários das farmácias estudadas, cujas reflexões foram fundamentais a este trabalho.

․ Aos consumidores participantes dos grupos focais, que tantas informações preciosas trouxeram a este trabalho. 
- Aos colegas da Associação de Farmacêuticos de Londrina, que por duas ocasiões se prontificaram a colaborar com esta pesquisa.

- À Poliana Vieira, cuja colaboração foi determinante para a realização dos estudos de caso.

口 Ao Jean e à Samantha, pelas entrevistas com os consumidores.

口 À Tabata Reis, pelo excelente trabalho de transcrição das entrevistas.

口 À Márcia e à Renilda, da CPG, pelo interesse e cuidado.

- À Vera Eterovic e à Maria Lúcia, pela excelente revisão das referências.

- Aos meus companheiros do Instituto Fonte, pela confiança e paciência em minhas ausências. Em especial ao Daniel Brandão, pela sabedoria, lealdade, sensibilidade e companheirismo.

- Ao colega Carlos Alberto Pereira Gomes e sua equipe, pela ideologia e pelo compromisso que compartilhamos ao longo dos trabalhos no Ministério da Saúde.

- Aos amigos Aline e Alberi, em Porto Alegre e à Cláuda, em Santa Maria, com quem pude contar em momentos importantes da minha vida.

- Ao Professor Cassyano Correr e a Gladys Marques, assessora do Centro de Informaçōes sobre Medicamentos do Conselho Regional de Farmácia do Paraná, pelas contribuições ao trabalho.

- A Fábio Gastal, da Organização Nacional de Acreditação, pelo diálogo que tivemos em relação ao modelo de acreditação aqui proposto.

- À Laura Feuerwerker, pelo incentivo, colaboração e pelas oportunidades a mim oferecidas ao longo de minha vida profissional.

- Ao amigo Thomaz Chianca, pelo apoio, oportunidades e ensinamentos.

- Aos meus familiares, sobretudo meu Pai, em quem me fortaleço para seguir meu caminho pela vida. Especialmente a minha irmã Vanessa, que transcreveu seis longas entrevistas.

․ Aos companheiros da Rede Brasileira de Avaliação, pelo apoio. 
口 A Fiodór Dostoiévski, por ter me oferecido a chance de mergulhar em outros mundos, por compartilhar a amargura de tantas horas no subsolo.

口 Aos especialistas, sujeitos essenciais na construção desta tese, pelas provocações, críticas, elogios e, sobretudo, pelo apoio incondicional.

\section{Dr. Humberto de Moraes Novaes}

Médico. Doutor em Saúde Pública e Livre Docente da Faculdade de Saúde Pública (FSP) da Universidade de São Paulo (USP). Supervisor do Programa de Administração de Sistemas de Saúde e Hospitalares da Organização Pan-americana de Saúde - OPAS em WDC.

\section{Dra. Lia Lusitana Cardozo de Castro}

Farmacêutica. Doutora em Saúde Püblica pela FSP/USP. Professora do Programa de PósGraduação em Ciências da Saúde da Universidade Nacional de Brasilia (UNB), na área de Farmacoepidemiologia. Coordenadora do Grupo de Pesquisa em uso Racional de Medicamentos - GRUPURAM.

\section{Dra. Vânia dos Santos}

Farmacêutica. Doutora em Saúde Pública pela FSP/USP. Professora do Departamento de Analises Clinicas, Bromatológicas e Toxicológicas da Faculdade de Ciências Farmacêuticas de Ribeirăo Preto - USP. Presidente do Núcleo de Assistência Famacêutica e Conselheira do Conselho Regional de Farmácia de São Paulo.

\section{Dr. Paulo Eduardo Mayorga}

Farmacêutico. Doutor em Ciências Farmacêuticas pela Universidade de Paris. Professor do Departamento de Produção e Controle de Medicamentos da Faculdade de Farmácia da Universidade Federal do Rio Grande do SUl - UFRGS.

\section{Dra. Gabriela Bittencourt Gonzalez Mosegui}

Farmacêutica. Doutora em Saúde Coletiva pela Universidade do Estado do Rio de Janeiro. Coordenadora do Curso de Farmácia da Universidade Estácio de Sá - UNESA - RJ.

\section{Dra. Adriana Mitsue Ivama}

Farmacêutica. Doutora em Farmácia pela Universidade de Alcalá. Profissional Nacional da Coordenação de Medicamentos e Tecnologias, OPAS/OMS - Brasil.

\section{Dr. Francisco José Pacheco dos Santos}

Farmacêutico. Doutor em Saúde Coletiva pela Universidade Federal da Bahia - UFBA. Professor e preceptor da residência em saúde da familia no Instituto de Saúde Coletiva da UFBA. Professor da Faculdade de Ciência e Tecnologia - FTC - Salvador - BA. 


\section{Micheline Marie Milward de Azevedo Meiners}

Farmacéutica. Mestre em Farmacologia pela Universidade Estadual de Campinas UNICAMP. Assessora Técnica na Unidade de Doenças Não Transmissiveis da OPAS em WDC. Aluna de Mestrado em Atenção Farmacêutica na Universidade de Granada - Espanha.

\section{Airton José Pétris}

Farmacêutico. Mestre em Saúde Pública pela UEL. Professor do Centro de Ciências da Saúde da UEL. Professor da Universidade do Norte do Paraná. Ex-presidente do Conselho Regional de Farmácia do Paraná e ex-diretor do Sindicato dos Farmacêuticos do Paraná.

\section{Augusto Afonso Guerra Júnior}

Farmacêutico. Mestre em Ciências Farmacêuticas pela Universidade Federal de Minas Gerais - UFMG. Professor do Centro Universitário Newton Paiva, Belo Horizonte - MG. Diretor técnico da Farmácia Apotek.

\section{Emilia Vitória Silva}

Farmacêutica. Mestre em Ciências da Saúde pela UNB. Assessora técnica do Centro Brasileiro de Informações sobre medicamentos do Conselho Federal de Farmácia - CEBRIM.

\section{Verlanda Lima Bontempo}

Farmacêutica. Especialista em Saúde Pública com área de concentração em medicamentos pela UFMG. Professora do Curso de Farmácia do Centro Universitário Newton Paiva, Belo Horizonte - MG.

\section{Josélia Cintya Quintão Pena Frade}

Farmacêutica. Especialista em Saúde Pública com concentração em medicamentos pela Escola de Farmácia da UFMG. Possui ampla experiência nacional e internacional no estudo e na organização de sistemas públicos e privados de assistência e atenção farmacêutica.

\section{José Renato Dias da Silva}

Farmacêutico. Diretor Técnico da Farmácia Companhia da Saúde. Ex-presidente da Associação de Farmacêuticos de Londrina.

\section{Wellington dos Santos}

Farmacêutico. Especialista em Imunologia Clínica pelo HSPE/SP. Consultor para programas de atenção farmacêutica. Atuou na estruturação da Rede de Farmácias Farmais em São Paulo.

\section{Paula Rossignoli}

Farmacêutica. Diretora Técnica da Farmácia Escola da UNICENP - PR. Aprimorou-se em atenção farmacêutica por meio de estudos e trabalhos em Portugal. 


\section{Resumo}

Silva RR. Acreditação de farmácias: a construção de um modelo. São Paulo; 2003. [Tese de Doutorado - Faculdade de Saúde Pública da Universidade de São Paulo].

Em uma sociedade em que os medicamentos são utilizados irracionalmente, em que são frágeis a organização das farmácias, a legislação sanitária e a educação farmacêutica, é importante que novos modelos de atenção sejam propostos e analisados, a fim de se constituirem em alternativas de mudança. Este estudo buscou construir um modelo de acreditação para farmácias com foco na atenção farmacêutica. Dezesseis especialistas foram envolvidos em um método não presencial de formação de consenso, que resultou na criação de um modelo de acreditação contendo vinte e oito padrões de qualidade a partir dos quais as farmácias podem ser classificadas em niveis $A$ e $B$. $O$ modelo elaborado envolve aspectos de estrutura, como as condições físicas e equipamentos, responsabilidade técnica, normas e procedimentos, registros de informações dos consumidores e responsabilidade ambiental; processos, como dispensação de medicamentos, acompanhamento farmacoterapêutico, realização de procedimentos sanitários, relacionamento com outros profissionais de saúde e ações de ampliação da adesão terapêutica; e resultados, como a identificação de problemas relacionados a medicamentos, acompanhamento de parâmetros fisiológicos e bioquímicos, satisfação dos consumidores, promoção da saúde e farmacovigilância. Dois estudos de caso foram realizados em farmácias na cidade de Londrina, nos quais farmacêuticos, balconistas, proprietários, consumidores e a associação de farmacêuticos local foram entrevistados revelando: (a) a importância do modelo proposto e as oportunidades para sua implementação; (b) as dificuldades de adaptação das farmácias aos padrões de qualidade presentes no modelo; (c) a necessidade que os processos de mudança sejam acompanhados de ações sensiveis de construção de sujeitos. 


\section{Summary}

Silva RR. Accreditation in Pharmacies: the construction of a model. São Paulo; 2003. [Doctoral thesis - Faculty of Public Health of the São Paulo University].

In a society where medicines are irrationally used, where the organization of pharmacies, health legislation and pharmaceutical education are weak, and where there are opportunities for change, the creation of organization models and the stimulation of debates become important. This study aimed at the construction of a accreditation model for pharmacies based on the pharmaceutical care concept. Sixteen specialists were involved in a method of non-presential consensus groups, which led to the creation of the accreditation model. It offers 28 quality patterns and classifies pharmacies as levels A or B based on these patterns. The model approaches aspects related to structure, such as physical conditions and equipment, technical responsibility, norms and procedures, consumers' information records and environmental responsibility; processes, such as medicines disposal, pharmacotherapeutic follow-up, execution of health procedures, relationship with other health professionals and actions to increase the adhesion to therapy; and results, such as the identification of medicine-related problems, monitoring of physiological and biochemical parameters, customer satisfaction, health promotion and pharmaceutical surveillance. Two case studies were also carried out in pharmacies in the city of Londrina, where pharmacists, attendants, proprietors, customers and the local Pharmacists' Association were interviewed revealing: (a) the importance of the model proposed and the opportunities for its implementation; (b) the pharmacies' difficulties to adapt to the quality standards and (c) the need for the organizational changes to be followed by sensitive subject-building actions. 


\section{İndice}

1. INTRODUÇÃO

1.1. Serviços de saúde: onde vive a mudança? ................................................. 18

1.2. Como fazer melhor? A busca por qualidade em saúde. ................................ 27

1.3. Qualidade em saúde: por que utilizamos padrões? ....................................... 37

1.4. Atenção Farmacêutica: a reinvenção da práxis profissional ............................56

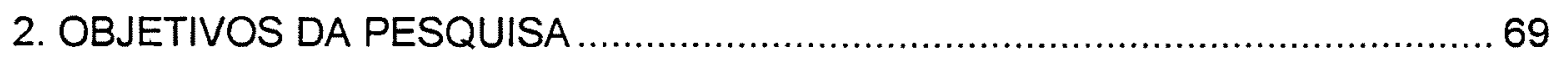

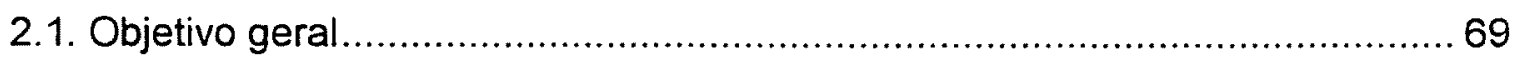

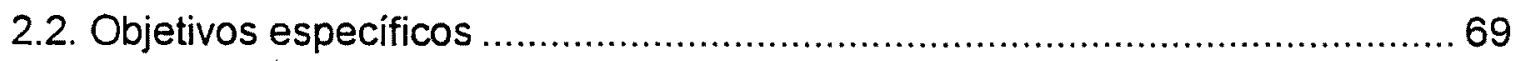

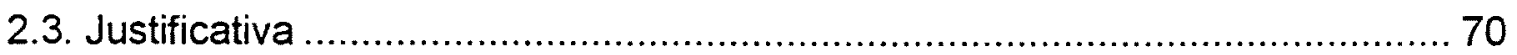

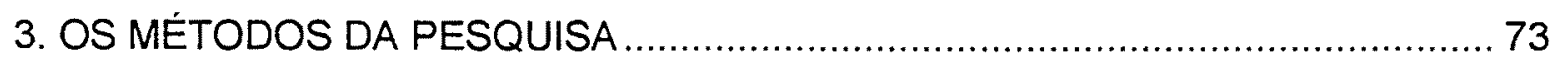

3.1. Reflexões sobre a relação pesquisador - objeto........................................... 73

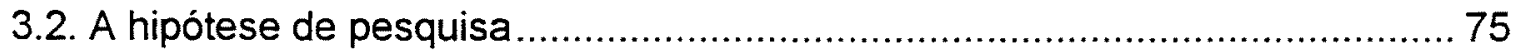

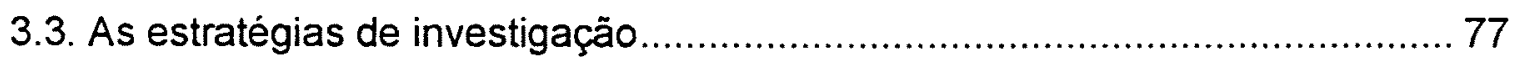

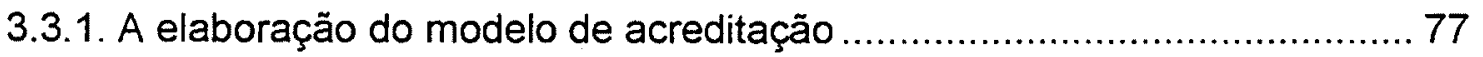

3.3.1.1. A técnica de formação de consenso ................................................. 78

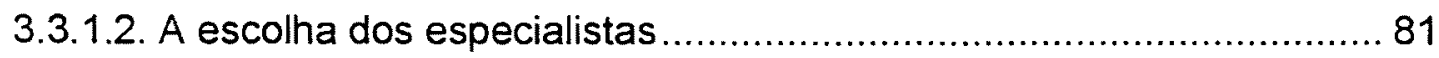

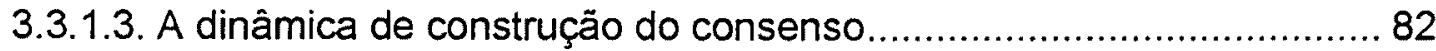

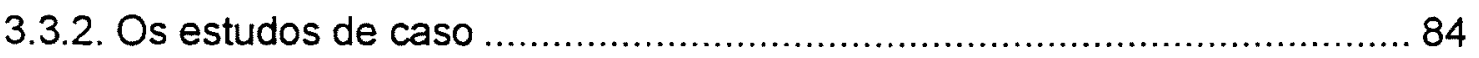

3.3.2.1. A escolha dos casos: as farmácias em Londrina ............................. 87

3.3.2.2. As dimensões exploradas nos estudos de caso................................ 91

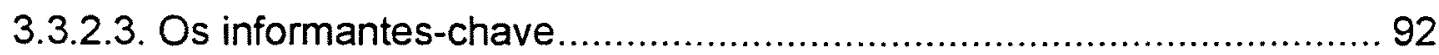

3.3.2.4. Formas de coleta de informação....................................................... 94

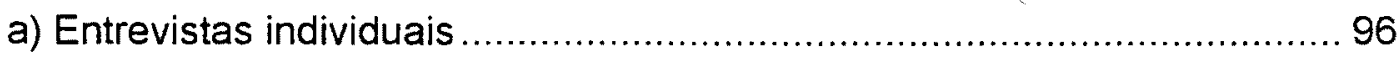

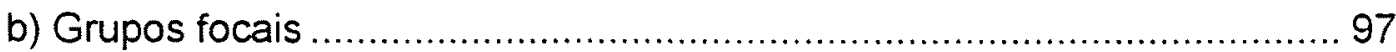

3.3.2.5. A forma de analisar as informações ............................................. 102

4. RESULTADOS

4.1. Um modelo para acreditar farmácias...................................................... 104

4.1.1. Modelo de acreditação de farmácias..................................................... 105 
III. Dos principios que regem a proposta ............................................. 106

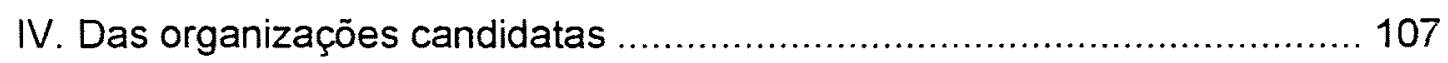

V. Da organização acreditadora ..................................................... 108

VI. Do processo de acreditação..................................................... 108

a) da periodicidade do processo e manutenção do certificado .................. 108

b) da classificação das farmácias...................................................... 109

c) do sigilo do processo e da divulgação dos resultados ......................... 109

d) da suspensão do certificado de acreditação................................... 110

Vil. Áreas e padrões de avaliação .................................................. 110

a) Seção 1. Estrutura .................................................................... 110

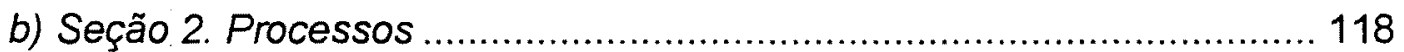

c) Seção 3. Resultados .............................................................. 125

4.2. Elementos dos estudos de caso..................................................... 128

4.2.1. Qual é o papel da farmácia? .................................................. 128

4.2.2. Qual é o papel do farmacêutico? ................................................ 134

4.2.3. Qual é o papel dos balconistas? ................................................. 143

4.2.4. O que percebem os consumidores?............................................ 153

4.2.5. O sentido do modelo de acreditação........................................... 160

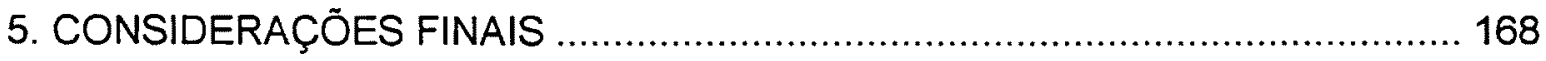

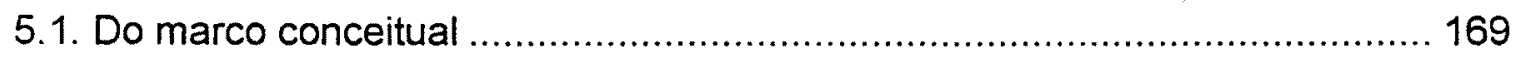

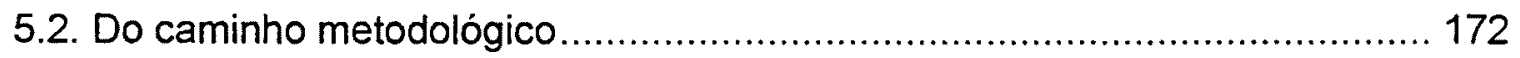

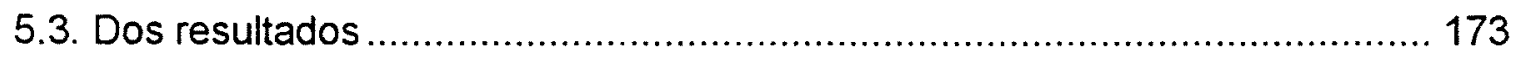

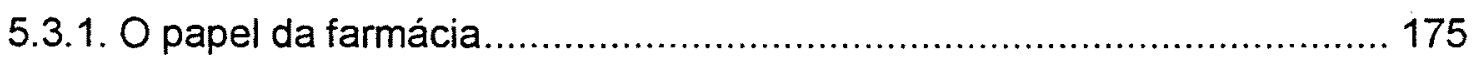

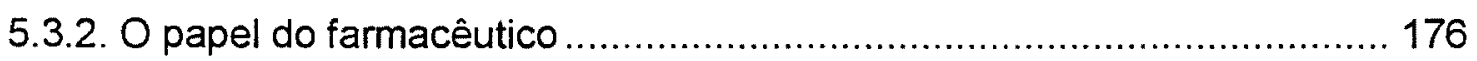

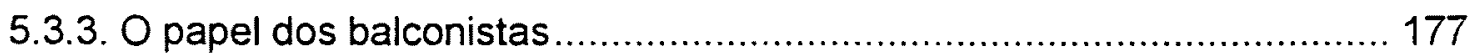

5.3.4. Percepções dos consumidores ........................................... 178

5.3.5. O sentido do modelo de acreditação ............................................ 178

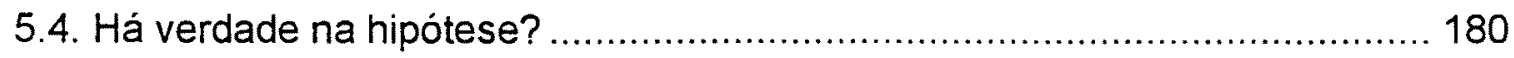

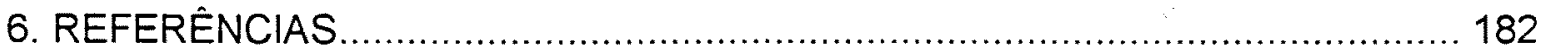

ANEXOS 


\section{Lista de Tabelas}

Tabela 1 Distribuição dos funcionários que trabalham nas farmácias.

Tabela 2 Volume de faturamento ao longo de 2001, em Reais.

Tabela 3 Origem do faturamento em percentual.

Tabela 4 Distribuição dos informantes-chave segundo técnicas e casos de estudo.

Tabela 5 Distribuição dos consumidores segundo faixa etária.

Tabela 6 Distribuição dos consumidores segundo o sexo.

Tabela 7 Distribuição dos consumidores segundo renda familiar.

Tabela 8 Distribuição dos consumidores segundo escolaridade.

Tabela 9 Distribuição dos consumidores segundo freqüência de visita à farmácia.

Tabela 10 Distribuição dos consumidores segundo uso contínuo de medicamentos.

Tabela 11 Distribuição dos consumidores que fazem uso contínuo de medicamentos segundo classe terapêutica.

\section{Lista de Figuras}

Figura 1 Taxonomia dos métodos para medir qualidade em saúde.

Figura 2 A linha metodológica da pesquisa.

Figura 3 Os temas e as categorias de análise. 


\section{Lista de Anexos}

Anexo 1 Termo de cooperação entre pesquisador e farmácia i

Anexo 2 Consentimento informado para entrevistas individuais. ii

Anexo 3 Roteiro de diagnóstico para as farmácias. iii

Anexo 4 Questionário para entrevista de consumidores. vii

Anexo 5, Procedimentos do trabalho de campo. viii

Anexo 6 Ficha de registro de negativas. xiii

Anexo 7 Consentimento informado para entrevistas em grupo focal. xiv

Anexo 8 Roteiro de entrevista com balconistas. XV

Anexo 9 Roteiro de entrevista com gerentes e sub-gerentes. xvi

Anexo 10 Roteiro de entrevista com farmacêuticos. xvii

Anexo 11 Roteiro de entrevista com a Associação dos Farmacêuticos. xviii

Anexo 12 Roteiro de grupo focal com consumidores. xix

Anexo 13 Carta de agradecimento para participantes nos grupos focais. $\quad$ xxi

Anexo 14 Roteiro de entrevista com proprietário da rede de farmácias. xxii

Anexo 15 Primeiro documento de trabalho com os especialistas. xxiii

Anexo 16 Segundo documento de trabalho com os especialistas. XV

Anexo 17 Convite aos especialistas. $\quad x x x$ 
Perguntas em forma de cavalo-marinho

Que metro serve para medir-nos?

Que forma é nossa o que é conteúdo?

Contemos algo? Somos contidos? Dão-nos um nome?

Estamos vivos?

A que aspiramos?

Que possuimos?

Que relembramos?

Onde jazemos?

(Nunca se finda nem se criara.

Mistério é o tempo, inigualável.) ${ }^{1}$

Carlos Drumond de Andrade

${ }^{1}$ Do livro Claro Enigma, publicado em 1951. 


\section{INTRODUÇÃO}

"Mas acontece que não posso me furtar,

a lhe contar as novidades"

Chico Buarque ${ }^{2}$

Este é um objeto histórico. Um objeto por isso mesmo imerso em seu contexto histórico e, em conseqüência, mergulhado na política de seu tempo, na ciência de seu tempo, em seus paradigmas, seus desafios e incertezas e sobretudo, inseparável da historicidade do pesquisador. Por ser também reflexo de uma consciência histórica, a ele está associada a condição natural de portar dúvidas. Afinal, como argumenta MORIN (2001), "o jogo da ciência não é o da posse e do alargamento da verdade, mas aquele em que o combate pela verdade se confunde com a luta contra o erro".

Em razão deste trabalho não ser um objeto dogmático ou doutrinário, nele está implicita a possibilidade dialética de sua falsidade, uma das essências da pesquisa qualitativa contemporânea. Por isso, aqueles que o estudarem estão convidados a separar o julgamento que farão de seu instrumental cientifico, daquele que farão da hipótese de pesquisa e da leitura do mundo que se apresenta a cada porção da tese. É bem possivel que opiniões diferentes e mesmo contraditórias coexistam, sobretudo para aqueles sujeitos sociais também históricos, cujas idéias e hipóteses sejam de outra natureza. A partir deste diálogo criar-se-á o novo.

A intrínseca possibilidade da falsidade não deve, contudo, ser confundida com irresponsabilidade científica. Ao contrário, esta responsabilidade é aqui compreendida como noção humanista ética de um pesquisador sujeito e consciente da noção da incerteza que, segundo MORIN (2001), é parte integrante desta responsabilidade.

\footnotetext{
2 Da música "Meu caro amigo", de Chico Buarque e Francis Hime, de 1976.
} 
A intenção é dizer que não são apenas as boas intenções adjacentes ao trabalho que configuram a responsabilidade do pesquisador, tampouco a busca por fundamentos conceituais, metodológicos e empíricos na realização do trabalho. Trata-se de uma associação entre estes elementos, equilibrada pela noção de que a verdade não é um valor absoluto.

A noção de responsabilidade se explicita também ao se admitir aqui a relação biográfica do pesquisador com o objeto, elemento que marca este trabalho. Neste sentido, como afirma MILLS (1975) no texto em que trata da "imaginação sociológica", este trabalho tem implicita a premissa que um individuo só pode compreender sua própria experiência ao localizar-se dentro de seu tempo. Só pode conhecer suas possibilidades ao tornar-se também consciente das possibilidades dos demais individuos nas mesmas circunstâncias que ele; ao compartilhar os sonhos, a força e os limites de sua geração.

Esta relação biográfica fundamenta também uma importante concepção a partir da qual este trabalho está estruturado: a de que o objeto de estudo da saúde coletiva é um objeto histórico e, nas palavras de MINAYO (1994), dotado de consciência histórica. Assim parece ser a produção teórica no campo da saúde coletiva. Precisa conhecer criticamente a formação histórica dos sujeitos e das práticas de seu campo de interesse, para seguir seu caminho de desenvolvimento e realizar suas metamorfoses.

Além disso, ainda que CHASIN (1987) afirme que da "morte de Marx aos dias atuais verte um século de inaudita complexificação: do homem, da sociedade e da história", o materialismo dialético que tanto influenciou a reforma sanitária brasileira, cumpre ainda um papel de grande importância na compreensão do objeto da saúde coletiva. Não com ares de dogmatismo, ou marcado pela visão cristalizada da luta entre o bem e o mal em uma sociedade que historicamente reproduz sua estrutura de classes. Mas sim com base na vontade de compreender as forças históricas que influenciam ou determinam o curso da sociedade, bem como da própria história. 
Lançando mão do argumento tão bem formulado por GRAMSCI (1995), a respeito de qual posição se quer ocupar em um cenário de investigação, pergunta-se: é possivel fazer ciência sem fazer escolhas ideológicas?

"É preferivel pensar sem disto ter consciência critica, de uma maneira segregada e ocasional, isto é, participar de uma concepção do mundo imposta mecanicamente pelo ambiente exterior (....) ou é preferivel elaborar a própria concepção do mundo de uma maneira critica e consciente e, portanto, em ligação com este trabalho do próprio cérebro, escolher a própria esfera de atividade, participar ativamente na produção da história do mundo, ser o guia de si mesmo e não aceitar do exterior, passiva e servilmente, a marca da própria personalidade?" (GRAMSCI 1995, p. 12).

Este trabalho quer significar uma resposta. Não uma resposta sobre a verdade da hipótese que o motiva, mas sim a respeito de qual posição se quer ocupar no mundo da investigação científica e da produção de conhecimentos. Por esta razão, a construção do trabalho se deu com base em questões essenciais à história do tema: analisou-se a mudança organizacional na perspectiva da construçāo de sujeitos, a história da qualidade relacionada à complexificação moderna do aparato médicohospitalar, o mercado farmacêutico ancorado no medicamento como mercadoria simbólica e por fim, a importância do método qualitativo na investigaçāo do objeto da saúde coletiva.

Assumir uma posição critica neste debate, apresentando, em cada um destes eixos, análises particulares das forças que historicamente têm determinado o uso irracional de medicamentos no Brasil é, aos olhos do pesquisador, condição necessária para que esta pesquisa possa ser identificada no campo da construção da saúde coletiva. 
Todavia, não é preciso alimentar ilusões. $O$ trabalho que ora se desenha e se define como inédito, desafiador e por isso mesmo angustiante e provocador, provavelmente virá a assumir um lugar igual entre outros tantos trabalhos iguais, dissolvendo-se nas caracteristicas gerais do conhecimento que se produz nesta época. Esta, aliás, parece ser a ordem natural da vida dos objetos. Que assim seja.

Contudo, a história de sua construção e suas implicações no campo da revisão bibliográfica, na descoberta das técnicas e métodos, nas interações sociais ao longo desta trajetória e na riqueza presente na geração de idéias, perguntas e hipóteses, tiveram um impacto de beleza e importância sem precedentes na vida do pesquisador.

Para aqueles que entendem que o objetivo de um programa de doutorado é preparar o pesquisador para enfrentar a arte de descobrir o mundo, alimentando seu espírito de investigação e lançando-o ainda mais fundo na aventura da busca e da descoberta, aí incluindo a revisão de sua própria existência, os esforços destes quatro anos de trabalho, aqui depositados em forma de extensas notas, valeram a pena.

E por falar em relação biográfica, é preciso encerrar com poesia esta porção de primeiras páginas. A adaptação do trecho final de um poema escrito em 1999, muito revela a respeito desta incomparável fase da vida.

"...Me percebo aos pedaços.

Um pedaço palavras,

um pedaço silêncio.

Um pedaço já foi,

um pedaço tem o pé na estrada,

um pedaço que não pode ficar.

Sou um pedaço maior,

em essência, na alma -

Sim! Um pedaço perdido,

mas um pedaço melhor,

um pedaço que tenho que voltar a encontrar..." 


\subsection{Serviços de saúde: onde vive a mudança?}

Por todas as partes, em todos os tempos, os sistemas de saúde têm experimentado diversas formas de mudança nos mais variados graus de intensidade. Por razões tão diferentes como as alterações na dinâmica populacional, as limitações de financiamento, a incorporação de novas tecnologias, a ampliação do controle social e da participação popular e, sobretudo, pela incorporação de direitos humanos nas formas de legislar e organizar os serviços de saúde, nenhuma época da história foi palco de tantas mudanças sanitárias como estes tempos contemporâneos.

No plano global, as mudanças podem ser percebidas ao se verificar alterações significativas em alguns indicadores clássicos de saúde. O declínio da taxa de mortalidade infantil, a ampliação da expectativa de vida, o declínio nos índices de natalidade e a marcante transição epidemiológica evidenciada pelas alterações na mortalidade proporcional em todas as regiões (WHO 1999) são evidências deste fenômeno. Além disso, as mudanças na área da educação de profissionais de saúde e os esforços que caracterizam o movimento pela qualidade em saúde são também fenômenos que ilustram esta época de transformações.

No cenário brasileiro, ao qual se relaciona este trabalho, as transformações mais recentes, sobretudo a partir da retomada do regime democrático, foram também muito significativas. Se por um lado é possivel reconhecer resultados sólidos nos indicadores clássicos de saúde, como o declínio da taxa de mortalidade infantil e a ampliação da expectativa de vida, por outro são visiveis os avanços na implementação do Sistema Único de Saúde, cujas doutrinas e principios - universalidade, equidade, integralidade, participação popular, municipalização, entre outros - têm servido de modelo para outras sociedades e resistido à reforma liberal do setor saúde empreendida ao longo dos últimos anos.

Para que se possa compreender e iniciar processos de mudança é preciso fazer escolhas. Mudança de quem? Mudança de onde para onde? 
Mudança com base em que? Se perguntas simples costumam fazer diferença para os interlocutores e provocá-los a refletir e a escolher, estas perguntas são fundamentais para que se possa explicitar as concepções sobre mudança que compõem este trabalho.

Considerando algumas idéias de CAMPOS (1997), no texto "Considerações sobre a arte e a ciência da mudança: revolução das coisas e reforma das pessoas. O caso da saúde", pretende-se, neste texto, fazer saber que não se pode falar em mudança sem falar em sujeitos. Conforme argumenta o autor, não se pode falar em mudança sem que exista ações conscientes que procurem articular 0 apoio de movimentos multicêntricos de pessoas que questionem sistematicamente o exercício de micropoderes e da micropolítica nas instituições de produção de bens e serviços, sejam elas da administração pública, de ensino, de representação política ou mesmo organizações religiosas.

Ainda segundo CAMPOS (1997), a construção de caminhos de mudança em saúde se dá também pela construção de novos conhecimentos, pela experimentação de novas formas de dirigir organizações de saúde, superando os eixos das escolas de administração que buscam, de diferentes maneiras, "reduzir sujeitos humanos à condição de instrumentos dóceis aos objetivos da empresa, transformando-os em insumos ou objetos".

O autor relaciona a estas reflexões a necessidade de construir um saber crítico que negue o determinismo absoluto do geral sobre o particular, do econômico e do político sobre as instituições e a hegemonia destas instituições sobre as pessoas e os grupos sociais. Na dialética que tão bem ajuda a compreender o jogo da dominação e da submissão entre organizações e indivíduos, pensar a mudança implica em inverter a correlação de forças: fazer a hegemonia do que é humano sobre o que é mecânico.

Considerando as afirmaçōes de CAMPOS (1997), a discussão dos processos de mudança organizacional, neles incluindo a busca por serviços de qualidade, encontrará sentido e sustentação somente a partir da criação de movimentos que busquem uma autêntica construção de sujeitos. Este retorno 
dos indivíduos à sociedade, esta (re)acomodação de cada um diante da totalidade hegemônica, encontra no conceito da individualização um sentido simbólico importante. Individualização aqui compreendida a partir das concepções apresentadas por BECK (1997).

"Individualização não significa atomização, isolamento, solidão
- o fim de todos os tipos de sociedade - ou desconexão (....)
significa, primeiro, desincorporação, e segundo, a
reincorporação dos modos de vida da sociedade industrial por
outros modos novos, em que os individuos devem produzir,
representar e acomodar suas próprias biografias" (BECK 1997,
p. 24).

É preciso ainda incorporar a este discurso a refutação das anomalias que costumam acompanhar o discurso da individualização ou, nas concepções de BAUMAN (1998), fugir das soluções fundamentalistas associadas à busca da pureza, à busca da limpeza e à manutenção da ordem, aspectos apontados pelo autor como mal estares da civilização pósmoderna. BECK (1997) acrescenta ainda a necessidade de fugir da individualização como compulsão, como fabricação de autoprojetos e como espaço de construção de auto-representações. É exatamente no combate aos extremos do fundamentalismo das organizações, do fundamentalismo dos modelos e do fundamentalismo da individualização que deve se localizar a busca por um caminho de mudança para as organizações de saúde.

Mas por onde andam os sujeitos? Conforme argumenta CHANLAT (1996), o interesse em estudar as organizações tomou vários caminhos nas últimas décadas do Século XX. Os da economia, da sociologia, da psicologia, das ciências políticas, da antropologia e da psicanálise. Enquanto isso, o estudo do comportamento humano nas organizações transformou-se gradativamente em um objeto de estudo especifico. 
CHANLAT (1996) prossegue sua argumentação criticando o fenômeno da coisificação do ser humano nas organizações, afirmando que o estudo do comportamento desenvolveu-se à sombra da psicologia e da sociologia e, mais recentemente, sofreu forte influência do modismo das ciências do management. MITCHELL e LARSON (1987) citados por CHANLAT (1996), explicitam uma das idéias centrais desse movimento de desconstrução de sujeitos.

"O comportamento organizacional é um campo que é orientado para o desenvolvimento da melhor compreensão do comportamento humano e que utiliza este saber para tornar as pessoas mais produtivas e mais satisfeitas nas organizaçōes" (MITCHELL e LARSON 1987 apud CHANLAT (1996, p. 22).

Negando o simplismo desta definição, é preciso entender que o caminho da mudança por meio de processos que construam sujeitos tornarse-á possivel à medida que as dimensões humanas passem ao centro das discussões e assumam maior importância nas organizações do que as correntes hegemônicas, utilitaristas e positivistas, costumam Ihes atribuir.

CHANLAT (1996) aponta ao menos seis dimensões que devem ser tratadas neste caminho. São elas (1) a dimensão cognitiva e da linguagem, (2) a dimensão espaço-temporal, (3) a dimensão psiquica e afetiva, (4) a dimensão simbólica, (5) a dimensão da alteridade e (6) a dimensão psicopatológica. Lidar com um ser humano ao mesmo tempo biológico, psicológico e social, conceito fortemente relacionado ao setor saúde, é inevitável neste tipo de mudança. Fugir das simplificações tradicionais e enfrentar as posições de incômodo que este esforço traz é o desafio subjacente para quem quer pensar e viver este exercício de libertação.

Em complemento à idéia de CHANLAT (1996), é preciso entender que pensar a mudança a partir da construção de sujeitos significa negar, em alguma medida, o que aqui se define como princípio do totalitarismo do 
mercado. Com base neste principio, as organizações têm sido inspiradas a desenhar suas estratégias de mudança com base nas constantes alterações nos panoramas político, econômico, tecnológico, cultural, demográfico e ecológico, procurando operar por meio de formas organizacionais flexíveis, adaptativas e responsivas aos clientes $e$ aos requisitos de mercado (PEREIRA 2000).

Por sua vez, este cenário de mudança é marcado por um movimento de não contentamento com 0 presente e de busca frenética pela sobrevivência da organização no futuro. Um fenômeno que rompe os mecanismos subjetivos que conectam a ação dos atores com seu passado e seu contexto, resultando na anulação de sua reflexividade. Dois elementos caracterizam este fenômeno e serão aqui conceituados: o culto à velocidade da mudança e o culto à externalidade da mudança. Ao utilizar a palavra culto, a intenção é marcar a posição de superioridade e inevitabilidade com que tais fenômenos costumam ser tratados por parte dos autores das ciências da administração.

Com relação ao culto à velocidade da mudança, são vários os autores, como por exemplo THEOBALD (1994), FERGUSON (1980), PEREIRA (2000), DRUCKER (2002), KISIL e PUPO (1998) e MOTTA (1999), que localizam a mudança organizacional como tendência natural inevitável em um ambiente de mudanças globais. Para estes autores, não respeitar este movimento fará com que as organizações não sobrevivam, pois é preciso que elas estejam permeáveis a todas as formas de mudanças e às pressões externas.

Frente a cenários tão turbulentos, o culto à velocidade da mudança constitui-se em uma premissa e um ambiente que pressionam as pessoas a fazerem parte da mudança que a empresa precisa para sobreviver. Isto pode implicar em que aceitem inóspitos processos de relação com o trabalho e que se submetam a sacrifícios em suas relações sociais fundamentais. Ainda que tais escolhas em nada se relacionem com sua subjetividade diante do mundo, estão ligadas às necessidades da organização e do mercado. 
Com relação à externalidade da mudança, é preciso retomar as afirmações de CHANLAT (1996) sobre a ausência da dimensão da subjetividade humana nas ciências da administração e enriquecê-las com as observações de CLEGG (1996). Este autor chama atenção para a uma determinada tendência destas ciências em separar a pessoa (tomada em seu conteúdo subjetivo) do ator social. Ao separar a pessoa do ator social, isolando-se a subjetividade de um lado e as ações concretas (como o trabalho) de outro, impede-se o processo de construção de sujeitos e anula-se sua presença nas ações sociais.

O culto à externalidade da mudança encontra na anulação dos sujeitos um instrumento fundamental de poder e de dominação nas organizações. Isto pode ser melhor compreendido ao tomarmos as concepções de WEBER (1987) a respeito do poder nas organizações. O autor, que entende o poder como "oportunidade existente dentro de uma relação social que permite a alguém impor sua própria vontade", constata que de um lado encontra-se a estrutura formal e hierárquica de coerção e dominação, o poder legítimo da organização, enquanto de outro definem-se as micro-estruturas de poder ilegítimo, que se configuram como perturbações na ordem formal de poder.

Ao localizar as pressões e a necessidade da mudança organizacional no ambiente externo às organizações, a luta dos atores passa a se localizar no campo da sobrevivência e da hegemonia da empresa no mercado - o que garante os postos de trabalho. No campo externo ao ambiente organizacional, - espaço para a construção dos sujeitos fica extremamente reduzido e pressionado, fazendo com que apenas a dimensão de ator social - aquele que realiza ações - sobreviva no ambiente organizacional. A pessoa, sem espaço e sem tempo, termina por se submeter ao contexto.

Neste fenômeno as organizações tanto ganham em suas estratégias de sobrevivência no mercado, pois permanecem produzindo e inovando, quanto encontram uma consistente forma de controle do jogo interno de micropoderes. Nas palavras de KOTTER (1999), ilustrativas desta idéia de coerção, muitas tentativas de transformação organizacional fracassam em 
razão de um "erro" sempre cometido pelas organizações em seus processos de mudança: elas fracassam em razão da "criação de uma coalizão orientadora insuficientemente poderosa".

Para pensar uma mudança que tome como base a construção de sujeitos e que por isso se constitua em um elemento de sentido para os sujeitos, ou seja, um elemento provido de significado subjetivo, algumas "dimensões esquecidas", nas palavras de CHANLAT (1996), precisam ser consideradas. A construção de sujeitos se daria à medida que o ser humano fosse compreendido nas organizações como: (a) um ser genérico e singular que deve ser considerado em suas dimensões biopsicosociais; (b) um ser ativo e reflexivo, que age e pensa de forma orgânica; (c) um ser de palavra, que precisa ser compreendido em suas significações; (d) um ser de desejo e pulsão, que é intenso em suas relações sociais; (e) um ser simbólico, com suas imagens, metáforas e mitos; ( $f$ ) um ser espaço temporal, por isso inseparável do que configura sua biografia e (g) um ser que é objeto e sujeito de sua ciência.

Segundo BOYETT e BOYETT (1999), com exceção do conceito de liderança, não há assunto entre os grandes pensadores da administração que desperte tanto fascínio quanto o processo, os problemas, as promessas e as possibilidades das mudanças organizacionais. $O$ que as discussões apresentadas neste capitulo querem destacar entretanto, é que a discussão da mudança merece um tratamento que vá além da objetividade da razão. Além disso, pretende-se que as formas de analisar e avaliar as mudanças organizacionais estendam-se além da pureza dos resultados.

A mudança organizacional vive nos sujeitos. Só haverá mudança organizacional verdadeira e sustentável se esta mudança for provocada e construida pelos sujeitos. Conforme apresenta SENGE (1998) ao discutir as "organizações que aprendem" [the learning organizations], a habilidade de articular competências pessoais (como o domínio pessoal e os modelos mentais) e competências sociais (como a aprendizagem em equipe e a construção de visão compartilhada) sob a regência de um pensamento 
sistêmico que articule tais competências, è um eixo elementar para fomentar uma práxis da mudança.

A história da construção das organizações e dos sistemas de saúde no mundo moderno está marcada pela busca por modelos capazes de conferir à humanidade o poder de controlar a dor e o sofrimento e de promover a saúde dos seres humanos. A reconstrução da história da saúde pública realizada por ROSEN (1994) e os textos de FOUCAULT (1996) relacionados à origem da medicina social, dos hospitais, dos manicômios e das políticas de saúde são importantes ilustrações dessas buscas.

Paradoxalmente, esta mesma história também está repleta de exemplos de organização do trabalho em saúde em sistemas hierárquicos e burocráticos que sufocaram a criatividade e as outras formas da subjetividade humana, que fragmentaram a atenção à saúde em diversas profissões e micro-especialidades, e que atribuiram à saúde um valor simbólico forte o bastante para transformar em comércio ações que deveriam, essencialmente, defender a vida.

Partindo das idéias de GIDDENS (1991), o momento atual é um momento de desenho da pós-modernidade, um tempo limite, um periodo denominado de alta-modernidade. Nele, a reconstrução de uma teoria crítica que seja sensivel ecologicamente, geopoliticamente tática, que seja geradora de modelos de uma sociedade melhor e formuladora de políticas emancipatórias, de auto-realização e vinculada a uma política da defesa da vida, parece ser uma ideal alcançável.

Se, como afirma GIDDENS (1991), os eixos da construção do novo mundo estão ai, com a participação democrática de múltiplas camadas sociais, com a humanização da tecnologia, com a luta pela desmilitarização e com a estruturação de um sistema pós-escassez - sendo estes seus contornos mais expressivos - então que esta construção se inicie em cada ação, em cada movimento, em cada organização, em cada sujeito.

$\mathrm{Na}$ formulação e no fortalecimento destas sementes da pósmodernidade, tratar a mudança de sistemas, a mudança do status, a 
mudança da superestrutura, é tratar da mudança das pessoas. Retomando GIDDENS (1991), "a politica da vida se refere a engajamentos radicais que procuram incrementar as possibilidades de uma vida realizada e satisfatória para todos, e para a qual não existem outros". É a esta mudança que as organizações de saúde precisam se vincular.

Falar em mudança em organizações de saúde é portanto falar em dimensões humanas esquecidas, em pós-modernidade, em políticas de defesa da vida e, sobretudo, falar de sujeitos, sujeitos e sujeitos. Nesta era de formulação do novo tudo é possível, embora, nas palavras de MALIK (1998), "nesse campo, nada é fácil e, decididamente, pouco é objetivo". 


\subsection{Como fazer melhor? A busca por qualidade em saúde.}

A história das ciências e da prática da saúde está marcada pela busca constante por tratamentos capazes de assegurar o bem estar e prolongar a vida do Homem. Como apontam AZEVEDO e KORYCAN (1999), o exame do Juramento de Hipócrates, elemento primário da prática das profissões de saúde, leva à conclusão de que lá estão explicitadas algumas das primeiras regras com vistas a garantir um certo padrão de qualidade nos cuidados com a saúde dos seres humanos.

Um breve exame dos estudos de ROSEN (1994), revela também as preocupações das civilizações da antigüidade, como as civilizações asiáticas pré-gregas, em regular seus sistemas de saneamento e de habitação para a melhorar a vida em aglomerações urbanas. Nestes mesmos estudos, ROSEN (1994) descreve também o processo de complexificação das ações sanitárias ao longo da história e a estruturação de um saber médico no mundo GrecoRomano que foi determinante para a evolução das ciências da saúde. Do ponto de vista sociológico é FOUCAULT (1996) que analisa o nascimento da medicina social, a organização dos hospitais e manicômios e a complexificação da política de saúde ao longo dos séculos XVIII e XIX.

A caminho dos tempos contemporâneos, deve-se destacar os trabalhos de Florence Nightingale, em meados do Século XIX, e os trabalhos de Abraham Flexner, no início do Século $X X$, como eventos marcantes ao desenvolvimento dos serviços de saúde, sobretudo no que diz respeito a sua organização, padronização e qualidade. Tanto as experiências de Florence no Invalid Gentlewomen's Institution e seus trabalhos como enfermeira na campanha militar inglesa na Guerra da Criméia (ULRICH 2003) quanto a investigação e as recomendações de FLEXNER (1910) a respeito dos hospitais norte-americanos e canadenses, trouxeram indícios de que 0 controle da prática profissional e a definição de padrões e regras de 
funcionamento para os serviços de saúde poderiam trazer benefícios à sociedade.

Em um momento da história da humanidade caracterizado por um periodo de crescente urbanização, forte crescimento demográfico, grande desenvolvimento das ciências, fortalecimento dos Estados-Nação e, em conseqüência disto, ampliação e complexificação das estruturas de ensino e produção, os trabalhos de Florence Nightingale e de Abraham Flexner encontraram grande apelo científico e social.

Também no início do Século $X X$, outro elemento contribuiu de forma significativa para a estruturação do pensamento a respeito da qualidade dos serviços de saúde. Segundo QUINTO NETO e GASTAL (1997), um trabalho apresentado por Ernest Codman - então cirurgião - à Sociedade Médica do Condado da Filadélfia em 1913, denominado "O Produto dos Hospitais" trouxe forte estímulo ao debate em torno do tema da padronização dos hospitais e à formação do Colégio Americano de Cirurgiões.

Este Colégio, organizado a partir da idéia de implantação de um sistema de medida de resultados nos hospitais, veio a criar, poucos anos depois, o Programa de Padronização de Hospitais. A aplicação dos "Padrões de Eficiência" do Programa resultou na reprovação de cerca de $87 \%$ dos hospitais norte-americanos que, à época, contavam com mais de cem leitos (SCHIESARI 1999). Este dramático resultado inicial levou a que cerca de $16 \%$ dos hospitais avaliados corrigissem suas deficiências em um curto período.

O Colégio Americano de Cirurgiões prosseguiu então na padronização dos hospitais e publicou, cinco meses depois, cinco padrões hospitalares mínimos de eficiência, definindo-os como critérios para a classificação dos hospitais norte-americanos. Apesar da restrição destes critérios exclusivamente à prática médica, o Programa de Padronização de Hospitais chegou à década de $1950 \mathrm{com}$ mais de três mil hospitais aprovados e com a necessidade de criar sua própria estrutura gestora (SCHIESARI 1999). 
Com a união do Colégio Americano de Cirurgiōes, o Colégio Americano de Médicos, a Associação Americana de Hospitais, a Associação Médica Americana e a Associação Médica Canadense surgiu, em 1951, a Comissão Conjunta de Acreditação Hospitalar (QUINTO NETO e GASTAL 1997, SCHIESARI 1999, DONAHUE e O'LEARY 2000). Esta foi a primeira organização exclusivamente voltada à melhoria da qualidade dos serviços de saúde, em particular, de hospitais.

A partir da consolidação desta organização viu-se, em 1959, a criação do Conselho Canadense de Acreditação Hospitalar e, em 1960, a adoção da classificação de hospitais da Comissão Conjunta de Acreditação Hospitalar como critério para que os mesmos participassem de um dos sistemas de pagamento por serviços de saúde do governo dos Estados Unidos, o Medicare (SCHIESARI 1999). Em 1974 a Austrália também inaugurava seu Conselho de Padrões Hospitalares inspirada no modelo norte-americano (DONAHUE e O'LEARY 2000), e o movimento em busca de qualidade em saúde ganhava contornos mundiais.

Ao mesmo tempo que surgiam organizações e programas voltados especificamente à melhoria da qualidade dos serviços hospitalares, um segundo conjunto de eventos também desempenhou um papel importante no movimento de ampliação da qualidade dos serviços de saúde: a expansão do consumo de medicamentos em todo o mundo ocidental. Como ilustração deste fenômeno, CIPOLLE, STRAND e MORLEY (1998) afirmam que entre 1910 e 1960 o número de patentes químico-farmacêuticas saltou de pouco mais de uma centena para quase sete mil.

Contudo, este vertiginoso crescimento da produção e do consumo de medicamentos foi acompanhado de graves acidentes. Entre os registros mais marcantes está o emprego do solvente Dietilenoglicol em um xarope de Sulfanilamida comercializado nos Estados Unidos na década de 1930, que provocou o óbito de mais de cem crianças (LAPORTE e TOGNONI 1993). Ao lado de outros acidentes, o evento contribuiu para a criação de um forte apelo por mudanças na legislação sanitária americana. Em 1932, a então 
Administração de Alimentos, Drogas e Inseticidas, alocada no Departamento de Agricultura, passou a ser denominada Administração de Alimentos e Drogas (FDA), agência que percorreu um caminho de autonomia e reconhecimento público (COSTA 1999) tornando-a um dos maiores órgãos mundiais de referência para o controle de produtos terapêuticos e alimentares.

Um segundo acidente terapêutico de proporções ainda maiores foi a epidemia de focomelia em conseqüência do uso da Talidomida por gestantes no inicio da década de 1960. Estima-se a ocorrência de mais de quatro mil casos de má formação fetal em todo o mundo ${ }^{3}$ com cerca de quinhentos óbitos (LAPORTE e TOGNONI 1993). Em 1962, a Talidomida foi retirada do mercado em muitos paises e segregada a regimes de controle especial em outros, como acontece no Brasil.

Muitos outros trabalhos voltados à identificação e análise de reações adversas a medicamentos, foram realizados ao longo das décadas de 1950 e 1960, como destacam LAPORTE e TOGNONI (1993), CIPOLLE, STRAND e MORLEY (1998), SOBRAVIMEIAIS-LAC (2001) e CASTRO (2000). Estes trabalhos contribuíram para intensificar os estudos de utilização de medicamentos e para a consolidar a farmacoepidemiologia como ciência, bem como a farmacovigilância como importante instrumento sanitário para a promoção da qualidade em saúde.

Segundo a ANVISA (2003) e COELHO (1998), sessenta e dois países, entre eles Argentina, México, Equador, Venezuela, Cuba, Costa Rica e Brasil, este a partir de 2001, integram o programa de farmacovigilância da Organização Mundial da Saúde (OMS). Em um contexto no qual a probabilidade de morte decorrente de reações adversas a medicamentos em pacientes hospitalizados (390 ao dia) é três vezes maior do que a decorrente

\footnotetext{
${ }^{3}$ Nos Estados Unidos, a FDA não havia permitido o registro da Talidomida, o que evitou que o pais apresentasse casos de Focomelia (LAPORTE e TOGNONI 1993).
} 
de acidentes automobilísticos, o programa da OMS cumpre um papel de grande relevância (BERLIN et al. apud CARVALHO, VIEIRA e MAGLUTA 2002).

Se o movimento de melhoria da qualidade em saúde tornou-se maior e mais complexo nas últimas três décadas do Século $X X$, estas conquistas sofreram também grande influência do movimento pela qualidade no setor industrial. Segundo BERWICK, GODFREY e ROESSNER (1991), enquanto o setor da atenção à saúde movia-se em direção a processos de maior qualidade pressionados por um certo grau de desconfiança e insegurança da sociedade em relação aos serviços, o setor industrial tinha como pressão sua própria existência e hegemonia na sociedade moderna.

No caso específico dos Estados Unidos, os avanços das empresas japonesas provocaram alterações em alguns setores do mercado, a ponto de algumas delas assumirem posições de liderança nesses setores. Ao apresentarem preços mais baixos, combinados a maiores avanços tecnológicos, essas empresas reuniam componentes explicitos da qualidade percebida pelos consumidores, fortalecendo constantemente sua hegemonia. Em razão dessa acirrada disputa pelo mercado consumidor, os avanços industriais foram alcançados de maneira bem mais rápida que no setor saúde, o qual vivia pressões de outra natureza.

Ainda segundo BERWICK, GODFREY e ROESSNER (1991), esta diferença não chega a causar surpresa na análise do desenvolvimento da qualidade no setor saúde. As diferentes linguagens de controle de qualidade desenvolvidas por Walter Shewhart e por aqueles que o seguiram, como Edwards Deming, Joseph Juran, Kaoru Ishikawa e Jorge Box não encontraram analogia imediata nos serviços de saúde.

Mesmo em paises como o Japão, berço do movimento mundial pela qualidade, a adaptação dos conceitos industriais para o setor saúde se deu de maneira bastante retardada. Segundo TAKAHASHI (1997), o paradoxo japonês da qualidade em saúde justifica-se na observação de que o médico é, 
naquela sociedade, o elemento orientador da forma de organização do sistema de saúde. Para TAKAHASHI (1997), a discussão da qualidade em saúde enfrenta, no Japão, problemas comuns a outros paises, como a falta de informações nos serviços, a submissão dos pacientes, as limitações da regulamentação e a escassez de padrōes e critérios para medir a qualidade dos serviços de saúde.

Foi na década de oitenta, sobretudo entre 1985 e 1989, que uma certa redução da distância entre os movimentos pela qualidade no setor industrial e na saúde veio a acontecer. Mais fortes do que quaisquer outros componentes, as pressões econômicas parecem ter sido as que mais motivaram estas alterações. Segundo AZEVEDO e KORYCAN (1999), a Comissão Conjunta de Acreditação de Serviços de Saúde - JCAHO ${ }^{4}$ publicou, em 1988, a Agenda para a Mudança, na qual a filosofia e a metodologia da gestão da qualidade eram reconhecidas como instrumentos válidos para o desenvolvimento dos serviços de saúde, em um cenário que exigia cada vez mais racionalidade.

Outras iniciativas posteriores da JCAHO, como a criação e estruturação de indicadores de efetividade, a definição de distintos niveis de acreditação, a inclusão da assistência domiciliar como serviço passivel de acreditação, a melhoria do perfil dos avaliadores e a ampliação da participação de representantes da sociedade civil na gestão da própria organização, ilustram o desenvolvimento de conceitos e métodos em busca de ampliar a qualidade em saúde (SCHIESARI 1999).

Em relação a outros países, as experiências de qualidade desenvolvidas pela Espanha a partir de 1994 (BOHIGAS 2000), pela Polônia na década de noventa (NIZANKOWSKI 2000), pela Zâmbia em 1997 (BUKONDA et al 2002), além da própria América Latina, que em 1990 lançou

\footnotetext{
${ }^{4}$ Joint Comission for Accreditation of Health Care Organizations. Até 1987 a JCAHO era conhecida como Joint Comission on Accreditation of Hospitals (SCHIESARI 1999).
} 
uma proposta de acreditação para os mais de catorze mil hospitais da região (PAGANINI e NOVAES 1992), são elementos que ilustram um fenômeno de disseminação do conceito e da busca por qualidade em saúde.

No cenário brasileiro, as marcas históricas do movimento pela qualidade são recentes. Embora existam registros de iniciativas no setor que remontam a meados do Século XX (SCHIESARI 1999), foi a partir de 1990 que surgiram as primeiras publicações e ações especificas sobre o tema. Estão inseridos neste movimento a criação da Comissão Especial Permanente de Qualificação de Hospitais pelo Colégio Brasileiro de Cirurgiões em 1986 (TEMPORÃO et al. 2000), o lançamento do Programa de Controle da Qualidade Hospitalar do Estado de São Paulo em 1991 (APM/CREMESP 1998), as pesquisas para Determinação de Padrões de Qualidade Hospitalar realizadas pelo Instituto de Administração Hospitalar e Ciências da Saúde do Rio Grande do Sul em 1995 (QUINTO NETO e GASTAL 1997), o lançamento do Programa de Avaliação e Certificação de Qualidade em Saúde em 1994 (TEMPORÃO et al. 2000) e a criação do Instituto Paranaense de Acreditação em 1996 (SCHIESARI 1999).

Em outros setores da economia, a criação do Programa Brasileiro de Qualidade e Produtividade em 1990 (MDIC 2003), da Fundação para o Prêmio Nacional da Qualidade em 1991 (FNPQ 2003), o surgimento dos prêmios estaduais de qualidade (FNPQ 2000) e o crescimento exponencial da certificação através das normas ISO, ilustram o espaço conquistado no Brasil pelo tema da qualidade a partir de 1990. Por sua vez, não se pode deixar de associar esta corrida pela qualidade à abertura econômica promovida pelo governo de Fernando Collor de Mello.

Também no início da década de 1990, um estudo do setor saúde brasileiro realizado pelo Banco Mundial e publicado em 1994, reunia um conjunto de elementos que apontavam fragilidades na qualidade da atenção à saúde no Pais. Ainda que as concepções ideológicas peculiares ao Banco Mundial sejam questionáveis, o documento apontava que a dimensão da baixa qualidade nos serviços era desconhecida em seus detalhes, e que não 
havia estudos confiáveis capazes de assegurar ou refutar que quaisquer dos serviços existentes - públicos, privados, filantrópicos, etc. - operassem de maneira superior ou inferior aos demais (WORLD BANK 1994).

O Capítulo 7 deste mesmo relatório, denominado "O componente esquecido: qualidade da atenção à saúde", apresenta um conjunto de experiências em qualidade hospitalar desenvolvidas a partir de 1970, mas menciona que boa parte destas experiências não foram sequer avaliadas, além de terem durado muito pouco nos hospitais. As ações de promoção da qualidade mais disseminadas entre as diferentes instituições investigadas pertenciam a quatro categorias: (a) ações de auditoria médica, (b) ações para o controle das infecções hospitalares, (c) ações de controle de qualidade dos profissionais de saúde e (d) controle farmacêutico (WORLD BANK 1994).

O documento trazia ainda quatro experiências consideradas exemplares na implantação de sistemas de garantia de qualidade - todas localizadas em hospitais de gestão privada ${ }^{5}$ - e recomendava que: (a) os mecanismos de garantia de qualidade definissem e monitorassem o acesso, a continuidade, a integralidade e a qualidade técnica das ações de saúde, (b) que os mecanismos de garantia de qualidade fossem prioritariamente internos e constituissem parte das atividades de todos os profissionais de saúde, (c) que a participação dos consumidores no monitoramento dos serviços fosse enfatizada, (d) que os mecanismos internos de inspeção fossem aplicados a hospitais públicos e privados, garantindo o cumprimento de um nível básico de qualidade e (e) que os serviços públicos e privados reorganizassem as ações de forma a proporcionar uma relação mais contínua com seus usuários (WORLD BANK 1994).

No mesmo ano em que se publicava o relatório do Banco Mundial, o Ministério da Saúde criava o primeiro programa nacional de qualidade em

\footnotetext{
${ }^{5}$ Instituto do Coração (INCOR), Hospital SEPACO, Hospital Albert Einstein e Hospital SiroLibanês, todos localizados a cidade de São Paulo.
} 
saúde, denominado de Programa de Melhoria da Qualidade. Neste ano, o Ministério instituia também a Comissão Nacional para Melhoria da Qualidade na Assistência à Saúde (NORONHA et al. 2000). Segundo os autores, uma das estratégias adotadas para que o Programa tivesse sucesso, foi a estratégia de dissociá-lo das atividades de auditoria e de vigilância sanitária, bem como a não adoção de um modelo ou de um conjunto específico de padrões a serem cumpridos.

Cinco princípios orientadores das ações de melhoria de qualidade foram adotados à época: (a) caminhar para o uso crescente de indicadores de resultados, (b) criar um programa nacional de acreditação, (c) enfatizar o uso de ferramentas da melhoria da qualidade, (d) adotar protocolos clínicos e (e) estimular o controle social (NORONHA et al. 2000).

A partir de 1998 as atividades do Programa de Melhoria de Qualidade passaram a se concentrar na área de acreditação (NORONHA et al. 2000), sendo que o Ministério da Saúde obteve apoio financeiro do Banco Mundial para a iniciativa. Naquele ano lançava-se o Programa Brasileiro de Acreditação (SCHIESARI 1999) com base nas experiências de São Paulo, Rio Grande do Sul, Paraná e Rio de Janeiro (ONA 2003).

A criação da Organização Nacional de Acreditação (ONA) em abril de 1999 foi de grande importância para as atividades de promoção do tema da qualidade em saúde no Brasil e para a consolidação do Programa Brasileiro de Acreditação. Atualmente as entidades fundadoras da ONA estão divididas em três grupos: (a) as entidades prestadoras de serviço ${ }^{6}$, (b) as entidades compradoras de serviço ${ }^{7} \mathrm{e}(\mathrm{c})$ as entidades privadas que se pautam pelos

6 ABRAHUE - Associação Brasileira de Hospitais Universitários e de Ensino; FBH Federação Brasileira de Hospitais; CMB - Confederação das Misericórdias do Brasil; CNS Confederação Nacional de Saúde - Hospitais, Estabelecimentos e Serviços.

${ }^{7}$ ABRASPE - Associação Brasileira de Autogestão em Saúde Patrocinadas pelas Empresas; ABRAMGE - Associação Brasileira de Medicina de Grupo; CIEFAS - Comitê de Integração de Entidades Fechadas de Assistência à Saúde; FENASEG - Federação Nacional das 
principios que regem o direito público ${ }^{8}$. Segundo a ONA (2003), até setembro de 2003, dezenove hospitais de sete estados brasileiros haviam sido acreditados segundo os critérios do programa nacional.

Como analisado neste capítulo, muitos movimentos de melhoria da qualidade das ações de saúde e dos serviços vêm sendo realizados ao longo da história, sobretudo no Século XX. No Brasil, os anos pós-redemocratização reúnem as experiências mais exitosas, sobretudo as que se relacionam à organização do Sistema Único de Saúde, à área de análise clinicas e patológicas e aos hospitais privados.

Em relação ao setor farmacêutico, especificamente nas farmácias e drogarias ainda são poucas as iniciativas para ampliar a qualidade do setor. Como será verificado no capitulo a seguir, o desenvolvimento de modelos de qualidade em saúde com base em padrões adequados para estrutura, processos e resultados, acompanhados da essencial construção de sujeitos nas organizações, como discutido no capitulo anterior, pode representar uma alternativa para as mudanças que promovam o uso racional de medicamentos e a defesa da vida.

Empresas de Seguros Privados e de Capitalização: UNIMED DO BRASIL - Confederação Nacional das Cooperativas Médicas.

${ }^{8}$ CONASS - Conselho Nacional dos Secretários Estaduais de Saúde; CONASEMS Conselho Nacional dos Secretários Municipais de Saúde. 


\subsection{Qualidade em saúde: por que utilizamos padrões?}

Muitos dos adjetivos utilizados para caracterizar os seres vivos, os objetos e os fenômenos naturais ou sociais são de natureza abstrata. Por serem abstratos, estes conceitos operam a partir de sensações e impressões subjetivas, mantendo-se muitas vezes distantes da realidade concreta que pode ser experimentada materialmente pelos sujeitos. Boa parte das classificações das coisas e dos fenômenos, realizadas diariamente pelas pessoas, se ancoram neste mundo de subjetividade. É a partir dele que valores são atribuídos, julgamentos são feitos, fenômenos e objetos são classificados e, sobretudo, escolhas são realizadas.

Este exercício realizado quotidianamente pelos individuos perde legitimidade à medida que o fenômeno ou objeto em julgamento tenha um apelo social ou desperte o interesse de mais de um indivíduo. Enquanto no interior de cada pessoa a subjetividade encontra limites apenas na própria experiência e historicidade, quando se trata de julgamentos e escolhas realizadas de forma coletiva é preciso construir imagens comuns, consensos, regras ou quaisquer outros elementos capazes de tornar o julgamento explicito e a escolha legitima para todos os interessados. Como afirma SINGER (1996):

\footnotetext{
"Enquanto em algum momento do passado nossa experiência com as coisas essenciais de nossas vidas - os serviços e os produtos de artesãos e outros profissionais - eram, na maioria das vezes individuais e empiricas, hoje em dia o processo de realização de julgamentos individuais tem sido progressivamente substituido por sistemas coletivos e instituições formais como as sociedades profissionais, organizações de teste e de classificação, departamentos governamentais e organizações internacionais" (SINGER 1996, p. 205).
} 
É a partir destes fundamentos que a avaliação dos fenômenos e das organizações da sociedade se fortalece e populariza. À medida que as ações do Estado, do mercado e da própria sociedade civil organizada alteram a vida das pessoas, tributam-nas, julgam-nas e até mesmo determinam o curso de sua vida e morte, é necessário que as políticas e as ações sejam conhecidas, julgadas e escolhidas por aqueles interessados nessas ações. Esta é uma das alternativas para que direitos, deveres e, sobretudo, a ética da sociedade, sejam construídos e respeitados.

No contexto histórico, GUBA e LINCOLN (1989) ressaltam que iniciativas para medir resultados de programas educacionais de forma sistemática são registradas desde a antigüidade em diversas civilizações. Contudo, foram educadores e pesquisadores franceses, ingleses e alemães ainda no Século XIX, que deram um caráter mais estruturado ao tema. Já nas primeiras duas décadas do Século $X X$, foram associações americanas, como a Associação Nacional de Educação e Associação Americana de Psicologia, que contribuíram de forma marcante para a estruturação do campo da avaliação.

Para GUBA e LINCOLN (1989), ao longo do Século XX a avaliação seguiu seu caminho de complexificação e desenvolvimento e quatro diferentes gerações podem ser identificadas: (a) a geração da mensuração, caracterizada pelo desenvolvimento das ciências sociais positivas e pelo gerenciamento cientifico das empresas; (b) a geração da descrição, influenciada pela antropologia e pelas teorias comportamentais; (c) a geração do julgamento, influenciada pelo nascimento do pensamento estratégico e (d) a geração da negociação. Esta última, proposta pelos autores com bases epistemológicas construtivistas, relativistas e utilizadoras da hermenêutica e da dialética como métodos de análise (GUBA e LINCOLN 1989, 2000).

Ao longo desse processo histórico, o desejo e a necessidade de melhor conhecer os resultados das intervenções sociais e das políticas públicas no contexto do Estado e da sociedade moderna, tornaram-se o elemento propulsor da avaliação. Segundo PATTON (2002), o movimento por ele 
chamado de avaliação responsável [accountability-driven evaluation], não apenas deu ênfase à descrição e análise dos resultados esperados das políticas e ações sociais, como também primou pela transparência do uso responsável dos recursos públicos.

No tocante ao movimento pela qualidade em saúde, discussão do capitulo anterior, é possivel identificar uma associação direta entre os temas da avaliação e da qualidade. São muitos os padrões e processos de verificação da qualidade formulados por diferentes organizações e autores ao longo dos anos e, como afirmam MALIK e SCHIESARI (1998), "qualquer discussão a respeito de qualidade em saúde traz implícita a noção de avaliação". Para que se possa afirmar o que é bom ou ruim, o que está ou não correto, o que vale ou não a pena, o que é mais custo efetivo, o que mais satisfaz profissionais, consumidores e financiadores, é necessário que critérios sejam estabelecidos pelos interessados e que o processo de avaliação se dê com base nestes critérios.

CESAR e TANAKA (1996) também explicitam de maneira clara a relação entre a necessidade de critérios e o processo de avaliação, definido por eles como $O$ ato de medir um fenômeno ou 0 desempenho de um processo, comparar os resultados obtidos com os critérios estabelecidos, e fazer uma análise destes resultados considerando-se a natureza da diferença.

De maneira mais específica, WORTHEN, SANDERS e FITZPATRICK (1997) definem avaliação como a identificação, clarificação e aplicação de critérios defensáveis para determinar o valor e o mérito de um determinado objeto avaliado, sua qualidade, utilidade, efetividade ou significado em relação a estes critérios, definição que é essencialmente compartilhada por outros autores, como COSTANZO e VERTINSKY (1975), PATTON (1997), CONTANDRIOPOULOS et al (1997), CARVALHO, ROSEMBURG e BURALLI (2000), SILVA e BRANDÃO (2003) e TANAKA e MELO (2001).

Um dos elementos comuns a todos estes autores, é o fato de colocarem a definição de critérios como condição essencial para se avaliar um 
determinado objeto ou fenômeno. Neste processo de elaborar critérios, a necessidade de chegar a consensos sobre o que seria qualidade em saúde tornou-se um importante objeto de estudo nas últimas décadas. Por sua vez, o crescente interesse pelo conceito qualidade fez com que seu emprego em produtos e serviços tão distintos e em cenários tão variados, sofresse um relativo processo de banalização.

Utilizado de forma pouco criteriosa, transmitiu-se à sociedade um valor simbólico para a palavra qualidade - um "ter qualidade" ou um "ser de qualidade" pouco criterioso - e, segundo SCHIESARI (1999), uma falsa imagem da facilidade na aplicação de seus principios e conceitos. Conforme alertava DONABEDIAN (1980), havia mesmo o risco da perda da utilidade analítica do conceito qualidade à medida que sua ampliação envolvesse elementos que não fossem, em realidade, seus componentes essenciais.

Há, contudo, uma concordância generalizada, entre os autores da área de saúde, a respeito das dificuldades implicadas na definição e na medida da qualidade. Para analisar uma destas dificuldades, pode-se por exemplo tomar o ponto de vista dos consumidores. Em todas as áreas em que se dá a utilização ou o consumo de produtos e serviços, os consumidores têm dificuldade em realizarem suas escolhas. Tratando-se de serviços de saúde, este fenômeno é ainda mais marcante. Conforme fundamenta o Código de Defesa do Consumidor, dois conceitos são de grande importância nesta discussão: a hipossuficiência e a vulnerabilidade (BRASIL 1990).

A hipossuficiência de consumidores e usuários diante das implicações técnicas da escolha de um procedimento e sua vulnerabilidade em razão de seu estado de saúde, têm grandes implicações em sua capacidade de julgar a qualidade do que lhes é oferecido. Se o consumidor já encontra dificuldades para distinguir, entre determinados bens de consumo, aquele que mais the agrada, que está a seu alcance financeiro, ou que the pareça tecnicamente superior, ao utilizar serviços de saúde, consumir exames laboratoriais ou medicamentos, sua capacidade de escolha está ainda mais reduzida. O risco 
associado ao procedimento realizado ou ao produto consumido aumenta de maneira exponencial.

Além dos consumidores, há também outros interessados nos serviços de saúde, para quem existem outros critérios de avaliação: familiares, profissionais de saúde, administradores, financiadores, órgãos de fiscalização, entre outros. Neste cenário, o desafio da avaliação da qualidade em saúde está em compreender o complexo e conflituoso jogo de interesses e construir critérios que atendam diferentes expectativas.

Na compreensão desse universo de interesses, um dos modelos de qualidade em saúde mais discutido é o proposto por DONABEDIAN (1990). Para $\circ$ autor, sete atributos devem ser considerados ao se falar sobre qualidade em saúde: (a) eficácia, habilidade dos serviços de saúde em promover, sob as melhores condições possiveis, os melhores resultados que visem o bem estar dos pacientes; (b) efetividade, que em contraste com a eficácia, representa a melhoria possível, em condições normais, no bem estar dos pacientes; (c) eficiência, custo associado a atenção à saúde; (d) otimização, forma de analisar efetividade e eficiência em termos relativos; (e) aceitabilidade, maneira de adaptar a atenção à saúde aos desejos, expectativas e valores dos pacientes; (f) legitimidade, forma de garantir que a atenção à saúde se dá com bases nos valores da sociedade e do individuo; e (g) eqüidade, forma de analisar o acesso dos individuos a atenção à saúde.

De maneira semelhante, outros componentes da qualidade são as oito dimensões apresentadas por VUORI (1991): (a) efetividade, (b) eficácia, (c) eficiência, (d) eqüidade, (e) aceitabilidade, (f) acessibilidade, (g) adequação e (h) qualidade científico-técnica. Ao lado de Avedis Donabedian, Hannu Vuori é um dos autores que mais influenciaram as publicações brasileiras sobre qualidade em saúde ao longo da década de 1990.

Ainda segundo DONABEDIAN (1966) apud VUORI (1991), os métodos de avaliação da qualidade em saúde poderiam ser divididos em três eixos construidos com base na teoria de sistemas: estrutura, processos e 
resultados. Um esquema conceitual apresentado por COSTANZO e VERTINSKY (1975) ilustra de maneira objetiva estes eixos. Os autores afirmam que o termo qualidade implica em comparar o nível alcançado por uma característica qualquer a critérios ou padrões estabelecidos, e propõem uma árvore de decisão para orientar os processos de avaliação da qualidade. Esta estrutura esta representada na figura a seguir.

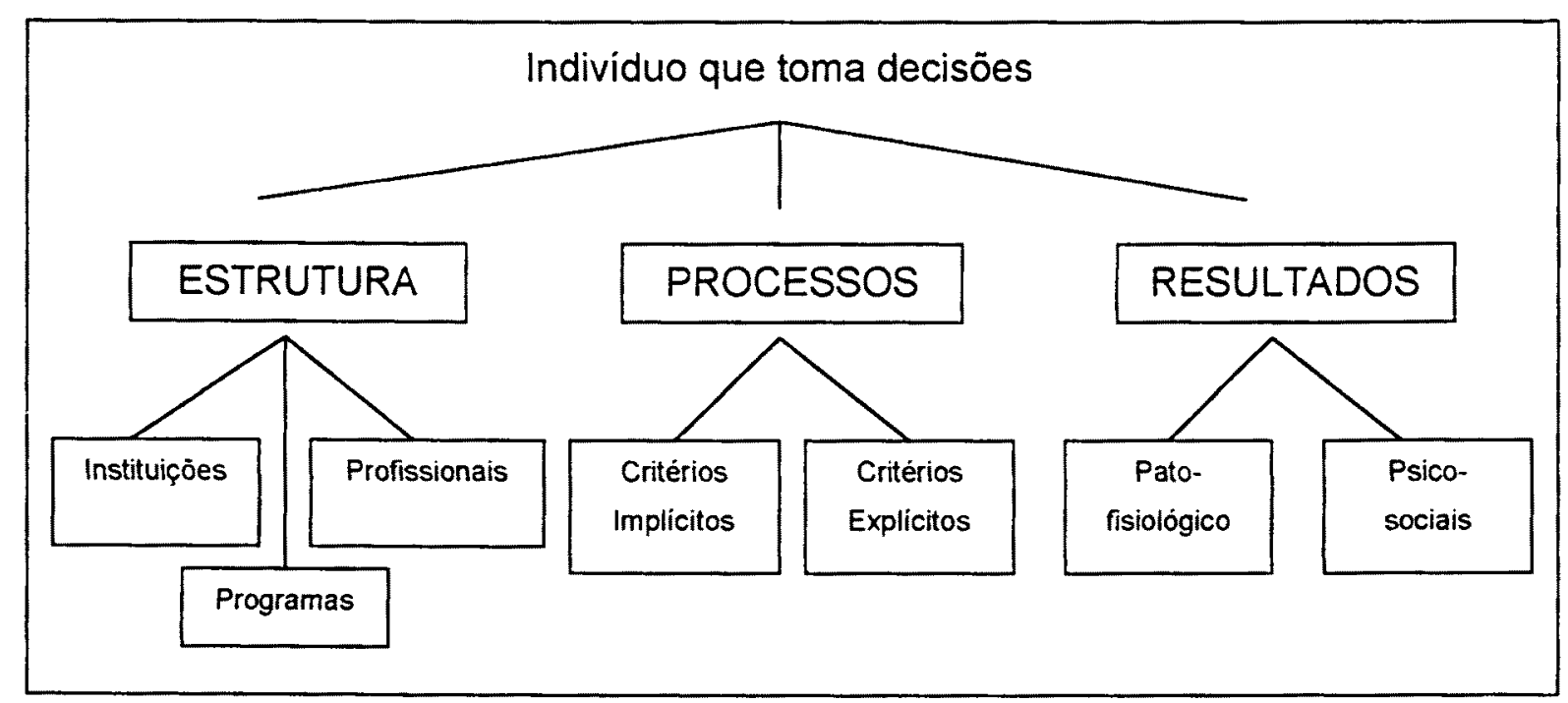

Figura 1. Taxonomia dos métodos para medir qualidade em saúde. ${ }^{9}$

DONABEDIAN (1980), VUORI (1991) e COSTANZO e VERTINSKY (1975) concordam que o eixo estrutura envolve as características estáveis dos serviços de saúde, como instalações, equipamentos, recursos humanos, materiais e financeiros. Que o eixo processos diz respeito às interações e procedimentos envolvendo profissionais de saúde e pacientes, e que o eixo resultados engloba a realização do objetivo de curar, barrar a progressão, restaurar a capacidade funcional, aliviar a dor, entre outros. Com base nestes autores, qualquer avaliação em saúde deveria levar em consideração critérios nestes três eixos, bem como não perder de vista a eficácia, efetividade, eficiência, otimização, aceitabilidade, legitimidade e eqüidade.

\footnotetext{
${ }^{9}$ Fonte: COSTANZO e VERTINSKY (1975).
} 
Muitas ferramentas têm sido utilizadas em busca de melhorar a qualidade dos serviços de saúde ao longo dos últimos anos (GURGEL JÚNIOR e VIEIRA 2002). A gerência pela qualidade total, as medidas de satisfação dos consumidores, a reengenharia, a aplicação do $5 \mathrm{~S}$, o uso das normas ISO, os prêmios de excelência e a acreditação são todas ilustrativas desta procura. Com suas diferentes caracteristicas, o uso destas abordagens ilustra a intenção do setor saúde em avaliar suas limitações e potencialidades, desejar a mudança e reunir as condições necessárias para que ela aconteça.

Dentre as várias abordagens voltadas à melhoria de qualidade, a acreditação ganhou bastante popularidade ao longo dos últimos anos (SCHIESARI 1999). Sua característica de atuar no sistema organização, com enfoques na estrutura, nos processos e nos resultados, foi um dos principais elementos a torná-la tecnicamente consistente no setor saúde, configurando sua expansão por todo o mundo, como anteriormente discutido.

A acreditação tem como características ser um processo periódico, voluntário e reservado que prepara e avalia aspectos de estrutura, processos e resultados segundo padrões previamente definidos, com vistas a estimular a melhoria contínua da qualidade das organizaçōes. Conforme alertam MALIK e SCHIESARI (1998), é preciso destacar que a palavra acreditação não está nos dicionários da lingua portuguesa, sendo portanto um anglicismo.

Para a OPAS (1997), a acreditação é um procedimento de avaliação dos recursos institucionais, voluntário, periódico e reservado que tende a garantir a qualidade da atenção através de padrões previamente estabelecidos. Os padrões podem ser mínimos ou mais elaborados e exigentes, definindo distintos niveis de satisfação. Poderia se afirmar que um estabelecimento assistencial "é acreditado" quando a distribuição e organização de seus recursos concorrem para um processo cujo resultado final é uma atenção com qualidade. 
Ao longo dos últimos anos, milhares de organizações em todo o mundo, sobretudo nos Estados Unidos, participaram de processos de acreditação. Além da área hospitalar, várias ações de saúde foram incorporadas pelos sistemas de acreditação, como os cuidados domiciliares, as redes de serviços e os laboratórios clínicos, tornando a abordagem ainda mais complexa e comum aos sistemas de saúde.

Entretanto, embora as formas de avaliação de qualidade, especialmente a acreditação, tenham avançado na área de saúde, marcando mudanças expressivas nos indicadores específicos à área hospitalar e contribuindo para a alteração dos indicadores de saúde, os serviços farmacêuticos, objeto deste trabalho, não passaram pelo mesmo processo.

Ainda que o setor farmacêutico esteja fortemente presente no mundo moderno, sobretudo no ocidente, seu desenvolvimento no campo da qualidade não teve a mesma intensidade da área hospitalar, configurando-se de forma bastante diferente. A criação de uma dicotomia expressa no medicamento produto e na farmácia serviço, resultou em um forte desenvolvimento do produto em detrimento do serviço. $\mathrm{Na}$ fraqueza do serviço, por sua vez, é que se fortaleceu o produto, favorecendo a industrialização do setor e a criação de uma das atividades econômicas de maior sucesso no mundo moderno.

No cenário internacional, algumas iniciativas importantes apontaram a necessidade de melhorar a qualidade do componente serviços, do setor farmacêutico. Em 1993, em sua reunião em Tóquio, a Federação Internacional dos Farmacêuticos (FIP) declarou a importância do desenvolvimento e da utilização de padrões de qualidade para os serviços farmacêuticos. Nas palavras expressas no documento:

"O estabelecimento de padrões são um componente importante na medição da qualidade dos serviços para o consumidor. A FIP, ao adotar referências internacionais de boas práticas em farmácia em sua conferência em Tóquio - Japão, acredita que 
padrões baseados nestas referências devem ser utilizados pelas agremiações nacionais de farmacêuticos, govemos e outras organizações internacionais de farmacêuticos para a adaptação de seus próprios padrões de referência de boas práticas em farmácia. As referências de boas práticas de farmácia baseiam-se na atenção farmacêutica desenvolvida pelos profissionais farmacêuticos. Elas recomendam que os padrões nacionais sejam orientados para a promoção da saúde, o suprimento de medicamentos e de equipamento médicos, o auto-cuidado em saúde e a melhoria da prescrição e do uso de medicamentos através de atividades desempenhadas pelos farmacêuticos" (FIP 1994, p. 1).

Esta pode ser identificada como a primeira declaração internacional que fala em estabelecer padrões para medir a qualidade dos serviços farmacêuticos. No mesmo encontro em Tóquio, produziu-se também o documento "Boas práticas em farmácias hospitalares e comunitárias" (OMS 1995), que enfatiza a importância do papel do farmacêutico na reorganização dos serviços de saúde, apontando os eixos principais das boas práticas.

"A missão da prática farmacêutica é prover medicamentos e outros produtos e serviços relacionados a atenção à saúde e ajudar aos indivíduos e a sociedade a utilizá-los da melhor maneira possivel (...) as Boas Práticas em Farmácia são a maneira de implementar a atenção farmacêutica.

a) as boas práticas em farmácia requerem que o farmacêutico tenha como sua primeira preocupação o bem estar do paciente, em todas as circunstâncias.

b) as boas práticas em farmácia requerem que a essência da prática farmacêutica seja o fornecimento de medicamentos e de outros produtos para a atenção à saúde, a informação e o apoio adequado aos pacientes e a observação dos efeitos de seu uso. 
c) as boas práticas em farmácia requerem que uma parte fundamental do papel do farmacêutico seja a promoção da prescrição racional e do uso correto dos medicamentos.

d) as boas práticas em farmácia requerem que o objetivo de cada etapa dos serviços farmacêuticos seja relevante para os individuos, esteja claramente definida e eficazmente comunicado a todos os interessados neste processo" (OMS 1995, p. 19).

Em artigo sobre avaliação de resultados da prática farmacêutica, KOZMA, REEDER e SCHULZ (1993) apresentam um modelo para planejamento e avaliação das ações farmacêuticas denominado Modelo ECHO - resultados econômicos, clínicos e humanísticos [The ECHO model economic, clinical and humanistic outcomes model], cujo principal objetivo é oferecer aos profissionais uma alternativa para melhor conhecer e avaliar os resultados de suas intervenções.

Posteriormente, KOZMA (1995) chama atenção para a crescente demanda por maior responsabilidade dos farmacêuticos em suas intervenções, tendo em vista a crescente ampliação dos custos da atenção à saúde. O autor aponta que os resultados produzidos pela farmacoterapia em seus aspectos econômicos, clínicos e humanos são importantes para a avaliação da qualidade da intervenção.

MULLINS, BALDWIN e PERFETTO (1996) também apontam a necessidade de se avaliar a prática farmacêutica através de resultados alcançados na farmacoterapia. Os autores discutem a importância de pensar a qualidade no setor de forma sistêmica, incorporando aspectos da estrutura e processo e trazendo exemplos de critérios de avaliação com base nos trabalhos de Avedis Donabedian.

Em 1998, a Associação Nacional de Autoridades Farmacêuticas Regulatórias do Canadá publicou um conjunto de padrões orientadores para a prática profissional naquele país (NAPRA 2003). O conjunto de seis padrões 
representou um passo importante na construção de um sistema farmacêutico de qualidade para o Canadá.

"Padrão 1: o farmacêutico, utilizando conhecimentos e habilidades únicas para identificar as necessidades farmacoterapêuticas dos pacientes, pratica uma atenção voltada ao paciente em parceria com o próprio paciente $e$ outros profissionais de saúde, a fim de alcançar resultados positivos e/ou manter ou melhorar a qualidade de vida do paciente.

Padrão 2: o farmacêutico atua dentro de limites legais e de princípios éticos, demonstra integridade profissional e age para preservar os padrões da prática profissional.

Padrão 3: o farmacêutico identifica, isola, avalia, interpreta e provê informações apropriadas sobre medicamentos e sobre a prática farmacêutica para garantir atenção segura e efetiva ao paciente.

Padrão 4: respeitando o direito do paciente a confidencialidade, - farmacêutico se comunica e educa para proporcionar adequada atenção ao paciente e promover a saúde.

Padrão 5: o farmacêutico gerencia a distribuição de medicamentos através da realização, supervisão e revisão das funções de seleção, preparo, distribuição e estoque de medicamentos a fim de assegurar a segurança, a precisão e qualidade dos produtos.

Padrão 6: o farmacêutico utiliza conhecimentos, principios e habilidades da prática farmacêutica com o objetivo de otimizar a atenção ao paciente e as relações inter-profissionais" (NAPRA 2003).

Em 1999, o documento publicado pela Associação Americana de Farmacêuticos do Sistema de Saúde (ASHP), denominado "Padrões mínimos 
para os serviços farmacêuticos ambulatoriais" apresentava quatro categorias de ações a serem desenvolvidas pelos farmacêuticos (ASHP 1999): (a) liderança e gerenciamento do serviço, envolvendo o preparo do farmacêutico, os critérios para a utilização de medicamentos, o desempenho em indicadores de reações adversas e erros de medicação, a distribuição dos serviços entre os membros da equipe e as questões financeiras da organização; (b) farmacoterapia e atenção farmacêutica, envolvendo os planos de atenção farmacêutica, a relação com os pacientes e as ações de educação em saúde; (c) controle e distribuição de medicamentos, envolvendo a aquisição, o armazenamento e a distribuição dos medicamentos e (d) instalaçães, equipamentos e outros recursos, envolvendo as áreas e equipamentos para as operações técnicas e administrativas.

Agregando as contribuições de SANCHEZ et al (2001), na publicação espanhola Gestão da Qualidade nas Farmácias, é possível identificar um conjunto razoável de documentos que enfatizam a necessidade de que o setor recupere o tempo perdido em sua qualificação em razão da hegemonia do produto. Para SANCHEZ et al (2001), um sistema de qualidade para farmácias é um sistema que facilita o desenvolvimento de todas as atividades realizadas pela farmácia, de forma mais adequada, de maneira controlada e seguindo procedimentos de trabalho previamente definidos. Para os autores é ainda necessário estabelecer objetivos e buscar, sistematicamente, formas de medir o alcance destes resultados.

No cenário brasileiro, as ações geradoras de padrões de referência ou normas que trataram dos serviços farmacêuticos, incluindo sua qualidade, estiveram exclusivamente no âmbito da vigilância sanitária até 1997 (BRASIL 1971, 1973, 1974, 1976a, 1976b, 1977a, 1977b; MS 1986a, 1986b). A partir daquele ano, duas resoluções do Conselho Federal de Farmácia (CFF 1997, 2001) passaram a tratar do assunto de maneira um pouco mais ampla.

Até 1997, a legislação sanitária era o único elemento que tratava das condições de funcionamento dos estabelecimentos farmacêuticos e que podia ser utilizada para fins de avaliação de qualidade. Contudo, sequer as 
condições de funcionamento dos estabelecimentos têm sido fiscalizadas de maneira satisfatória. As leis federais $5.991 / 73$ e $6.360 / 76$ e seus decretos lei correspondentes $74.170 / 74$ e $79.094 / 77$, os mais importantes na regulação do setor, contribuíram para que a prática farmacêutica se configurasse como a prática do comércio de drogas, descaracterizando o papel de unidade sanitária que a farmácia poderia ocupar no Brasil (BRASIL 1973, 1976a, 1974, 1977a).

Estas leis e decretos definiram ainda o conceito drogaria. Este conceito não apenas regulamentou a criação de um espaço exclusivo ao comércio de drogas, como também remeteu as ações de manipulação de medicamentos, inexistentes sem a presença do profissional farmacêutico, a um espaço marginal à grande rede varejista à época estruturada. Como na lei 5.991/73:

"X - Farmácia - estabelecimento de manipulação de fórmulas magistrais e oficinais, de comércio de drogas, medicamentos, insumos farmacêuticos e correlatos, compreendendo 0 de dispensação e o de atendimento privativo de unidade hospitalar ou de qualquer outra equivalente de assistência médica.

$X I$ - Drogaria - estabelecimento de dispensação e comércio de drogas, medicamentos, insumos farmacêuticos e correlatos em suas embalagens originais" (BRASIL 1973).

Em 1997, em busca de avanços na definição de campos de atividade profissional e de qualificação do setor, o Conselho Federal de Farmácia publicou a Resolução 308, que dispõe sobre a assistência farmacêutica em farmácias e drogarias (CFF 1997). Nesta resolução, tanto o conceito de assistência farmacêutica quanto as práticas nas quais se admite e se espera a participação de farmacêuticos, é possível reconhecer avanços importantes. 
"Artigo $1^{\circ}$ - compreende-se por assistência farmacêutica, para fins desta resolução, o conjunto de ações e serviços com vistas a assegurar a assistência farmacêutica integral, a promoção e recuperação da saúde, nos estabelecimentos públicos e privados que desempenham atividades de projeto, pesquisa, manipulação, produção, conservação, dispensação, distribuição, garantia e controle de qualidade, vigilância sanitária e epidemiológica de medicamentos e produtos farmacêuticos" (CFF 1997).

Outras passagens desta resolução reconhecem um novo papel para as farmácias e as drogarias no Brasil e inauguram um debate em torno de novas práticas farmacêuticas que têm ganho força desde então. Entre estas passagens está o reconhecimento da farmácia como unidade de saúde pública, o reconhecimento de que deve haver espaços reservados para o diálogo com os pacientes (consulta farmacêutica), que é preciso criar e manter fichas farmacoterapêuticas de pacientes e, sobretudo, que é preciso "elaborar manuais de procedimentos, buscando normatizar e operacionalizar o funcionamento do estabelecimento, criando padrões técnicos e sanitários de acordo com a legislação" (CFF 1997).

Dois anos depois desta publicação, a então recém criada Agência Nacional de Vigilância Sanitária (BRASIL 1999a) publicou a Resolução 328/99, estabelecendo, no âmbito do Aparelho de Estado, o primeiro instrumento nacional que trata de boas práticas em farmácia (ANVISA 1999). Por um lado o regulamento foi o primeiro a explicitar de forma objetiva a necessidade de que as farmácias e drogarias mantenham "infra-estrutura fisica, equipamentos, recursos humanos e procedimentos que atendam às boas práticas em farmácia" (ANVISA 1999), conceito importante para que a avaliação da qualidade destes estabelecimentos fosse orientada pelos eixos de estrutura e processos anteriormente aceitos em outras áreas da saúde.

Por outro lado, a Resolução $328 / 99$ veta a utilização de aparelhos de uso médico ambulatorial e não incorpora a demanda por este tipo de 
procedimento - sobretudo a aferição de pressão arterial - nos estabelecimentos farmacêuticos. A Resolução 328/99 também não trata da avaliação de resultados terapêuticos, cuja ausência contribui para que farmácias e drogarias se mantenham à margem de um sistema de saúde que, além de estrutura e processos, precisa ser avaliado por seus resultados.

Em 2001, o Conselho Federal de Farmácia publicou a Resolução 357/01 (CFF 2001), aprovando um regulamento técnico de boas práticas em farmácia diferente do instrumento normativo publicando pela ANVISA dois anos antes (ANVISA 1999). Neste regulamento estão os maiores avanços no que diz respeito a redefinição da farmácia e da atividade farmacêutica como ações de saúde. A resolução, que pioneiramente dispõe sobre a redefinição da prática profissional, apresenta alguns elementos que são fundamentais para a compreensão da reorganização destes serviços.

"6.20) Assistência farmacêutica - é o conjunto de ações e serviços que visam assegurar a assistência integral, a promoção, a proteção e a recuperação da saúde nos estabelecimentos públicos e privados, desempenhados pelo farmacêutico ou sob sua supervisão.

6.21) Assistência técnica - é o conjunto de atividades profissionais que requer obrigatoriamente a presença física do farmacêutico nos serviços inerentes ao âmbito da profissão farmacêutica efetuando a assistência e atenção farmacêutica.

6.22) Atenção farmacêutica - é um conceito de prática profissional no qual o paciente é o principal beneficiário das ações do farmacêutico. A atenção é o compêndio das atitudes, dos comportamentos, dos compromissos, das inquietudes, dos valores éticos, das funções, dos conhecimentos, das responsabilidades e das habilidades do farmacêutico na prestação da farmacoterapia, com objetivo de alcançar resultados terapêuticos definidos na saúde e na qualidade de vida do paciente. 
6.37) Farmácia - estabelecimento de prestação de serviços farmacêuticos de interesse púbico e/ou privado, articulada ao Sistema Único de Saúde, destinada a prestar assistência farmacêutica e orientação sanitária individual ou coletiva, onde se processe a manipulação e/ou dispensação de produtos e correlatos com finalidade profilática, curativa, paliativa, estética ou para fins de diagnóstico.

6.64) Procedimento operacional padrão - descrição escrita pormenorizada de técnicas e operaçōes a serem utilizadas na farmácia e drogaria, visando proteger, garantir a preservar a qualidade dos produtos, a uniformidade dos serviços e a segurança dos profissionais" (CFF 2001).

Esta resolução dispõe também sobre os critérios para a avaliação da qualidade das prescrições, veta a dispensação de medicamentos em sistemas de auto-atendimento, autoriza a orientação farmacêutica e a dispensação de medicamentos livres de prescrição, a aplicação de injetáveis, a realização de pequenos curativos, a realização de nebulização, a verificação de temperatura e pressão e a determinação de parâmetros bioquímicos e fisiológicos (CFF 2001).

Além das tentativas de redefinição de atribuições e de reorganização da atividade profissional expressa por estas resoluções, alguns outros elementos caracterizaram o movimento pela qualidade no setor farmacêutico nos últimos anos. Nas farmácias de manipulação, nas farmácias hospitalares e nos laboratórios de análises clínicas, campos de atuação dos profissionais farmacêuticos, alguns importantes avanços podem ser identificados.

$\mathrm{Na}$ construção de padrões de qualidade para as farmácias que realizam manipulação de fórmulas, a Resolução da Diretoria Colegiada da ANVISA $n^{\circ} 33$ desempenhou um papel importante para o setor (ANVISA 2000). Voltada à manipulação, fracionamento, conservação, transporte e dispensação das preparações magistrais e oficinais, alopáticas e 
homeopáticas, a resolução aponta a garantia de qualidade como ação fundamental para os estabelecimentos.

Na área da farmácia hospitalar, a publicação do Guia da Farmácia Hospitalar pelo Ministério da Saúde em 1994, foi o primeiro instrumento objetivo a contribuir para o fortalecimento do setor, que já vinha sendo alvo de discussōes no movimento pela melhoria da qualidade hospitalar (MS 1994). Para MARIN, CHAVES e ZANINI (2001), a farmácia hospitalar, em boa parte das organizações hospitalares ao longo dos últimos anos, evoluiu de uma simples unidade de armazenamento e distribuição, "para um centro de manipulação altamente especializado, responsável pelo processamento de centenas de requisições clínicas".

Segundo WILKEN e BERMUDEZ (1999), ao longo da década de 1990 este setor enfrentou grandes desafios, como o baixo número de farmacêuticos aptos a atuar em farmácia hospitalar ${ }^{10}$, a falta de cursos de especialização, mestrados e doutorados e a escassez de padrões de avaliação dos serviços. Na terceira edição do manual brasileiro de acreditação hospitalar (MS 2001), percebe-se a incorporação de elementos que estimulam a organização das farmácias, principalmente à medida que a acreditação do sistema hospital passa a depender também da farmácia.

Nos laboratórios de análises clinicas, é importante destacar as duas principais iniciativas de mudanças nos padrões de qualidade do setor: (a) o Programa Nacional de Controle de Qualidade de Laboratórios Clínicos, promovido pela Sociedade Brasileira de Análises Clínicas (SBAC 2003) e (b) - Programa Nacional de Acreditação de Laboratórios Clínicos, promovido desde o ano 2000 pela Sociedade Brasileira de Patologia Clínica. Este último, já contando com cinqüenta laboratórios acreditados (SBPC 2003).

\footnotetext{
${ }^{10}$ Um farmacêutico para cada 655 leitos, contra um farmacêutico para cada 100 leitos como preconiza a Organização Mundial de Saúde (WILKEN e BERMUDEZ 1999).
} 
Ao compararmos os casos das farmácias hospitalares, dos laboratórios de análises clínicas e mesmo das farmácias de manipulação com as farmácias e drogarias, maiores avanços no campo da qualidade podem ser percebidos naquelas em detrimento das farmácias e drogarias. Neste sentido, algumas das perguntas que estimularam o desenvolvimento deste trabalho aqui residem: por que as farmácias e drogarias não implementaram programas de qualidade apoiados na atenção farmacêutica? Por que as farmácias magistrais e hospitalares e os laboratórios de análises clínicas ampliaram seus padrões de qualidade, passaram a utilizar modelos de certificação e acreditação, enquanto as farmácias e drogarias não o fizeram? Um modelo visando a melhoria de qualidade dos serviços seria mais efetivo nas farmácias e drogarias do que as ações compulsórias realizadas pela vigilância sanitária?

Muitas experiências nacionais e internacionais apontam para a relevância do desenvolvimento de padrões de qualidade na melhoria da atenção aos pacientes. Assim como resultados têm sido alcançados pelos sistemas de acreditação e pelas várias outras abordagens de garantia de qualidade, a acreditação de farmácias e drogarias pode vir a ser uma alternativa para apoiar a melhoria de qualidade dos serviços farmacêuticos no Brasil. O desenvolvimento de uma experiência de auto-regulação no setor de serviços farmacêuticos, não apenas com base na lógica do mercado, mas sobretudo com base na politica de defesa da vida, pode significar o surgimento de um novo espaço de construção da saúde.

Nos dias atuais, é possivel identificar experiências e fatores que têm configurado um contexto de mudança no setor farmacêutico. O lançamento da Lei dos Genéricos (BRASIL 1999b, 1999c), a publicação da Política Nacional de Medicamentos (MS 1999), a adequação da legislação sanitária em curso no Congresso Nacional e as estratégias de fiscalização da profissão farmacêutica construídas em parceria entre conselhos regionais de farmácia, Ministério Público e serviços locais de vigilância sanitária (MINISTÉRIO PÚBLICO FEDERAL 2001) são pilares importantes deste movimento. 
O lançamento do Selo de Atenção Farmacêutica pelo Conselho Regional de Farmácia de São Paulo também é uma sinalização deste caminho. Ainda que trabalhando com critérios simples e com pouco apelo social, há mérito na iniciativa de provocar as farmácias e as drogarias a aprimorarem seus padrões técnicos de funcionamento (CRF-SP 1999). Há mérito em buscar a mudança e a construção de uma nova natureza na identidade desses estabelecimentos.

Neste sentido, o desenvolvimento de um modelo de avaliação de qualidade dos serviços farmacêuticos, que tenha como núcleo temático o desenvolvimento de padrões de qualidade orientados pelos eixos de estrutura, processos e resultados pode contribuir para a mudança necessária.

Em um contexto de construção de sujeitos capazes de escolher a mudança, em um setor com grande acúmulo de experiências a partir do movimento da qualidade em saúde, intenso em produção científica na área farmacêutica, sensivel à humanização das práticas de saúde, aberto às melhorias na formação de novos profissionais de saúde e sensivel aos desejos dos consumidores, a construção do novo não é apenas uma utopia possivel, como também um caminho provável. 


\subsection{Atenção Farmacêutica: a reinvenção da práxis profissional}

Entre os instrumentos terapêuticos modernos, os medicamentos ocupam posição central. Sua utilização, acompanhada ou não da prescrição, tornou-se uma prática social tão comum na sociedade moderna, que os mesmos passaram a ocupar um lugar de destaque na economia global, tamanho o crescimento da demanda por todos os tipos de drogas e da correspondente ampliação das indủstrias farmacêuticas.

Segundo JONCHEERE (1997), o percentual de gastos com medicamentos varia entre $8 \%$ - em paises desenvolvidos - e $40 \%$ - em paises em desenvolvimento. Para melhor compreender a magnitude destes gastos, ao início da década de 1990, o mercado mundial estava estimado em cifras da ordem de 170 a 186 bilhōes de dólares anuais (BERMUDEZ 1995; SOBRAVIMEIAIS-LAC 2001). Em 2002, as estimativas são da ordem de 400 bilhões de dólares, mostrando que, apesar da recessão econômica mundial, o mercado de medicamentos continua crescendo.

Nos paises ocidentais, sobretudo no Brasil, os medicamentos têm sido tratados como um problema de saúde pública. Ao menos dois eixos podem ser identificados neste problema. O primeiro deles diz respeito ao limitado acesso aos medicamentos por parte da população, eixo que compreende a pesquisa e a produção de medicamentos, a politica de regulação de preços e a distribuição dos medicamentos nas redes pública e privada. Segundo BERMUDEZ (1997), ao longo da década de 1980 , não mais do que $23 \%$ da população brasileira consumia $60 \%$ da produção nacional de medicamentos. Por outro lado, $52 \%$ da população não tinha sequer acesso a medicamentos essenciais.

O segundo eixo do problema diz respeito à elevada incidência dos problemas relacionados ao uso de medicamentos, o que compreende sua segurança, a automedicação, a baixa adesão aos tratamentos, as reaçōes adversas e as interações medicamentosas. Ainda que estes dois eixos sejam importantes na compreensão da questão do medicamento no Brasil, a opção 
neste capítulo é analisar algumas das razões que determinam os problemas relacionados ao uso de medicamentos, em particular a relação existente entre estes problemas e a prática farmacêutica no Brasil.

Para LEFÉVRE (1991), a compreensão do objeto medicamento na sociedade brasileira deve considerar três dimensões: (1) o medicamento agente quimioterápico, (2) o medicamento mercadoria e (3) o medicamento símbolo. Segundo o autor, ao se analisar o objeto medicamento é preciso considerar um objeto que ao mesmo tempo cura, controla e previne por ser agente terapêutico; que aliena e domina por ser mercadoria; e que representa e simboliza, por significar aquilo que contém a cura, o alivio e a proteção.

As três dimensões do medicamento propostas por LEFÉVRE (1991) ajudam também a melhor compreender a forma como a prática farmacêutica está organizada no Brasil. Em razão de sua dimensão terapêutica, o medicamento foi eleito o núcleo da atividade farmacêutica à medida que a profissão se estruturou no Brasil. Conforme 0 arsenal terapêutico medicamentoso crescia e o trabalho em saúde tornava-se mais institucional (os sistemas passavam a controlar o trabalho), os profissionais prescritores viram seu dominio técnico e disponibilidade para lidar com o medicamento diminuir, cabendo aos farmacêuticos ocupar este espaço.

Quanto a segunda dimensão, a crescente valorização do medicamento como mercadoria determinou a organização atual de farmácias e drogarias à luz de uma ótica predominantemente comercial, reduzindo a dimensão sanitária dessas organizações. Conforme apontado no capítulo anterior, uma das evidências deste fenômeno pode ser encontrado na Lei 5.991/73, cuja definição para farmácia é "estabelecimento de comércio de drogas" (BRASIL 1973), aspecto que contribuiu para o enfraquecimento da dimensão sanitária das farmácias.

A terceira dimensão diz respeito ao valor simbólico do medicamento. $\dot{A}$ medida que a compreensão sobre saúde também se estruturou segundo a ótica da mercadoria ao longo do Século $X X$, materializando o conceito na forma de coisas "saudáveis" a serem adquiridas e consumidas, o 
medicamento tornou-se um dos mais importantes símbolos de saúde (LEFÉVRE 1991). Neste papel, por meio do medicamento se oferece cura, tranqüilidade, potência sexual e até mesmo a própria vida fragmentada em pequenas pilulas ou em gotas de um líquido qualquer.

Neste contexto, a prática farmacêutica sofreu um grande processo de deformação ao longo do Século $X X$. A hegemonia do medicamento mercadoria traduzido em valores simbólicos, em detrimento do medicamento instrumento terapêutico, contribuiu para que o objeto (medicamento) e não o sujeito (paciente), se consolidasse como elemento central da prática farmacêutica. Esta conjunção contribuiu de forma marcante para que a prática farmacêutica estruturasse um pensar e um agir não humanizados, criando mesmo barreiras e um não reconhecimento mútuo entre farmacêuticos e pacientes.

Esta prática farmacêutica não humanizada trouxe muitos problemas à sociedade moderna. De acordo com JOHNSON e BOOTMAN (1997), os gastos em conseqüência da morbidade e da mortalidade provocada pelo uso de medicamentos prescritos alcançavam a alarmante cifra de 73 bilhões de dólares por volta de 1995 nos EUA. Este valor crescia ainda mais, ultrapassando os 100 bilhões de dólares, caso se considerasse também o uso de medicamentos não prescritos.

Embora não existam estimativas econômicas equivalentes para o Brasil, estudo de BORTOLETTO e BOCHNER (1999) mostrou que $27 \%$ dos 217.512 casos de intoxicação registrados pelo Sistema Nacional de Informações Tóxico-Farmacológicas (SINITOX), ocorreram em razão do uso irracional de medicamentos.

Frente a tantos problemas decorrentes do uso de medicamentos que já marcavam vários países do mundo desde meados do Século $X X$, a prática farmacêutica veio a se deparar com uma importante demanda social. A necessidade de diminuir os problemas relacionados a medicamentos e de aplicar os recursos econômicos disponiveis de forma racional. Neste contexto é que surgiu a atenção farmacêutica. 
O conceito atenção farmacêutica [pharmaceutical care] foi primeiramente definido por Mikeal et al. como "a atenção que um paciente necessita e recebe, assegurando a ele o uso seguro e racional de medicamentos" (MIKEAL et al 1975 apud CIPOLLE, STRAND e MORLEY 1998). Apesar de primária, na definição é possivel reconhecer evidências de que a construção da nova prática profissional deveria ter o paciente, e não o medicamento, como foco da atenção.

O conceito atenção farmacêutica recebeu de Brodie et al. a sugestão de que também faria parte de sua definição a "determinação das necessidades medicamentosas de um paciente e a provisão não apenas do medicamento necessário, mas também de serviços - antes, durante e depois do tratamento - que assegurassem uma terapia ótima e efetiva" (BRODIE et al. 1980 apud CIPOLLE, STRAND e MORLEY 1998). Esta definição atribuía ao farmacêutico um papel não apenas restrito à terapêutica medicamentosa, mas compreendendo também as ações de promoção da saúde, elemento que seria afirmado pela FIP e pela OMS anos mais tarde.

Foram Charles Hepler e Linda Strand que em 1990 definiram atenção farmacêutica da maneira como o conceito ganhou maior popularidade.

"Atenção farmacêutica é a provisão responsável da farmacoterapia com o propósito de alcançar resultados claros que melhorem a qualidade de vida de um paciente. Estes resultados são (1) cura da doença, (2) eliminação ou redução de sintomas; (3) interrupção ou diminuição de um processo de doença ou (4) prevenção de uma doença ou de sintomas. Atenção farmacêutica envolver um processo por meio do qual um farmacêutico coopera com um paciente e com outros profissionais na definição, implementação e monitoramento de um plano terapêutico que produzirá resultados terapêuticos específicos no paciente. Em conseqüência, isto envolve três funções maiores: (1) identificar problemas relacionados a medicamentos atuais e potenciais, (2) resolver atuais 
problemas relacionados a medicamentos e (3) prevenir potenciais problemas relacionados a medicamentos. $A$ atenção farmacêutica é um elemento necessário à atenção à saúde, e deve estar integrado a outros elementos" (HEPLER e STRAND 1990, p. 539).

Os autores enfatizavam que duas atividades deveriam ser realizadas a fim de garantir a prática da atenção farmacêutica. Primeiro, que o farmacêutico dedicasse tempo para determinar os desejos, as preferências e as necessidades dos pacientes frente a seus processos saúde-doença. Segundo, que o farmacêutico estivesse comprometido para seguir com as atividades de atenção uma vez que as mesmas tivessem início.

Destes dois conjuntos de atividades nascia uma premissa importante: que a atenção farmacêutica seria a provisão responsável de farmacoterapia, com o propósito de alcançar resultados definitivos que melhorassem a qualidade de vida dos pacientes (HEPLER e STRAND 1990).

A partir de 1992, a experiência denominada "The Minesota Pharmaceutical Care Project" serviu como laboratório para precisar o conceito atenção farmacêutica. A partir de um estudo junto a vinte farmácias e cinqüenta e quatro farmacêuticos, dois conjuntos de responsabilidades da prática foram definidos pelos autores: (1) assegurar que toda a farmacoterapia de um paciente seja a mais apropriada, a mais efetiva, a mais segura e a mais conveniente possivel e (2) identificar, resolver e - mais importante - prevenir qualquer problema relacionado a medicamentos que possa interferir no alcance do primeiro conjunto de responsabilidades (CIPOLLE, STRAND e MORLEY 1998; TOMECHKO et al. 1995).

Fruto destas experiências, a definição de atenção farmacêutica apresentada pelos autores esta descrita a seguir.

"Atenção farmacêutica é a prática na qual o farmacêutico assume a responsabilidade sobre as necessidades 
farmacoterapêuticas de um paciente e permanece responsável [accountable] por este compromisso" (CIPOLLE, STRAND e MORLEY 1998, p. 13).

Para a Organização Mundial de Saúde, o papel do farmacêutico nos sistemas de saúde e a estratégia de apoio ao uso racional de medicamentos vinham sendo discutidos em diversas esferas ao longo das décadas de 1970 e 1980. Nestas discussões tiveram destaque a Primeira Reunião da WHO sobre Medicamentos em 1976, a publicação da primeira Lista de Medicamentos Essenciais em 1977, a Conferência de Peritos sobre Uso Racional de Medicamentos em 1985, a publicação do Guia para Desenvolvimento de Políticas Nacionais de Medicamentos em 1988, a declaração de Tóquio em 1993 e as decisões da $47^{\mathrm{a}}$ Assembléia Mundial de Saúde em 1994 (BONFIM 1997; OMS 1994).

Como resultado da reunião realizada em Tóquio e intitulada "O papel do farmacêutico no sistema de atenção à saúde", a FIP e a OMS declararam seu conceito de atenção farmacêutica (OMS 1995).

\footnotetext{
"Atenção farmacêutica é um conceito de prática profissional na qual o paciente é o principal beneficiado pelas ações do farmacêutico. A atenção farmacêutica é o conjunto de atitudes, comportamentos, compromissos, inquietudes, valores éticos, funções, conhecimento, responsabilidades e habilidades do farmacêutico na provisão da farmacoterapia, com objetivo de alcançar resultados terapêuticos definidos na saúde e na qualidade de vida do paciente" (OMS 1995, p. 3).
}

Em 1998, a FIP divulgou documento que procurava trazer mais precisão ao conceito declarado em 1993, apontando também os eixos sobre os quais a prática da atenção farmacêutica deveria ser construída. 
“Atenção farmacêutica é a provisão responsável da farmacoterapia com o propósito de alcançar resultados definitivos que melhorem ou mantenham a qualidade de vida do paciente. É um processo de colaboração que procura prevenir ou identificar e resolver problemas relacionados a medicamentos (...) para alcançar estes objetivos uma técnica estruturada é necessária, contemplando diferentes passos:

a. a atenção farmacêutica requer que se estabeleça e se mantenha uma relação profissional entre o farmacêutico e o paciente;

b. a atenção farmacêutica requer que os registros dos medicamentos administrados ao paciente sejam arquivados, e que, com o consentimento informado do paciente se colete, organize, registre, monitore e conserve informações adicionais especificas sobre o paciente;

c. a atenção farmacêutica requer que se avalie a informação médica específica de cada paciente, e que, nos casos onde existam medicamentos prescritos, se desenvolva um plano terapêutico que conte com a participação do paciente e do prescritor" (FIP 1998, p. 2).

Ao final da década de 1990, depois de quase dez anos da introdução do conceito por Hepler e Strand, estudo de KENNIE, SCHUSTER e EINARSON (1998) mostrou que a atenção farmacêutica havia conquistado grande espaço entre educadores, organizações profissionais e pesquisadores de muitos paises do mundo. Uma busca dos autores em duas bases de dados internacionais - MEDLINE e The International Pharmaceutical Abstracts revelou um total de 979 citações entre os anos de 1989 e 1998.

Em outro estudo publicado em 2001, FERNÁNDEZ-LLIMÓS, FAUS e MARTIN (2001) apud OPAS (2001), 2510 trabalhos foram identificados a partir da palavra-chave pharmaceutical care, tendo sido 1894 trabalhos nos EUA, 139 no Reino Unido, 107 na Holanda, 92 no Canadá, 61 na Alemanha e 
40 na Espanha. No caso do Brasil, um levantamento realizado no mês de setembro de 2003, compreendendo todas as bases de dados acessiveis pelo sistema de bibliotecas integradas da Universidade de São Paulo, resultou na identificação de quatro publicações sobre o tema.

Nos paises europeus, a implantação da prática de atenção farmacêutica se deve sobretudo aos esforços do Europharm Forum, entidade de cooperação entre a OMS e diversas organizações nacionais profissionais. Segundo VAN MIL (2000), os conceitos de atenção farmacêutica utilizados na Europa são inspirados em Hepler e Strand e diferentes graus de desenvolvimento da prática coexistem nos paises da região. Para VAN MIL (2000), estas diferenças se dão em razão das distintas culturas (com forte peso para a questão lingüística), forma de operação das farmácias e forma de organização dos sistemas de saúde.

No Brasil, a origem histórica do conceito atenção farmacêutica guarda intensa relação com autores ibéricos, chilenos e argentinos que depositaram seus estudos sobre o tema situando-o no cerne da renovação da prática farmacêutica em seus países (PIÑOL 1999; ORREGO et al. 1993; PERETTA e CICCIA 1998). Atualmente dois conceitos podem ser identificados no país.

O primeiro deles foi definido pelo CFF por meio da Resolução 357 (CFF 2001) e traz a tradução literal do conceito publicado pela OMS e pela FIP em 1993. O segundo conceito, que assume a posição de consenso nacional, resultou da oficina "Atenção farmacêutica no Brasil: trilhando caminhos", realizada em 2001 pela Organização Pan-americana de Saúde (OPAS), Conselho Federal de Farmácia, Federação Nacional dos Farmacêuticos (FENAFAR), Ministério da Saúde, Rede UNIDA, Secretaria Estadual de Saúde do Ceará (SESA-CE) e Sociedade Brasileira de Farmácia Hospitalar (SBRAFH). Este consenso é definido a seguir.

"Atenção farmacêutica é um modelo de prática farmacêutica, desenvolvida no contexto da assistência farmacêutica. Compreende atitudes, valores éticos, comportamentos, 
habilidades, compromissos e co-responsabilidade na prevenção de doenças, promoção e recuperação da saúde, de forma integrada à equipe de saúde. É a interação direta do farmacêutico com o usuário, visando uma farmacoterapia racional e a obtenção de resultados definidos e mensuráveis, voltados para a melhoria da qualidade de vida. Esta interação também deve envolver as concepções dos seus sujeitos, respeitadas as suas especificidades bio-psico-sociais, sob a ótica da integralidade das ações de saúde" (OPAS 2001, p. 1516).

Segundo a OPAS (2001), a construção do consenso se deu com base na identificação de sete pontos criticos da prática farmacêutica no Brasil: (a) crise de identidade do profissional farmacêutico; (b) deficiências na formação dos profissionais farmacêuticos, excessivamente tecnicista e com incipiente formação na área clinica; (c) dissociação entre os interesses econômicos e os interesses da saúde coletiva, com predomínio daqueles em detrimento destes; (d) prática profissional desconectada das politicas de saúde e de medicamentos; (e) iniqüidade no acesso aos medicamentos; (f) inefetividade na implementação da política nacional de medicamentos; (g) falta de integração entre as entidades farmacêuticas.

Para analisar o conceito de atenção farmacêutica publicado pela OPAS (2001), relacionando-o às mudanças no setor, três vertentes de análise podem ser consideradas: (1) a vertente político-sanitária; (2) a vertente cognitiva; (3) a vertente humanística.

A primeira vertente de análise, denominada político-sanitária, é útil para que se compreenda que, no Brasil, a atenção farmacêutica está situada no contexto da assistência farmacêutica, área de maior amplitude na percepção dos atores sociais do setor. As definições de assistência farmacêutica atribuem ao farmacêutico o papel central nas ações, posicionam outros profissionais de saúde e os usuários do sistema em papéis diferentes e tratam, também de forma distinta, a relação do conceito com os sistemas de 
saúde. Nas três definições a seguir, publicadas pelo Ministério da Saúde na Política Nacional de Medicamentos (MS 1999), pelo CFF (2001) e na oficina promovida pela OPAS (2001), estas caracteristicas estão explícitas.

"Assistência farmacêutica é o grupo de atividades relacionadas com o medicamento, destinadas a apoiar as ações de saúde demandadas por uma comunidade. Envolve o abastecimento de medicamentos em todas e em cada uma de suas etapas constitutivas, a conservação e controle de qualidade, a segurança e a eficácia terapêutica dos medicamentos, 0 acompanhamento e a avaliação da utilização, a obtenção e a difusão de informação sobre medicamentos e a educação permanente dos profissionais de saúde, do paciente e da comunidade para assegurar o uso racional de medicamentos" (MS 1999, p. 34).

"Assistência farmacêutica é o conjunto de ações e serviços que visam assegurar a assistência integral, a promoção, a proteção e a recuperação da saúde nos estabelecimentos públicos e privados, desempenhados pelo farmacêutico ou sob sua supervisão" (CFF 2001).

"Assistência farmacêutica é um conjunto de ações desenvolvidas pelo farmacêutico, e outros profissionais de saúde, voltadas à promoção, proteção e recuperação da saúde, tanto no nivel individual como coletivo, tendo o medicamento como insumo essencial e visando o acesso e o seu uso racional. Envolve a pesquisa, o desenvolvimento e a produção de medicamentos e insumos, bem como a seleção, programação, aquisição, distribuição, dispensação, garantia da qualidade dos produtos e serviços, acompanhamento e avaliação de sua utilização, na perspectiva da obtenção de 
resultados concretos e da melhoria da qualidade de vida da população" (OPAS 2001, p. 14).

A segunda vertente de análise, denominada cognitiva, é útil para se perceber que a nova prática profissional começa a se estruturar a partir de uma ciência das atitudes, dos valores, dos comportamentos, das habilidades e das responsabilidades dos profissionais em um cenário multiprofissional de intervenção no processo saúde-doença. O conceito convida o farmacêutico a intervir neste processo e justifica, de certa maneira, a existência da profissão no contexto social atual.

A terceira vertente de análise, denominada humanistica, serve ao propósito de explicitar a valorização da interação farmacêutico-usuário, aspecto buscado na reorganização da prática profissional. O conceito aponta que esta interação deve se dar em um sentido amplo e integral, no qual o farmacêutico direciona suas ações na busca de resultados positivos concretos e sustentáveis na qualidade de vida do paciente, tomando como base uma compreensão integral das manifestações clínicas, expectativas, sensações, crenças, relações e limitações que caracterizam um paciente.

Ao realizar a análise do conceito de atenção farmacêutica segundo as vertentes político-sanitária, cognitiva e humanistica, a intenção é colocar em evidência a importância da adoção do conceito como elemento orientador da prática profissional em farmácias e drogarias do Brasil. Embora não seja uma ciência natural o foco desta discussão, considerar a prática farmacêutica um reflexo de uma "ciência normal" (KUHN 1996), colabora para alcançar o ponto no qual a argumentação neste capítulo quer chegar ao abrir a possibilidade de tratar do conceito de paradigma. Para KUHN (1996):

"Ciência normal significa a pesquisa firmemente baseada em uma ou mais realizações cientificas passadas. Essas realizações são reconhecidas durante algum tempo por alguma 
comunidade cientifica especifica como proporcionando os fundamentos para sua prática posterior" (KUHN 1996, p. 29).

Considerando o ponto de vista de KUHN (1996), é possível identificar dois grandes conjuntos de realizações - princípios e métodos - coexistentes dentro dos quais se estruturou a prática farmacêutica atual. Cada um destes conjuntos de realizações partilham duas caracteristicas essenciais: (a) "suas realizaçōes foram suficientemente sem precedentes para atrair um grupo duradouro de partidários, afastando-os de outras formas de atividade cientifica" e (b) "simultaneamente, suas realizações eram suficientemente abertas para deixar toda a espécie de problemas para serem resolvidos pelo novo grupo redefinido de praticantes da ciência". A cada um destes conjuntos de realizações atribui-se o conceito paradigma.

Para KUHN (1996), os paradigmas coexistem durante um determinado tempo, a partir do qual o novo adquire relevância por ser melhor sucedido que seu competidor na resolução de problemas que a comunidade reconhece como graves. Contudo, este fenômeno não possui dimensão temporal que possa levar a expectativas a respeito do momento em que se dará a ruptura. Uma das hipóteses fomentadoras deste trabalho, é que a prática farmacêutica encontra-se em um momento de pré-ruptura.

Tomando como base a observação da realidade das farmácias, das agremiações profissionais, das universidades, dos congressos científicos e da literatura da área, fontes de informação para esta análise, percebe-se que, se existe um paradigma hegemônico que caracteriza esta comunidade, o mesmo pode ser definido como paradigma tecnicista.

Estruturada a partir da escola médica positivista e forjado na sociedade moderna capitalista e industrialista, a prática farmacêutica tecnicista se caracteriza por um trabalho não humanizado, alienado de sentido e pobre de sujeitos. Nesta prática, o culto ao medicamento estrutura-se como processo central, e o medicamento reafirma-se como objeto simbólico essencial. 
Paralelamente a este fenômeno e fruto da inevitável coexistência de paradoxos nestes tempos contemporâneos, o paradigma não hegemônico e portanto em construção, pode ser chamado de paradigma humanístico.

Estruturada na interface das escolas da teoria crítica e do construtivismo, a práxis farmacêutica humanistica se caracteriza por trabalhar com o humano e a partir do humano, por relativizar os saberes e as certezas, por valorizar a individualização da necessidade e do desejo, por assumir a autenticidade dos sujeitos, a busca dos consensos e, por fim, por atribuir aos medicamentos e aos demais insumos terapêuticos o papel coadjuvante que cabe a eles, diante da integralidade das ações de saúde como estratégia da política da vida.

Conforme KUHN (1996), é possivel supor que as "crises são uma précondição necessária para a emergência de novas teorias" e que sua superação requer a renúncia concreta do paradigma tecnicista. A construção da nova práxis farmacêutica, na qual a atenção farmacêutica assume um papel fundamental, quer se constituir em um campo da ruptura. 


\section{OBJETIVOS DA PESQUISA}

"É tempo que o homem tenha um objetivo.

É tempo que o homem cultive o germe da sua mais elevada esperança."

Zaratustra $^{11}$

\subsection{Objetivo geral}

Desenvolver um modelo de acreditação de farmácias e drogarias e explorar as oportunidades de mudança na prática farmacêutica com base neste modelo.

\subsection{Objetivos específicos}

a) Desenvolver um modelo de acreditação de farmácias e drogarias com base no modelo de acreditação hospitalar e na atenção farmacêutica.

b) Investigar a relação do modelo de acreditação com a realidade das farmácias e drogarias, considerando as práticas, crenças, necessidades e desejos de empresários, farmacêuticos, balconistas, consumidores e entidades de classe.

c) Reunir informações que ajudem pesquisadores e gestores do campo farmacêutico a realizar ações acadêmicas e técnico-politicas que busquem a melhoria da qualidade das farmácias e drogarias no Brasil.

\footnotetext{
${ }^{11}$ Em "Assim falou Zaratustra", de Nietzsche, publicado em meados dos anos 1880.
} 


\subsection{Justificativa}

A realização desta pesquisa está fundamentada em uma análise de conjuntura que envolve cinco categorias explicativas: (1) cenário político; (2) organização do Estado; (3) tendências sociais contemporâneas; (4) cenário de articulações; (5) modelos existentes. Estas categorias foram construidas tomando como base SOUZA (2000), para quem a análise de conjuntura deve considerar os acontecimentos, os cenários, os atores, as relações de força e as articulações.

Considerando que muitos elementos contextuais destas categorias foram discutidos nos capítulos anteriores, o objetivo deste capitulo não é aprofundar a análise destas categorias, mas sim articular fatos e opiniões que ilustram o contexto no qual surgiu o tema deste trabalho.

Para que se compreenda melhor a escolha do tema e do objetivo do trabalho, interessa em primeiro lugar lembrar que a análise de conjuntura, como definida por SOUZA (2000), é em si mesma um ato político. Ou seja, a intenção presente nesta argumentação é mostrar aos interessados que existe mérito e relevância no tema proposto. Nas palavras de SOUZA (2000):

"A análise de conjuntura è uma mistura de conhecimento e descoberta, é uma leitura especial da realidade que se faz sempre em função de alguma necessidade ou interesse. Nesse sentido não há análise de conjuntura neutra, desinteressada: ela pode ser objetiva mas estará sempre relacionada a uma determinada visão do sentido e do rumo dos acontecimentos" (SOUZA 2000, p. 8).

O cenário político brasileiro é um cenário favorável às propostas de mudança. A vitória do Partido dos Trabalhadores e da aliança popular nas eleições de 2002, ainda que relativamente marcada por um discurso liberal 
estabilizador, não pode negar seu sentido de renovação de energias utópicas para as mudanças desejadas, necessárias ou simplesmente inevitáveis. A maior parte das forças articuladas em torno do Governo, desempenhou seu papel histórico como forças de ruptura e, mesmo que contingenciadas por pressões elitistas locais e internacionais, são forças dotadas de legitimidade e poder de convocação suficiente para alterar o curso de muitas das políticas sociais brasileiras, incluindo as políticas de saúde.

Neste sentido, à medida que no Governo estão presentes sujeitos historicamente relacionados às forças de ruptura, sobretudo os partidos de esquerda e os movimentos sociais, estão sendo articuladas as forças necessárias para alterar a formulação e a implementação das políticas sociais no Brasil. No caso do Ministério da Saúde, aqui de maior interesse, é possível reconhecer um intenso movimento de mudança a partir da chegada de quadros ligados ao movimento sanitário brasileiro.

Especificamente no campo dos medicamentos, a criação do Departamento de Assistência Farmacêutica na nova Secretaria de Ciência, Tecnologia e Insumos Estratégicos do Ministério da Saúde, a realização da I Conferência Nacional de Assistência Farmacêutica em setembro de 2003 e o processo de reorganização da Agência Nacional de Vigilância Sanitária são claras indicadores de que o setor está em busca de mudanças.

Do ponto de vista das articulações, ao menos dois elementos merecem destaque especifico. O primeiro deles diz respeito ao movimento de reforma curricular, cujos protagonistas - faculdades de farmácia, agremiações profissionais e movimento estudantil ${ }^{12}$ - alcançaram resultados importantes ao longo dos últimos anos.

Em 2002, a publicação das novas diretrizes curriculares para o curso de Farmácia pelo Conselho Nacional de Educação, convidou as organizações

\footnotetext{
${ }^{12}$ Foi a Executiva Nacional dos Estudantes de Farmácia (ENEFAR) que, na década de 1980, iniciou o processo de reforma curricular. Posteriormente as universidades e as associações profissionais passaram compor este movimento.
} 
formadoras a formar farmacêuticos com "formação generalista, humanista, crítica e reflexiva, para atuar em todos os niveis de atenção à saúde" (CFE 2002), fortalecendo a possibilidade das mudanças, como já analisaram SANTOS (1999) e IVAMA (1999).

Da mesma forma, a articulação da Organização Pan-americana de Saúde (OPAS), Conselho Federal de Farmácia, Federação Nacional dos Farmacêuticos (FENAFAR), Ministério da Saúde (MS), Rede UNIDA, Sociedade Brasileira de Farmácia Hospitalar (SBRAFH) e outros órgãos de governo e organizações da sociedade civil, em torno do tema da atenção farmacêutica, é reveladora da disposição destas organizações estratégicas em se envolverem em um processo de mudança para o setor.

Em relação aos modelos, um olhar sobre as experiências já realizadas revela que muito se pode aproveitar no processo de reorganização da assistência farmacêutica no Brasil. Os diversos programas de qualidade e acreditação hospitalar e laboratorial, a certificação de farmácias de manipulação e a gestão da qualidade total nas indústrias farmacêuticas, são alguns dos exemplos capazes de gerar boas aprendizagens para o setor.

Em um momento de tantas mudanças, em que há uma tendência social contemporânea da busca pelo novo, o exercicio de repactuar as forças e de construir a alteridade em todas as relações, os esforços de pesquisar a mudança e entender suas forças e contra-forças, de construir argumentos e provocar boas perguntas, parece ser uma tarefa justificável. Parece justificar o tema deste trabalho. 


\section{OS MÉTODOS DA PESQUISA}

"Nós nos forjaremos na ação cotidiana, criando um homem novo com uma nova técnica" Che Guevara ${ }^{13}$

\subsection{Reflexões sobre a relação pesquisador - objeto}

Uma das idéias centrais que inaugura o trabalho "O desafio do conhecimento. Pesquisa qualitativa em saúde" (MINAYO 1994) é a passagem que expressa o pensamento de BOURDIEU (1972), que afirma que "qualquer investigador deve colocar em questão os pressupostos inerentes a sua qualidade de observador externo, que tende a importar para o objeto os princípios de sua relação com a realidade, incluindo-se ai suas relevâncias".

Talvez seja este o grande desafio do conhecimento. Entre as diversas dimensões envolvidas em uma pesquisa, encontra-se o desafio de fugir das simplificações que tendem a rotular o pesquisador como dotado de uma neutralidade estéril e, por outro lado, de combater a tendência às abstrações nilistas que pouco contribuem para que a realidade seja compreendida, para que uma hipótese seja investigada e para que as perguntas da pesquisa possam ser respondidas com responsabilidade.

Há mérito e utilidade na intenção de trazer e manter este desafio na consciência do pesquisador. Há mérito, considerando que terá maior qualidade a pesquisa que, por operar um objeto na interface da sociologia e da saúde, se pautar pela compreensão de que a realidade social tem uma natureza distinta das ciências naturais. Esta diferença levará à necessidade de buscar o significado e não a freqüência ou qualquer outra dimensão exata, das práticas e do pensamento dos diversos sujeitos e grupos sociais.

\footnotetext{
${ }^{13}$ Extraido do livro Cartas a Che Guevara. O mundo, trinta anos depois, de Emir Sader.
} 
Há utilidade na medida em que a pesquisa orientada por um principio compreensivo da realidade social, esta compreendida também no universo social, como mais um agente na plural construção do conhecimento e organização da sociedade, o que relativiza sua autoridade acadêmica técnica e sua importância política; esta, não maior do que a importância dos diversos outros sujeitos e grupos componentes desta pluralidade.

Estas definições são de grande importância para a escolha do modelo da pesquisa e, sobretudo, para justificar a linha metodológica que serviu de orientação a este trabalho. As reflexões provocadas pelo estudo destes principios levaram à construção de um modelo de acreditação com base em um método de inspiração compreensiva que, segundo BRUYNE, HERMAN e SCHOUTHEETE (1991), visa apreender e explicitar o sentido da atividade social individual e coletiva enquanto a realização de uma intenção.

A realização dos estudos de caso se orienta pela mesma escola. Foram elaborados a fim de oferecer elementos úteis ao julgamento do mérito do trabalho e à utilização do conhecimento aqui construído na reorganização da práxis farmacêutica. A figura a seguir resume esta linha metodológica.

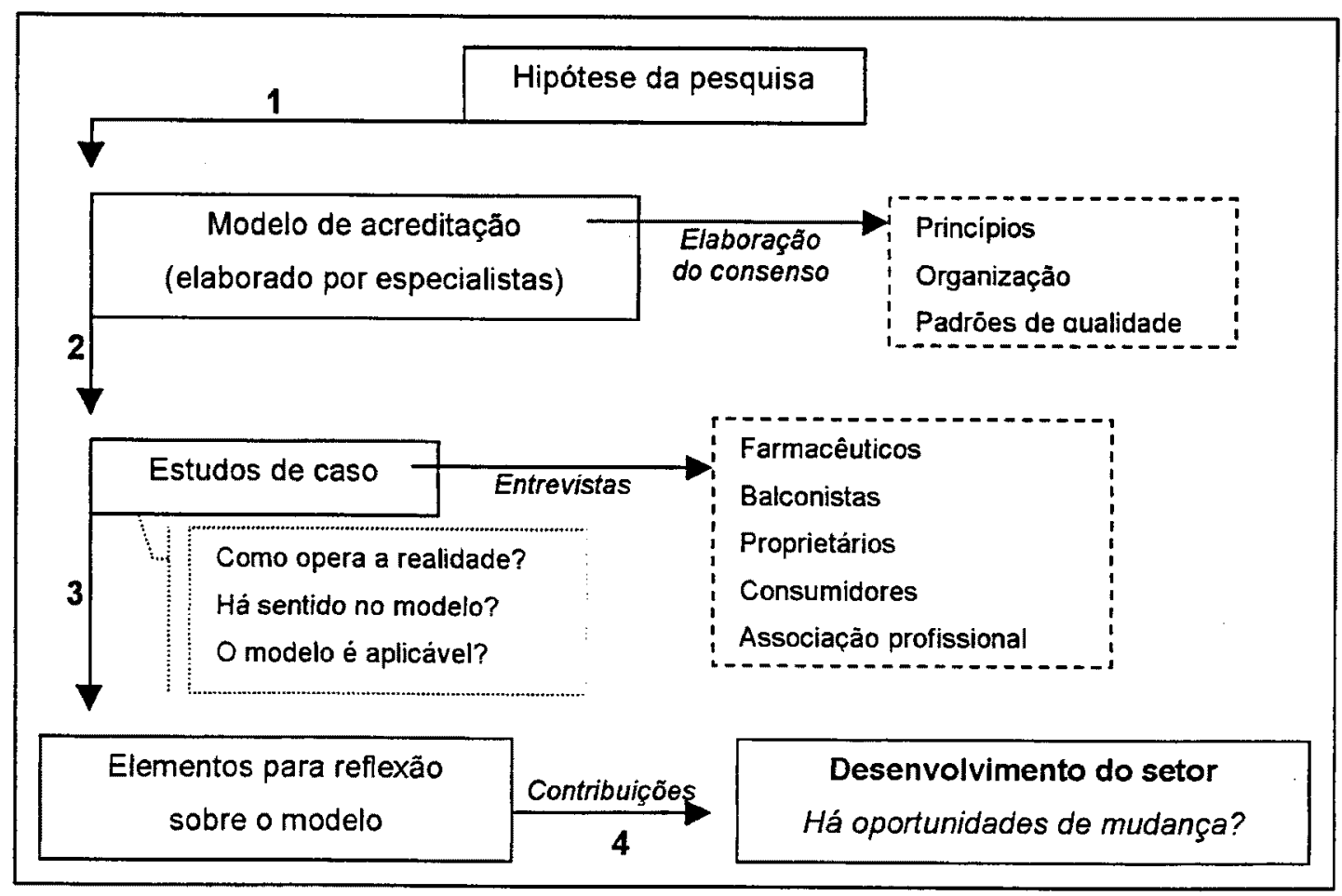

Figura 2. A linha metodológica da pesquisa. 
O desenho desta linha metodológica quer também evidenciar uma preocupação adjacente à pesquisa. Trata-se do desejo do pesquisador em colaborar para a produção de conhecimento na área da saúde e para o desenvolvimento da sociedade em um sentido mais amplo. Tomando como base THIOLLENT (1998), em seus estudos relacionados à pesquisa-ação, este trabalho se desenvolveu como uma pesquisa social com base empírica, tendo sido concebida e realizada em estreita associação com a necessidade de resolução de um problema coletivo.

Com a consciência de que este trabalho não se desenvolveu nos moldes de uma pesquisa-ação, e também que não esteve revestida de uma premissa utilitarista, ele foi gerado e tratado como uma contribuição técnica e política do pesquisador à reorganização da prática farmacêutica no Brasil. A hipótese adjacente ao trabalho reforça esta idéia.

\subsection{A hipótese de pesquisa}

Um dos papéis mais importantes que programas de melhoria de qualidade e de mudança podem cumprir nas organizações é incentivar e desenvolver atitudes de mudança nos sujeitos. Em última instância podem também contribuir para a construção de uma cultura de qualidade na organização, ponderadas as questões apresentadas no capitulo 1.1 .

Considerando esta premissa, bem como a favorável conjuntura para mudanças exploradas nos capitulos 1.1 a 1.4 e no item 2.3, a hipótese formulada para este trabalho é a seguinte: uma intervenção nas farmácias e drogarias por meio de um programa de acreditação tendo como eixos a avaliação da qualidade - com padrões para estrutura, processos e resultados - e a atenção farmacêutica, é capaz de desencadear processos de mudança que estimulem as organizações a desenvolverem seu papel sanitário com base em práticas humanizadas, centradas na construção de sujeitos e que contribuam para política de defesa da vida. 
Na poética afirmação de NOVALIS (n.d.) apud POPPER (2003), "as hipóteses são redes: só quem as lança colhe alguma coisa" encontra-se o convite para que os cientistas se lancem ao desafio de formular enunciados e de investigá-los. Além da sensibilidade, a afirmação de Novalis apresenta também um elemento fundamental à formação do pesquisador; a de que não haverá tese de fato, sem que uma hipótese anterior tenha sido formulada, como alerta TURATO (2003).

\begin{abstract}
"Não haverá tese de fato sem que tenha havido proposição de hipóteses, estranhamos a freqüência com que tantos trabalhos ditos científicos são apresentados e aprovados nas universidades sem que este caminho hipótese-tese seja explicitado nos relatórios" (TURATO 2003).
\end{abstract}

É preciso, contudo, relativizar o conceito hipótese, a fim de que ele não provoque os leitores a considerarem a hipótese segundo uma orientação positivista que, nas palavras de MINAYO (1994) "crê na possibilidade do conhecimento objetivo da realidade e nas provas estatístico-matemáticas como comprovadoras da objetividade". O papel da hipótese neste trabalho é apresentar parâmetros básicos (crenças do pesquisador) e orientar a investigação empirica qualitativa. Seu papel é também o de motivar o pesquisador a procurar respostas e a reformular hipóteses.

Não se trata, portanto, de analisar a hipótese com o mesmo papel que ela desempenha nos métodos indutivos, em que o desejo de enunciar leis gerais a partir de eventos singulares é a mola mestra da pesquisa. Nas palavras de POPPER (2003), "independente de quantos casos de cisnes brancos possamos observar, isso não justifica a conclusão de que todos os cisnes são brancos".

O desenvolvimento do marco conceitual deste trabalho e a adoção da linha metodológica que será detalhada a seguir, buscaram, acima de tudo, uma articulação coerente com esta argumentação. 


\subsection{As estratégias de investigação}

A realização desta pesquisa compreendeu duas intervenções distintas dentro da linha metodológica demonstrada na Figura 2. A primeira delas foi a elaboração do modelo de acreditação através de uma técnica não presencial de construção de consenso entre especialistas da área de saúde.

A segunda intervenção foi a realização de dois estudos de caso com o objetivo de recolher elementos do contexto das farmácias e drogarias que fossem úteis ao julgamento do mérito e relevância do modelo de acreditação, considerando expectativas e limitações daqueles que seriam seus principais atores interessados: consumidores, farmacêuticos, proprietários, gerentes das farmácias e a associação local farmacêuticos. Estas intervenções estão descritas ao longo deste capítulo.

\subsubsection{A elaboração do modelo de acreditação}

A elaboração do modelo de acreditação apresentado no capítulo 4, procurou seguir uma abordagem orientada por especialistas. Esta abordagem, conforme apontam WORTHEN, SANDERS e FITZPATRICK (1997) ao discutirem a avaliação orientada por especialistas [expertise-oriented evaluation], é conhecida como uma das mais antigas formas de elaborar padrões de orientação - ou padrões de qualidade - para determinadas áreas de conhecimento, especialmente em saúde e educação. A utilização de conhecimentos técnicos acumulados nas ciências das profissões associada à experiência prática dos profissionais no assunto específico é de grande ajuda na proposição e na escolha de protocolos de funcionamento e de padrões de qualidade.

Com base na argumentação apresentada por PATTON (2002), a construção do modelo de acreditação tomou como base um modelo metodológico prospectivo. Ou seja, a partir de intervenções qualitativas junto 
a especialistas, buscou-se construir uma imagem de padrões de qualidade que poderiam existir no futuro, servindo então como inspiração para processos de mudança e para ampliar as discussões relacionadas ao tema no momento atual.

Além da caracteristica prospectiva do envolvimento de especialistas, a técnica utilizada também apresentou as características de buscar a construção de consenso em torno de determinadas idéias, e de ser realizada de forma não presencial. Articulando idéias e princípios relacionados às técnicas Delphi (JONES e HUNTER 1999), Grupo Nominal (WKKF 1998) e Grupos de Consenso (LIST 2003), a escolha foi pela elaboração de um método de trabalho aqui denominado de formação qualitativa e não presencial de consenso, descrita e analisada a seguir.

\subsubsection{A técnica de formação de consenso}

A busca de consenso através da comunicação é um elemento fundamental para que diferentes sujeitos compartilhem suas relações objetivas, sociais e subjetivas frente a determinada situação e, a partir de então, coordenem seus planos e ações relacionadas a esta situação. Ao apresentar esta argumentação, a intenção é demonstrar que as crenças que fundamentaram a formação do consenso, têm como base algumas das concepções de HABERMAS (1989) a respeito da ação comunicativa.

"Quando um falante diz algo dentro de um contexto quotidiano, ele se refere não somente a algo no mundo objetivo (como a totalidade daquilo que é ou poderia ser o caso), mas ao mesmo tempo a algo do mundo social (como a totalidade de relações interpessoais reguladas de um modo legitimo) e a algo existente no mundo próprio, subjetivo, do falante (como a totalidade das vivências manifestáveis, às quais tem um acesso privilegiado (....) Deste ponto de vista a linguagem preenche 
três funções: (a) a função da reprodução cultural ou da presentificação das tradições (....), (b) a função da integração social ou da coordenação dos planos de diferentes atores na interação social (é nessa perspectiva que desenvolvi uma teoria do agir comunicativo), e (c) a função da socialização da interpretação cultural das necessidades" (HABERMAS $1989 \mathrm{p}$. 41).

Agir com base nestes conceitos trouxe grandes desafios à elaboração da pesquisa. Em primeiro lugar, o desafio de se posicionar em uma perspectiva de quem procura compreender o que lhe é dito ou, considerando HABERMAS (1989), assumir uma posição performativa em detrimento de uma atitude de terceira pessoa, que "diz simplesmente como as coisas se passam". Este pensamento "implica na renúncia à superioridade da posição privilegiada do observador" HABERMAS (1989), tendo em vista que o próprio pesquisador se torna sujeito da ação comunicativa e se envolve na atribuição de sentido e na validação dos discursos.

No processo de trabalho com os especialistas para a construção do consenso em torno dos padrões de qualidade da acreditação, foi inevitável que uma posição política fosse assumida no diálogo. A posição politica pode ser traduzida em quatro dimensões: (a) a posição de gerador da idéia tema; (b) a posição de provocador do debate; (c) a posição de estímulo à construção prospectiva dos padrões, evitando as amarras contextuais presentes nas quais a concretização do futuro muitas vezes parece impossivel; (d) a posição diplomática de negociação entre os especialistas do grupo. A partir destes elementos é que a "renúncia à superioridade da posição privilegiada do observador" (HABERMAS 1989) se concretizou.

Esta posição política como evidência concreta da reflexividade presente na pesquisa, também guarda em si um paradoxo positivo na construção da interação entre o pesquisador e os sujeitos da pesquisa. Para HABERMAS (1989), ao mesmo tempo que o intérprete (pesquisador) perde o 
privilégio do observador não participante, passa também a dispor de meios para manter, desde dentro, uma posição de certa imparcialidade.

O segundo desafio foi o de superar a limitação do pesquisador na interpretação dos discursos dos especialistas. Com base em HABERMAS (1989), não há qualquer garantia de que existe um fundo comum de suposições e práticas a guiar os sujeitos - especialistas e pesquisador - no processo de diálogo. Como não foi possível a identificação deste fundo comum para fins de uma pré-compreensão dos discursos, há risco de que concepções e acordos imprecisos possam ter se firmado no processo de trabalho.

Este risco é ainda reforçado pelo terceiro desafio adjacente à técnica, o desafio de compreender a integralidade dos discursos. No caso da construção não presencial, este elemento foi o mais imponderável. Para entendê-lo, é preciso considerar que "a linguagem cotidiana se estende a proferimentos não-descritivos e a pretensões de validez não cognitivas" (HABERMAS 1989). Ou seja, nos discursos estão presentes elementos simbólicos, suposições, crenças, palpites, que são a fragmentação da integra dos discursos dos sujeitos, e que precisam ser apreendidos pelo intérprete (pesquisador) a fim de avançar na construção das ações mútuas a partir da comunicação. Nas palavras de HABERMAS (1989):

\begin{abstract}
"Uma interpretação correta não é simplesmente verdadeira, como é o caso de uma proposição relatando uma interpretação correta; poder-se-ia antes dizer que uma interpretação correta convém a, é adequada a ou explicita o significado do interpretandum que os intérpretes devem alcançar" (HABERMAS 1989 p. 43).
\end{abstract}

Estes foram portanto os exercícios-desafio vinculados à elaboração de um pensamento que trouxesse sentido ao processo de construção de consenso entre os especialistas. Ao considerar as falas dos sujeitos suas 
ações verbais, provocando a construção de conhecimento a partir destas ações e explorando a relação interativa de desequilibrio e equilibrio cognitivos entre os sujeitos (SIMÃO 2000), optou-se por um caminho metodológico compreensivo, fundamental para lidar com as limitações provocadas pelo contexto não presencial em que se deu a construção.

\subsubsection{A escolha dos especialistas}

A escolha dos especialistas para a elaboração do modelo de acreditação, procurou levar em conta critérios técnicos em detrimento da inserção politica dos sujeitos no setor farmacêutico. A intencionalidade de trabalhar com critérios técnicos, baseou-se na compreensão de que o modelo a ser elaborado se configurava em um exercício acadêmico, contendo assim limitações de tempo e de legitimidade política. Não havia a expectativa de que a modelo gerado se tornasse um programa concreto ou politica setorial a partir de sua conclusão.

A utilização de um critério político para este processo, implicaria na escolha de diferentes sujeitos legítimos às organizações relacionadas ao tema da assistência farmacêutica para que o processo de elaboração e o modelo fossem legitimados nestes espaços. Para isso, além do envolvimento dos órgãos de classe da profissão farmacêutica, como conselhos profissionais, associações e sindicados; de órgãos de defesa do consumidor; de órgãos ligados ao Ministério da Saúde e da Organização Nacional de Acreditação, seria também necessário um processo de construção mais extenso, provavelmente presencial, e que fosse capaz de responder às diferenças técnicas e às divergências políticas entre estes atores.

Com isso, a escolha dos especialistas, apresentados nas primeiras páginas deste trabalho, se deu com base nos critérios listados a seguir. 
- Experiência de trabalho ${ }^{14}$ no tema da acreditação hospitalar;

- Experiência de trabalho em organismo internacional com o tema atenção farmacêutica;

- Experiência de trabalho em organismo nacional na área da construção da política nacional de medicamentos e da política nacional de assistência farmacêutica;

- Experiência de trabalho em instituição acadêmica nas áreas da saúde pública, assistência farmacêutica, farmácia hospitalar, estágio supervisionado em farmácia, ética e legislação da área farmacêutica;

口 Experiência de trabalho em farmácia ou drogaria;

- Experiência de trabalho na área da farmacovigilância;

․ Experiência de trabalho em centro de informações sobre medicamentos;

A escolha dos especialistas se deu de forma que cada um deles apresentava ao menos um dos critérios de seleção.

\subsubsection{A dinâmica de construção do consenso}

Considerando os critérios de escolha dos especialistas, entre 22 de abril e 15 de maio de 2002, 26 pessoas foram contatadas e convidadas a participar da pesquisa, conforme mostra o convite eletrônico apresentado como anexo 17. Entre os 26 convidados, 17 responderam positivamente ao convite. Ao longo dos meses de junho de 2002 a maio de 2003 de trabalho, 16 especialistas enviaram suas contribuições.

\footnotetext{
${ }^{14}$ O conceito de trabalho reúne atividade profissional como gestor, consultor e também possuir publicações na área.
} 
Entre os especialistas que responderam negativamente ao convite, a principal justificativa de não participação foi a falta de tempo para a interação com o pesquisador. Em dois casos o fator de não participação foi a dificuldade de trabalhar com o correio eletrônico. Apesar da perda inicial de cerca de 35\% dos convidados, os critérios de escolha dos especialistas permaneceram representados no grupo que prosseguiu na pesquisa.

Antes do envio do primeiro documento de trabalho aos especialistas, foi realizado um pré-teste junto a seis farmacêuticos escolhidos intencionalmente pelo pesquisador. A escolha destes atores levou em consideração parte dos critérios utilizados para a seleção dos especialistas, além do interesse em colaborar no projeto de pesquisa em seu momento de pré-teste de instrumentos.

A partir do pré-teste realizado no mês de maio de 2002 , que serviu para confirmar a clareza do primeiro documento de trabalho, este foi então enviado aos especialistas. Como pode ser visto no anexo 15 , o documento apresentava três premissas básicas da pesquisa: (a) para que estabelecimentos o modelo seria voltado; (b) a hipótese de pesquisa; (c) os princípios básicos da acreditação. Além de apresentar as premissas, solicitouse aos especialistas que listassem elementos que seriam importantes para a avaliação da estrutura, das atividades e dos resultados de uma farmácia.

A partir das primeiras contribuições dos especialistas, coube ao pesquisador realizar um processo de análise e harmonização dos pontos destacados pelo grupo. Houve, neste periodo, a necessidade de trocar correspondências eletrônicas específicas com alguns dos especialistas, considerando suas áreas de maior conhecimento e interesse. Foram também realizadas algumas conversas telefônicas com membros do grupo para elucidar pontos mais complexos ou conflituosos.

Ao final desta primeira rodada, um segundo documento de trabalho foi preparado e enviado aos especialistas. Este documento continha uma versão inicial dos padrões de qualidade para estrutura, processos e resultados. $O$ envio de documentos complementares se repetiu por mais duas vezes, sendo 
que cada nova versão do documento incorporava alterações e consensos alcançados no trabalho. Nesta fase, a idéia de que as farmácias fossem classificadas em três diferentes níveis de qualidade foi apresentada pelo pesquisador, elemento que gerou novas discussões e a construção de padrões que fossem capazes de diferenciar os estabelecimentos.

O processo de construção destes consensos passou pela leitura dos diferentes pontos de vista, pela busca por conceitos que tornassem a linguagem mais homogênea, pela idéia de que as diferentes legislações ou limitações atuais do setor, não impedissem a criação de bons padrões de qualidade e pelo princípio de que na construção do modelo, poderiam efetivamente coexistir posições antagônicas, sem que isso significasse ruptura ou oposição.

Em fevereiro de 2003, o terceiro documento era enviado aos especialistas. Além dos padrões já acordados, o documento apresentava também as primeiras idéias para o processo de acreditação, bem como a proposta de que as farmácias fossem classificadas em dois diferentes níveis de acreditação. Este documento gerou um intenso volume de trabalho e de discussões e adaptações até chegar ao documento final em abril de 2003.

\subsubsection{Os estudos de caso}

Em termos específicos, a discussão do método de estudos de caso poderia considerar o princípio de que para o estudo das ciências humanas, 0 caso mais importante é o caso do individuo específico. Sem negar a primeira asserção, STAKE (1995) acrescenta que os casos de interesse no cenário social são as "pessoas e os programas". Para ele, cada caso será similar a outras pessoas e programas de muitas maneiras, mas também serão únicos de muitas maneiras. Exatamente por compreenderem a dualidade do comum e do único, é que os estudos de caso são elementos tão interessantes no campo da pesquisa social. 
Considerando os interesses particulares desta pesquisa, os estudos de caso foram realizados com o propósito de aproximação e investigação da realidade de duas farmácias específicas. As farmácias foram tomadas como cenário a partir do qual se refletiu sobre o modelo proposto e no qual os atores puderam refletir sobre o modelo proposto, um importante movimento de duplo sentido para os sujeitos da pesquisa; aqui em seu sentido mais amplo: sujeitos nos casos, especialistas, pesquisador, orientador e membros da banca examinadora.

Para melhor compreender a opção pelos casos e as razões teóricas que levaram a sua escolha, algumas considerações são necessárias. Em linhas gerais, é preciso destacar que os casos geralmente possuem limites específicos, sejam organizacionais, geográficos ou inerentes à sua natureza por exemplo, quando o caso é um indivíduo. Nas palavras de STAKE (1995), "em nosso trabalho na área social, um caso chega a ser quase resoluto" ${ }^{15}$ [purposive], quase possuidor de seu próprio eu".

Ainda segundo STAKE (1995), três diferentes agrupamentos de estudos de caso são importantes para se escolher os instrumentos de investigação e análise a serem utilizado: (a) os estudos de caso intrínsecos, em que existe um interesse genuíno do pesquisador por conhecer em profundidade um caso específico; (b) os estudos de caso instrumentais, em que existe uma pergunta ou problema geral motivador do estudo, que é tomado como elemento particular de análise do problema; (c) os estudos de caso coletivos, que em certa medida compartilham as duas naturezas de maneira conjugada.

No caso da presente pesquisa, a identificação se dá com um estudo de caso instrumental, em que a pergunta essencial reside no mérito e aplicabilidade do modelo de acreditação. Esta afirmação não deve, contudo,

\footnotetext{
15 "Resoluto" foi considerada a melhor tradução contextual para "purposive", a fim de demonstrar autoconsciência e capacidade de se movimentar, de se desenvolver de forma autônoma.
} 
levantar o pressuposto de que a intenção dos estudos de caso foi oferecer um exemplo representativo dos milhares de outros casos existentes e que poderiam ser estudados. Como afirma STAKE (1995), "nós não estudamos casos primariamente para entendermos outros casos", mas sim para ajudar na compreensão do sentido da hipótese de pesquisa.

Da forma como argumenta STAKE (1995), o primeiro critério de escolha de estudos de caso como técnicas é a maximização daquilo que se pode aprender de sua especificidade ou da pergunta instrumental. Estudos de caso podem ser uma base pobre para generalizações, mas um excelente espaço para o exercicio da interpretação. Esta mesma afirmação encontra apoio em diversos autores-chave para a pesquisa social em saúde, entre eles MINAYO (1994), TURATO (2003), ZIONI (1994) e REY (2002). BRUYNE (1982) apud ZIONI (1994) afirma que um estudo de caso constitui-se em:

"uma análise intensiva empreendida numa única ou em algumas organizações reais (...) Reúne informações tão numerosas e detalhadas quanto possivel com vistas a apreender a totalidade de uma situação (....) Por isso recorre à técnica de coleta de informações igualmente variadas (observações, entrevistas, documentos)" (BRUYNE apud ZIONI 1994, p. 65).

Os próximos sub-capítulos explicitam a mecânica de estruturação dos dois estudos de caso, incluindo a escolha das farmácias, dos indivíduos, das técnicas de coleta de dados e de sua análise. Nas palavras de STAKE (1995), ainda que "um olhar afiado" e "estar aberto para novas impressões" sejam elementos importantes para a pesquisa qualitativa, "bons estudos de caso dependem de disciplina". 


\subsubsection{A escolha dos casos: as farmácias em Londrina}

Londrina situa-se na região norte do Estado do Paraná, a $379 \mathrm{Km}$ da capital do Estado, Curitiba. Possui uma área de $1724,7 \mathrm{~km}^{2}$ e ocupa aproximadamente $1 \%$ do território do Estado, sendo o centro econômico e cultural de referência para uma região de cerca de um milhão e meio de habitantes. O clima local caracteriza-se como subtropical úmido com temperaturas que oscilam entre 27,0 e $15,5^{\circ} \mathrm{C}$ nas estações de verão e inverno, respectivamente (PML 1996).

A região norte do Paraná recebeu grande imigração nas décadas de 1950 e 1960, ocasionada principalmente pelo crescimento vertiginoso da cafeicultura, o que conferiu à cidade o titulo de capital mundial do café naquela época (SILVA 1999). Conseqüência de uma constante urbanização, Londrina, hoje com 65 anos, possui uma população de 447.065 habitantes, com $96,93 \%$ deles na zona urbana, e uma taxa de alfabetização de $93,6 \%$ (FIBGE 2000). Atualmente Londrina tem a soja, além de outros negócios agropecuários e o setor de serviços, como principais atividades econômicas.

Sua população distribui-se pelo território municipal de forma a concentrar-se no extremo norte, onde está a zona urbana. A pequena parcela rural da população encontra-se distribuida em vários distritos, principalmente na região sul do municipio (RODELLO 1998).

A pirâmide populacional do município revela uma concentração da população nas faixas etárias entre 30 e 59 anos. A população acima de 60 anos soma $7,32 \%$ do total, enquanto a população de 0 a 4 anos alcança os 10\% (PML 1996). Em 2002 Londrina apresentou um Coeficiente de Mortalidade Infantil igual a 10,8 por mil nascidos vivos (PML 2003). A estrutura do sistema de saúde local, considerando setores privado e público, é bastante desenvolvida, como confirmam as análises da história da implementação do Sistema Único de Saúde no município, extensamente explorada em outras pesquisas (ALMEIDA 1979; SILVA 1996; SILVA 1999; PÉTRIS 1999). 
Quanto à organização do setor farmacêutico, dados do Conselho Regional de Farmácia do Estado do Paraná (CRF 2003a, 2003b), revelam a existência de 211 farmácias e drogarias no município. Segundo PÉTRIS (1999), a categoria farmacêutica no municipio é formada por 413 profissionais. Para estes, as duas principais áreas de atuação profissional são a dispensação de medicamentos, onde atuam 159 (38,49\%) farmacêuticos e as análises clínicas, onde atuam $91(22,03 \%)$.

Ainda segundo o autor, a faixa etária média dos profissionais é de 35,6 anos de idade, sendo que entre aqueles que atuam em farmácias, este número é menor $(33,8)$. Para os profissionais ligados diretamente às atividades de dispensação, a média do tempo de formado é de 10,7 anos, sendo que $50 \%$ deles se formaram a menos de 7 anos. Dentre estes profissionais, 66,0\% são do sexo feminino (PÉTRIS 1999).

Dentre os 413 farmacêuticos em atividade, 59,0\% possuem formação em farmácia com habilitação para o exercício das análises clínicas, sendo que $82,8 \%$ deles graduaram-se em universidades localizadas no Estado do Paraná. Entre os farmacêuticos do municipio, 13,0\% possuem curso de pósgraduação. Considerando os farmacêuticos que atuam diretamente em farmácias, 37,0\% são proprietários das mesmas (PÉTRIS 1999).

Alguns elementos determinaram a escolha do municipio de Londrina para a realização dos estudos de caso: (a) organização sanitária, (b) perfil de assistência farmacêutica; (c) existência de pesquisadores no município interessados em colaborar com a pesquisa; (d) interesse da associação local de farmacêuticos em colaborar com a pesquisa; (e) existência de farmácias interessadas em colaborar com a pesquisa; (f) existência de farmácias de duas naturezas na região (unidades de redes e farmácias isoladas); (g) possibilidade de realização da coleta de dados de acordo com o cronograma previsto para a pesquisa. Cada um destes elementos está analisado a seguir.

O Estado do Paraná possui uma legislação sanitária na área farmacêutica que resultou na ampliação da oferta de procedimentos técnicos nas farmácias do Estado. Entre os procedimentos estão a aferição de pressão 
arterial, as medidas de glicemia e colesterolemia, a administração de inaloterapia e a administração de medicamentos injetáveis. Em razão deste arcabouço, definido principalmente na Resolução 54 (SESA/PR 1996), o parque estadual farmacêutico apresenta melhores condições que outros Estados da União para o estudo do modelo de acreditação proposto.

Historicamente, o Conselho Regional de Farmácia do Estado do Paraná é reconhecido pela seriedade e severidade com que exige a presença de profissionais farmacêuticos nas farmácias. Como será ilustrado adiante, nas farmácias escolhidas para o estudo de caso havia a presença de farmacêuticos durante todo o horário de funcionamento, mesmo naquela que configura o Caso 1, operando em regime 24 horas.

No processo de escolha do local dos estudos de caso, o interesse de pesquisadores locais em colaborar com a pesquisa exerceu também um papel importante. O papel destes pesquisadores, tanto vinculados à Universidade Estadual de Londrina quanto a Universidade do Norte do Paraná, foi de grande importância para a articulação das várias atividades compreendidas pela pesquisa.

Foi também importante o interesse da Associação de Farmacêuticos de Londrina (AFL) em debater o modelo de acreditação, assim como em participar como um dos atores entrevistados na fase dos estudos de caso. $\mathrm{Na}$ compreensão desta Associação, o modelo de acreditação poderia trazer elementos para reflexão sobre a prática profissional, além de ajudá-los a planejar suas ações de educação continuada para os associados.

Por fim, o interesse e a disposição das farmácias consultadas em participar da pesquisa foram determinantes. Quatro redes de farmácias foram identificadas em Londrina, além de duas cooperativas e um grande número de farmácias isoladas. Com a decisão de estudar duas farmácias de natureza diferente, um refinamento dos critérios foi realizado, sendo eles: (a) excluir as cooperativas, pois sua organização nem configurava uma rede de propriedade e padrões únicos, nem uma farmácia isolada; (b) excluir as farmácias isoladas que não fossem de propriedade de farmacêuticos, pois a intenção era estudar 
a realidade de um profissional que cumpre tanto a função gerencial quanto a técnica; (c) estudar uma farmácia que estivesse localizada em uma área de grande movimentação populacional; (d) estudar uma farmácia localizada em um local de pequena movimentação populacional; (e) operar com farmácias que pudessem atender às limitações do cronograma da pesquisa.

Duas redes de farmácia e uma farmácia isolada foram contatadas e a elas foram expostas as intenções e os procedimentos da pesquisa. Tendo uma das redes e a farmácia isolada aceitado participar da pesquisa, foram então propostas a unidade da rede a ser estudada bem como o cronograma do estudo, sugestões que não encontraram qualquer barreira. $O$ anexo 1 apresenta o termo de cooperação estabelecido entre o pesquisador e estas farmácias.

A seguir são apresentadas algumas caracteristicas das duas farmácias estudadas, com base no roteiro de diagnóstico das farmácias (anexo 3). 0 caso 1 diz respeito à farmácia da rede e o caso 2 à farmácia isolada.

Tabela 1. Distribuição dos funcionários que trabalham nas farmácias.

\begin{tabular}{lcc}
\hline Função & Caso 1 & Caso 2 \\
\hline Proprietários $^{16}$ & 0 & 1 \\
Gerentes $^{\text {Sub-gerentes }}$ & 1 & 0 \\
Farmacêuticos & 2 & 0 \\
Balconistas / Atendentes & 3 & 1 \\
Caixas & 5 & 1 \\
Entregadores / Office-boy & 3 & 0 \\
Total & 1 & 1 \\
\hline
\end{tabular}

Fonte: Diário de campo, Londrina, 2003.

\footnotetext{
${ }^{16}$ No caso 2 a farmacêutica é sócia-proprietária da farmácia.
} 
Tabela 2. Volume de faturamento ao longo de 2001 , em Reais.

\begin{tabular}{lcc}
\hline Trimestres & Caso 1 & Caso 2 \\
\hline Primeiro trimestre & $355.738,87$ & $27.000,00$ \\
Segundo trimestre & $374.339,70$ & $24.000,00$ \\
Terceira trimestre & $346.053,12$ & $30.000,00$ \\
Quarto trimestre & $364.599,82$ & $33.000,00$ \\
Total & $1.440 .731,51$ & $114.000,00$ \\
\hline
\end{tabular}

Fonte: Diagnóstico das farmácias (anexo 3), Londrina, 2003.

Tabela 3. Origem do faturamento em percentual.

\begin{tabular}{lcc}
\hline Origem & Caso 1 & Caso 2 \\
\hline Convênios & $30,0 \%$ & $10,0 \%$ \\
Venda espontânea & $70,0 \%$ & $90,0 \%$ \\
Total & $100,0 \%$ & $100,0 \%$ \\
\hline Fonte: Diagnóstico das farmácias (anex0 3), Londrina, 2003.
\end{tabular}

Fonte: Diagnóstico das farmácias (anexo 3), Londrina, 2003.

\subsubsection{As dimensões exploradas nos estudos de caso}

As técnicas de coleta de dados utilizadas nos estudos de caso, descritas em detalhes no item 3.3.2.4, procuraram explorar dois aspectos. Em primeiro lugar o estado da arte dos serviços oferecidos pelas farmácias, a fim de reunir elementos para melhor compreender a importância da utilização do modelo de acreditação como ferramenta de qualificação das farmácias. Em segundo lugar, os pontos críticos para a implementação do modelo de acreditação na realidade dos casos.

As duas dimensões não foram consideradas categorias de análise estabelecidas a priori. Foram sim construidas como forma de sustentar a

\footnotetext{
${ }^{17}$ Valores aproximados.
} 
coleta de dados, elemento diretamente relacionado à exploração da hipótese da pesquisa. A partir da atitude intencional de se explorar estas dimensões, se deu a escolha dos informantes-chave ${ }^{18} e$, posteriormente, das técnicas a serem utilizadas.

A articulação entre as dimensões a serem exploradas e os informanteschave escolhidos, sustentou a decisão de se trabalhar sobretudo com entrevistas que pudessem trazer componentes biográficos dos entrevistados. Buscar estes componentes foi uma forma de investigar a realidade nos casos sob a influência da pergunta fundamental da etnografia: qual é a cultura deste grupo de pessoas? Este parece ter sido um elemento fundamental para se compreender os processos de mudança organizacional, como anteriormente discutido no capítulo 1.2 à luz da argumentação de CHANLAT (1996).

A fim de relativizar o peso do conceito "etnografia" neste estudo, considerando que ele não está sob a batuta da antropologia, pode-se citar PATTON (2002), que discute o conceito de etnografia aplicada, como ciência interessada em entender a cultura, especialmente em relação aos esforços de mudança. PATTON (2002) reforça a importância desta discussão, tendo em vista o crescente interesse pela cultura nos estudos organizacionais.

Estes foram portanto os elementos que delimitaram a escolha dos informantes-chave e das técnicas de coleta de dados.

\subsubsection{Os informantes-chave}

A escolha dos informantes-chave se deu a partir do contato inicial com as farmácias a serem estudadas, momento em que o roteiro de diagnóstico foi aplicado. A partir da compreensão do cenário, foram realizados convites

\footnotetext{
${ }^{18}$ O conceito informante-chave será utilizado no contexto das técnicas e procedimentos de coleta de dados, para indicar o indivíduo intencionalmente escolhido para a entrevista ou grupo focal. Neste texto entrevistado é sinônimo de informante-chave.
} 
individuais para a participação nas entrevistas e grupos focais, conforme poderá ser melhor compreendido adiante. Os informantes-chave escolhidos e a razão da escolha estão a seguir.

- Farmacêuticos: escolhidos em razão de ocuparem um papel estratégico na reorganização da prática profissional e na melhoria das condições estruturais e processuais das farmácias. Os farmacêuticos são os agentes centrais na implantação e implementação da atenção farmacêutica, eixo fundamental do modelo de acreditação.

Atendentes (balconistas): escolhidos em razão de ocuparem um papel de grande importância na qualidade dos serviços desenvolvidos pela farmácia, sobretudo por seu papel primário de venda de medicamentos. Em razão desta atividade e, ao mesmo tempo, do potencial que possuem para se transformarem em agentes sanitários, está reservado a eles um papel importante nos processos de mudança.

- Gerentes e subgerentes: escolhidos em razão de exercerem um papel de decisão que tem grande importância na qualidade dos serviços e nos processos de mudança organizacional.

Proprietários das farmácias: escolhidos em razão de exercerem o papel fundamental de decisão do investimento em processos de mudança.

- Consumidores: escolhidos em razão de serem o sujeito central das ações desenvolvidas por uma farmácia e em razão da posição central que ocupam nos processos de atenção farmacêutica. 
- Presidente da Associação dos Farmacêuticos de Londrina: escolhido em razão de seu papel de liderança da categoria, de interlocução com outros setores e organizações da sociedade e de reorganização da prática farmacêutica.

\subsubsection{Formas de coleta de informação}

Duas técnicas foram utilizadas para a coleta de informaçōes junto aos informantes-chave: (a) entrevistas individuais e (b) grupos focais. O motivo central da escolha das entrevistas para o trabalho encontra-se no lugar de destaque que a comunicação ocupa na pesquisa qualitativa. Além das considerações já realizada a respeito da ação comunicativa de HABERMAS (1989), destaca-se as palavras de REY (2002).

\footnotetext{
"É preciso aceitar a natureza diferenciada do objeto de pesquisa das ciências sociais e humanas, o qual é um sujeito interativo, motivado e intencional, que adota uma posição em fase das tarefas que enfrenta. A investigação sobre esse sujeito não pode ignorar essas características gerais; é, entre outras coisas, um processo de comunicação entre pesquisador e pesquisado, um diálogo permanente que toma diferentes formas" (REY 2002, p. 53).
}

Os espaços criados pelas entrevistas individuais e coletivas são privilegiados na atribuição de sentido ao processo de coleta de dados - para pesquisador e pesquisado - e também na contextualização das informações recolhidas, considerando a impossibilidade de isolar as caracteristicas subjetivas dos indivíduos do contexto em que se manifestam. $A$ intenção de obter informações de caráter biográfico e que contivessem também posturas desejosas destes entrevistados, não poderia prescindir de criar e cuidar dos espaços de diálogo face a face. 
Este cuidado pode ser expresso em quatro premissas relacionadas às interações pesquisador-entrevistados, criadas a partir de uma reflexão crítica da argumentação de REY (2002) a respeito do lugar ocupado pela comunicação na pesquisa qualitativa. São elas: (a) a presença do pesquisador representa um elemento de sentido que influencia de forma marcante o envolvimento do entrevistado na pesquisa; (b) os entrevistados não respondem linearmente às perguntas de natureza aberta que Ihes são feitas, mas sim constróem argumentos na interação com o pesquisador e manifestam em suas respostas, contradições estimuladas pelo próprio exercício de comunicação; (c) uma pergunta aberta não encerra seu potencial nas categorias estabelecidas a priori e mesmo no momento único em que ela ocorre, mas costuma se desdobrar e manter-se latente em outros espaços e momentos vividos pelo entrevistado; (d) todo contato pesquisadorentrevistado é uma intervenção. $A$ tabela 4 resume os informantes-chave e as técnicas de coleta.

Tabela 4. Distribuição dos informantes-chave segundo técnicas e casos de estudo.

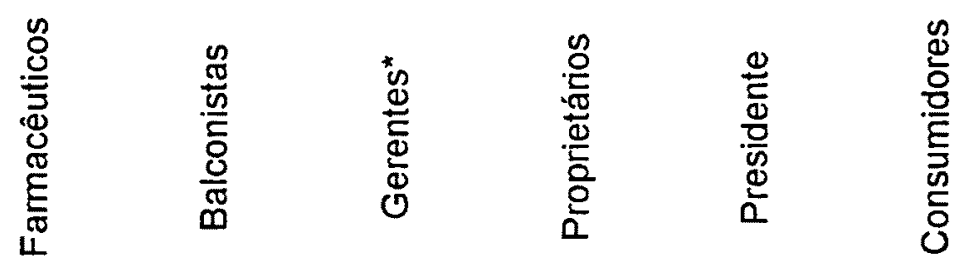

\section{Caso 1}

$\begin{array}{lllllll}\text { Entrevistas individuais } & 3 & 4 & 3 & 2 & 0 & 0 \\ \text { Grupo focal } & 0 & 0 & 0 & 0 & 0 & 4\end{array}$

Caso 2

\begin{tabular}{lllllll} 
Entrevistas individuais & 1 & 1 & 0 & 0 & 0 & 0 \\
Grupo focal & 0 & 0 & 0 & 0 & 0 & 7 \\
AFL & 0 & 0 & 0 & 0 & 1 & 0 \\
Total & 4 & 5 & 3 & 2 & 1 & 11 \\
\hline
\end{tabular}

Fonte: Diário de campo, Londrina, 2003. 


\section{a) Entrevistas individuais}

A técnica de entrevistas individuais foi escolhida em razão da possibilidade que oferecem para a exploração das dimensões subjetivas dos entrevistados. Segundo MINAYO (1994), ao lado da observação participante, a entrevista, "tomada no sentido amplo de comunicação verbal, e no sentido estrito de colheita de informações sobre determinado tema científico" é a técnica mais utilizada na pesquisa social em saúde. Neste estudo, em que a intenção era explorar aspectos subjetivos dos entrevistados - atitudes, opiniões e valores - e não objetivos, a técnica assumiu um papel de grande relevância para a compreensão da hipótese de pesquisa.

Para PATTON (2002), o propósito das entrevistas é permitir que o entrevistador consiga entrar na perspectiva do entrevistado, o que define um pressuposto de que a perspectiva do entrevistado realmente faz sentido, pode gerar novos conhecimentos e pode ser explicitada para a sociedade. Em complemento à afirmação de PATTON (2002), JAHODA (1951) apud MINAYO (1994), afirma que as entrevistas, como fontes de informação, podem fornecem informações de diversas naturezas.

\footnotetext{
"Fatos, idéias, crenças, maneira de pensar; opiniões, sentimentos, maneiras de sentir; maneiras de atuar; conduta ou comportamento presente ou futuro; razões conscientes ou inconscientes de determinadas crenças, sentimentos, maneiras de atuar ou comportamento" (JAHODA 1951 apud MINAYO 1994, p. 108).
}

Ainda segundo MINAYO (1994), o que torna a entrevista um instrumento privilegiado de coleta de informações para as ciências sociais é a possibilidade da fala ser reveladora de condições estruturais, de sistemas de valores, normas e simbolos (sendo ela mesma um deles), e ao mesmo tempo ter a magia de transmitir, através de um informante-chave, as representações 
de determinado grupo em seu contexto especifico. Os anexos $8,9,10,11$ e 14 trazem os roteiros de entrevistas utilizados neste trabalho.

\section{b) Grupos focais}

A técnica de grupo focal tem grande valor para a pesquisa em saúde. Surgida na década de 1950 no campo da pesquisa de mercado (PATTON 2002), os grupos focais tornaram-se uma importante técnica de pesquisa qualitativa em diversas áreas de conhecimento (MINAYO 1994). Dentre as várias definições existentes para grupos focais (PATTON 2002; MINAYO 1994; LIST 2003; WORTHEN, SANDERS e FITZPATRICK 1995) a adotada neste trabalho é a apresentada por DEAN (1994).

"Um grupo focal é uma discussão informal realizada em pequenos grupos, preparada para obter informações qualitativas em profundidade. Individuos são especificamente convidados para participarem na discussão e geralmente têm alguma coisa em comum (....) e são encorajados a falar uns com os outros a respeito de suas experiências, preferências, necessidades, observações e percepções. A conversação é conduzida por um moderador que tem o objetivo de promover a interação" (DEAN 1994).

Neste estudo em particular, a escolha da técnica se baseou na necessidade de conhecer as percepções e os desejos de consumidores freqüentadores das farmácias em estudo. Os grupos focais foram importantes para criarem um ambiente propício à discussão e reflexão do tema da qualidade das farmácias, no qual se pôde alcançar maior profundidade na investigação. Dois grupos focais foram realizados, um em cada caso. 
Para a escolha dos consumidores que participaram dos grupos focais, foi realizado um estudo de freqüência de utilização da farmácia com base em um recorte de semana típica. Na semana de 7 a 11 de abril, que compreendeu uma semana sem feriados ou quaisquer tipos de eventos que pudessem interferir de maneira significativa na freqüência às farmácias, pesquisadores auxiliares aplicaram um questionário a fim de explorar o perfil dos consumidores das farmácias a serem estudadas.

Os pesquisadores atuaram ao longo do horário comercial (das 08:00 às 19:00 horas), abordando consumidores que deixavam a farmácia utilizando o questionário presente no anexo 4, além de uma ficha para registro daqueles que se recusassem a responder ao questionário (anexo 6). Considerando os elementos no pré-teste deste procedimento, realizado na semana anterior à intervenção, um termo de consentimento informado foi incorporado ao questionário (anexo 4) e foi descartado o recolhimento da assinatura dos entrevistados nesta primeira abordagem.

O pré-teste revelou que quando os consumidores eram abordados pelos pesquisadores auxiliares ao sairem da farmácia, o índice de rejeição à participação na pesquisa era muito elevado (cerca de 60\%) quando o entrevistado tinha que ler e assinar o termo de consentimento informado. Considerando a natureza do questionário aplicado aos consumidores, a assinatura do consentimento informado foi descartada, mantendo-se sua leitura e verificação de entendimento. Este foi o caminho viável da pesquisa considerando as normas para pesquisa envolvendo seres humanos (CNS/CONEP 1996).

A técnica de recorte por semana típica permitiu a caracterização dos consumidores da farmácia, como mostram as tabelas 5 a 11 , resultando na escolha posterior dos consumidores que participariam nos grupos focais. As informaçōes aqui apresentadas foram sistematizadas no Software Epi-Info versão 6.0. de 1995. 
Tabela 5. Distribuição dos consumidores segundo faixa etária.

\begin{tabular}{lcccc}
\hline Faixa etária & \multicolumn{2}{c}{ Caso 1 } & \multicolumn{2}{c}{ Caso 2 } \\
\hline & $n$ & $\%$ & $n$ & $\%$ \\
17 a 25 anos & 39 & 17,5 & 25 & 19,8 \\
26 a 35 anos & 58 & 26,0 & 33 & 26,2 \\
36 a 45 anos & 57 & 25,6 & 31 & 24,6 \\
46 a 55 anos & 41 & 18,4 & 16 & 12,7 \\
56 a 65 anos & 18 & 8,1 & 13 & 10,3 \\
66 anos e mais & 10 & 4,5 & 8 & 6,3 \\
Total & 223 & 100,0 & 126 & 100,0 \\
\hline
\end{tabular}

Fonte: Questionário para os consumidores (anexo 4), Londrina, 2003.

Tabela 6. Distribuição dos consumidores segundo o sexo.

\begin{tabular}{lcccc}
\hline Sexo & \multicolumn{2}{c}{ Caso 1 } & \multicolumn{3}{c}{ Caso 2 } \\
\hline \multirow{3}{*}{ Feminino } & $\mathrm{n}$ & $\%$ & $\mathrm{n}$ & $\%$ \\
Masculino & 104 & 46,6 & 85 & 67,5 \\
Total & 119 & 53,4 & 41 & 32,5 \\
\hline Fon & 223 & 100,0 & 126 & 100,0 \\
\hline
\end{tabular}

Fonte: Questionário para os consumidores (anexo 4), Londrina, 2003.

Tabela 7. Distribuição dos consumidores segundo renda familiar.

\begin{tabular}{lcccc}
\hline Salários mínimos & \multicolumn{2}{c}{ Caso 1 } & \multicolumn{3}{c}{ Caso 2 } \\
\hline & $n$ & $\%$ & 15 & 11,9 \\
De 0 a 2 & 18 & 8,1 & 23 & 18,3 \\
De 2 a 4 & 46 & 20,6 & 16 & 12,7 \\
De 4 a 6 & 32 & 14,3 & 40 & 31,7 \\
De 6 a 10 & 52 & 23,3 & 10 & 7,9 \\
De 10 a 14 & 24 & 10,8 & 5 & 4,0 \\
De 14 a 18 & 22 & 9,9 & 17 & 13,5 \\
Acima de 18 & 29 & 13,0 & 126 & 100,0 \\
Total & 223 & 100,0 &
\end{tabular}

Fonte: Questionário para os consumidores (anexo 4), Londrina, 2003. 
Tabela 8. Distribuição dos consumidores segundo escolaridade.

\begin{tabular}{lcccc}
\hline Escolaridade & \multicolumn{2}{c}{ Caso 1 } & \multicolumn{2}{c}{ Caso 2 } \\
\hline Nunca freqüentou a escola & $\mathrm{n}$ & $\%$ & $\mathrm{n}$ & $\%$ \\
Ensino fundamental incompleto $\left(4^{\mathrm{a}}\right)$ & 2 & 0,9 & 2 & 1,6 \\
Ensino fundamental incompleto $\left(8^{\mathrm{a}}\right)$ & 15 & 6,7 & 16 & 12,7 \\
Ensino fundamental completo & 17 & 7,6 & 11 & 8,7 \\
Ensino médio incompleto & 12 & 5,4 & 10 & 7,9 \\
Ensino médio completo & 86 & 8,1 & 7 & 5,6 \\
Ensino superior incompleto & 21 & 38,6 & 30 & 23,8 \\
Ensino superior completo & 51 & 22,4 & 18 & 14,3 \\
Năo respondeu & 1 & 0,4 & 0 & 0,0 \\
Total & 223 & 100,0 & 126 & 100,0 \\
\hline
\end{tabular}

Fonte: Questionário para os consumidores (anexo 4), Londrina, 2003.

Tabela 9. Distribuição dos consumidores segundo freqüência de visita à farmácia.

\begin{tabular}{lcccc}
\hline Escolaridade & \multicolumn{2}{c}{ Caso 1 } & \multicolumn{2}{c}{ Caso 2 } \\
\hline & $n$ & $\%$ & $n$ & $\%$ \\
Uma vez ao mês & 87 & 39,0 & 25 & 19,8 \\
Duas vezes ao mês & 48 & 21,5 & 53 & 42,1 \\
Três vezes ao mês & 23 & 10,3 & 6 & 4,8 \\
Quatro vezes ao mês & 17 & 7,6 & 15 & 11,9 \\
Cinco vezes ao mês ou mais & 45 & 20,2 & 21 & 16,7 \\
Não respondeu & 3 & 1,3 & 6 & 4,8 \\
Total & 223 & 100,0 & 126 & 100,0 \\
\hline
\end{tabular}

Fonte: Questionário para os consumidores (anexo 4), Londrina, 2003.

Tabela 10. Distribuição dos consumidores segundo uso contínuo de medicamentos.

\begin{tabular}{lcccc}
\hline Salários mínimos & \multicolumn{2}{c}{ Caso 1 } & \multicolumn{2}{c}{ Caso 2 } \\
\hline \multirow{2}{*}{ Sim } & $n$ & $\%$ & $n$ & $\%$ \\
Não & 69 & 30,9 & 53 & 42,1 \\
Total & 154 & 69,1 & 73 & 57,9 \\
& 223 & 100,0 & 126 & 100,0 \\
\hline
\end{tabular}

Fonte: Questionário para os consumidores (anexo 4), Londrina, 2003. 
Tabela 11. Distribuição dos consumidores que fazem uso contínuo de medicamentos segundo classe terapêutica.

\begin{tabular}{lcccc}
\hline Salários mínimos & \multicolumn{2}{c}{ Caso 1 } & \multicolumn{2}{c}{ Caso 2 } \\
\hline Medicamentos que atuam no Aparelho Circulatório & $n$ & $\%$ & $n$ & $\%$ \\
Medicamentos Hipoglicemiantes & 17 & 24,6 & 13 & 24,5 \\
Medicamentos Contraceptivos & 8 & 11,6 & 2 & 3,8 \\
Antidepressivos e outros que atuam no SNC & 16 & 23,2 & 10 & 18,9 \\
Medicamentos que atuam no Aparelho respiratório & 3 & 4,3 & 9 & 17,0 \\
Outros & 1 & 1,4 & 3 & 5,7 \\
Total & 24 & 34,8 & 16 & 30,2 \\
\hline
\end{tabular}

Fonte: Questionário para os consumidores (anexo 4), Londrina, 2003.

Além dos 349 consumidores entrevistados ao longo da semana nos dois casos, foram registradas 83 recusas neste processo de coleta de informações no Caso 1 e 49 recusas no Caso 2, totalizando 481 consumidores abordados ao longo da semana típica.

Com base nestas informações, sete consumidores foram convidados a participar nos grupos de estudo em cada caso. Com base nas informações recolhidas nas entrevistas, os consumidores foram escolhidos com base no seguinte perfil: (a) faixa etária entre 36 e 55 anos; (b) homens e mulheres na mesma proporção; (c) renda familiar entre 4 a 10 salários minimos; (d) estar cursando ou ter cursado o ensino médio; (e) visitar a farmácia até duas vezes ao mês; (f) fazer uso contínuo de algum tipo de medicamento.

$O$ roteiro utilizado nos grupos focais, moderados pelo pesquisador, estão presentes no anexo 12. Nos anexos 7 e 13 estão presentes, respectivamente, o termo de consentimento para participação no grupo focal, lido e assinado em duas vias pelos participantes e a carta de agradecimento por sua participação no grupo, entregue a eles ao final da atividade. No anexo 5 está o documento "Procedimentos de Pesquisa" que foi preparado para o treinamento dos pesquisadores auxiliares que realizaram parte dos procedimentos de pesquisa em Londrina. 


\subsubsection{A forma de analisar as informações}

A análise das informações recolhidas através das entrevistas individuais e grupos focais, se deu através da técnica de análise temática. Considerando as diferentes interpretações possiveis para as diversas correntes que trabalham com a análise das falas dos indivíduos, como pode ser visto em MINAYO (1994), o caminho adotado neste trabalho foi a valorização qualitativa de determinados aspectos presentes nas falas dos entrevistados, sem qualquer pretensão de considerar a dimensão quantitativa da freqüência dos temas.

Para MINAYO (1994), a "noção de tema está ligada a uma afirmação a respeito de determinado assunto". Citando BARDIN (1979) e UNRUG (1974) apud MINAYO (1994), a importância do tema como fundamentação da análise temática é destacada em duas passagens.

"O tema é a unidade de significação que se liberta naturalmente de um texto analisado segundo critérios relativos à teoria que serve de guia da leitura" (BARDIN 1979 apud MINAYO 1994, p. 208).

"Uma unidade de significação complexa de comprimento variável, a sua validade não é de ordem lingüística, mas antes de ordem psicológica. Pode constituir um tema tanto uma afirmação como uma alusão" (UNRUG 1974 apud MINAYO 1994, p. 209).

O percurso percorrido na análise temática tomou como base o sugerido por MINAYO (1994), que o classifica em três fases: (a) a fase de pré-análise, (b) a fase de exploração do material e (c) a fase de interpretação. Os procedimentos realizados em cada um destes passos estão brevemente descritos a seguir. 
A fase de pré-análise compreendeu a transcrição das entrevistas e grupos focais e o processo de leitura exaustiva deste material. Este, por sua vez, compreendeu a leitura em triplicata do material, acompanhada dos destaques aos temas de maior relevância para a compreensão da hipótese e o primeiro recorte das falas mais significativas dos indivíduos segundo os temas levantados. A unidade de registro da fase de pré-análise, que persistiu nas fases seguintes e está presente neste trabalho, foram os conjuntos articulados de frases.

Como poderá ser percebido na leitura destas análises, os discursos são relativamente longos, considerando sua riqueza biográfica e a liberdade de construção de idéias promovida pelo pesquisador nos espaços das entrevistas. Os temas que se destacaram neste processo e que conformam a divisão do item 4.2. estão dispostos a seguir. A fim de estimular a busca de sentidos e as descobertas por parte dos leitores, os temas foram tratados na forma de perguntas: (a) Qual é o papel da farmácia? (b) Qual é o papel do farmacêutico? (c) Qual é o papel dos balconistas? (d) O que percebem os consumidores? (e) Qual é o sentido do modelo de acreditação?

A segunda fase, denominada fase de exploração do material, assumiu um caráter de identificação dos desejos, dos símbolos e das crenças presentes nas falas dentro de cada um dos cinco temas citados. Este processo permitiu o aprofundamento na análise do material coletado e criou condições concretas para a realização da terceira fase da análise temática, a fase de interpretação.

Nesta fase, o objetivo foi atribuir um sentido de organicidade aos discursos e, sobretudo, construir uma linha de argumentação capaz de proporcionar maior compreensão da hipótese de pesquisa. Em busca de atribuir a este processo uma característica não atomizada, ou do destaque ao fragmento pelo fragmento, é necessário explicitar que os pontos chave construídos pelo pesquisador ao longo da pesquisa, já destacados em cada um dos sub-capitulos que compõem o capítulo 1 , foram os elementos que pautaram a interpretação do material de campo. 


\section{RESULTADOS}

"Descobri aos 13 anos que o que me dava prazer nas leituras não era a beleza das falas, mas a doença delas."

Manuel de Barros ${ }^{19}$

Os resultados da pesquisa são apresentados através de dois conjuntos de informações. O primeiro deles trata do modelo de acreditação de farmácias, resultado da interação do pesquisador com os especialistas com base da construção de consensos. O segundo trata dos estudos de caso realizados nas farmácias no município de Londrina, que procuraram enriquecer a análise do modelo à luz da realidade das farmácias e das possibilidades de mudança na prática farmacêutica identificadas.

\subsection{Um modelo para acreditar farmácias}

Antes de mergulhar na apresentação do modelo de acreditação, é preciso ressaltar que seu processo de construção foi de intenso valor para o pesquisador e revelou um genuíno interesse no tema por parte dos especialistas. $O$ interesse pôde ser percebido não apenas na disposição em colaborar com o trabalho, mas na prontidão do grupo em responder às questões, assim como em seu senso crítico e provocativo em relação a algumas delas.

As perguntas e as provocações continuam vivas, e o modelo aqui apresentado não quer cumprir outro papel que não seja estimular e provocar pesquisadores e gestores a inventarem a mudança. Se a capacidade de provocar existir, ela deve ser compreendida como um dos resultados primordiais desta pesquisa.

\footnotetext{
${ }^{19}$ Trecho de Mundo Pequeno, no livro "O livro das ignorãças", $4^{a}$ ed. de 1997.
} 


\subsubsection{Modelo de acreditação de farmácias}

\section{Apresentação}

Este documento é fruto de um trabalho de doutorado na área de saúde pública que buscou desenvolver bases para a criação de um modelo de acreditação de farmácias. Ele é apresentado na forma de um manual de acreditação, no qual estão expostos os principios básicos que levaram a sua construção, os principios de funcionamento de um sistema de acreditação e um conjunto de 28 padrões de qualidade em dois niveis de complexidade.

A elaboração deste manual foi possivel a partir da colaboração de um grupo de 16 especialistas que, ao longo do segundo semestre de 2002 e primeiro trimestre de 2003, participaram do trabalho de forma voluntária e não presencial - por meio eletrônico.

Este documento não é um roteiro de inspeção. Por isso ele não está formulado de maneira a exprimir o conjunto de indicadores observáveis, dentro de cada padrão de qualidade e niveis de complexidade, necessários a implantação de um processo de acreditação. Os roteiros de inspeção poderão ser elaborados por aqueles que desejarem operar este modelo no futuro.

Como poderá ser percebido na leitura deste documento, alguns dos padrões de qualidade definidos para os estabelecimentos farmacêuticos encontrarão diferentes legislações sanitárias estaduais e municipais que legislam de forma diferente para os mesmos aspectos, sobretudo no campo dos procedimentos técnicos realizados nas farmácias.

Estes elementos foram apontados pelos especialistas e sua presença aqui revela a intenção de que o debate em torno das legislações sanitárias federal, estaduais e municipais seja ampliado, o que viria a apoiar a reorganização da prática farmacêutica em todo o país.

É ainda necessário destacar que este modelo não é voltado às farmácias que realizam manipulação de fórmulas, cujos elementos de orientação de qualidade são encontrados na RDC 33 da ANVISA. Contudo, 
sua adaptação à área da manipulação não apenas é possivel, como tem total apoio dos pesquisadores.

Espera-se que as contribuições apresentadas aqui sejam úteis ao desenvolvimento da atenção farmacêutica, à melhoria da qualidade das farmácias e à promoção do uso racional de medicamentos no Brasil.

\section{Do conceito de acreditação}

A acreditação é um procedimento de avaliação dos recursos institucionais, que tem caráter voluntário, periódico e reservado. Ela tende a garantir a qualidade da atenção à saúde através de padrões previamente estabelecidos que orientam a estruturação, organização e busca de resultados pelos serviços de saúde.

Pode-se afirmar que um estabelecimento é acreditado quando a distribuição e a organização de seus recursos e processos tendem a resultar em ações de adequada qualidade. Em última instância, espera-se que ações de qualidade gerem benefícios aos consumidores e aos sistemas de saúde.

\section{Dos princípios que regem a proposta}

Dois grandes eixos devem ser identificados no núcleo de formulação desta proposta:

(a) o respeito a princípios da Organização Nacional de Acreditação, especificamente, que o processo de acreditação é um método com base em um enfoque sistêmico e de avaliação global do estabelecimento. O método é também de consenso, racionalização e ordenação da organização, além de procurar estabelecer uma dinâmica de educação permanente de seus profissionais.

(b) a orientação pelos principios da atenção farmacêutica, conjunto de ações desenvolvidas pelo farmacêutico, e outros profissionais de saúde, 
voltadas à promoção, proteção e recuperação da saúde, tanto no nível individual como coletivo, tendo o medicamento como insumo essencial e visando o acesso e o seu uso racional. Envolve a pesquisa, o desenvolvimento e a produção de medicamentos e insumos, bem como a sua seleção, programação, aquisição, distribuição, dispensação, garantia da qualidade dos produtos e serviços, acompanhamento e avaliação de sua utilização, na perspectiva da obtenção de resultados concretos e da melhoria da qualidade de vida da população (OPAS 2001).

\section{Das organizações candidatas}

Tendo em vista que o processo de acreditação é voluntário, cabe às organizações interessadas aderirem ou não ao programa. Para que uma farmácia ou drogaria possa participar do programa de acreditação, é necessário que os seguintes requisitos mínimos sejam cumpridos pela organização candidata.

a) contar com a presença de ao menos um profissional farmacêutico por, no mínimo, 40 horas semanais. O profissional farmacêutico responsável técnico pela organização candidata deve ser graduado em curso de farmácia reconhecido pelo Ministério da Educação, devidamente inscrito no conselho regional de farmácia correspondente e não deve estar respondendo a processo ético disciplinar;

b) estar em situação de total regularidade com as exigências do conselho regional de farmácia e do órgão de vigilância sanitária correspondentes;

c) estar em funcionamento regular há pelo menos 180 dias, ou seja, possuir o conjunto de documentos sanitários e fiscais exigidos pelo conselho profissional correspondente, órgão de vigilância sanitária correspondente, agência nacional de vigilância sanitária, prefeitura municipal e secretaria da receita federal;

d) concordar em cumprir as exigencias contratuais do Termo de Cooperação a ser firmado entre a organização candidata e a organização acreditadora, 
incluindo os investimentos financeiros relacionados ao processo de acreditação.

\section{Da organização acreditadora}

A organização acreditadora deve se constituir como uma sociedade civil pública, sem fins lucrativos, e gozar de reconhecimento por sua capacidade técnica e idoneidade pela comunidade local. Espera-se que o conselho estadual de saúde, o órgão de vigilância sanitária, o conselho regional de farmácia e a associação de farmacêuticos correspondentes, além da Organização Nacional de Acreditação, reconheçam e legitimem o papel desta organização.

\section{Do processo de acreditação}

\section{a) da periodicidade do processo e manutenção do certificado}

O processo de acreditação tem caráter temporário, ou seja, ele não atribui um certificado que se estende infinitamente à organização acreditada. A partir do momento em que se confere o certificado de acreditação à organização candidata, esta ficará acreditada pelo periodo de 360 dias, sendo que no último mês deste período de tempo, poderão ser realizadas novas visitas à organização para a revalidação do certificado.

O processo de atribuição do certificado se inicia a partir da assinatura do Termo de Cooperação entre a organização acreditadora e a organização candidata, e não deve se estender por mais de 180 dias até o certificado de acreditação ser conferido.

O Termo de Cooperação é o documento que rege contratualmente a relação entre a organização candidata e a organização acreditadora. Nele devem ser estabelecidas as condições do trabalho, como investimentos necessários, período do processo de acreditação e o cronograma de visitas e de preparo da organização candidata. 
b) da classificação das farmácias

Cinco categorias de classificação das farmácias estão definidas.

Organização não acreditada: organização que não manifestou interesse em participar do processo de acreditação.

Organização em processo acreditação: organização que manifestou interesse na acreditação e que assinou o Termo de Cooperação com a organização acreditadora. Esta classificação não se estenderá além do período máximo de 180 dias.

Organização não aprovada: organização que participou do processo de acreditação e que, ao longo de 180 dias, não conseguiu cumprir os critérios para obtenção do certificado de acreditação.

Organização acreditada Nível B: organização que participou do processo e que cumpriu todos os critérios relacionados ao Nivel $B$, ou seja, critérios que demonstram que a organização possui as condições mínimas necessárias ao desenvolvimento de serviços farmacêuticos de qualidade.

Organização acreditada Nível A: organização que participou do processo e que cumpriu todos os critérios do Nível $B$, bem como todos os critérios do Nivel $A$, ou seja, critérios que demonstram que a organização possui condições avançadas necessárias ao desenvolvimento de serviços farmacêuticos de qualidade.

c) do sigilo do processo e da divulgação dos resultados

Cabe a organização candidata divulgar para fins de publicidade sua adesão ao processo de acreditação, bem como sua classificação em qualquer um dos cinco niveis descritos acima. Permite-se que a organização utilize o 
certificado de acreditação para fins de publicidade em quaisquer meios que julgar conveniente, segundo o estabelecido no Termo de Cooperação.

A organização acreditadora poderá divulgar aos interessados, desde que não existam fins de publicidade, a lista de organizações que tenham aderido ao programa de acreditação e que tenham sido classificadas como: (a) organização em processo de acreditação; (b) organização acreditada Nível $B$; (c) organização acreditada Nível $A$.

\section{d) da suspensão do certificado de acreditação}

A organização acreditadora poderá suspender o certificado de acreditação em caso de (a) término do período de 360 dias após o certificado ter sido conferido, (b) fechamento do estabelecimento, (c) mudança da propriedade do estabelecimento, (d) no caso de padrões de qualidade deixarem de ser cumpridos pela organização acreditada.

\section{VII. Áreas e padrões de avaliação}

\section{a) Seção 1. Estrutura}

Compreende as condições disponiveis de estrutura e a forma de utilização das mesmas - documentação sanitária, estrutura fisica, equipamentos e recursos humanos - para a realização de serviços de qualidade pelo estabelecimento farmacêutico.

\subsection{Documentação sanitária}

Compreende a avaliação do cumprimento das características necessárias ao credenciamento da farmácia ${ }^{20}$ segundo o órgão local da vigilância sanitária, a prefeitura municipal e o conselho regional de farmácia correspondente.

\footnotetext{
${ }^{20}$ Neste modelo, o termo farmácia compreende também o conceito de drogaria, não contemplando as farmácias em que se realiza a manipulação de fórmulas.
} 


\section{Indicadores de Nível Único - condições obrigatórias}

A farmácia possui documentos originais e atualizados que significam 0 cumprimento de leis e normas do órgão local de vigilância sanitária, da prefeitura municipal e do conselho regional de farmácia correspondente para fins de funcionamento.

- Cadastro Nacional de Pessoa Jurídica.

- Inscrição Estadual no ICMS.

- Alvará de funcionamento emitido pela prefeitura municipal.

- Licença sanitária concedida pelo órgão local de vigilância sanitária.

- Certificado de regularidade conferido pelo conselho regional de farmácia.

- Autorização de funcionamento emitida pela ANVISA.

\section{Observação}

_A condição representada pelo indicador de nível único é condição essencial para permitir a participação do estabelecimento no processo de acreditação.

\subsection{Estrutura fisica}

Compreende a avaliação da disposição de equipamentos, acesso, circulação interna, higiene sanitária, facilidades para consumidores, área para realização de tarefas administrativas e áreas para realização de procedimentos técnicos.

\section{Indicadores Nivel B}

A farmácia possui área física dividida em, ao menos, quatro ambientes distintos: 1 ambiente destinado a realização de tarefas administrativas, 1 ambiente destinado a realização de procedimentos técnicos, 1 ambiente destinado ao armazenamento e dispensação de medicamentos e 1 sanitário.

\section{Indicadores Nivel A}

A farmácia possui 1 ambiente separado destinado ao recebimento e armazenamento de medicamentos e demais produtos comercializados e, ao 
menos, 1 ambiente separado destinado ao atendimento aos consumidores, de forma a oferecer-Ihes conforto e privacidade.

\section{Observações}

_No caso das farmácias localizadas em centros comerciais ou outros espaços de condomínio em que há circulação coletiva, dispensa-se a existência de sanitário no estabelecimento.

_É desejável a existência de 1 área separada para copa do estabelecimento. Em caso de inexistência de copa, não é permitido o uso de qualquer tipo de alimento nas dependências do estabelecimento.

_A sala de procedimentos técnicos será utilizada para a função exclusiva de aplicação de injetáveis ou nebulização (inaloterapia) ou realização de pequenos curativos e colocação de brincos ou medida da glicemia. Não se permite a existência de sala destinada a finalidades diferentes, a não ser o acúmulo de quaisquer uma destas atividades com a aferição de pressão arterial.

\subsection{Equipamentos}

Compreende a avaliação da existéncia de equipamentos necessários a realização das atividades técnicas (medição de pressão arterial, de temperatura, de glicemia, realização de curativos, aplicação de injetáveis e nebulização), a conservação de medicamentos (refrigeradores); a realização das atividades administrativas e às condiçōes de segurança da farmácia.

\section{Indicadores Nivel B}

A farmácia possui mobiliário destinado a atividades administrativas e técnicas em bom estado de conservação, possui geladeira destinada exclusivamente ao armazenamento de medicamentos termolábeis, possui equipamento de combate a incêndio em acordo com as orientações do corpo de bombeiros do município ou região correspondentes. 


\section{Indicadores Nivel A}

A farmácia possui microcomputadores destinados a ajudar no controle das funções administrativas e possui equipamentos para a realização de tarefas técnicas relacionadas à atenção ao consumidor em bom estado de manutenção e calibração.

\section{Observação}

-Caso a farmácia possua copa, é necessária a existência de refrigerador específico para esta função localizado no interior da área da copa.

\subsection{Armazenamento de medicamentos}

Compreende a avaliação das condições de armazenamento de medicamentos e de controle de estoque na farmácia.

\section{Indicadores Nivel B}

A farmácia armazena os medicamentos de forma a preservar-lhes suas características físico-quimicas e a facilitar a identificação de diferentes produtos, e controla seu estoque de forma a evitar perdas e faltas de medicamentos que comprometam a atenção aos consumidores. Os consumidores não têm livre acesso a medicamentos que sejam de venda sob prescrição médica, em gôndolas ou prateleiras,.

\section{Indicadores Nível A}

A farmácia possui controle informatizado do estoque; não permite livre acesso a quaisquer tipos de medicamentos por parte dos consumidores, havendo livre acesso apenas a correlatados e demais produtos comercializados.

\subsection{Medicamentos sujeitos a controle especial}

Compreende a avaliação do cumprimento da Portaria 344/98 da ANVISA, voltada a regular o comércio de drogas sujeitas a controle especial. 


\section{Indicadores Nivel B}

A farmácia possui armário com fechadura destinado ao armazenamento dos medicamentos sujeitos a controle especial, cuja chave é de posse exclusiva do farmacêutico. A farmácia possui sistema de registro, informatizado ou não, de dispensação dos medicamentos e arquivamento de receitas atualizado; possui o último balanço enviado e aprovado pelo órgão local de vigilância sanitária e o estoque físico dos medicamentos sujeitos a controle especial corresponde aos registros de estoque eletrônicos ou escriturados.

\section{Indicadores Nivel A}

A farmácia possui $100 \%$ das notificações de receita dispensadas aos pacientes rigorosamente preenchidas segundo as orientações da Portaria 344/98. A farmácia possui termo de devolução de medicamento sujeito a controle para situações de devolução destes medicamentos ao órgão de vigilância sanitária correspondente.

\subsection{Responsável técnico}

Compreende a avaliação da disponibilidade, formação, condições de trabalho e remuneração do(s) farmacéutico(s) responsável(is) técnico(s) pela farmácia.

\section{Indicadores Nivel B}

A farmácia conta com a presença de ao menos um farmacêutico graduado e inscrito no Conselho Regional de Farmácia correspondente, cumprindo jornada de trabalho de 40 horas semanais. O farmacêutico trabalha uniformizado e identificado por crachá. O farmacêutico é proprietário ou funcionário contratado em regime formal de trabalho segundo os acordos sindicais locais.

\section{Indicadores Nivel A}

A farmácia conta com farmacêuticos graduados durante todo seu período de funcionamento. Não há sistema de comissão sobre vendas para os profissionais farmacêuticos. 


\subsection{Equipe técnica}

Compreende a avaliação das condições de treinamento, condiçães de trabalho e remuneração dos demais componentes da equipe técnica da farmácia.

\section{Indicadores Nivel B}

A farmácia conta com profissionais não farmacêuticos uniformizados e identificados por crachá; conta com profissionais contratados em regime formal de trabalho remunerados em acordo as orientações sindicais locais; oferece treinamentos internos ou externos para estes profissionais com vistas a melhor atender os consumidores.

\section{Indicadores Nivel A}

A farmácia conta com profissionais não farmacêuticos em atividades de atendimento e dispensação formados em cursos técnicos de auxiliares de farmácia. Não há sistema de comissão sobre vendas de medicamentos para os profissionais da equipe de trabalho.

\subsection{Normas e Procedimentos}

Compreende a avaliação da existência e da utilização de normas e procedimentos para as atividades desenvolvidas na farmácia.

\section{Indicadores Nivel B}

A farmácia possui normas e procedimentos escritos e conhecidos pelos funcionários para as atividades de limpeza e manutenção de materiais, equipamentos e ambiente; segurança; recebimento e armazenamento de materiais; controle de temperatura e umidade do estoque; controle de temperatura do refrigerador destinado ao armazenamento de medicamentos termolábeis; descarte de materiais que ofereçam risco ambiental; dispensação de medicamentos de venda sob prescrição médica, venda livre e medicamentos sujeitos a controle especial; aplicação de medicamentos 
injetáveis; nebulização; realização de curativos; determinação de peso e altura; medição de pressão arterial; determinação de glicemia; colocação de brincos; encaminhamento de consumidores a serviços especializados; comunicação com prescritores; atendimentos a situações de emergência; venda por telefone ou Internet; entregas domiciliares e marketing dos serviços e produtos. Existem livros específicos para o registro destes procedimentos nas salas correspondentes.

\section{Indicadores Nivel A}

A farmácia possui normas e procedimentos escritos e conhecidos pelos funcionários para as atividades de acompanhamento farmacoterapêtico e notificação de reações adversas.

\subsection{Registros de informafóes dos consumidores}

Compreende a avaliaçáo da existéncia de registros dos procedimentos realizados junto aos consumidores.

\section{Indicadores Nivel B}

A farmácia possui um sistema de cadastramento dos consumidores com informações básicas sobre os mesmos, como endereço, sexo, idade, morbidade referida, medicamentos recentemente utilizados, medicamentos em uso e serviço médico de referência.

\section{Indicadores Nivel A}

A farmácia possui um sistema de prontuários nos quais se registram, ao menos, as visitas dos consumidores ao estabelecimento, os medicamentos dispensados, os procedimentos realizados, o tratamento em curso e a programação do acompanhamento farmacoterapêutico.

\subsection{Material de consulta, pesquisa e atualização}

Compreende a avaliação da disponibilidade de fontes de consulta, pesquisa e atualização para a equipe técnica da farmácia. 


\section{Indicadores Nivel B}

A farmácia possui ao menos 1 dicionário terapêutico atualizado que permita consulta a diferentes especialidades terapêuticas e possui a lista atualizada dos medicamentos genéricos no mercado publicada e atualizada pela ANVISA.

\section{Indicadores Nivel A}

A farmácia possui ao menos 1 livro de referência sobre farmacologia e terapêutica, ao menos 1 dicionário de termos médicos e acesso, via Internet ou telefônica, a um centro de informações sobre medicamentos.

\section{Observação}

_É desejável, no Nivel A, o acesso a bases de dados sobre medicamentos via Internet.

\subsection{Responsabilidade ambiental}

Compreende a avaliação do cumprimento de boas práticas de descarte de residuos sanitários produzidos pela farmácia.

\section{Indicadores Nivel B}

A farmácia possui lixeira destinada ao descarte exclusivo de ampolas, seringas e agulhas e lixeira destinada ao descarte de material contaminado com resíduos biológicos, que são recolhidas semanalmente pelo serviço local recomendado pela vigilância sanitária. Há estratégias definidas para que medicamentos vencidos sejam enviados ao órgão local de vigilância sanitária segundo as orientações do mesmo.

\section{Indicadores Nivel A}

A farmácia possui programa de coleta seletiva de todo o resíduo sólido produzido pelo estabelecimento. 


\section{b) Seção 2. Processos}

Compreende as atividades técnicas desenvolvidas na farmácia com o objetivo de alterar, de forma positiva, a condição de saúde dos consumidores. Compreendem a relação entre os profissionais e os consumidores, a relação da organização com prescritores e as ações de comunicação e marketing.

\subsection{Qualidade dos medicamentos e demais produtos}

Compreende a avaliação da procedência e qualidade dos medicamentos e demais produtos comercializados pela farmácia, de forma a respeitar as determinações legais e de colaborar para o consumo de medicamentos de qualidade, evitando falsificaçōes, produtos fora do prazo de validade, produtos de procedència duvidosa e produtos com alteraçōes farmacotécnicas visiveis.

\section{Indicadores Nivel B}

A farmácia comercializa apenas medicamentos e correlatos registrados no órgão competente do Ministério da Saúde, adquire medicamentos apenas em distribuidoras que possuem autorização de funcionamento emitida pelo órgão de vigilância sanitária e conselho regional de farmácia correspondentes, não comercializa medicamentos com prazo de validade vencido e possui notas fiscais que comprovam o lote e a origem dos produtos comercializados.

\section{Indicadores Nivel A}

A farmácia seleciona as distribuidoras das quais adquire os produtos que comercializa, avalia sua licença sanitária e realiza visita anual de inspeção nestas distribuidoras. A farmácia realiza inspeção macroscópica dos medicamentos que dispensa, a fim de verificar sua validade e suas características farmacotécnicas.

\subsection{Dispensação de medicamentos}

Compreende a avaliação do processo de dispensação de medicamentos aos consumidores e a documentação do procedimento. 


\section{Indicadores Nivel B}

A farmácia dispensa os medicamentos para os consumidores mediante prescrição médica (para medicamentos que assim necessitam) ou mediante indicação farmacêutica, confirmando a compreensão do consumidor quanto a dosagem e posologia (estabelecidas na prescrição ou não).

\section{Indicadores Nivel A}

Na farmácia, todos os medicamentos dispensados são verificados pelos farmacêuticos quanto a dosagem e a posologia, bem como a possibilidade de preexistência de reações adversas ou intolerância. Toda dispensação é registrada nos prontuários dos consumidores.

\subsection{Acompanhamento farmacoterapeutico}

Compreende a a avaliação do processo de acompanhamento farmacoterapêutico dos consumidores e o registro do procedimento.

\section{Indicadores Nivel B}

A farmácia orienta os consumidores a respeito das implicações do uso dos medicamentos dispensados procurando ampliar a compreensão dos consumidores de sua condição de saúde, sua terapêutica e seu prognóstico.

\section{Indicadores Nivel A}

A farmácia possui um sistema de acompanhamento de consumidores que compreende o registro de visitas, dispensação de medicamentos e demais procedimentos, estabelecendo com eles e com outros profissionais de saúde a eles relacionados um sistema de referência e contra-referência da farmacoterapia.

\subsection{Administração de medicamentos injetáveis}

Compreende a avaliação do processo de administração de medicamentos injetáveis aos consumidores e a documentação do procedimento. 


\section{Indicadores Nivel B}

$\mathrm{Na}$ farmácia, os injetáveis são administrados exclusivamente pelo farmacêutico ou técnico legalmente habilitado, exclusivamente mediante a apresentação de receituário médico. O procedimento segue as normas expressas no manual disponivel na sala de aplicação e é registrado em livro especifico.

\section{Indicadores Nível A}

Na farmácia, as administrações de medicamentos injetáveis são registradas nos prontuários dos consumidores para fins de acompanhamento farmacoterapêutico.

\subsection{Realizaçao de pequenos curativos}

Compreende a avaliação do processo de realização de pequenos curativos junto aos consumidores e a documentação do procedimento.

\section{Indicadores Nivel B}

A farmácia realiza curativos nos casos em que há ausência de sangramento arterial e ausência ou risco iminente de quadro infeccioso. Os procedimentos seguem a orientação expressa no manual disponivel na sala de pequenos curativos, incluindo o uso exclusivo de materiais descartáveis. Este procedimento é registrado em livro específico.

\section{Indicadores Nível A}

Na farmácia, todos os pequenos curativos realizados são registrados nos prontuários dos consumidores para o acompanhamento farmacoterapêutico.

\section{Observações}

_Os casos de mordidas de animais, perfurações profundas, retiradas de pontos, curativos na região dos olhos, ouvidos e órgãos genitais, e a lavagem de ouvidos não se caracterizam como pequenos curativos. 
_A colocação de brincos está incluída na categoria de pequenos curativos e deverá seguir as orientações expressas em manual especifico.

\subsection{Realização de nebulização (inaloterapia)}

Compreende a avaliação do processo de realização de nebulização nos consumidores e a documentação do procedimento.

\section{Indicadores Nivel B}

A farmácia realiza nebulização (inaloterapia) exclusivamente mediante a apresentação de receita médica datada de no máximo três dias ou com clara indicação e justificativa para a extensão da terapia. Este procedimento é registrado em livro específico.

\section{Indicadores Nivel A}

$\mathrm{Na}$ farmácia, todas as nebulizações realizadas são registradas nos prontuários dos consumidores para o acompanhamento farmacoterapêutico.

\subsection{Controle de parâmetros antropométricos, bioquímicos e fisiológicos} Compreende a avaliação do processo de determinação de peso e altura, a aferição de pressão arterial, a aferição de temperatura, a determinação da glicemia e a documentação do procedimento.

\section{Indicadores Nivel B}

A farmácia realiza procedimentos de determinação de peso e altura, aferição de pressão arterial, aferição de temperatura e determinação de glicemia atendendo as solicitações dos consumidores. Estes procedimentos são registrados em livros individuais específicos.

\section{Indicadores Nivel A}

A farmácia oferece aos consumidores procedimentos que visam o controle de parâmetros antropométricos, fisiológicos e bioquimicos. Os procedimentos são registrados em prontuários individuais para fins de acompanhamento 
farmacoterapêutico. A aferição da pressão arterial é realizada exclusivamente em aparelhos operados manualmente por profissionais farmacêuticos ou técnico legalmente habilitado.

\subsection{Relacionamento com outros profissionais de saúde}

Compreende a avaliação do processo de contato dos profissionais da farmácia com profissionais de saúde de outros senviços de saúde, sobretudo médicos e dentistas.

\section{Indicadores Nível B}

A farmácia mantém contato telefônico com prescritores a fim de esclarecer eventuais dúvidas em prescrições recebidas.

\section{Indicadores Nivel A}

A farmácia é pró-ativa na busca de profissionais de saúde parceiros que possam ser beneficiados por um sistema de referência e contra-referência relacionado ao acompanhamento farmacoterapêutico dos consumidores.

\subsection{Açóes para ampliaçâo da adesão terapêutica}

Compreende a avaliação de processos que buscam ampliar a adesão dos consumidores aos medicamentos dispensados na farmácia.

\section{Indicadores Nivel B}

A farmácia dispensa os medicamentos dando ênfase a diálogos e condutas que ajudem os consumidores a compreenderem a posologia do medicamento que irão utilizar, as possíveis reações adversas e a importância do uso correto do medicamento em sua condição de saúde.

\section{Indicadores Nivel A}

A farmácia mantém investigações sistemáticas da adesão ao tratamento com base nos prontuários dos pacientes e com base em parâmetros de acompanhamento do tratamento farmacoterapêutico; lança mão de práticas e 
instrumentos que possam aumentar a adesão, como o uso de ilustrações, as visitas domiciliares, a verificação de embalagens, o estímulo a parente cuidador, entre outros que sejam definidos pelo estabelecimento e que não estejam em discordância com os demais critérios deste modelo.

\subsection{Vendas por telefone ou Internet}

Compreende a avaliação do processo de venda de medicamentos e outros produtos por telefone ou Internet pela farmácia.

\section{Indicadores Nivel B}

A farmácia comercializa medicamentos sob prescrição médica por telefone ou Internet exclusivamente mediante a apresentação da receita no ato da entrega. Para viabilizar a entrega do medicamento, permite-se o envio prévio do receituário médico por meio eletrônico ou por fax. Para os medicamentos que dispensam o receituário médico, a venda é realizada sob orientação do profissional farmacêutico.

\section{Indicadores Nivel A}

A farmácia dispõe de serviço telefônico, sendo também possivel dispor de serviço eletrônico, para que os farmacêuticos esclareçam as dúvidas de consumidores em aspectos relacionados a seu tratamento farmacoterapêutico. Todas as vendas são registradas nos prontuários dos consumidores para fins de acompanhamento farmacoterapêtico.

\subsection{Entregas domiciliares}

Compreende a avaliação do processo em que se dá a entrega de medicamentos em domicilio.

\section{Indicadores Nível B}

A farmácia entrega os medicamentos adquiridos por telefone ou Internet por meio de um sistema que garante as qualidades farmacotécnicas do medicamento, incluindo os medicamentos termolábeis. As entregas são 
acompanhadas de um protocolo de verificação da receita médica, verificação da posologia e identificação do paciente.

\section{Indicadores Nivel A}

A farmácia dispõe de farmacêutico para fazer visitas domiciliares aos casos necessários. Antes de serem entregues, os medicamentos são verificados pelos farmacêuticos com base na receita médica (para os medicamentos que assim necessitem) ou com base na solicitação do consumidor. Os medicamentos entregues são acompanhados de instruções para sua utilização assinadas por um dos farmacêuticos do estabelecimento. A qualidade da entrega, considerando as características do medicamento, a compreensão da dosagem, posologia e possiveis reações adversas, é verificada pela farmácia através de serviço de telemarketing.

\subsection{Comunicação e marketing dos serviços e produtos}

Compreende a avaliação do processo de comunicação da farmácia com os consumidores, considerando a confecção de folhetos explicativos, a utilização de cartazes, painéis ou murais nos ambientes interno e externo à farmácia, a disposição de medicamentos em góndolas de livre acesso, o comércio de produtos não medicamentosos e a prestação de serviços caracterizados como não sanitários, como o pagamento de tarifas, contas e taxas públicas.

\section{Indicadores Nivel B}

A farmácia possui folhetos explicativos relacionados a questões de educação em saúde, não existem cartazes, painéis ou murais que caracterizam propaganda de medicamentos ou que incentivem o consumo de medicamentos.

\section{Indicadores Nivel A}

A farmácia não possui serviços de pagamentos de tarifas, contas ou quaisquer tipos de taxas públicas; não se comercializa refrigerantes, sorvetes 
ou outros tipos de gêneros alimentícios que não possuam finalidade terapêutica.

\section{c) Seção 3. Resultados}

Compreende as alterações provocadas e alcançadas na saúde dos consumidores da farmácia em razão da farmacoterapia e das demais ações de prevenção e promoção da saúde realizadas na farmácia.

\subsection{Identificação de problemas relacionados a medicamentos (PRM) Compreende a avaliação da identificação, intenvenção e resolução de problemas relacionados a medicamentos junto aos consumidores.}

\section{Indicadores Nivel B}

A farmácia possui uma sistemática de identificação de problemas relacionados a medicamentos com vistas a orientar intervenções junto aos consumidores e a outros profissionais de saúde, sobretudo médicos e dentistas, para resolver os problemas encontrados.

\section{Indicadores Nivel A}

A farmácia possui sistemática de identificação de problemas relacionados a medicamentos, registra os problemas identificados no prontuário dos consumidores, planeja, executa e avalia o resultado das intervenções que visam resolver estes problemas e garantir a racionalidade da farmacoterapia.

\subsection{Controle de parâmetros fisiológicos e bioquímicos}

Compreende a avaliação do controle de parâmetros fisiológicos e bioquímicos dos consumidores.

\section{Indicadores Nível B}

A farmácia realiza medidas de controle de parâmetros fisiológicos e bioquímicos, auxiliando os consumidores a acompanharem os resultados da 
terapêutica à qual estão submetidos.

\section{Indicadores Nivel A}

A farmácia utiliza os prontuários para acompanhar a evolução dos resultados terapêuticos apresentados pelos consumidores, intensificando o sistema de referência e contra-referência com outros profissionais de saúde. A farmácia procura registrar e analisar sua contribuição para a diminuição dos riscos associados ao descontrole destes parâmetros, como as hospitalizações em fases agudas e a prevalência de morbidade e a mortalidade.

\subsection{Satisfação de consumidores}

Compreende a avaliação da satisfação dos consumidores com o serviço desenvolvido pela farmácia, considerando os seguintes critérios: aceitabilidade, relação profissional de saúde - consumidor, alcance das expectativas do consumidor, sigilo, conforto e custos.

\section{Indicadores Nivel B}

A farmácia possui uma estratégia de registro da opinião dos consumidores para aferição de sua satisfação com os serviços e produtos.

\section{Indicadores Nivel A}

A farmácia diferencia a avaliação realizada pelos consumidores segundo o tipo de procedimento realizado e produto adquirido e mantém um serviço de atendimento ao consumidor para resolução de problemas.

\subsection{Ações de promoção da saúde}

Compreende a avaliação da realização de açōes de promoção de saúde, como: imunização, orientação alimentar, incentivo às atividades físicas, e combate ao tabagismo, alcoolismo e automedicação. 


\section{Indicadores Nivel B}

A farmácia possui ações de incentivo a imunização, a melhoria de padrões alimentares, a importância das atividades físicas, a importância do não tabagismo, ao uso controlado do álcool e ao combate à automedicação, através de reuniões, panfletos e cartazes.

\section{Indicadores Nivel A}

A farmácia desenvolve ações em parceria com outros serviços, profissionais, estabelecimentos, organizações da sociedade civil e poder público com vistas a incentivar a promoção da saúde.

\subsection{Farmacovigilância}

Compreende a avaliação da identificação e notificação de suspeitas de reações adversas a medicamentos.

\section{Indicadores Nível B}

A farmácia desenvolve estratégias de informação dos prescritores quando da suspeita de reações adversas a medicamentos.

\section{Indicadores Nivel A}

A farmácia notifica o serviço local de vigilância sanitária ou serviço nacional de farmacovigilância em relação a suspeita de reações adversas a medicamentos e procura desenvolver cooperações de referência e contrareferência neste sentido. 


\subsection{Elementos dos estudos de caso}

As interpretações do material de natureza qualitativa recolhido por meio das entrevistas realizadas nos estudos de caso, configuram um certo lugar a partir do qual é possivel refletir a respeito da hipótese de pesquisa e julgar seu mérito, relevância e plausibilidade, pois não se trata de um teste de hipótese com base no positivismo lógico.

A riqueza da coleta de dados e, sobretudo, a riqueza dos depoimentos que originaram este sub-capítulo conferem a ele uma extensão considerável, sobretudo no que diz respeito aos fragmentos das entrevistas. Entretanto, a extensão das falas é essencial para a compreensão da realidade das farmácias e para que as categorias de análise aqui apresentadas possam ser efetivamente compartilhadas com os interessados.

\subsubsection{Qual é o papel da farmácia?}

A análise dos elementos dos estudos de caso tem início com uma pergunta cuja resposta é de difícil obtenção. Entre as concepções políticoideológicas expostas no marco conceitual do trabalho e as argumentações apresentadas pelos entrevistados em cada um dos estudos de caso, há um abismo de grande extensão.

No campo conceitual, a farmácia surge como um serviço articulado ao sistema de saúde por meio de ligações mais legitimas do que somente as comerciais. Nos estudos de caso, a farmácia se caracteriza essencialmente pelo comércio de drogas, procurando reafirmar sua posição hegemônica de venda de medicamentos dia após dia. A análise que se inicia agora reúne elementos para que se possa refletir com propriedade a respeito desta diferença. 
Tomando como base este primeiro fragmento ${ }^{21}$, ganha corpo a categoria de análise mais presente neste tema: a farmácia como lugar de comércio de medicamentos. A primeira evidência analisada diz respeito à forma como o entrevistado percebe a farmácia: um local de prestação de serviço de grande importância para a comunidade - ele a relaciona de forma sistêmica a um hospital. Contudo, ao buscar mais elementos em sua argumentação, percebe-se que a atividade de prestação de serviço da qual fala o entrevistado, não vai além da venda de medicamentos prescritos no hospital.

[Balconista 1 - Caso 1] "...o papel da farmácia eu acho assim, hoje em dia, é como se fosse uma prestadora de serviço mesmo. Não mais importante que um hospital, mas vem em segundo plano, em segundo lugar, porque ali a pessoa sai do hospital, sai com a receita e vai direto aonde?..."

No fragmento a seguir alguns outros elementos ajudam a reforçar a categoria de análise em questão. Embora o comércio de medicamentos continue sendo o elemento central da identidade da farmácia, não se trata apenas de falar de um local em que se dispensa medicamentos prescritos em um serviço de saúde qualquer, mas sim de uma farmácia na qual também são realizados diagnósticos e, com base neles, comercializados medicamentos, atividades de gozam de intensa sinergia.

Segundo o entrevistado, diante de um sistema de saúde que funciona em más condições, "...esse nosso suS 'aí, na verdade é uma coisa muito demorada...", cabe à farmácia cumprir o duplo papel de local de diagnóstico e também de comércio de medicamentos. Ainda no fragmento a seguir, 0 entrevistado reconhece que, em na maioria das vezes o consumidor "...deixa de procurar o médico e vai direto à farmácia...".

21 Sempre em referência a um fragmento da fala dos entrevistados. 
[Sub-gerente - Caso 1] "...se for ver pela lógica, o papel principal da farmácia, que é atender algo receitado pelo médico, isso seria a lógica, 'só que não é. A gente recebe obviamente bastante coisa receitada pelo médico, 'só que o povo vai nas indicações. Que na maioria das vezes a pessoa deixa de procurar o médico e vai direto na farmácia. Creio eu por causa do atendimento. E esse nosso SUS 'aí, na verdade é uma coisa muito demorada, as vezes não é atendido, as vezes a pessoa chega lá e fala que mal o médico olhou na cara dela. Acho que por causa dessa referência, muda também o conceito da farmácia..."

As evidências que conferem à farmácia a condição de ser um local de diagnósticos e também de indicação e venda de medicamentos são reforçadas e tratadas com intenso detalhe no fragmento a seguir. Nele está descrita uma lógica de trabalho que contempla os processos de diagnóstico, de indicação e de dispensação de medicamentos.

Surge também neste fragmento um segundo elemento de análise. Por meio dele percebe-se que a farmácia, além de cumprir seu papel de local de comércio de medicamentos, também é um lugar de conveniência no qual vários outros produtos não medicamentosos são comercializados, categoria que também merece destaque nesta análise.

Ser um local de conveniência é uma importante demonstração de como as forças do mercado constróem estruturas e estratégias para garantir o sucesso da gigantesca e lucrativa indústria farmacêutica. Não havendo aqui a ingenuidade ou a ignorância de negar a importância do insumo medicamento na vida moderna, como afirma TANCREDI (1986), é preciso ressaltar o mecanismo através do qual a dimensão simbólica do medicamento e sua mais intensa reificação é construída na realidade das farmácias.

Disperso entre tantos outros produtos que são adquiridos pelos consumidores para suprir seus intensos desejos e fantasiosas necessidades, também fruto da sociedade midiática (FRIDMAN 1999), os medicamentos são 
incorporados em um mecanismo de consumo tão banal quanto o consumo de sorvetes, refrigerantes, biscoitos ou cremes de beleza, o que se configura na raiz central da irracionalidade. Na farmácia, os medicamentos são alcançados pelos consumidores em gôndolas mais semelhantes a bancas de verduras em feiras matinais, do que a espaços nos quais se comercializa adjuvantes terapêuticos dotados de elevado risco à saúde.

[Balconista 2 - Caso 1] "...muitas pessoas entram na farmácia porque tiraram um pouco daquela idéia de doença. Tem gente que entra na farmácia 'pra comprar sorvete. Tem pessoas que vão 'só 'pra conveniência e enchem o carrinho (....) Mas você 'tá perguntando da farmácia (...) a gente tá ali 'pra dar saúde 'pras pessoas, auxiliar em alguma doença. A pessoa chega na farmácia com a receita, a gente tem que vender 0 medicamento, auxiliar o paciente como vai tomar aquele medicamento certinho, pedir 'pras pessoas ligarem 'pra gente novamente se tiver alguma dúvida. As vezes quer entrar em contato com o médico e não consegue, as vezes sente algum efeito do medicamento e liga 'pra farmácia 'pra pedir auxilio sobre alguma coisa. Muitas pessoas vêm procurar indicação também. Tem muitos que não vão ao médico. Tem pessoas que me conhecem há muito tempo e vêm me procurar. Eles confiam em mim, eu sempre fiz alguma indicação e as vezes vem com uma gripe, com torcicolo, uma dor de cabeça, uma infecção de garganta. Eu sei que hoje não é certo a farmácia fazer indicação de medicamento, só que eu, quando eu vejo que vai fazer bem 'pra aquela pessoa, eu faço a indicação com segurança, responsabilidade e certeza daquilo que eu estou fazendo. Quando eu tenho alguma dúvida, eu mando ir 'pro médico, eu falo: olha você tem que ir no médico. Ou a pessoa chega na farmácia com uma dor de cabeça e a gente indica algum analgésico: se persistir tem que ir no médico. Antes de tudo a gente mede a pressão, porque tem medicamento hoje que abaixa a pressão, tem outros que sobem. A gente tem que 
perguntar muito sobre medicamentos que a pessoa está tomando também. As vezes tem algum medicamento que não pode ser tomado com outro. Porque hoje tem pessoas que chegam na farmácia e se eu falar que eu não posso dar indicação 'pra ela, ela não vai mais voltar..."

A análise e a interpretação de outros fragmentos das entrevistas revelam a terceira categoria presente neste tema: farmácia como lugar de valor sanitário para a comunidade. Os fragmentos a seguir argumentam a respeito da forma como a farmácia está inserida na comunidade. A primeira evidência diz respeito à necessidade de legitimação da farmácia frente a seus consumidores. Nesta busca, uma determinada linguagem e uma determinada tecnologia sanitária, estão incorporadas às ações da farmácia. Percebe-se uma farmácia campanhista e promotora de açōes de saúde, tais como a distribuição de panfletos e a realização de palestras, de tratamentos de beleza, e de testes de glicemia e colesterolemia.

É preciso compreender também que a realização de tais atividades não se fundamenta em principios de atenção farmacêutica. A legitimação da farmácia através da valorização de sua imagem sanitária tende a potencializar a venda de medicamentos e outros produtos e não está acompanhada de ações que visem a promoção do uso racional de medicamentos. $A$ análise crítica destas campanhas resulta em questionamentos do mérito da iniciativa e a hipótese de que estas ações são mais um mecanismo de alienação a fundamentar a farmácia como lugar de comércio de medicamentos.

[Farmacêutica 3 - Caso 1] "...hoje você tem que interagir com a comunidade. A comunidade tem que ver que você está presente. Que nem a nossa Rede, que vive fazendo campanha.

\footnotetext{
22 A terceira categoria presente nesta fala, que é o preparo técnico dos balconistas, será analisada mais a frente.
} 
Põe às vezes testes de glicose, verificação de pressão, automaquiagem. Por exemplo, na semana da mulher, geralmente a gente faz lá no shopping. Ela coloca todas essas situações, palestras (...) O pessoal da terceira idade recebe uma revista e tem pontuação para comprar na nossa loja, a gente tem um relatório de tudo o que eles tomam num mês, sabe mais ou menos que dia eles vão na loja, você já está com o produto dele lá certinho. É seis caixas de tal produto que ele usa, já está lá separado 'pra aquele cliente. Então o cliente chega lá, "Oi, tudo bem, vim pegar meus medicamentos". $E$ as vezes você já está com a cesta pronta, já vai 'pra ele assim, pronta..."

[Proprietária - Caso 1] "...porque a gente está aqui, integrado em uma comunidade e nós queremos ter resultado, ter lucro sim, porque nós temos funcionários (...) Mas nós temos que estar conscientes do nosso papel dentro dessa comunidade e de prestação de informações, de senviços. Nós fizemos $n$ folhetos sobre higiene bucal, sobre AIDS, sobre doenças, sobre a obesidade, que é um material puramente de informação. Ele visa apenas orientar as pessoas, esclarecer as pessoas 'pra que elas busquem ajuda e resolvam seus problemas..."

Ainda em relação ao papel sanitário, outra importante evidência foi encontrada nos discursos. Tomando como base o Caso 2, que trata de uma farmácia de pequeno porte em uma base territorial mais clara, percebe-se a existência de maior inserção da organização na comunidade e, e por isso, maior vínculo. Os fragmentos a seguir revelam maior proximidade entre farmácia e consumidores uma vez que essas relações parecem ser mais longitudinais. No entanto, essa relação não é capaz de garantir ações no campo da atenção farmacêutica. A farmácia também não possui informações concretas a respeito de resultados na vida dos consumidores. 
[Farmacêutica - Caso 2] "...os resultados seriam assim, não sei. Por eu conversar com os clientes, eles voltam a me procurar. Então esse seria o enfoque maior: A farmacêutica está aí? Justamente a satisfação: a farmacêutica está ai? Eu posso conversar com ela? Então, quer dizer, isso te satisfaz, porque ele viu que você conversou. As vezes você fala: será que eu convenci ela? Será que eu falei alguma coisa certa? As vezes, fica pensando: será que ela gostou ou não? Mas ai você vê que ela retomou na sua farmácia, então ela reteve a confiança em você..."

[Balconista - Caso 2] "...Eu acho mais interessante farmácia de bairro porque a gente conhece o cliente, a gente tem aquela amizade (....) vai conhecendo até os problemas que o cliente tem (....) e sabe a medicação que existe, que ele já tomou. As vezes o cliente vai 'num médico nesse ano, no ano que vem ele volta em outro médico (....) sendo que no primeiro ele tomou um medicamento que não resolveu e no ano seguinte passam a mesma medicação (....) Então a gente já conhece o paciente e pode até dar uma sugestão, falar assim: Ah, você já tomou esse medicamento, você lembra, ou foi bom ou foi ruim. Então a gente conhece melhor, tem um contato mais direto. Agora já na farmácia central o negócio fica mais superficial mesmo. No bairro a gente já conhece a familia, já conhece melhor os problemas, conhece mais a pessoa..."

\subsubsection{Qual é o papel do farmacêutico?}

A entrada neste tema foi de grande importância ao se tratar da mudança organizacional nas farmácias. Sua análise terminou por significar um dos pontos centrais para a compreensão do atual estado da arte da prática farmacêutica, apontando as lacunas e oportunidades existentes para a mudança no setor. Algumas categorias importantes são discutidas a seguir. 
A primeira categoria de análise, também a mais presente nas falas analisadas é aqui denominada o agir técnico do farmacêutico. No primeiro fragmento analisado, o entrevistado identifica sua prática com base em três elementos principais. O primeiro deles é sua atividade de avaliar e julgar o diagnóstico realizado por outro profissional de saúde, em geral o médico, avaliar a prescrição associada a este diagnóstico e recomendar determinadas ações que assegurem o uso correto do medicamento pelo consumidor.

É com base nestas atividades que o farmacêutico se coloca como um profissional que realiza uma importante atividade complementar à prática médica. Segundo os entrevistados, a relação de confiança construída com o consumidor o credencia a opinar no campo do diagnóstico e da prescrição, papel que ele afirma desempenhar com conforto e responsabilidade.

[Farmacêutica - Caso 2] "...eles me procuram muito 'pra saber como tomar o medicamento, ou falar: eu estou tomando tal remédio, o que eu poderia estar tomando? Eu posso estar tomando em horário de almoço? E as vezes ligam 'pra falar: eu fui ao médico e aconteceu isso e isso. Esta certo? Dou uma opinião. Na maioria das vezes é isso..."

No campo do saber técnico estão também fundamentadas as ações descritas pelos entrevistados como de indicação e dispensação de medicamentos e de acompanhamento terapêutico. Os fragmentos reunidos a seguir mostram que estas atividades se dão em um cenário de pouca consistência técnica, no qual o farmacêutico tem seu saber técnico ora reduzido ao ato da comercialização do medicamento, ora voltado de forma distorcida à atividade de diagnóstico e de indicação de medicamentos.

Ao assumir que faz diagnósticos e que indica medicamentos, os farmacêuticos entrevistados procuraram tanto revestir essa atividade com preocupações éticas e responsabilidades técnicas, como a realização de uma anamnese que ajude a precisar a indicação e a eliminar os riscos de reações 
adversas. Atribuíram também a ela um contorno circunstancial, identificado como "...se eu não fizer alguém pior o fará..." ou "...o posto de saúde não funciona...". Entre outras justificativas, sempre há um porquê.

[Farmacêutica 2 - Caso 1] "... você recepciona o cliente, pega o receituário, mostra o medicamento que tá no receituánio e explica 'pra ele como ele vai tomar. Caso ele ache muito caro o medicamento e peça pelo genérico a gente propõe o genérico, quando tem. E quando não tem ele tem que levar o do médico mesmo. 'Aí é explicado o modo de tomar. 'Aí, vamos supor, que lá tem uma Amoxilina e um Cataflam. Você explica que Cataflam é um anti-inflamatório, que ele tem que tomar certinho senão o efeito não vai ser o desejado (....) 'Dai depende também do cliente. Se é um cliente mais simples, não adianta você ficar explicando muita coisa que ele não vai entender..."

[Farmacêutica 1 - Caso 1] "...chegam as pessoas reclamando de dor de garganta, ou criança que está com febre e vai lá. Geralmente já é com indicação. O pessoal chega querendo, não tem receita nem nada, é isso. Mas muitas vezes a gente pega receituário médico mesmo (....) a gente pega mais os $\mathrm{OTC}^{23}$, no caso de pastilha para garganta, ou tem alguns remédios 'pra gripe que não necessitam de receita, as parasitoses, essas coisas a gente indica, vitamina C. É mais OTC mesmo que é indicado. Medicamento tarjado é mais com receita (....) mas as vezes acontece, não vou negar para você, mas as vezes acontece sim..."

\footnotetext{
${ }^{23}$ OTC é a sigla em inglês para [over the counter], medicamentos que não necessitam de prescrição médica. No Brasil, estes medicamentos são conhecidos como medicamentos de venda livre, e não possuem tarjas vermelha ou negra.
} 
[Farmacêutica 3 - Caso 1] "...o que acontece muito com antibiótico é principalmente mãe. Teve uma, ela deu Amoxil. Estava no final de semana. Vai passar o dia no posto de saúde? Ela não quer ir, muitas vezes quando a gente não pega, ela chega direto no balcão, isto é automedicação do próprio paciente. Se eu disser 'pra você que ninguém indica antibiótico, estou mentindo. É indicado antibiótico, mas assim, tem um certo critério, sempre que é possivel a gente está ali do lado, a gente faz inúmeras perguntas. A primeira pergunta que eu faço 'pra pessoa é se ela tem convênio médico. Se ela não pode ir até o próximo posto de saúde, criança é muito difícil, a gente indica..."

Retomando o aspecto do acompanhamento terapêutico, as evidências mostram que trata-se de uma prática estruturada como estratégia para garantir um consumidor fiel, e não como forma de acompanhar e intervir consciente e eticamente no processo saúde-doença dos pacientes em busca de melhorias em sua qualidade de vida. O acompanhamento terapêutico é um campo de indefinições no qual impera um vazio de razões práticas tão grande que torna o conceito superficial e até dispensável.

[Farmacêutica - Caso 2] "...o acompanhamento hoje em dia está por eu lembrar o remédio que um cliente sempre usa, porque ele sempre vai à farmácia e compra (...) Tem cliente que chega lá e diz: você lembra o remédio que eu comprei mês passado? Como é que é mesmo o nome que eu não lembro? Então, as vezes eu relaciono o produto com o cliente. Eu sei que ele sempre está comprando. As vezes é um remédio que só ele usa, então eu sei, como eu faço compra, que tenho que pedir 'pra ele, que hoje eu tenho que comprar o remédio $x$ porque a pessoa vai usar semana que vem, então hoje mais ou menos seria isso..." 
[Farmacêutica 1 - Caso 1] "...eu estava até conversando com o gerente da gente implantar, principalmente para os medicamentos que a gente indica, pegar o telefone da pessoa e acompanhar. Isso a gente ainda não faz infelizmente. $A$ não ser que sejam aqueles clientes fiéis que vão um dia sim um dia não na farmácia (...) Quem a gente tem contato sempre, a gente sempre está acompanhando. Quando vai à farmácia eu pergunto: melhorou? Está bem? Não está? Então o que aconteceu? Mas agora a pessoa que entra lá e não tem o costume de freqüentar a farmácia, a gente ainda não está acompanhando..."

[Farmacêutica 2 - Caso 1] "...eu procuro orientar da melhor forma possivel. É lógico que não tem como eu ficar de cliente em cliente perguntando: são sete horas, você tomou seu remédio agora? Isso 'aí não existe, não tem jeito de fazer. Mas quando uma pessoa vai lá e leva um antibiótico, eu falo que é um medicamento caro, é um medicamento que se você tomar abusivamente, na hora que você precisar ele pode não fazer o efeito desejado, se você não tomar no horário certo pode também não fazer efeito. $O$ ideal é que você tome no horário certo, tome os dias certos, porque muitas vezes a pessoa leva um anti-inflamatório, toma dois dias, a garganta para de doer, 'ai fala: sarei. E para de tomar. Eu procuro falar tudo isso, eu oriento da melhor forma possivel e coloco tudo isso, que se ele não tomar certo às vezes pode voltar a infecção ou a inflamação e cada vez que ele tomar esse medicamento ele pode estar criando certos tipos de resistência. Eu oriento da melhor forma possivel pra fazer com que ele tome. Geralmente, graças a Deus, tenho tido resultados. Todas as pessoas que retornam à farmácia eu procuro perguntar e eles tomam certinho tudo, pelo menos é o que eles falam..." 
Em outra característica do acompanhamento terapêtico, o procedimento é destacado como atividade que tem finalidade de servir de suporte ao médico. Pode também dar um conforto, uma sensação de acompanhamento ao consumidor que tem sua pressão arterial ou glicemia registradas periodicamente. Avançando na interpretação crítica, o acompanhamento terapêutico aqui descrito - que assim nem deveria ser chamado - fundamenta-se como ação que fortalece a relação da farmácia com o médico prescritor, elemento de grande importância comercial.

[Farmacêutica 2 - Caso 1] "...eu acho que tanto é bom para o paciente como é bom para a farmácia. É o que eu te falei, é mais um ponto de confiança. Aqui a gente tem um cartão onde todo paciente que chega e verifica a pressão ou faz um teste ou vai verificar seu peso, a gente dá aquele cartão 'pra ele, coloca a data, os valores que ele teve de pressão arterial, peso, enfim, o que ele foi verificar ali, quem verificou, o horário que foi verificado. Cada vez que ele volta ou ele traz o cartão pra mim ou a gente tem um arquivo onde a gente arquiva a informação desses pacientes. Cada vez que ele vai a gente busca o cartão dele e pega as informações. Quando ele vai no médico, ele leva, fica até mais fácil de se saber diariamente, porque às vezes você vai no médico, verifica a pressão no médico, naquela hora sua pressão vai estar aquele tanto, mas a pessoa que monitora todo dia leva aquele cartão para o médico e ele tem mais ou menos uma referência de valores..."

Como última evidência desta categoria surge o papel do farmacêutico em zelar pela responsabilidade técnica da farmácia, obrigação legal. Esta ação se dá fundamentalmente no cuidado com aspectos estruturais da farmácia (salas de procedimento), com os medicamentos sujeitos a controle especial e com a supervisão do trabalho dos balconistas. 
[Farmacêutica 1 - Caso 1] "...assim que eu chego dou uma olhada geral na loja, vejo se a sala de aplicação está certa, se - Descartex não está cheio, o algodão, todo o procedimento básico da sala vou conferir. Dou uma olhada no armário de controlados, porque como sou eu que assino, também sou eu que mexo com os livros, mexo com todo o controle e vou para - balcão. Daí a maior parte do tempo é no balcão mesmo, atendendo o pessoal. E geralmente eu dou uma olhada nas prateleiras para ver também se tem medicamento vencido..."

[Farmacêutica 1 - Caso 1] "...qualquer venda que eles vão fazer, pulando essa parte do horánio que eu não fico, a gente costuma prestar atenção e estar acompanhando. Se você vê que a pessoa está extrapolando a gente interfere meio discretamente para o cliente que está ali não perceber. Mas eu chamo um pouquinho e falo: isso está errado. Eles aceitam bem a nossa atuação nessa parte. Se eu vejo uma coisa errada, assim que a pessoa sai da farmácia, eu chamo atenção, eu falo: isso não pode..."

Cabe ainda ao farmacêutico, sobretudo nas farmácias de pequeno porte, a atividade de administrar a organização, categoria aqui definida como - agir administrativo do farmacêutico. Como se percebe na análise do fragmento a seguir, a atividade administrativa exige tempo e atenção. Isto implica, por sua vez, em que o farmacêutico tenha que escolher entre administrar e desempenhar sua atividade técnica, atividades muitas vezes incompativeis no dia-a-dia.

[Farmacêutica - Caso 2] "...Se você for ver é uma loucura, porque eu sou farmacêutica, presto assistência pra minha farmácia, mas de um modo geral eu sou tudo, sou caixa, sou gerente, sou administradora, faço compra. Então sou 
compradora, acerto o estoque com as contas, com as vendas, faço tudo na farmácia. Então é bem corrido. Todas as funções, bem dizer. no momento sou eu (...) Cada dia eu programo. Ou eu entro em pedido de perfumaria, então eu pego aquela manhã pra estar dando enfoque a isso. Chegou mercadoria eu mando um balconista me ajudar. Ele confere a mercadoria com a nota fiscal, 'ai eu lanço no computador, dou uma olhada nos preços e ele guarda. 'Ai é pedir medicamento 'pra vir no dia seguinte (...) e mais ou menos você vai conciliando isso aí..."

A terceira e última categoria de análise não diz respeito ao desempenho de um papel específico, mas sim daquilo que aqui se denomina o agir anônimo do farmacêutico, evidência de uma profunda crise de identidade profissional. Têm destaque nesta categoria um determinado sentimento de confusão e de desamparo revelados pelos profissionais entrevistados.

Seja em razão de deficiências reconhecidas em sua formação universitária, de problemas na divisão do trabalho nas farmácias, de baixos valores de remuneração, de falta de suporte a sua prática e estudos ou do pequeno reconhecimento que a sociedade dá a seu trabalho, um sentimento marcante de baixa auto-estima pôde ser identificado ao se analisar e interpretar as falas dos farmacêuticos.

[Farmacêutica 1 - Caso 1] "...eu estou no escuro ainda, eu estou no balcão. Eu gosto muito do que eu faço, mas eu quero ir para algum lugar que dê mais valor na gente como profissional da saúde, tanto em relação à remuneração, quanto reconhecimento mesmo no nosso trabalho..."

[Farmacêutica 3 - Caso 1] "...até esses dias eu estive numa reunião só de farmacêuticos e eu até coloquei para o pessoal a seguinte situação. A gente tem que mostrar pra eles que a 
gente também dá lucros. Só que o nosso lucro é que o cliente chega lá e eu nunca penso em vender algo a mais da área de medicamento. Eu vou pra área de perfumaria, eu vou 'pra estas situações, ou mesmo então dou uma boa orientação..."

[Farmacêutica - Caso 2] "...O que eu acho que falta foi sair da faculdade crua. Como eu falei, fiz indústria, então vai pra um outro lado: manipulação, produção, controle de qualidade. A bioquímica vai mais pra área de exames laboratoriais. Então você acaba não se aprofundando mais na área de medicamentos, de remédio, de doenças. Só que lá você vê muita teoria. Na prática, na área comercial mesmo, é totalmente diferente. Muitas vezes a pessoa não que saber 0 que o remédio vai fazer, onde é o mecanismo de ação. Ela quer simplesmente saber o que? Como toma, onde toma, se toma com alimento ou não, é só isso que ele quer saber..."

[Farmacêutica 2 - Caso 1] "...Na farmácia não tenho nenhum livro. Eu procuro na Intemet, que eu entro todos os dias. Não na farmácia, mas em casa. Eu faço visualização em casa e o que eu acho interessante o pessoal da farmácia ler, eu imprimo e levo para eles. Lá na farmácia só tem o DEF e um outro livro que é aquele guia de medicamentos (....) só os dois que eu tenho, não tenho mais nada..."

Evidência também marcante deste fenômeno de crise é o fato de que os próprios farmacêuticos recebem comissão sobre vendas de medicamentos, assunto a respeito do qual têm dificuldade em falar. Sem exceção, todos os entrevistados concordam que uma farmácia sem comissão sobre vendas seria melhor, embora reconheçam que esta pode ser uma realidade impossivel. 
[Farmacêutica 1 - Caso 1] "...a comissão estimula, a mim não tanto. Claro que a gente quer ganhar um pouco mais, mas muitas vezes a pessoa chega e fala: eu estou com a garganta assim. Eu falo: não, não toma nada porque você não tem nada. Eu já fiz isso várias vezes, mas para os balconistas é um estímulo (....) É um estímulo para eles, e muitas vezes quando eu faço isso o pessoal olha torto e fala assim para mim: Como você está fazendo isso? Mas é um estímulo para eles, então isso não tem como negar (....) Querendo ou não, medicamento é uma coisa perigosa, e que a gente não pode ficar dando 'pra todo mundo. Então eu acho que seria melhor uma farmácia sem comissão, por mais que eu não ganhe mais com isso, eu acho que seria melhor para o cliente que a gente está atendendo, não teria aquela ganância..."

[Farmacêutica 3 - Caso 1] "..eu tenho certeza que eu tenho clientes hoje que só compram lá comigo, pela minha pessoa, pelo meu profissionalismo. Então você acaba fazendo, como que eu posso dizer, a sua comissão, mais em cima do teu profissionalismo. Não é "eu vou vender mais esse negócio porque eu tenho que vender tanto hoje", não é mais ou menos assim. É mais um trabalho que fideliza o cliente..."

\subsubsection{Qual é o papel dos balconistas?}

Se as concepções conceituais e a realidade empirica em relação ao papel da farmácia estavam marcadas por uma grande diferença, a prática dos balconistas também se constitui em um grande contraste com as concepções de atenção farmacêutica que fundamentam o trabalho. Por formarem a grande massa de agentes de venda nas farmácias estudadas, como o são em todo o Brasil, suas crenças e práticas são fortes componentes na definição do papel das farmácias na sociedade brasileira. Por isso mesmo são essenciais 
para que se possa compreender os mecanismos associados ao uso irracional de medicamentos e à desorganização do setor.

Nos fragmentos a seguir, dois conjuntos de evidências sustentam a principal categoria de análise da prática dos balconistas: vendedores de medicamentos. O primeiro conjunto de elementos pode ser identificado na forma como o consumidor é atendido nas farmácias. Elementos que são importantes na organização de qualquer tipo de serviço, são também encontrados na prática dos balconistas. A importância de tratar bem o cliente, de se colocar a disposição para ajudar, de encontrar uma forma melhor para o pagamento das despesas, de transmitir as informações essenciais ao uso correto do medicamento (em especial a posologia), encerram o objetivo central da prática dos balconistas: vender medicamentos.

O segundo elemento de análise nesta categoria é ainda mais intrigante. Trata-se de interpretar as razões encontradas pelos balconistas para justificarem a prática da indicação de medicamentos, atividade popularmente conhecida como empurroterapia. As razões, fundamentadas em aspectos simbólicos, morais e sociais, podem ser divididas em cinco fenômenos. A indicação ocorre quando: (a) o consumidor não pode ou não quer procurar um médico; (b) o consumidor já procurou o médico mas o medicamento prescrito não resolveu o problema; (c) o consumidor possui uma relação de confiança com o balconista, e por isso o procura para resolver seus problemas de saúde; (d) o balconista é um instrumento a serviço de Deus para fazer com que o medicamento e a cura cheguem ao o consumidor; (e) em um mundo em que as pessoas vivem estressadas, se alimentam mal e são intoxicadas por tantas coisas ruins, é importante contar com o apoio do balconista para um diálogo, assim como com alguns medicamentos, como as vitaminas.

Nos fragmentos apresentados a seguir, ricos em evidências destas práticas, encontra-se também dois argumentos preciosos para a interpretação dos fatos: (a) que os balconistas possuem capacidade técnica, critérios e noções de seus limites de ação para realizar os diagnósticos e as indicações, tudo dentro de um padrão de segurança; (b) que a comissão sobre vendas de 
medicamentos não é o fator mais importante a influenciar a indicação de medicamentos, ainda que existam depoimentos contraditórios a isso. Esta conjunção de fatores constrói uma sensação de omnipotência que marca a prática dos balconistas.

[Balconista 1 - Caso 1] "...na hora de vender medicamento, quando a gente pega um receituário, vamos pegar um receituário médico, a gente cumprimenta o cliente, pergunta o nome dele. Após isso pergunta qual o problema dele, o que ele está sentindo, pegamos os medicamentos, colocamos em cima do balcão, chamamos um colega da farmácia ou um farmacêutico mesmo, para conferir se bate com o medicamento que está na receita (...) Explico para o paciente, cliente, o modo de tomar, o modo de usar, por quanto tempo ele vai usar, e depois entra no caso de preços. Muitas vezes a pessoa não tem condições. Tem gente que tem condições, ainda chora por mais desconto. Hoje em dia farmácia é isso, desconto, e muitas vezes a pessoa não tem condição. A gente tenta arrumar várias condições, cheque pré-datado, segura o cheque para a trinta, sessenta, tem o nosso cartão que divide em três vezes acima de trinta reais. A gente chega até o caixa, coloca-se a disposição mesmo, tem o nosso telefone, qualquer dúvida, qualquer reação que der, se o médico não estiver a disposição pode ligar 'pra a nós, e se nós sabemos responder a gente vai responder..."

[Auxiliar de gerente noturno $0^{24}$ - Caso 1] "...o cliente chega, muitas vezes é uma infecção, vamos dizer assim, urinána, alguma coisa do gênero assim, que o cliente chega e fala: eu estou tomando um medicamento e não está resolvendo. No caso é um anti-inflamatório. Muitas vezes ele vai no médico, o

\footnotetext{
${ }^{24}$ Desempenha o papel de atendente e acumula a função de auxiliar de gerente.
} 
médico indica, receita um anti-inflamatório 'pra ele, ele toma, não resolve, 'ai ele volta. Já tomou um anti-inflamatório, não resolveu. 'Ai a gente chega e até dependendo da situação a gente põe um antibiótico. Casos de garganta também. A gente vai ver a temperatura da pessoa, se tá com uma febre muito alta, se já tomou um medicamento 'pra abaixar, não abaixou, já tomou um anti-inflamatório, não resolveu, as vezes a gente sugere um antibiótico, antibiótico de via respiratória 'né, 'pra melhorar..."

[Balconista 2 - Caso 1] "...Se é uma pessoa colega minha, que eu conheço há muito tempo, que 'tá acostumada ir na farmácia comprar comigo e deixa de ir no médico 'pra vir comprar comigo, eu peço 'pra deixar olhar a garganta, vejo se a pessoa tem febre, se tiver febre é sinal de alguma infecção. Muitas vezes a gente olha a garganta da pessoa e vê o foco de pus, aí tem infecção mesmo. Se for muita infecção a gente manda 'pro médico. Se vê que está começando, a gente pergunta 'pra pessoa se já tomou algum antibiótico. Se ela responde que já tomou Amoxilina, é um dos mais usados hoje 'né, a gente dá um anti-inflamatório e um antibiótico. Manda tomar durante sete dias Amoxilina e eu sempre procuro ter uma agenda e eu marco o nome da pessoa, marco o telefone. No outro dia eu estou ligando 'pra pessoa 'pra ter certeza que ela tá passando bem. Se persistirem os sintomas a gente manda ir "pro médico bem rápido mesmo. E quando vem uma inflamação que é só vermelho, não 'tiver sério, 'ai a gente indica só um antiinflamatório, mas nem 'pra todas as pessoas, só se a gente conhece a pessoa, vê que não vai ter problema nenhum mesmo, muita segurança..."

[Balconista 1 - Caso 1] "...eu coloco o meu ser mesmo. Eu penso não na pessoa como se fosse um cliente, eu coloco a pessoa como precisando de mim. Eu me coloco à disposição. 
Eu acho que se a pessoa chegou a mim, Deus quis assim. É porque eu sou muito religioso. Deus quis usar de mim naquele momento (...) Que Deus, para mim, criou o remédio e usa de mim para que eu passe aquela coisa, aquele remédio, alguma ajuda, algum conselho também. Muita gente chega com depressão, você sempre oferece algo a mais: vamos levar uma vitamina, uma coisa para evitar algumas outras coisas. Por exemplo, tem o Natugerim que está em promoção, a gente oferece. Todo cliente que chegava: vamos levar um Natugerim? (...) Hoje com esse negócio de estresse, cansaço fisico, mental, a gente oferece algo a mais e muitas vezes a gente não oferece medicamento a mais (...) Tá certo, eu sou comissionado, tem medicamentos que eu ganho mais, claro que eu vou indicar um, mas eu sei, eu tenho consciência de que aquilo lá vai fazer o que ela precisa, eu tenho consciência que aquilo lá vai resolver o problema dela..."

[Balconista 2 - Caso 1] "...a gente ganha muita comissão em vitamina 'né. Hoje existe na farmácia energético, vitamina que as pessoas precisam muito, com a correria do dia-a-dia, com alimentação que é fraca, tudo que a gente come hoje tem conservante. A carne hoje é cheia de hormônio, então em vez de fortalecer acaba fazendo mal para as pessoas. Então dificilmente hoje uma pessoa não precisa de um suplemento vitaminico. Correria, muito estresse, então a gente ganha muita comissão de vitamina. Quando a gente faz medicação sempre a gente coloca também uma vitamina junto "pra pessoa tomar, um energético 'né, alguma coisa que não engorda..."

[Gerente - Caso 1] "...aqui na farmácia, os funcionários, não posso falar em nome de todos, mas é uma norma, a maioria, se eu falar que todos praticam estaria mentindo, deve ter exceções, pouquissimas, eles respeitam muito a indicação 
médica e a enfermidade das pessoas que estão vindo procurar..."

[Gerente - Caso 1] “...na realidade esse nome comissão, ele foi dado, vamos falar, há 19 anos, 20 anos atrás. Desde quando eu trabalho eu conheço como comissão. Na realidade essa comissão, para mim, hoje eu não utilizo mais essa palavra (....) Eu acho que você é premiado para atender bem o cliente (....) Eu fiscalizo a quantidade de medicamento que ele dá, se está tendo a consciência daquilo, da quantidade de medicamento que está dando, porque normalmente o comissionado ele faz várias vendas casadas. Mas os nossos fazem vendas com perfumarias, conveniência, que tem bastante, em termo de medicamento assim eu vejo pouco. Eu acho que são bem conscientes naquilo que o cliente deve receber. Então hoje eu não utilizo mais comissão, eu acho que eles são premiados com x por cento a cada venda..."

[Sub-gerente - Caso 1] "...então vai continuando a mesma coisa, guardando a mercadoria, tipo assim, pressionando o pessoal, olha o cliente lá, vamos vender, aquela cobrança que tem que se feita diariamente..."

Uma segunda categoria, aqui denominada agentes hegemônicos, encontra nos fragmentos a seguir um conjunto de evidências muito interessantes a respeito da força dos balconistas nas farmácias. São elas: (a) os balconistas sentem-se muito mais realizados e reconhecidos pelo trabalho que desenvolvem do que os farmacêuticos; (b) os balconistas sentem-se vitoriosos ao ocuparem a posição que ocupam atualmente. Para alguns, a ocupar a posição de vendedor é a realização de um sonho. Em muitos discursos percebe-se que vários deles iniciaram sua carreira profissional com funções mais simples nas farmácias, com limpeza e entrega de produtos, e 
hoje sentem-se no topo de uma carreira; (c) que as farmácias reforçam esta posição hegemônica dos balconista ao oferecerem a eles, e não aos farmacêuticos, cursos de formação, premiações e mobilidade na hierarquia da empresa.

[Balconista - Caso 2] “...eu estudei, terminei o $2^{\circ}$ grau e parei já faz uns dez anos (....) Aqui é um trabalho bom, é um serviço assim, reconhecido, um serviço mais limpinho, negócio que mexe com a saúde. As pessoas te vêem com os olhos diferentes porque você mexe com saúde, mexe com o corpo. 0 pessoal sempre tem curiosidade de tirar dúvidas, tem essas coisas e eu gosto do ramo (....) Existe um reconhecimento, principalmente clientes que a gente tem de muitos anos e que tiram muitas dúvidas. Ele vai ao médico tudo, mas as vezes tiram até alguma dúvida que faltou perguntar 'pro médico..."

[Balconista 1 - Caso 1] "...tenho 19 anos e trabalho na farmácia há quatro anos (...) Terminei o segundo grau e prestei vestibular para química e não consegui (....) Há mais de três anos eu comecei como boy, como entregador de farmácia (....) Antes trabalhava em açougue, que não tinha nada a ver, e dai eu, a farmácia foi dando curso 'pra nós, me esforcei, me esforcei, até que fui 'pra expedição de entregas, fui 'pro atendimento, atendia telefone e hoje eu estou onde eu estou, no balcão já há três meses. Trabalhava na tele-vendas, agora eu estou 'num balcão de farmácia..."

[Sub-gerente - Caso 1] "...comecei em farmácia quando eu tinha apenas dez anos de idade. Comecei fazendo limpeza de loja, fazendo entrega em domicilio, fazendo cobrança, função de um boy na verdade. Fiquei durante aproximadamente seis anos nessa empresa, obviamente não só fazendo a função do boy, mas comecei a atender balcão. Comecei a fazer técnicas 
de aplicação, a fazer aplicação não só na loja mas fora também, em residências e fui me desenvolvendo..."

[Auxiliar de gerente Noturno - Caso 1] "...iniciei a principio como um boy e fui aprendendo, fui conhecendo, fui tendo conhecimento e conforme o passar do tempo fui adquirindo uma certa experiência. Depois de três anos eu passei a exercer a função de balconista, e nesta função eu fiquei mais ou menos uns três anos, três a quatro anos antes de exercer, antes de entrar aqui onde eu estou hoje, isso numa outra farmácia. Aqui eu já entrei como um balconista, eu já tinha cinco anos de farmácia, um conhecimento bom na área, que a gente aprende na prática mesmo..."

[Balconista 2 - Caso 1] "...eu comecei na farmácia enchendo vidrinho de mercúrio, Methiolate. Ajudava o farmacêutico, que era o dono da farmácia (...) Vai completar vinte e oito anos que eu trabalho em farmácia. Eu sempre trabalhei na farmácia, nunca sai da farmácia, nunca fiquei um mês parado ou desempregado..."

[Proprietária - Caso 1] "...todo o pessoal que vinha de fora vinha com outros vícios de atendimento, tinha umas práticas de venda que não eram eticamente aquilo que a gente queria. Então nós começamos a formar o nosso próprio pessoal. Nós criamos uma escolinha de trainees, em que eles, os alunos, se habilitavam para ir à escola. Por que nós sempre fizemos gincanas de conhecimentos, que eram coisas sempre aplicadas na loja. As pessoas que tiravam notas mais altas iam 'pra essa escolinha. Podia ser caixa, podia ser entregador, e se habilitavam para ir 'pra escolinha 'pra serem atendentes. 'Ai eles passavam por este processo, eram dois anos, até hoje são dois anos que eles passam estudando, e os farmacêtiticos dão 
aula. Tem um dia da semana que eles são dispensados 'pra ir 'pra escolinha, em que eles recebem informações e eles só vão depois 'pro atendimento, depois que eles fazem estágio na central de entrega, na separação de mercadorias, depois eles vão 'pro call-center, depois que eles vão 'pra loja (....) Foi o melhor jeito que a gente encontrou de ter atendentes mais preparados e dando mais segurança às farmacêuticas..."

Mesmo para os farmacêuticos entrevistados, a análise que fazem da prática dos balconistas não está acompanhada de maiores preocupações relacionadas à empurroterapia. Os fragmentos a seguir evidenciam a visão dos farmacêuticos de que o balconista precisa ser preparado, admitindo inclusive a realização de indicações, elemento percebido como inevitável no atual contexto.

[Farmacêutica - Caso 2] “... eu acho importante uma formação de auxiliar de farmácia, balconista, realmente, e por quê? (...) Hoje muitas farmácias pegam (...) uma pessoa que fala que tem experiência porque já trabalhou em farmácia, mas na verdade não tem, e contratam como balconista e é um vendedor de remédio (...) Sabe só os nomes, não sabe como indicar, ou como tomar, ou abre uma bula 'pra ler, ou alguma coisa assim, não tem currículo 'pra ser um balconista. Eu acho que teria que passar por um processo, um curso técnico, alguma coisa, na qual a pessoa é qualificada..."

[Farmacêutica 3 - Caso 1] "...o pessoal lá é muito bem treinado, então a gente fica sempre de ouvido de fundo. As vezes a gente interfere cautelosamente, verifica se está passando a posologia correta, esse tipo de situação. As vezes você interfere 'pra que não se faça indicação. A gente é respeitado (...) Mas se alguém aqui disser 'pra você que não é feito indicação está mentindo. E é a realidade do Brasil, a 
nossa infra-estrutura infelizmente, as pessoas acabam indo ainda 'pra farmácia..."

[Balconista 2 - Caso 1] "...O farmacêutico está ali na farmácia, está observando tudo. Hoje o farmacêutico quase não interfere na gente que tem muita prática. Ele sabe que a gente trabalha com honestidade, trabalha com segurança. Então hoje em dia o farmacêutico que tem lá hoje, faz pouco tempo que saiu da universidade, a gente vê que ele está tentando aprender com a gente um pouco. Está observando. Mas eu nunca tive problema com farmacêutico de chegar e falar 'pra mim que eu não posso fazer algo..."

Ainda em relação ao papel dos balconistas, não poderia deixar de surgir um elemento paradoxal na análise. No fragmento a seguir, a própria farmacêutica, e também proprietária, afirma que o papel do atendente é mesmo vender, e que recompensá-los com comissão sobre vendas é um mecanismo legítimo. Além do mais, o argumento seguinte é construído na premissa de que "...ou se estimula a venda, pois o mercado é assim, ou então a farmácia vai fechar. É inevitável...".

[Farmacêutica - Caso 2] "...hoje em Londrina, tem farmácias que já pagam só um fixo. Porque eu não optei por isso? Porque não daria dentro do meu caso. As vezes, se você paga um fixo como salário, eles ficam esperando você atender o cliente. Se você o contratou, é 'pra ele vender o produto. Ele está ali pra dar uma assistência igual a você. Você está ocupada em outros sentidos, ele teria que ter seu papel ali dentro também. As vezes a cliente vem até você e você não se prontifica de vender ou vender algo a mais, então a pessoa pede uma acetona: ah! Vou vender só a acetona? Eu sempre ofereço: você não precisa de algodão, uma lixa de unha? Então eu acho 
que é um bom vendedor também, ele tem que oferecer alguma coisa a mais, então se a pessoa não é comissionada, ele vai ficar acomodado..."

[Farmacêutica 2 - Caso 1] "...na verdade seria o certo, mas isso não acontece e eu acho muito difícil, acho que nunca vai acontecer. Isso é um prática que se você fizer, você não vai vender e a sua farmácia vai fechar, enquanto as outras vão vender. É um negócio que eu acho muito dificil controlar, é inviável hoje em dia, pelo menos na situação que o Brasil se encontra, na minha opinião é inviável..."

\subsubsection{O que percebem os consumidores?}

$\mathrm{Na}$ análise temática do material produzido pelos grupos focais com os consumidores, três categorias de análise foram isoladas. Estas categorias foram denominadas de: (a) forças alienantes, categoria marcada pela percepção das farmácias como um ponto comercial qualquer, sem que qualquer relação com o uso racional de medicamentos seja feita; (b) forças de resistência, categoria marcada por posições criticas dos consumidores às farmácias; (c) desejos de cidadãos, categoria marcada pelo desejo de que farmácias melhores possam ser organizadas.

A primeira categoria de análise foi construída a partir das argumentaçöes dos consumidores a respeito de passagens em que se sentiram bem atendidos pela farmácia e em que perceberam um serviço de qualidade. Os elementos trazidos por eles como fruto desta reflexão foram: (a) a rapidez dos serviços de entrega; (b) o esforço da farmácia em obter um remédio que o consumidor não conseguia encontrar em outras farmácias; (c) a presteza da farmácia em realizar a troca de um produto defeituoso; (d) a educação de vendedores atenciosos e prestativos. 
Estes elementos são tratados aqui como forças alienantes, à medida que praticados de forma isolada, sem vínculos com o serviço de atenção à saúde que deveria ser desempenhado pela farmácia, tais atributos falseiam uma imagem de qualidade para a farmácia: entregar rápido, trocar produtos, obter os remédios que outros não têm, ter vendedores gentis. Fazer entregas rápidas, trocar produtos com problemas e poder oferecer $\circ$ que os concorrentes não têm são também bons critérios para julgar a qualidade de uma pizzaria, bem como de várias outras atividades comerciais.

Considerando então o que os consumidores chamaram de presteza e educação dos balconistas, mais argumentos são reunidos como evidências de que um grande cenário é montado para que o consumidor se sinta confortável para comprar. Assim nasceram os centros comerciais, assim nasceram os hipermercados, assim nasceram as conveniências em postos de venda de combustivel, e assim está estruturada a farmácia moderna.

[Consumidor 2 - Grupo Focal 1] "...Eu tenho, como eu disse, eu sou casada, tenho duas filhas, e elas têm problema de bronquite. Apesar que eu tenho inalador, teve um dia que precisou fazer uma inalação mais profunda. Eu liguei 'pro pediatra e o pediatra falou: olha, vou te dar um outro produto 'pra colocar dentro da inalação, mais forte. 'Ai eu liguei 'pra farmácia e falei: olha, eu estou nesse estado, eu estou muito tensa porque a minha filha esta com bronquite muito atacada, não quero levá-la no médico, vou tentar inalação. E foi muito rápido, depressa mesmo. E eu não moro perto não..."

[Consumidor 4 - Grupo Focal 1] "...as minhas filhas também têm problemas respiratórios. Então, muitas vezes dá problema de pulmão, enche o pulmão, tem que fazer inalação e meu inalador deu problema. Eu tinha comprado lá na farmácia (....) e liguei para eles: Deu problema o inalador. Eles foram lá, me levaram outro inalador, pegaram o meu que estava estragado, 
trouxeram um novo, eu continuei fazendo o mesmo tratamento que eu estava fazendo. Então isso 'ai eu gostei..."

[Consumidor 3 - Grupo Focal 1] "...há um mês e 15 dias eu precisei de uma medicação que o médico me indicou. Uma medicação nova, uma medicação que no mercado você talvez hoje pode ser que ache, mas há um mês e pouco atrás eu não conseguia. Então eu fui na farmácia, mostrei a receita, é um remédio controlado, e o farmacêutico simplesmente falou que não tinha. Eu falei: você não tem na outra farmácia? Ele disse: acho que não tem, quer que dê uma verificada? Não tinha. Eu fui embora e (...) fui até a farmácia ali na frente. $O$ farmacêutico que me atendeu procurou e não encontrou. Foi perguntar para o chefe dele lá, procuraram, viram também que nas outras farmácias não tinha e me dispensaram. 'Aí eu fui numa outra farmácia aqui na Rua (....) O farmacêutico procurou e não achou também. E disse: escuta, eu posso fazer o seguinte - e o cara não me conhecia - eu anoto o nome do medicamento e segunda-feira - isso foi no sábado - segundafeira peço 'pra nossa central pedir 'pra distribuidora e eles conseguem esse medicamento. Se eu conseguir, eu ligo para você, tudo bem? Eu falei: ótimo. Passei meu telefone, perguntaram o medicamento e eu fui embora. Surpresa. Na segunda-feira por volta de umas nove, dez horas, ele ligou para mim dizendo que o medicamento chegaria a uma hora da tarde na central dele que fica em tal rua. Eu fui lá e busquei o medicamento. Veja só, de todos, acho que passei por quatro farmácias diferentes, esse me atendeu de uma maneira especial. Ele se comprometeu, eu não sabia que tinha esse lugar, me admiro com essa boa vontade..."

Por outro lado, alguns outros componentes apresentados pelos consumidores são analisados como evidências das forças de resistência ao grande centro comercial em que se transformaram as farmácias. Estes pontos 
ajudam ainda a reafirmar a propriedade da categoria anterior. São eles: (a) a pressão dos balconistas para que o consumidor adquira mais produtos; (b) a existência de comissão de vendas; (c) o despreparo dos balconistas para levar informações aos consumidores; (d) a falta de um ambiente que confira privacidade ao diálogo entre o consumidor e o farmacêutico; (e) a vulnerabilidade do consumidor em relação à farmácia, sobretudo nos estágios patológicos; (f) a transformação da farmácia em loja de conveniência.

[Consumidor 4 - Grupo Focal 1] '...me lembro que na compra foi um pouco chato (....) pedi onde estava o produto porque eu não estava vendo. Ele (balconista) veio com muita boa vontade me mostrar onde estava o produto. 'Daí ele disse o porquê de eu estar escolhendo o produto. Eu disse o porquê. 'Aí ele me orientou dizendo que não seria tão importante aquele produto, que não seria muito bom aquilo lá não, que aquilo lá estava até saindo de linha, em desuso, meio fora de moda, que ele tinha uma alcachofra lá, que era muito superior e se eu comprasse aquela eu ia me dar muito bem, realmente eu ia emagrecer. $E$ a pergunta para fazer agora: custava quatro vezes mais do que o produto que eu estava comprando..."

[Consumidor 1 - Grupo focal 2] "...neste ano eu queria comprar um remédio 'pra me livrar de alguns problemas, e tinha um farmacêutico, que eu me senti mal de falar com ele, na frente dos outros fregueses, não tinha espaço, um momento confidencial, e tinha que explicar o meu problema com todo mundo lá, inclusive para quem eu nem conhecia, então eu me senti um pouco mal com isso, não que ele não estava querendo ajudar..."

[Consumidor 1 - Grupo focal 2] "...eu acho que a pessoa quando chega na farmácia, muitas vezes, nem sempre, mas 
muitas vezes, esta em uma situação vulnerável, que precisa encontrar com uma pessoa que está disposta a ajudar, a responder perguntas, a dar dicas..."

[Consumidor 2 - Grupo Focal 1] "...por que a farmácia paga comissão? 0 objetivo dela, de pagar melhor através de comissão, não é que você seja melhor atendido no final das contas. O objetivo principal é fazer você comprar mais, porque aquele cara que vai lá te atender, ele vai querer te enfiar creme, negócio para o cabelo é excelente, é assim, eles ganham forçando a venda. Então, de repente, você entra 'pra buscar um Melhoral, e você sai com uma sacola na mão, não é o ideal, você precisava só do Melhoral. Então isso me imita muito. Eu quero ir lá buscar determinado produto, é só aquilo que eu quero, não gosto que tente me fazer comprar mais do que eu preciso, do que eu estou buscando. Então esse atendimento eu acho que não é justo que ele queira me enfiar produtos, mas sim atender o que eu necessito (....) A solicitude, a disponibilidade é válida, mas se eu precisar..."

[Consumidor 1 - Grupo Focal 1] “...eu também não gosto que fiquem enfiando coisas que eu não fui lá comprar, e sim eu fui lá pedir o medicamento, o produto é tudo aquilo que eu fui comprar: vai querer ver mais isso aqui, ou aquilo ali? Eu falo: não, é só isso que eu vim comprar. As vezes eu sou até grossa mesmo: é aquilo que eu vim comprar e acabou. Eu também não gosto de empurrar, como diz o outro, a "goela abaixo" uma coisa que a gente não foi buscar..."

[Consumidor 3 - Grupo Focal 1] "...Alguma coisa que me chateia muito ver é que a cada vez que o tempo passa, o espaço determinado 'pra farmácia está mais escondido, mais reduzido, e o espaço para as baboseiras, para mim são 
baboseiras, por que não servem, produtos de beleza, produtos de higiene pessoal, aqueles remédios feijão com arroz, Flogoral, Sacarina, Novalgina, ficam todos ali expostos, como num supermercado, então isso não me agrada. Farmácia 'pra mim tinha que ser exclusiva 'pra vender remédios..."

[Consumidor 1 - Grupo Focal 1] “...eu também acho que a farmácia não deveria ficar colocando essas mercadorias de mercado na farmácia, e sim os remédios que são necessários. Se é farmácia tem que vender remédios e não bolachas..."

Com relação à discussão a respeito do desconforto do consumidor com a comissão dos balconistas, um argumento diferente foi levantado por um dos entrevistados: a comissão é importante para que o atendente seja estimulado a atender bem, a estar disponivel e interessado no consumidor. $O$ argumento é também questionado por outros consumidores, como mostra o segundo fragmento.

[Consumidor 2 - Grupo Focal 1] "...Tem um lado também, que se não ganham comissão, eles não atendem bem, e isso aí é ruim. Você vai numa loja onde uma funcionária recebe comissão, o teu atendimento é outro. As farmácias estão atendendo muito bem por causa de comissão. Infelizmente é assim. Você só é atendido bem em um lugar, se a pessoa é comissionada..."

[Consumidor 3 - Grupo Focal 1] “...vamos citar um exemplo. Tem uma padaria aqui na Rua (....) Eu fui lá e fui bem atendido, muito bem atendido. Ninguém quis me enfiar mais pães do que eu precisava, ninguém quis vender nada mais. A presteza, a educação no tratar e no falar foi o suficiente..." 
A terceira e última categoria de análise foi denominada desejos de cidadãos, por reunir reivindicações dos consumidores por um serviço mais organizado e mais confiável, no qual exista um profissional farmacêutico que possa atuar de maneira mais próxima, que possa acompanhar o consumidor e assim Ihe trazer informações. Este desejo é acompanhado da reivindicação de uma farmácia que associe também bons preços a bons serviços.

[Consumidor 3 - Grupo Focal 1] "...eu acho que o importante, e a gente não está vendo isso, é um profissional, é um farmacêutico de verdade, que a gente não vê nas farmácias. Nós vemos lá 0 atendente, normalmente não está preparado para falar a respeito da medicação que está vendendo. Se você tem dúvida, se você quer optar por um mais barato, você sabendo que ele não é um farmacêutico, ele é apenas um vendedor, não estou menosprezando, mas ele é apenas vendedor. O que ele vai poder te orientar? Você pode ter fé na orientação que está passando 'pra você? Eu acho que a presença do farmacêutico, o que eu acho que é muito importante dentro da farmácia, e isso a gente não viu. É difícil você ver uma farmácia que têm farmacêutico mais de um período por dia. Eles devem estar, só que eu nunca vi (....) Eu gostaria de ter alguém capacitado para dar as informações que eu preciso sobre medicamentos aliado a um bom preço. Eu não uso muito esses serviços de entrega, não gosto muito, acho que não tem muito a ver comigo, então 'pra mim o importante é isso na farmácia. Quando eu busco uma farmácia, eu busco medicamentos..."

[Consumidor 1 - Grupo Focal 1] "...Também acho importante que seja um farmacêutico culto 'pra tirar as dúvida da gente. Por que às vezes com a receita lá na farmácia eu pergunto: 'pra quê é que serve este remédio? Eu estou sabendo para que - médico receitou, mas eu quero tirar minhas dúvidas. 'Af o 
rapaz lê a bula. A bula eu leio, não precisa ele ler 'pra mim. 0 farmacêutico não precisa, vai falar alguma coisa 'pra gente..."

\subsubsection{O sentido do modelo de acreditação}

Algumas categorias de análise foram criadas a partir da interpretação dos fragmentos extraídos das falas que serão apresentados a seguir. Quando as entrevistas com os informantes-chave compreenderam a investigação deste tema, a tentativa foi tanto buscar um sentido técnico para o conjunto de padrões de qualidade propostos no modelo, quanto buscar um sentido de sustentação política para o mesmo. Além destes sentidos, o componente subjetivo da mudança tanto foi acessado na análise deste tema, quanto nos quatro temas anteriormente discutidos.

$O$ fragmento a seguir reúne duas evidências que fundamentam a categoria denominada busca da mudança, que procura compreender um determinado desejo de proprietários, balconistas e farmacêuticos, de que suas farmácias se diferenciem no mercado. Nenhuma das estratégias para concretizar este desejo constituem ações de atenção farmacêutica ou de construção de sujeitos.

São elas: (a) a política de preços ancorada nos descontos na hora da compra, que tem sido a tentativa mais concreta de diferenciação. Entre os entrevistados existe a percepção de que tal política não é suficiente para diferenciar farmácias, muito menos sustentável economicamente, considerando a situação atual do setor; (b) a tentativa de se diferenciar além dos preços, fazendo com que as farmácias procurem oferecer serviços ao consumidor, como a criação de um centro de beleza voltado a mulher, a adoção de vendas de produtos em um setor de conveniência, o serviço de entregas em domicilio e a realização de campanhas por meio da distribuição de panfletos, testes de glicemia, colesterolemia e pressão arterial. 
[Proprietária - Caso 1] "...essas redes que começaram a fazer isso (dar elevados descontos), hoje estão chegando à conclusão que elas estão simplesmente, mesmo se beneficiando coisas informais, elas estão repassando tudo, não estão ganhando também. Hoje, se eles pararem de dar esse desconto elevado eles param de vender, e eu sempre achei que a gente tinha que ir por outro caminho. Como a gente estava sempre baseado na parte de atendimento, eu achei sempre que tinha que investir no atendimento e no serviço. Então nós criamos esse centro de beleza, que essa farmacêutica treina essas moças, 'pra a gente vender produtos, não medicamentos. Eu acho que farmácia tem que estar cada vez menos dependente do medicamento, essa é a minha visão..."

Em busca da diferenciação, outra evidência que fundamenta a categoria é a de que algumas farmácias, especificamente as de manipulação, têm buscado a certificação das normas ISO e também buscado selos específicos, como o emitido pela Associação Nacional de Farmácias Magistrais (ANFARMAG) para boas práticas de fabricação. A argumentação é acompanhada da preocupação em tornar estes e quaisquer outros processos de classificação, efetivamente úteis aos consumidores.

[Presidente - AFL] "...uma acreditação de farmácias, isso 'daí chama muito a atenção, chama mesmo. Nós temos farmácias de manipulação que têm a ISO 9001, etc. Por aí todas elas estampando, batendo no peito, dizendo que têm ISO 9002..."'

[Presidente - AFL] "...a população não entende nem o que é medicação genérica, não entende nem o que é uma medicação similar, nem o que é ético, não sabe nem quem que é o farmacêutico dentro de uma farmácia, ele vai saber o quê que é uma acreditação?..." 
A proposta do modelo de acreditação é também analisada por um dos entrevistados com base nas experiências negativas atuais de fiscalização do setor, categoria denominada nova forma de controle. Entre os entrevistados, há dúvidas em relação a quem seria o responsável pela fiscalização. Nas entrevistas a imagem da acreditação foi bastante comparada à fiscalização profissional, fiscal e sanitária atualmente existes.

Surgiu ainda a idéia de que a gestão do processo de acreditação, bem como as atividades de fiscalização, contassem com uma estrutura colegiada, o que traria maior confiança ao processo. Este argumento é reforçado por outro entrevistado preocupado em que o processo de acreditação tenha uma estrutura de fiscalização que funcione para todos. O mesmo entrevistado argumenta também que se houver fiscalização séria, é possivel que os padrões sejam cumpridos, mas que diante da organização atual do trabalho nas farmácias, há dúvidas se é possivel cumprir tantas exigências.

[Presidente - AFL] "...eu acredito que se a certificação ou essa estrutura for feita em parceria com todos os órgãos, vai ser de confiança. Agora, se for criado um órgão para fazer isso, eu fico na dúvida (....) Agora, se todos os órgãos interagirem juntos, vamos supor que ai tenha uma pessoa do Conselho de Saúde, uma pessoa do Conselho de Farmácia, uma pessoa da Associação, uma pessoa de qualquer outro órgão, que saírem juntos para fazer isso, que dizer, são 4 entidades diferentes, $e$ 4 pensamentos diferentes, 4 linhas diferentes, ligados a uma linha de saúde. Eu acredito que 'aí dê certo..."

[Farmacêutica - Caso 2] “....achei uma idéia muito boa, é como você diz, teórica. As vezes na prática não é tão fácil conseguir todas essas normas (....) Precisa ter um órgão ou alguém que venha fiscalizar, e que você está sempre fiscalizado, e que é fiscalizado você vai fazer, você vai cumprir, entendeu? Então eu acho assim, é muito bom, aumenta a qualidade, a 
qualificação, tudo, a limpeza, a higiene, a vigilância sanitária. Só que se for ver, teoricamente é muito bom, só que na prática não sei não. Com certeza pode melhorar, pode acontecer por em prática isso, só que é difícil, não sei, eu penso assim, pela vida agitada que a gente leva..."

A análise do fragmento a seguir revela uma outra categoria de análise, aqui tratada de credibilidade externa. As evidências que fundamentam esta categoria são: (a) a valorização do estabelecimento junto à comunidade, por contar com a credibilidade de um agente externo que afirma que a farmácia realiza serviços de qualidade, (b) a valorização do farmacêutico por pertencer a uma organização credenciada (acreditada); (c) a importância da acreditação ser feita por um órgão especializado no tema, qualificando a farmácia e seus profissionais.

[Farmacêutica - Caso 2] "...ainda mais 'pra gente farmacêutico, eu acho que é muito bom. Vai te qualificar, vai te dar um certificado. Tipo a sua farmácia tem, a da vizinha não tem, então a pessoa vai ter preferência 'pra ir no seu estabelecimento, você tem algo a mais 'pra oferecer. Está tudo esquematizado lá que você tem um certificado, tem uma vigilância sanitária, está mostrando isso 'pra o cliente, então isso é bom, isso qualifica tanto o farmacêutico, como o estabelecimento, eu acho que é coerente sim, é bom..."

[Auxiliar de gerente noturno - Caso 1] "...Com certeza, ajudaria. Acho que a credibilidade (...) Chamaria mais a atenção do cliente, saber que a farmácia tem uma avaliação de pessoas de um grau superior, que avalie, 'pra gente seria muito melhor, a confiança do cliente é maior, mais segurança 'pra nosso trabalho..." 
Dois fragmentos apresentam também argumentações que fundamentam a categoria aqui denominada de resultados positivos. Este resultados, relacionados a benefícios para o consumidor, poderiam ser conquistados em razão de um sistema de acreditação que reduzisse a empurroterapia e ampliasse a atenção aos consumidores.

[Farmacêutica 1 - Caso 1] "...é complicado, mas eu acho que pode melhorar muito 0 atendimento e a atenção para as pessoas. Porque a nossa, eu não posso reclamar de nada, mas eu já vi muita farmácia querendo empurrar tudo. Vocês vão avaliar isso também? Essa parte de comissão, e eu acho que ia melhorar bastante o serviço da farmácia..."

[Farmacêutica 2 - Caso 1] "...eu acho que é fundamental porque se você chega numa farmácia, que não é uma farmácia de confiança, o que vai acontecer? Você pode estar levando um produto errado, você pode estar levando uma receita e a pessoa estar trocando sua receita por outro medicamento ou até mesmo não interpretando sua receita direito, te vendendo 0 produto errado. Então eu acho que tudo isso, se tiver uma qualificação, uma inspeção a partir da qual o cliente possa ter uma confiança na farmácia, eu acho que tudo isso é melhorado..."

Nos dois fragmentos a seguir, a categoria identificada é aqui denominada de sistema de referências. Nas evidências trazidas pelos entrevistados, identifica-se que a sociedade reconhece um amplo conjunto de referências para outros tipos de produtos e serviços. mas que isso ainda não existe para a área farmacêutica. Assim, vêem no modelo de acreditação um caminho de criação destes padrões. 
[Farmacêutica 2 - Caso 1] "...eu acho fundamental isso aí porque a gente vê isso em empresas de tudo, de alimentos, das menores coisas, de veículos, de tudo. Enfim, o que você está comprando por aí tem esse certificado. Essas qualificações são coisas úteis, elas servem 'pra você. Só que eu acho que nada é mais importante que a sua saúde, então uma empresa que tem uma qualificação destas, acho que a credibilidade do cliente é muito importante..."

[Gerente - Caso 1] "...isso aí já devia ter surgido há muitos e muitos anos, nos países hoje de primeiro mundo. Esses são os pensamentos, você conseguir direcionar empresas sérias e garantir para o cliente. O cliente vai ficar satisfeito ao saber que ali tem qualidade..."

Em outro fragmento, a categoria identificada é definida como instrumento para o consumidor, que reconhece o modelo de acreditação como dimensão importante para que o consumidor possa diferenciar o que é bom do que não é, com critérios mais adequados do que aqueles representados nas forças alienantes, tratadas anteriormente.

A argumentação aponta claramente o fato de que é difícil para o consumidor fazer escolhas com base em elementos técnicos, o que o faz julgar e escolher com base apenas no preço, na educação dos balconistas, nos serviços de entrega rápida, entre outros que, em se tratando de saúde, não são suficientes.

[Proprietária - Caso 1] "...eu acho importante tudo o que você for fazer no sentido de diferenciar o que é bom e o que não é bom. Eu acho que é super válido porque a comunidade, a população, as vezes ela não tem elementos. Que você fala que o cliente percebe quem faz, quem não faz. Não é bem assim na prática. Então eu acho que esse critério de você estar podendo 
medir, avaliar, é muito importante e deve ser apoiado, principalmente se as empresas querem fazer as coisas certas, querem fazer as coisas 'pra realmente proporcionar um bem "pra sua comunidade..."

Além das seis categorias identificadas neste tema, dois elementos de fundo também foram percebidos no processo de interpretação. Em primeiro lugar, que as opiniões dos entrevistados muitas vezes situaram o processo de mudança em um lugar externo e distante de suas práticas, por isso também distantes de sua possibilidade de escolha e decisão. Em segundo lugar, que a compreensão dos esforços implicados no cumprimento dos padrōes de qualidade do modelo de acreditação também não foi acessada pelos entrevistados em profundidade.

O primeiro elemento pôde ser percebido à medida que nenhum dos entrevistados questões que relacionassem criticamente as implicações para a farmácia, em participar de um processo de acreditação. Nenhum dos entrevistados argumentou a respeito do que significaria o processo de mudança em seu processo de trabalho e muitos deles trouxeram comentários relacionados à fiscalização externa ou à importância do agente de acreditação externo, para garantir que as farmácias se reorganizassem, como se a eles mesmos não coubesse esta tarefa atualmente.

O segundo elemento pôde ser identificado à medida que muitos dos entrevistados, incluindo farmacêuticos e balconistas, afirmaram que 0 processo de acreditação seria bem vindo e que só traria benefícios e vantagens para a farmácia na qual trabalham atualmente. Alguns deles afirmaram que em Londrina a farmácia do Estudo de Caso 1 seria a única a ser acreditada, o que definitivamente não é verdade.

[Gerente - Caso 1] "...Eu falo assim hoje, porque eu estou numa empresa que ela se beneficiaria com isso. Esse é o meu pensamento porque nós temos uma mercadoria, vamos falar 
assim, que é o nosso atendimento, nossa disponibilidade para esses clientes que precisam de um atendimento dessa forma $e$ do profissionalismo que tem ali dentro. Eu acredito que dentro de Londrina hoje, se tivesse esse trabalho, nós seriamos o número um, porque nós respeitamos todas essas normas que tem dentro do texto..."

Nos cinco temas analisados neste capitulo, dezessete categorias de análise (figura 3) foram identificadas e discutidas. A intenção desta discussão foi reunir elementos pudessem ajudar na compreensão e na reflexão a respeito da hipótese de pesquisa. É preciso ainda entender que este conjunto de categorias encontra bons argumentos de reflexão em muitos dos padrões de qualidade propostos pelo modelo de acreditação.

\begin{tabular}{|ll|}
\hline Qual é o papel da farmácia? & O que percebem os consumidores? \\
1. Lugar de comércio de medicamentos & 9. Forças alienantes \\
2. Lugar de conveniência & 10. Forças de resistência \\
3. Lugar de valor sanitário & 11. Desejos de cidadãos \\
Qual é o papel do farmacêutico? & Qual é o sentido do modelo? \\
4. Agir técnico & 12. Busca de mudança \\
5. Agir administrativo & 13. Nova forma de controle \\
6. Agir mecânico & 14. Credibilidade externa \\
Qual é o papel dos balconistas? & 15. Resultados positivos \\
7. Vendedores de medicamentos & 16. Sistema de referências \\
8. Agentes hegemônicos & 17. Instrumento para o consumidor \\
\hline
\end{tabular}

Figura 3. Os temas e categorias de análise.

O capítulo a seguir procura intensificar este debate e reunir argumentos que relacionem a hipótese de pesquisa, o processo metodológico e os resultados que aqui foram apresentados. 


\section{CONSIDERAÇÕES FINAIS}

Só o desejo inquieto, que não passa,

faz o encanto da coisa desejada...

E terminamos desdenhando a caça pela doida aventura da caçada. Mário Quintana ${ }^{25}$

Como tornar belas e atribuir sentido às sutilezas do óbvio? Como encerrar uma tese depois de tão prazeroso mergulho em tantas porções de produndidades? Como concluir um trabalho que inaugura um novo tempo biográfico? Como lidar com o fim de um longo processo de trabalho? Como estar seguro dos resultados? Como escrever as considerações finais?

Compreender o verso de Mário Quintana ajuda a entender em que contexto está sendo escrito este capitulo: o fim de um intenso processo de trabalho, marcado por leituras, análises e reflexões, pela busca de um sentido para cada idéia e capitulo da tese e pela construção de um sujeito. Por isso a beleza e os resultados deste processo precisam ser olhados tanto da perspectiva de construção desse sujeito, quanto da produção de conhecimento. Por isso há perguntas. Por isso a caçada está em evidência.

Para escrever as considerações finais, é preciso lançar mão de um método de trabalho e iniciar a construção a partir de algumas escolhas. Já que, ao contrário de Gregor Samsa ${ }^{26}$, não é possivel permanecer entre quatro paredes depois de viver a metamorfose, algumas idéias precisam ser retomadas e discutidas, para que outras possam ser construídas e explicitadas. E quais são essas idéias?

Quatro componentes foram escolhidos e receberão atenção neste capítulo: o marco conceitual do trabalho, a linha metodológica, os resultados e a hipótese de pesquisa. Compreendê-los através da revisão de algumas

\footnotetext{
25 "Da eterna procura", poema que compõe o livro Espelho Mágico de 1951.

${ }^{26}$ Personagem do livro A Metamorfose, publicado por Franz Kafka em 1916.
} 
passagens do trabalho e da apresentação de novas idéias é importante para conferir maior estrutura orgânica à tese e para que considerações em torno da hipótese de pesquisa sejam estruturadas. Vamos a eles.

\subsection{Do marco conceitual}

O primeiro componente analisado trata da construção do marco conceitual do trabalho, que teve no primeiro capítulo a apresentação e a fundamentação das premissas conceituais que orientaram a elaboração da tese e a explicitação daqueles que são os principais autores dos temas discutidos.

Os primeiros parágrafos do capítulo foram escritos a fim de demonstrar o papel do programa de doutorado na aquisição de elementos críticos que ajudaram o pesquisador a construir sua visão da ciência e a manter uma postura crítica frente a qualidade e a importância deste trabalho. Foram escritos também para oferecerem um breve, mas importante depoimento do pesquisador a respeito da sua forma de olhar o mundo e analisá-lo segundo um pensamento que procura construir-se na linha da dialética.

Ao advertir que este trabalho não contém a ingenuidade da certeza ou a doce ilusão da verdade, e que a possivel falsidade das interpretações não poderia ser negada, tampouco tratada de irresponsabilidade científica, desejou-se assumir uma posição crítica diante da ciência. Entre René Descartes com sua afirmação que dos objetos deve-se investigar "aquilo do que podemos ter uma intuição clara e evidente, ou que podemos deduzir com certeza, pois de outro modo não se adquire a ciência" (DESCARTES 2000) e os dias atuais, um grande pincel embebido de incertezas conferiu outra cor às ciências.

Por fim, ao afirmar entre os primeiros parágrafos, que este trabalho "que ora se desenha e se define como inédito, desafiador e por isso mesmo angustiante e provocador, provavelmente virá a assumir um lugar igual entre 
outros tantos trabalhos iguais, dissolvendo-se nas características gerais do conhecimento que se produz nesta época" não se desejou outra coisa que não falar da clássica, talvez irrefutável, afirmação de Karl Marx e Friedrich Engels no Manifesto Comunista de 1847: "tudo que é sólido desmancha no ar" (MARX e ENGELS 1998).

Com a visäo marcada por elementos construtivistas, compreensivos e subjetivos, no sub-capítulo 1.1 estruturou-se um discurso em torno da mudança nas organizações, que procurou articular autores que valorizam intensamente a construção de sujeitos e resgatam a necessidade de privilegiar as ações humanas dotadas de sentido (GIDDENS 1991; CHANLAT 1996; CAMPOS 1997; BECK 1997; BAUMAN 1998).

Neste capitulo foram também elaboradas críticas importantes à forma tradicional de se compreender a mudança, como os argumentos em torno do culto à velocidade da mudança e do culto à externalidade da mudança. $O$ capítulo procurou reunir idéias favoráveis a que processos de mudança, independente da ferramenta que utilizem, por exemplo a acreditação, sejam acompanhados de um processo sensivel de construção de sujeitos.

Por sua vez, a discussão realizada no sub-capítulo 1.2 teve a intenção de situar este trabalho diante do contexto histórico no qual se insere o movimento da qualidade em saúde, ao longo do Século $X X$. Duas considerações devem ser realizadas a respeito desta discussão. A primeira é que o capitulo procurou oferecer um panorama geral das origens e da estruturação da qualidade, aspecto útil para ampliar a compreensão do modelo de acreditação aqui desenvolvido.

A segunda consideração é que o capítulo não foi escrito com a intenção de realizar uma análise crítica do movimento da qualidade no contexto da evolução das organizações e, sobretudo, dos paradigmas da administração e da economia, hegemônicos no Século XX. A opção foi seguir um caminho mais descritivo do que analítico, registrando os momentos e fatos históricos que influenciaram o surgimento e desenvolvimento dos sistemas de qualidade em saúde. 
O marco conceitual recebeu no sub-capítulo 1.3 a discussão sobre as razōes que levaram à utilização de padrões de qualidade em vários setores da sociedade. Argumentos de autores como SINGER (1996), GUBA e LINCOLN (1989), PATTON (2002), entre outros, foram utilizados para mostrar a importância que a avaliação tem na sociedade atual e para registrar algumas de suas características históricas.

A relação entre avaliação e qualidade em saúde foi então explorada com base em MALIK e SCHIESARI (1998), CÉSAR e TANAKA (1996), TANAKA e MELO (2001) e discutida em seus componentes intrinsecos e extrínsecos à luz dos modelos propostos por COSTANZO e VERTINSKY (1975), DONABEDIAN (1990) e VUORI (1991), autores fundamentais para o tema da avaliação da qualidade em saúde.

O capítulo também reuniu elementos da qualidade na área farmacêutica com base em documentos produzidos por órgãos internacionais de cooperação e por organizações brasileiras em anos recentes. A valorização dos padrões de qualidade no campo farmacêutico e um breve diagnóstico das mudanças na área da qualidade vividas no setor - farmácias hospitalares, farmácias de manipulação e laboratórios de análises clínicas foram utilizados para explicitar a existência de um ambiente mundial de busca de qualidade, no qual o uso de padrões desempenha um papel estratégico.

O capítulo 1.4, último componente do marco conceitual, procurou explorar a possibilidade de construção de uma nova práxis profissional com base na filosofia da atenção farmacêutica. Através de autores como BERMUDEZ (1995, 1997) e LEFÉVRE (1991), foram realizadas análises críticas dos efeitos nocivos decorrentes do uso irracional de medicamentos e do lugar que estes objetos ocupam na sociedade moderna.

Nesta argumentação foram construídas críticas importantes à reificação do medicamento e estruturada uma importante premissa do trabalho: a análise do mecanismo de ruptura e afastamento do medicamento mercadoria da farmácia serviço, estratégia que conferiu ao medicamento 
mercadoria, posição hegemônica em relação ao papel sanitário que deveria caracterizar a farmácia.

Com base nesta argumentação, foram descritas as origens do conceito da atenção farmacêutica no cenário norte-americano. A presença deste conceito neste trabalho foi determinante em sua estruturação. $O$ conceito atenção farmacêutica foi analisado tanto a partir de seus precursores HEPLER e STRAND (1990), quanto a partir de versões internacionais patrocinadas pela OMS e FIP e da versão brasileira (OPAS 2001).

A análise do conceito atenção farmacêutica a partir de seus componentes político-sanitário, cognitivo e humanista, foi enriquecida com a argumentação de KUHN (1996) a respeito dos paradigmas científicos. Com base neste diálogo estruturou-se a idéia de que esta área de conhecimento vive um momento de ruptura entre um paradigma tecnicista e um paradigma humanistico, premissa também importante neste trabalho.

O marco conceitual articulado em torno destes autores, princípios e reflexões, permitiu a definição do objetivo do trabalho e de sua justificativa, assim como da hipótese de pesquisa. Considerando esta produção, foram então escolhidos a abordagem e os passos metodológicos que sustentariam o trabalho, elementos tratados a seguir.

\subsection{Do caminho metodológico}

O segundo componente abordado neste capítulo de considerações finais diz respeito ao caminho metodológico utilizado na pesquisa. A respeito disto é importante destacar que boa parte do caminho metodológico, incluindo a explicitação da relação pesquisador-objeto, o trabalho com o grupo de consenso, a escolha do método de estudo de caso e das técnicas de coleta e análise das informações, foram fundamentados principalmente em MINAYO (1994), PATTON (2002), STAKE (1995), LIST (2003) e HABERMAS (1989). 
Com base nestes autores, o uso da técnica de formação qualitativa não presencial de consenso levou à produção do modelo de acreditação a partir de um amplo e consistente processo de interação e criação. Além disso, a realização dos estudos de caso nas duas farmácias em Londrina, tendo como eixo as entrevistas individuais e os grupos focais, foi de grande importância na construção da consciência crítica do pesquisador em relação ao objeto de pesquisa, e na produção de elementos capazes de atribuir um contorno reflexivo ao modelo de acreditação.

A análise do material recolhido no campo foi orientada por cinco grandes temas: (a) papel da farmácia; (b) papel do farmacêutico; (c) papel do balconista; (d) percepção dos consumidores; (e) sentido do modelo, foi também fruto de um processo metodológico intenso, cuidadoso e apropriado. O uso da linha analítica sugerida por MINAYO (1994), trouxe grande relevância e profundidade ao processo de análise. Ainda que cansativo, foi um processo elucidativo e dotado de elevado potencial de aprendizagem, como mostram as dezessete categorias de análise identificadas nas falas dos participantes (figura 3 ).

Como não houve possibilidade de que as mais de duzentas páginas de transcrição pudessem ser conhecidas integralmente, a expectativa é de que os fragmentos utilizados no texto, tenham simbolizado a riqueza das entrevistas e dimensionado o grau de contribuição que os entrevistados deram a este trabalho. A partir deste percurso metodológico é que os resultados foram alcançados.

\subsection{Dos resultados}

O terceiro componente analisado neste capítulo são os resultados alcançados com a pesquisa. Considerando que seu objetivo geral foi o de desenvolver um modelo de acreditação de farmácias e drogarias e explorar as oportunidades de mudança na prática farmacêutica com base neste modelo, é possível afirmar que ele foi alcançado, e que 
importantes descobertas, bem como novas perguntas, estão associadas tanto ao processo de construção do modelo de acreditação, quanto aos dois estudos de caso realizados em Londrina.

Com relação à construção do modelo, alguns elementos merecem destaque nesta argumentação. O primeiro deles diz respeito ao caráter de ineditismo que o acompanha. Ainda que sua aplicabilidade e utilidade venham apenas a ser testadas futuramente, a articulação de conhecimentos e de experiências ao redor do modelo, poderá resultar em boas contribuições para o desenvolvimento do setor farmacêutico.

A proposição dos padrões e seus dois niveis de qualidade $A$ e $B$ nas questões de estrutura, processos e resultados, poderão servir de elementos de discussão e orientação para novos trabalhos e programas que, assim como esta pesquisa, queiram servir à promoção do uso racional de medicamentos no Brasil. Para os especialistas que participaram de sua criação, todos com importante inserção profissional, o modelo de acreditação poderá se constituir em uma consistente base de discussões e de práticas em seus espaços técnicos e politicos.

Dos especialistas nasceram também algumas perguntas de grande importância para a consolidação do modelo de acreditação desenvolvido nesta pesquisa. Considerando o eixo epistemológico ao redor do qual este trabalho está estruturado, a produção de novas e estimulantes perguntas é tão importante quanto o mais concreto dos resultados esperados. As provocações lançadas por eles estão listadas a seguir.

a) Que organizações devem ser convidadas a debater os resultados desta pesquisa, em ordem de aproveitar esta produção no desenvolvimento do setor farmacêutico?

b) Como encontrar uma alternativa para que, a partir dos padrões que foram construídos, roteiros de avaliação sejam elaborados e experimentos piloto sejam realizados? 
c) Como fazer com que o modelo de acreditação estimule um processo de aprendizagem no setor, garantindo um período de adaptação para que as farmácias possam cumprir os padrões e serem acreditadas?

d) Como harmonizar padrões de qualidade para procedimentos tratados de forma diferente pela legislação sanitária dos estados, dos municipios e da União?

e) Como construir um processo de acreditação que seja compreensivo com as marcantes diferenças regionais do Brasil?

f) Como articular a discussão da qualidade em farmácias aos movimentos de reforma curricular e de discussão da atenção farmacêutica?

Em complemento às perguntas, diversas evidências e provocaçōes foram também reunidas pelos estudos de caso. Estas informações constituíram-se em ilustrações consistentes da necessidade e oportunidade de mudança existente nas farmácias. Revelaram também a distância entre os padrões de qualidade presentes no modelo de acreditação e a realidade das farmácias. Algumas considerações a respeito destes elementos, aí incluindo suas relaçōes com a hipótese de pesquisa, precisam ser realizadas aqui.

\subsubsection{O papel da farmácia}

Com base na análise temática que amparou o estudo qualitativo, três categorias foram identificadas como componentes do papel da farmácia para os entrevistados: (a) a farmácia lugar de comércio de medicamentos; (b) a farmácia lugar de conveniência; (c) a farmácia lugar sanitário. Esta composição, óbvia por um lado e paradoxal por outro, é reveladora tanto das dificuldades quanto das oportunidades de mudança identificadas com os estudos de caso. 
Se existem dificuldades em superar a orientação comercial hegemônica no setor, cujas conseqüências são a distorção do papel da farmácia, a banalização do uso dos medicamentos e a ampliação do risco para os consumidores, oportunidades de mudança também podem ser identificadas. A capilaridade alcançada pelas farmácias nas comunidades, a imagem de um lugar sanitário que ainda sobrevive na sociedade e a evolução do setor, ora impulsionada por ações de vigilância sanitária, ora por ações comerciais, podem criar um caminho sustentável de desenvolvimento.

Frente ao cenário revelado pelos estudos de caso quanto ao papel da farmácia, o modelo de acreditação aqui proposto poderá ocupar um lugar de grande importância estratégica para a mudança. Ao procurar redesenhar as atividades técnicas desenvolvidas pela farmácia, criando um novo ambiente sanitário na sociedade, uma nova forma de interação com consumidores e uma inédita interação e complementaridade ao trabalho de outros profissionais de saúde, o modelo de acreditação pode, de maneira concreta, ajudar na redefinição do papel social da farmácia no Brasil.

\subsubsection{O papel do farmacêutico}

Assim como a discussão a respeito do papel da farmácia revela incongruências e paradoxos, o papel do farmacêutico está marcado por uma crise de identidade instalada a partir dos diferentes papéis identificados nos estudos de caso: (a) um agir técnico; (b) um agir administrativo; (c) um agir anônimo. A análise destas categorias revelou a necessidade de que açōes que ajudem a reestruturar a prática farmacêutica sejam desenvolvidas. Mesmo os profissionais que têm procurado alterar seu papel na farmácia, possuem pouco preparo técnico e quase nenhuma autonomia gerencial para promover mudanças.

Algumas características do modelo de acreditação desenvolvido na pesquisa poderão ter grande importância na reconstrução do papel profissional, agora com bases sociais e organizacionais legítimas e 
sustentáveis. A necessidade de que as farmácias realizem, documentem e acompanhem todos os procedimentos técnicos, possuam quadros com responsabilidades bem definidas e desenvolvam uma efetiva rotina de acompanhamento dos pacientes, pode dar ao farmacêutico a chance de uma transformação radical em suas atividades, especialmente apoiada em sua importância na nova organização.

\subsubsection{O papel dos balconistas}

Dentre as evidências reunidas com os estudos de caso, a posição hegemônica dos balconistas nas farmácias foi uma das mais expressivas. À medida que a natureza comercial das farmácias se ancora na venda de medicamentos praticada pelos balconistas, a relação farmácia-balconista possui bases estruturais muito mais sólidas do que a relação farmáciafarmacêutico. Como revelado pelos estudos de caso, as biografias dos balconistas estão repletas de casos de ascendência organizacional e de conquistas pessoais importantes a partir do trabalho nas farmácias.

Este fenômeno é enriquecido à medida que os balconistas, principais elos de ligação entre as farmácias e os consumidores, são orientados por uma visão que reifica o medicamento e banaliza seu consumo com base em argumentos frágeis mas perigosos: "se eu não vender o outro vende", "eu indico com responsabilidade e sei até onde posso ir", "o sistema de saúde não funciona e a farmácia precisa resolver", "a cultura do brasileiro é de automedicação"27. Beneficiados pela comissão sobre vendas, pelas premiações e pela mobilidade que podem ter na organização, os balconistas desempenham o papel desejado pela indústria farmacêutica.

Diante deste contexto, a implementação de um modelo pautado em valores e procedimentos, cuja intenção é também impedir este atropelo da

\footnotetext{
${ }^{27}$ Frases retiradas das entrevistas apresentadas e analisadas no capítulo 4.
} 
racionalidade, parece ser bastante importante para o setor. A revisão da prática da comissão sobre vendas, da venda de medicamentos não prescritos e da prática irracional do diagnóstico e da empurroterapia, elementos críticos do modelo de acreditação, não podem estar no limbo da agenda da mudança.

\subsubsection{Percepções dos consumidores}

Frente à complexa realidade que caracteriza farmácias, farmacêuticos e balconistas revelada nos estudos de caso, a percepção dos consumidores surgiu como um elemento estratégico no pensamento sobre a mudança. Sua vulnerabilidade diante de um setor fortemente marcado pela técnica, sua resistência à empurroterapia e seus desejos por um farmacêutico que cumpra um papel de profissional de saúde, foram riscos e oportunidades reconhecidos no universo destes atores.

Neste universo, o papel que pode ser desempenhado pelo modelo de acreditação aqui desenvolvido é bastante importante. A possibilidade de criar mecanismos que ajudem os consumidores a ganharem consciência a respeito do uso de medicamentos, a exigirem seus direitos como cidadão e fazerem escolhas autônomas em um mercado plural e desconhecido, frente ao qual o consumidor torna-se hipossuficiente, pode vir a ser de grande relevância social.

\subsubsection{O sentido do modelo de acreditação}

O cenário encontrado nas duas farmácias estudadas não apenas demonstrou admitir algum nivel de mudança, como também reconheceu precisar dela. Nas falas dos informantes-chave percebe-se também que o modelo de acreditação proposto pode vir a ser um caminho possivel. Um traço comum às falas dos entrevistados foi a idéia de que as farmácias precisam encontrar alternativas para operarem melhor como negócio e para 
conseguirem melhorar sua inserção na sociedade, cumprindo um papel mais relevante. Essas necessidades podem encontrar apoio no modelo de acreditação.

Contudo, os entrevistados ainda falam da mudança de um ponto de vista ideal ou utópico, tendo dificuldade de relacionar a mudança a suas ações cotidianas. A dependência de fatores ou programas externos ainda é marcante e por isso tais processos ainda são imbuidos de pouco sentido e carregam uma visão alienada do trabalho em saúde. Por sua vez, esta condição pode ser entendida como uma oportunidade de mudança que precisa ser preenchida por um processo socialmente legitimo, um processo que construa sujeitos, reorganize a atenção e procure redefinir a natureza das farmácias.

Neste cenário, ferramentas que apenas simbolizem burocracia ou que tendam a coibir o frágil agir sanitário atual, precisam ser evitadas a todo custo. As criticas elaboradas pelos entrevistados aos mecanismos tradicionais de controle exercidos pelos órgãos de vigilância sanitária e pelo conselho profissional da categoria são evidências desta premissa. A importância dada ao modelo de acreditação em razão de sua credibilidade externa e do sistema de referências que ele apresenta, apenas cumprirá um papel efetivo como catalisador da mudança, se trabalhada com base na preocupação de não burocratizar, não coibir e não fazer do uso da ferramenta a própria mudança.

Para que o modelo de acreditação possa cumprir seu papel, farmacêuticos, balconistas e empresários precisam ser capazes de encontrar diferentes formas de organizar o trabalho. $\dot{E}$ necessário que estes atores construam, em colaboração, alternativas para que as farmácias possam romper seu invólucro comercial e estabelecerem uma nova prática sanitária. Um novo cenário em que a orientação das indústrias - com suas revistas e ações publicitárias, campanhas para premiar vendas, bonificação de medicamentos - e as práticas de mercado desleais e ilegais, não sejam hegemônicas. 
A força para enfrentar este cenário pode residir em modelos e sistemas conceitualmente consistentes e socialmente engajados. Modelos que confiram credibilidade aos serviços em razão de sua busca por resultados positivos na saúde dos consumidores. Da reconstrução da práxis farmacêutica e da reorganização das farmácias pode nascer um sentido também novo para o trabalho e a existência dos profissionais e das organizações.

Este sentido deve reforçar o papel dos medicamentos como instrumentos de apoio à terapêutica, definir com clareza o papel dos farmacêuticos, balconistas e das próprias farmácias, e se preocupar em estabelecer mecanismos e instrumentos para que o consumidor faça seus julgamentos com propriedade e consciência e, a partir deles, faça suas escolhas.

\subsection{Há verdade na hipótese?}

Com base nas considerações presentes neste capítulo, bem como no extenso conteúdo analítico apresentado no capítulo quatro, é possivel reconhecer que há mérito, relevância e plausibilidade na hipótese de pesquisa: uma intervenção nas farmácias e drogarias por meio de um programa de acreditação tendo como eixos a avaliação da qualidade com padrões para estrutura, processos e resultados - e a atenção farmacêutica, é capaz de desencadear processos de mudança que estimulem as organizações a desenvolverem seu papel sanitário com base em práticas humanizadas, centradas na construção de sujeitos e que contribuam para política de defesa da vida.

Falar de mérito, relevância e plausibilidade é a interpretação possivel neste momento. Que outras verdades estão presentes na hipótese? Não é possivel saber. Como afirma WEBER (1987), "nem mesmo a interpretação mais verificável pode reclamar o caráter de casualmente válida". Por isso 0 que se faz aqui não é reclamar a validade da hipótese, mas sim reconhecer nela um sentido que a faça viver naqueles que constróem o setor 
farmacêutico no Brasil por meio de ações cientificas, técnicas e políticas. Apenas as reconstruções que poderão ser feitas a partir daqui, serão capazes de revelar mais elementos a respeito de sua consistência e, talvez, afirmar ou refutar a validade do modelo como catalisador da mudança.

Se este modelo virá a ser utilizado? Terá sentido para outros sujeitos sociais? Será capaz de gerar reflexões naqueles que pensam a profissão farmacêutica? Incomodará quem pensa o setor com base no paradigma tecnicista? Não há como saber; apenas acreditar que o caminho do novo poderá ter este modelo como um de seus paralelepipedos.

Tantas perguntas para encerrar um trabalho levam a pensar que neste final reside o começo de uma outra história. A história de que é preciso seguir na aventura do conhecimento, de que é preciso provar o que apenas a ciência é capaz de oferecer, de que é preciso seguir descobrindo autores, vivendo suas euforias e dividindo suas amarguras.

A história de que é preciso também seguir pensando e escrevendo. Seguir no campo e nas ruas, ouvindo, dialogando, reinventando. É preciso seguir como sujeito na construção do mundo novo e do novo Brasil. Seguir a caminhada de tantos outros, como a luta em defesa da vida travada pelo companheiro David Capistrano, a quem este trabalho é dedicado.

Copiando uma gota da genialidade de Dostoiévski, é preciso dizer que todas essas necessidades, todos esses desejos, todo o vir a ser, tudo isto "poderia ser o tema de um novo relato - mas este está concluído"28.

Inverno, 2003.

${ }^{28}$ Palavras finais do livro Crime e Castigo, publicado por Fiodór Dostoiévski em 1866. 


\section{REFERÊNCIAS}

Almeida M. A organização de serviços de saúde a nivel local: registros de uma experiência em processo. Rio de Janeiro; 1979. [Dissertação de Mestrado - Instituto de Medicina Social da Universidade Estadual do Rio de Janeiro].

[ANVISA] Agência Nacional de Vigilância Sanitária. Programa Internacional de Monitorização/OMS. Brasília: ANVISA. Disponivel em <URL:http: www.anvisa.gov.br/farmacovigilancia/programa.htm> [2003 jul 02].

[ANVISA] Agência Nacional de Vigilância Sanitária. Resolução 328 de 22 de julho de 1999: Dispõe sobre requisitos exigidos para a dispensação de produtos de interesse à saúde em farmácias e drogarias. Brasília; 1999. Disponivel em <URL:http:www.anvisa.gov.br/legis/resol/328_99.htm > [2003 fev 16].

[ANVISA] Agência Nacional de Vigilância Sanitária. Resolução da Diretoria Colegiada - RDC 33 de 19 de abril de 2000: Aprova o regulamento técnico sobre boas práticas de manipulação de medicamentos em farmácias e seus anexos. Brasília; 2000.

[APM/CREMESP] Associação Paulista de Medicina, Conselho Regional de Medicina de São Paulo. Controle de qualidade do atendimento médicohospitalar no Estado de São Paulo: manual de orientações aos hospitais participantes. $2^{\text {a }}$ ed. São Paulo: Atheneu; 1998.

[ASHP] American Society of Health-System Pharmacists. ASHP guidelines: minimum standards for pharmaceutical services in ambulatory care. Am J Health-Syst Pharm 1999; 56:1744-53.

Azevedo AC, Korycan TL. Transformar las organizaciones de salud por la calidad. Santiago: Parnassah; 1999.

Bauman Z. O mal-estar da pós-modernidade. Rio de Janeiro: Jorge Zahar; 1998. 
Beck U. A reinvenção da política: rumo a uma teoria da modernização reflexiva. In: Giddens A, Beck U, Lash S. Modernidade reflexiva: política, tradição e estética na ordem social moderna. São Paulo: UNESP; 1997. p. $11-7 \cdot 1$.

Bermudez JAZ. Indústria farmacêutica, Estado e sociedade. São Paulo: Hucitec; 1995.

Bermudez JAZ. Produção de medicamentos no setor governamental e as necessidades do Sistema Único de Saúde. In: Bonfim JRA, Mercucci VL, organizadores. A construção da política de medicamentos. São Paulo: Hucitec/Sobravime; 1997. p. 72-80.

Berwick DM, Godfrey $A B$, Roessner J. Curing health care: new strategies for quality improvement. San Francisco: Jossey-Bass; 1991.

Bohigas L. Acreditação além fronteiras: a introdução da acreditação da joint commission na Espanha. Ensaio: Aval Pol Públ Educ 2000; 9: 17-28.

Bonfim JRA. Os dédalos da politica brasileira de medicamentos. In: Bonfim JRA, Mercucci VL, organizadores. A construção da política de medicamentos. São Paulo: Hucitec/Sobravime; 1997. p. 21-37.

Bortoletto ME, Bochner R. Drug impact on human poisoning in Brazil. Cad Saúde Pública 1999; 15: 859-69.

Boyett J, Boyett J. O guia dos gurus. Os melhores conceitos e práticas de negócios. $3^{\mathrm{a}}$ ed. Rio de Janeiro: Campos; 1999.

Brasil. Decreto 3.181 de 23 de setembro de 1999. Estabelece o medicamento genérico, dispõe sobre a utilização de nomes genéricos em produtos farmacêuticos, e dá outras providências. [on line] Brasilia;1999c. Disponivel em <URL: http://www.anvisa.gov.br/legis/consolidada/decreto _3181_99.htm> [2003 set 10]

Brasil. Decreto 74.170 de 10 de junho de 1974. Regulamenta a Lei 5.991 de 17 de dezembro de 1973, que dispõe sobre o controle sanitário do comércio de drogas, os insumos farmacêuticos e correlatos, e dá outras providências. 
Brasilia; 1974. In: Lima LFM et al. Vigilância sanitária de medicamentos e correlatos. Rio de Janeiro: Qualitymark Ed.; 1994. p. 125.

Brasil. Decreto 79.094 de 05 de janeiro de 1977. Regulamenta a Lei 6.360 de 23 de setembro de 1976, que dispõe sobre a vigilância sanitária a que ficam sujeitos os medicamentos, as drogas, os insumos farmacêuticos e correlatos, cosméticos, saneantes e outros produtos, e dá outras providências. Brasilia; 1977a. In: Lima LFM et al. Vigilância sanitária de medicamentos e correlatos. Rio de Janeiro: Qualitymark Ed; 1994. p. 134.

Brasil. Lei 5.726 de 01 de novembro de 1971. Dispõe sobre medidas preventivas e repressivas ao tráfico e uso de entorpecentes ou que determinem dependência física ou psíquica, e dá outras providências. Brasilia; 1971. In: Lima LFM et al. Vigilância sanitária de medicamentos e correlatos. Rio de Janeiro: Qualitymark Ed.;1994. p. 78.

Brasil. Lei 5.991 de 17 de dezembro de 1973. Dispõe sobre o controle sanitário do comércio de drogas, medicamentos, insumos farmacêuticos e correlatos, e dá outras providências. Brasilia; 1973. In: Lima LFM et al. Vigilância sanitária de medicamentos e correlatos. Rio de Janeiro: Qualitymark Ed.;1994. p. 78.

Brasil. Lei 6.360 de 23 de setembro de 1976. Dispõe sobre a vigilância sanitária a que ficam sujeitos os medicamentos, as drogas, os insumos farmacêuticos e correlatos, cosméticos, saneantes e outros produtos, e dá outras providências. Brasilia; 1976a. In: Lima LFM et al. Vigilância sanitária de medicamentos e correlatos. Rio de Janeiro: Qualitymark Ed.; 1994. p. 83.

Brasil. Lei 6.368 de 22 de outubro de 1976. Dispõe sobre medidas de prevenção e repressão ao tráfico ilicito e uso indevido de substâncias entorpecentes ou que determinem dependência física ou psíquica, e dá outras providências. Brasília; 1976b. In: Lima LFM et al. Vigilância sanitária de medicamentos e correlatos. Rio de Janeiro: Qualitymark Ed.; 1994. p. 92.

Brasil. Lei 6.437 de 20 de agosto de 1977. Configura infrações à legislação sanitária federal, estabelece sanções respectivas, e dá outras providências. 
Brasilia; 1977b. In: Lima LFM et al. Vigilância sanitária de medicamentos e correlatos. Rio de Janeiro: Qualitymark Ed.; 1994. p. 96.

Brasil. Lei 8.078 de 11 de setembro de 1990. Dispõe sobre a defesa do consumidor e dá outras providências. Brasília; 1990. In: Lima LFM et al. Vigilância sanitária de medicamentos e correlatos. Rio de Janeiro: Qualitymark Ed.; 1994. p. 101.

Brasil. Lei 9.782 de 27 de janeiro de 1999. Dispõe sobre o sistema nacional de vigilância sanitária e dá outras providências [on line]. Brasília; 1999a. Disponivel em < URL: http://www.anvisa.gov.br/legis/leis/9782_99.htm $>$ [2003 ago 27]

Brasil. Lei 9.787 de 10 de fevereiro de 1999. Estabelece o medicamento genérico, dispõe sobre a utilização de nomes genéricos em produtos farmacêuticos, e dá outras providências. Diário Oficial da República Federativa do Brasil. Brasilia 11 fev 1999b. Seção 1, p.1.

Bruyne $\mathrm{P}$, Herman J, Schoutheete $\mathrm{M}$. Dinâmica da pesquisa em ciências sociais: os pólos da prática metodológica. $3^{\text {a }}$ ed. Rio de Janeiro: Francisco Alves; 1991.

Bukonda $\mathrm{N}$, Tavrow $\mathrm{P}$, Abdallah $\mathrm{H}$, Hoffner $\mathrm{K}$, Tembo J. Implementing a national hospital accreditation program: the Zambian experience. Int J Qual Health Care 2002; 14 suppl 1: 7-16.

Campos GWS. Considerações sobre a arte e a ciência da mudança: revolução das coisas e reforma das pessoas: o caso da saúde. In: Cecilio LCO. Inventando a mudança na saúde. $2^{a}$ ed. São Paulo: Hucitec; 1997. p. 29-87.

Carvalho G, Rosemburg CP, Buralli KO. Avaliação de ações e serviços de saúde. Mundo Saúde 2000; 24(1): 72-88.

Carvalho M, Vieira AA, Magluta C. Erro no uso de medicamentos. In: Minayo MCS, Deslandes SF, organizadores. Caminhos do pensamento: epistemologia e método. Rio de Janeiro: Fiocruz; 2002. p. 363-79 
Castro LLC, organizador. Fundamentos de farmacoepidemiologia. Campo Grande: AG Gráfica e Editora; 2000.

César CLG, Tanaka OY. Inquérito domiciliar como instrumento de avaliação de serviços de saúde: um estudo de caso na região sudoeste da área metropolitana de São Paulo, 1989-1990. Cad Saúde Pública 1996; 12 supl 2: 59-70.

[CFE] Conselho Federal de Educação. Resolução no CNE/CES 2, de 19 de fevereiro de 2002: institui diretrizes curriculares nacionais do curso de graduação em farmácia [on line] Brasilia: CFE/CES; 2002. Disponivel em < http://www.mec.gov.br/cne/pdf/CES022002.pdf. [2003 ago 27].

[CFF] Conselho Federal de Farmácia. Resolução no 308 de 02 de maio de 1997: dispõe sobre a assistência farmacêutica em farmácias e drogarias [on line]. Brasilia: CFF; 1997. Disponivel em <http:/l www.cff.org.br/legis/resolucoes/res_308_97.html> [2003 ago 26]

[CFF] Conselho Federal de Farmácia. Resolução no 357 de 20 de abril de 2001. Aprova o regulamento técnico das boas práticas em farmácia [on line]. Brasilia: CFF; 1997. Disponivel em <http:/l www.cff.org.br/legis/resolucoes/res_357_2001.htm> [2003 ago 26]

Chanlat JF. Por uma antropologia da condição humana nas organizações. In: Chanlat JF, organizador. $O$ individuo na organização: dimensões esquecidas. São Paulo: Atlas; 1996. v.1, p. 21-45.

Chasin J. Marx: da razão do mundo ao mundo sem razão. In: Chasin J, organizador. Marx hoje. São Paulo: Ensaio; 1987. p. 13-52. (Cadernos Ensaio. Série Grande Formato, 1).

Cipolle RJ, Strand LM, Morley PC. Pharmaceutical care practice. New York: McGraw-Hill; 1998.

Clegg S. Poder, linguagem e ação nas organizações. In: Chanlat JF, organizador. $O$ indivíduo na organização: dimensões esquecidas. São Paulo: Atlas; 1996. v.1, p. 47-66. 
[CNS/CONEP] Conselho Nacional de Saúde. Comissão Nacional de Ética em Pesquisa. Normas para pesquisa envolvendo seres humanos: Resolução CNS 196/96 e outras. Brasilia: Ministério da Saúde; 2000. (Série Cadernos Técnicos).

Coelho HL. Pharmacovigilance: a necessary tool. Cad Saúde Pública 1998; 14: $871-75$.

Contandriopoulos AP, Champagne F, Denis JL, Pineault R. A avaliação na área da șaúde: conceitos e métodos. In: Hartz ZMA, organizador. Avaliação em saúde: dos modelos conceituais à prática na análise da implantação de programas. Rio de Janeiro: Editora Fiocruz; 1997. p. 29-47.

Costa EA. Vigilância sanitária: proteção e defesa da saúde. São Paulo: Hucitec/Sobravime; 1999.

Costanzo GA, Vertinsky I. Measuring the quality of health care: a decision oriented typology. Med Care 1975; 13: 417-31.

[CRF-PR] Conselho Regional de Farmácia do Estado do Paraná. Declaração número 026/03. Curitiba: CRF-PR; 2003b.

[CRF-PR] Conselho Regional de Farmácia do Estado do Paraná. Lista de farmácias cadastradas no municipio de Londrina. Curitiba: CRF-PR; 2003a.

[CRF-SP] Conselho Regional de Farmácia do Estado de São Paulo. Farmacêutico, habilite-se ao Selo de Assistência Farmacêutica do CRF-SP. J Farmacêutico 1999; 35: 4-5.

Dean D. How to use focus grups. In: Wholey J, Hatry HP, Newcomer KE, editors. Handbook of practical program evaluation. San Francisco: JosseyBass; 1994. p. 338-49.

Descartes R. Discurso do método: regras para a direção do espírito. São Paulo: Martin Claret; 2000. (Coleção A Obra Prima de Cada Autor). 
Donabedian A. Explorations in quality assessment and monitoring. Ann Arbor: Health Administration Press; 1980. Basic approaches to assessment: structure, process and outcome; v. 1, p. 77-125.

Donabedian A. The seven pillars of quality. Arch Pathol Lab Med 1990; 114: 1115-8.

Donahue KT, O'Leary DS. A evolução dos sistemas de acreditação de instituições de saúde. Ensaio: Aval Pol Públ Educ 2000; 9: 5-16.

Drucker.PF. Administrando em tempos de grandes mudanças. São Paulo: Pioneira Thomson Learning; 2002.

Ferguson M. A conspiração aquariana. $3^{\text {a }}$ ed. Rio de Janeiro: Record; 1990.

[FIBGE] Fundação Instituto Brasileiro de Geografia Estatística. Censo 2000: resultados do universo [on line]. Disponivel em <URL http:// www.ibge.gov.br/home/estatistica/populacao/censo2000/default.shtm> [2003 mai 01].

[FIP] International Pharmaceutical Federation. FIP statement of professional standards: pharmaceutical care - 1998 [on line]. Available from <URL: http://www.fip.org/pdf/pharmcare.pdf> [2003 Mar 02].

[FIP] International Pharmaceutical Federation. The Tokyo declaration: standards for quality of pharmacy services. The Hague; 1994.

Flexner A. Medical education in the United States and Canada: a report to the Carnegie Foundation for advancement of teaching. New York: Carnegie Foundation; 1910.

[FNPQ] Fundação para ○ Prêmio Nacional da Qualidade. Critérios de excelência: o estado da arte da gestão para a excelência do desempenho. São Paulo; 2000.

[FNPQ] Fundação para o Prêmio Nacional da Qualidade. FPNQ completou 12 anos [on line]. Disponível em <URL: http://www.fpnq.org.br/so_hist.htm> [2003 jan 27]

Foucault M. Microfísica do poder. $12^{\mathrm{a}}$ ed. Rio de Janeiro: Graal; 1996. 
Fridman LC. Pós-modernidade: sociedade da imagem e sociedade do conhecimento. Hist Ciênc Saúde [on line]1999; 6: 353-75. Disponível em <URL: http://www.scielo.br> [2003 mai 28]

Giddens A. As conseqüências da modernidade. São Paulo: UNESP; 1991.

Gramsci A. Concepção dialética da história. $10^{a}$ ed. São Paulo: Civilização Brasileira; 1995.

Guba EG, Lincoln YS. Fourth generation evaluation. Thousand Oaks: Sage Publications; 1989.

Guba EG, Lincoln YS. Paradigmatic controversies, contradictions, and emerging confluences. In: Denszin N, Lincoln YS editors. Handbook of qualitative research. $2^{\text {nd }}$ ed. Thousand Oaks: Sage Publication; 2000. p. 16388.

Gurgel Junior GD, Vieira MMF. Qualidade total e administração hospitalar: explorando disjunções conceituais. Ciênc Saúde Coletiva [on line] 2002; 7 : 325-34. Disponivel em <URL:http://www.scielo.br> [2003 jul 02].

Habermas J. Consciência moral e agir comunicativo. Rio de Janeiro: tempo brasileiro; 1989.

Hepler CD, Strand LM. Opportunities and responsabilities in pharmaceutical care. Am J Hosp Pharm 1990; 47: 533-43.

Ivama AM. La educación y la práctica farmacéutica em Brasil y España em el contexto de la globalización. Madrid; 1999. [Tesis Doctoral Universidad de Alcalá].

Johnson JA, Bootman JL. Drug-related morbidity and mortality and the economic impact of pharmaceutical care. Am J Health-Syst Pharm 1997; 54:554-8.

Joncheere $\mathrm{K}$. A necessidade e os elementos de uma política nacional de medicamentos. In: Bonfim JRA, Mercucci VL, organizadores. A construção da política de medicamentos. São Paulo: Hucitec/Sobravime; 1997. p. 4963. 
Jones $\mathrm{J}$, Hunter D. Using the delphi and nominal group technique in health services research. In: Pope C, Mays N, editors. Qualitative research in care. London: BMJ; 1999.

Kennie NR, Schuster BG, Einarson TR. Critical analysis of the pharmaceutical care research literature. Ann Pharmacother 1998; 32: 17-26.

Kisil M, Pupo TRGB. Gestão da mudança organizacional. São Paulo: Instituto para o Desenvolvimento da Saúde/ FSP/USP/ Banco Itaú; 1998. (Saúde \& Cidadania, 4).

Kotter JP. Liderando a mudança: por que fracassam as tentativas de transformação. In: Kotter JP et al. Mudança: Harvard business review. Rio de Janeiro: Editora Campus; 1999. p. 9-26.

Kozma CM, Reeder CE, Schulz RM. Economic, clinical, and humanistic outcomes: a planning model for pharmacoeconomic research. Clin Ther 1993; 15: 1121-32.

Kozma CM. Outcomes research and pharmacy practice. J Am Pharm Assoc 1995; 35(7): 35-41.

Kuhn TS. A estrutura das revoluções cientificas. $4^{a}$ ed. São Paulo: Perspectiva; 1996.

Laporte JR, Tognoni G. Principios de epidemiología del medicamento. $2^{\mathrm{a}}$ ed. Barcelona: Masson; 1993.

Lefévre F. O medicamento como mercadoria simbólica. São Paulo: Cortez; 1991.

List D. The consensus group technique in social research. innovationResearch [on line] 2003. Available from <URL:http//business. unisa.edu.au/innovres/papers/consensus.htm> [2003 Sept 14]

Malik AM, Schiesari LMC. Qualidade na gestão local de serviços e ações de saúde. São Paulo: Instituto para o Desenvolvimento da Saúde/ FSP/USP/ Banco Itaú; 1998. (Saúde \& Cidadania, 3). 
Malik AM. Gestão de recursos humanos. São Paulo: Instituto para o Desenvolvimento da Saúde/FSP/USP/ Banco Itaú; 1998. (Saúde \& Cidadania, 9).

Marin MLM, Chaves CE, Zanini AC, Faintuch J, Faintuch D, Cipriano SL. Cost of drugs manufactured by the University Hospital - role of the Central Pharmacy. Rev Hosp Clin [on line] 2001; 56(2). Disponivel em $<$ URL:http://www.scielo.br> [2003 jul 02]

Marx K, Engels F. O manifesto comunista. $6^{\text {a }}$ ed. São Paulo: Paz e Terra; 2000 .

[MDIC] Ministério do Desenvolvimento, Indústria e Comércio Exterior. Histórico do Programa Brasileiro de Qualidade e Produtividade [on line]. Disponivel em <URL: http://www.mdic.gov.br/progacoes/desenvolvimento> [2003 jan 27]

Mills CW. A imaginação sociológica. $4^{\mathrm{a}}$ ed. Rio de Janeiro: Zahar; 1975.

Minayo MCS. O desafio do conhecimento: pesquisa qualitativa em saúde. $3^{\text {a }}$ ed. São Paulo: Hucitec/ Rio de Janeiro: ABRASCO; 1994.

Ministério Público Federal. Procuradoria da República no Rio Grande do Sul. Termo de ajustamento de Conduta. Porto Alegre: Procuradoria da República no Rio Grande do Sul; 2001.

Morin E. Ciência com consciência. $5^{a}$ ed. Rio de Janeiro: Bertrand Brasil; 2001.

Motta PR. Transformação organizacional: a teoria e a prática de inovar. Rio de Janeiro: Qualitymark; 1999.

[MS] Ministério da Saúde. Coordenação de Controle de Infecção Hospitalar. Guia básico para a farmácia hospitalar. Brasília; 1994.

[MS] Ministério da Saúde. Divisão de Medicamentos - DIMED. Portaria $n^{\circ} 27$, de 24 de Outubro de 1986. Baixa instruções sobre a produção, comercialização, importação, exportação, prescrição e uso de drogas e especialidades capazes de produzir modificações nas funções nervosas 
superiores ou por exigirem orientação médica continuada devido à possibilidade de induzirem efeitos colaterais indesejáveis. Brasília; $1986 a$.

[MS] Ministério da Saúde. Divisão de Medicamentos - DIMED. Portaria $n^{\circ} 28$, de 13 de Novembro de 1986. Baixa instruções com vistas a normatizar os procedimentos referentes ao controle das atividades correlacionadas as substâncias entorpecentes ou que determinem dependência. Brasilia; 1986b.

[MS] Ministério da Saúde. Secretaria de Assistência à Saúde. Manual brasileiro de acreditação hospitalar. $3^{\text {a }}$ ed. Brasília; 2001.

[MS] Ministério da Saúde. Secretaria de Políticas de Saúde. Política Nacional de Medicamentos. Brasília; 1999.

Mullins CD, Baldwin R, Perfetto EM. What are outcomes? J Am Pharm Assoc 1996; 36: 39-49.

[NAPRA] National Association of Pharmacy Regulatory Authorities. Model standards of practice for Canadian pharmacists [on line]. Available from <URL: http://www.napra.org/docs/0/95/123.asp> [2003 Mar 03]

Nizankowski R. A experiência da Polônia em acreditação. Ensaio: Aval Pol Públ Educ 2000; 9: 53-60.

Noronha JC, Travassos CM, Garcia Rosa ML, Temporão JG. Iniciativas em qualidade no Brasil. Ensaio: Aval Pol Públ Educ 2000; 9: 61-72.

[OMS] Organización Mundial de la Salud. Función del farmacéutico em apoyo de la estrategia revisada de la OMS em materia de medicamentos: resoluciones y decisiones [Anexo]. In: $47^{\mathrm{a}}$ Asamblea Mundial de la salud; 1994 mayo 2-12; Ginebra: OMS; 1994. (WHA47/1994/REC/1).

[OMS] Organización Mundial de la Salud. El papel del farmaceutico en el sistema de atencion de salud. Washington: OPAS; 1995. 
[ONA] Organização Nacional de Acreditação. Conheça a ONA/histórico. Organizações hospitalares acreditadas [on line]. Disponivel em <URL: http://www.ona.org.br> [2003 set 15]

[OPAS] Organização Pan-Americana da Saúde. Atenção farmacêutica no Brasil - trilhando caminhos. Brasília; 2001. [Relatório da oficina de trabalho realizada em Fortaleza, Ceará, de 11 a 13 de setembro de 2001].

[OPAS] Organização Pan-Americana da Saúde. Manual de acreditação de hospitais para América-Latina e Caribe [Anexo]. In: Gilmore CM, Novaes $\mathrm{H}$ de M. Gerência de Qualidade. Washington DC: OPAS; 1997. Série HSPUNI/Manuais Operacionais PALTEX, v.3, n.9).

Orrego AA, Cárcamo EC, Jeldres CD, Arenas CP, Valenzuela MP, Roa EP, García MR, Alvarez IR, Cvitanio MV. Fundamentos de farmácia clínica. Santiago: Universidad de Chile; 1993.

Paganini JM, Novaes HM, editores. Desarrollo y fortalecimiento de los sistemas locales de salud: la garantia de calidad: acreditacion de hospitales para America Latina y Caribe. Washington; 1992 (OPS. Serie HSD/SILOS-13).

Patton MQ. Qualitative research \& evaluation methods. $3^{\text {rd }}$ ed. Thousand Oaks: Sage Publications; 2002.

Patton MQ. Utilization-focused evaluation: the new century text. $3^{\text {rd }}$ ed. Thousand Oaks: Sage Publications; 1997.

Pereira MF. Mudanás estratégicas em organizações hospitalares: uma abordagem contextual e processual. Rev Adm empres 2000; 40(3):83-96.

Peretta M, Ciccia G. Reingeniería de la práctica farmacéutica: guía para implementar atención farmacéutica em la farmácia. Buenos Aires: Panamericana; 1998.

Pétris AJ. A prática farmacêutica e sua relação com o ensino: um estudo sobre os farmacêuticos de Londrina/PR. Londrina; 1999. [Dissertação de Mestrado - Centro de Ciências da Saúde da Universidade Estadual de Londrina]. 
Piñol FP. La atención farmacéutica. Situacion actual y evolución de la prestación farmacéutica: motivos del cambio. Pharm Care Esp 1999; 1:48-51. [PML] Prefeitura do Municipio de Londrina. Autarquia dos Serviços Municipais de Saúde (ASMS). Rumos da saúde para Londrina: Plano Municipal de Saúde para o biênio 1996 - 1997. Londrina; 1996.

[PML] Prefeitura do Municipio de Londrina. Autarquia Municipal de Saúde. Mortalidade infantil cai para 10,8. In: BIS - Bol Inform Saúde [on line] 2003; 35: 4-5. Disponivel em <URL:http://www.londrina.pr.gov.br/saude/bis/bis35. pdf $>$ [2003 set 24]

Popper K. A lógica da pesquisa científica. 16ª ed. São Paulo: Cultrix; 2003.

Quinto Neto A, Gastal FL. Acreditação hospitalar: proteção dos usuários, dos profissionais e das organizações de saúde. Porto Alegre: Dacasa; 1997.

Rey G. Pesquisa qualitativa em psicologia: caminhos e desafios. São Paulo: Pioneira/Thomson Learning; 2002.

Rodello CCM. A saúde como a gente quer: a participação e o controle social enquanto estratégias facilitadoras do acesso da população à saúde. São Paulo; 1998. [Dissertação de Mestrado - Faculdade de Saúde Pública da Universidade de São Paulo].

Rosen G. Uma história da saúde pública. São Paulo: Ed. UNESP/Hucited Rio de Janeiro: ABRASCO; 1994. (Saúde em Debate, 74).

Sanches HB, et al. Gestión de la calidad en la oficina de farmacia: manual para la implantación de un sistema de la calidad em la oficina de farmacia, conforme a la Norma ISO 9001:2000. Madrid: Amigo; 2001.

Santos MRC. Profissão farmacêutica no Brasil: história, ideologia e ensino. Ribeirão Preto: Holus; 1999.

[SBAC] Sociedade Brasileira de Análises Clínicas. Programa Nacional de Controle de Qualidade em Laboratórios Clínicos Ltda [on line]. Disponivel em <URL: http://www.pncq.org.br> [2003 mar 04] 
[SBPC] Sociedade Brasileira de Patologia Clínica. Programa de acreditação de laboratórios clínicos: manual do laboratório [on line]. Disponível em <URL: http://www.sbpc.org.br/download/manual_do_laboratorio.doc> [2003 mar 04]

Schiesari LMC. Cenário da acreditação hospitalar no Brasil: evolução histórica e referências externas. São Paulo; 1999. [Dissertação de Mestrado - Faculdade de Saúde Pública da Universidade de São Paulo].

Senge P. A quinta disciplina: arte e prática da organização que aprende. Uma nova e revolucionária concepção de liderança e gerenciamento empresarial. São Paulo: Best Seller; 1998.

[SESA/PR] Secretaria do Estado de Saúde do Paraná. Resolução 54 de 03 de junho de 1996. Aprova norma técnica para orientar a abertura, funcionamento, as condições físicas, técnicas e sanitárias, e a dispensação de medicamentos em farmácias e drogarias. Curitiba; 1996.

Silva RR, Brandão DB. Os quatro elementos da avaliação [on line]. Disponivel em <URL: http://www.fonte.org.br/artigos/elementos_da_avaliacao. pdf $>$ [2003 jun 20]

Silva RR. O Projeto UNI e os movimentos populares de saúde na região sul de Londrina. São Paulo; 1999. [Dissertação de Mestrado - Faculdade de Saúde Pública da Universidade de São Paulo].

Silva SF. A construção do SUS a partir do município. São Paulo: Hucitec; 1996.

Simão LM. Desequilibrio e co-regulação em situação de ensinoaprendizagem: análise segundo o conceito de ação comunicativa (Habermas). Psicol Reflex Crit 2000; 13(1): 33-8.

Singer BD. Toward a sociology of standards: problems of a criterial society. Can J Sociol 1996; 21; $203-21$.

[SOBRAVIME/AIS-LAC] Sociedade Brasileira de Vigilância de Medicamentos. Acción Internacional para la Salud - América Latina y El Caribe. O que é uso racional de medicamentos. São Paulo: Sobravime; 2001. 
Souza HJ. Como se faz análise de conjuntura. $21^{\mathrm{a}}$ ed. Petrópolis: Vozes; 2000.

Stake RE. The art of case study research. Thousand Oaks: Sage Publications; 1995.

Takahashi T. The paradox of Japan: what about CQI in health care? J Qual Improv 1997; 23(1);60-64.

Tanaka OY, Melo C. Avaliação de programas de saúde do adolescente: um modo de fazer. São Paulo: EDUSP; 2001.

Tancredi FB. Consumo de medicamentos benzodiazepínicos no Brasil 1970 a 1985. Estudo comparativo de tendências. São Paulo; 1986. [Tese de Doutorado - Faculdade de Saúde Pública da Universidade de São Paulo].

Temporão JG, Garcia Rosa ML, Maglutta C, Berenger M. O consórcio brasileiro de acreditação de sistemas e serviços de saúde (CBA): origens e experiência atual. Ensaio: Aval Pol Públ Educ 2000; 9: 73-96.

Theobald R. New success criteria for a turbulent world. Plan Rev 1994; 22(6) 10-13.

Thiollent M. Metodologia da pesquisa-ação. $8^{a}$ ed. São Paulo: Cortez; 1998. Tomechko MA, Strand LM, Morley PC, Cipolle RJ. Q and A from the pharmaceutical care project in Minnesota. Am Pharm 1995; 35(4): 30-39.

Turato ER. Tratado da metodologia da pesquisa clínico-qualitativa: construção teórico-epistemológica, discussão comparada e aplicação nas áreas da saúde e humanas. Petrópolis: Vozes; 2003.

Ulrich BT. "Still so much to do": the legacy of Florence Nightngale [on line]. Available from <URL: http://www.nurseweek.com/ce/ce1650'ahtml> [2003 Feb 10]

Van Mil JWF. Atención farmacéutica em farmacia comunitaria em Europa, retos y barreras. Pharm Care Esp 2000; 2: 42-56.

Vuori H. A qualidade da saúde. Divulg Saúde Debate 1991; 1(3): 17-25.

Weber M. Conceitos básicos de sociologia. São Paulo: Moraes; 1987. 
[WHO] World Health Organization. The World health report 1999: making a difference. Geneva; 1999.

Wilken PRC, Bermudez JAZ. A farmácia no hospital: como avaliar? Estudo de caso nos hospitais federais do Rio de Janeiro. Rio de Janeiro: Ágora da Ilha; 1999.

[WKKF] W.K.Kellogg Foundation. W.K.Kellogg foundation evaluation handbook. Battle Creek; 1998.

World Bank. The organization, delivery and financing of health care in Brazil: agenda for the 90s. Washington: World Bank; 1994. (Report N. 12655-Br)

Worthen BR, Sanders JR, Fitzpatrick JL. Program evaluation: alternative approaches and practical guidelines. $2^{\text {nd }}$ ed. New York: Longman; 1997.

Zioni F. Pesquisa participante: relato e avaliação de uma experiência. São Paulo; 1994. [Tese de Doutorado - Faculdade de Saúde Pública da Universidade de São Paulo]. 
ANEXOS 


\section{Faculdade de Saúde Pública da Universidade de São Paulo Departamento de Prática de Saúde Pública - Administração Hospitalar Projeto de Pesquisa para Doutorado em Saúde Pública Acreditação de Farmácias: a construção de um modelo} Termo de Cooperação entre Pesquisador e Farmácia

$\mathrm{Eu}$, responsável pela farmácia localizada a

concordo em participar, em caráter voluntário, da pesquisa Acreditação de Farmácias: a construção de um modelo, de autoria do pesquisador Rogério Renato Silva, sob orientação do Professor Doutor Francisco Bernardini Tancredi, desenvolvida no Departamento de Prática de Saúde Pública da Universidade de São Paulo, com fins de outorgar ao pesquisador o título de Doutor em Saúde Pública.

Estou ciente de que a participação deste estabelecimento farmacêutico na referida pesquisa implica em que (a) pesquisadores entrevistarão consumidores (clientes) da farmácia na semana de 7 a 11 de abril, durante todo o período de funcionamento da farmácia, quando estes consumidores tiverem deixado as dependências internas do estabelecimento $\mathrm{e}$ concordarem em responder à pesquisa; (b) serão agendadas entrevistas com o farmacêutico responsável, proprietário, gerente e balconistas da farmácia, cuja realização será de acordo com agenda previamente estabelecida entre o pesquisador e o estabelecimento, para que não existam prejuízos para ambos; (c) que a farmácia procurará preencher o roteiro de diagnóstico em conjunto com o pesquisador da forma mais precisa possivel, (d) que nenhuma informação relacionada à pesquisa, sejam elas coletadas com consumidores ou funcionários, será utilizada sem a expressa autorização do estabelecimento, a não ser aquelas que, em caráter sigiloso (mantendo o anonimato), sejam analisadas no corpo da tese de doutorado relacionada a esta pesquisa, exclusivamente para fins acadêmicos; e (e) que a partir da defesa da tese, o estabelecimento poderá utilizar o protocolo de acreditação para melhorar sua qualidade.

Firmo o presente.

Londrina, de de 2003. 
Faculdade de Saúde Pública da Universidade de São Paulo

Departamento de Prática de Saúde Pública - Administração Hospitalar

Projeto de Pesquisa para Doutorado em Saúde Pública

Acreditação de Farmácias: a construção de um modelo

Consentimento Informado para Entrevistas Individuais

Eu,

na farmácia

situada à

concordo em participar, em caráter voluntário, da pesquisa Acreditação de Farmácias: a construção de um modelo, de autoria do pesquisador Rogério Renato Silva, sob orientação do Professor Doutor Francisco Bernardini Tancredi, desenvolvida no Departamento de Prática de Saúde Pública da Universidade de São Paulo, com fins de outorgar ao pesquisador o título de Doutor em Saúde Pública.

Estou ciente de que minha participação na referida pesquisa implica em que serei entrevistado de forma individual e sigilosa pelo pesquisador, que está autorizado a gravar a referida entrevista em fita cassete e utilizá-la, preservando quaisquer identificações pessoais, para estrita finalidade acadêmica.

Firmo o presente.

Londrina, __ de abril de 2003. 
Faculdade de Saúde Pública da Universidade de São Paulo

Departamento de Prática de Saúde Pública - Administração Hospitalar

Projeto de Pesquisa para Doutorado em Saúde Pública

Acreditação de Farmácias: a construção de um modelo

\section{ROTEIRO DE DIAGNÓSTICO PARA AS FARMÁCIAS}

O presente roteiro procura explorar as principais dimensões relacionadas ao comportamento deste estabelecimento no mercado, a fim de proporcionar aos pesquisadores elementos para melhor compreender os resultados a serem obtidos juntos às entrevistas com consumidores e funcionários das farmácias.

\section{Informações gerais}

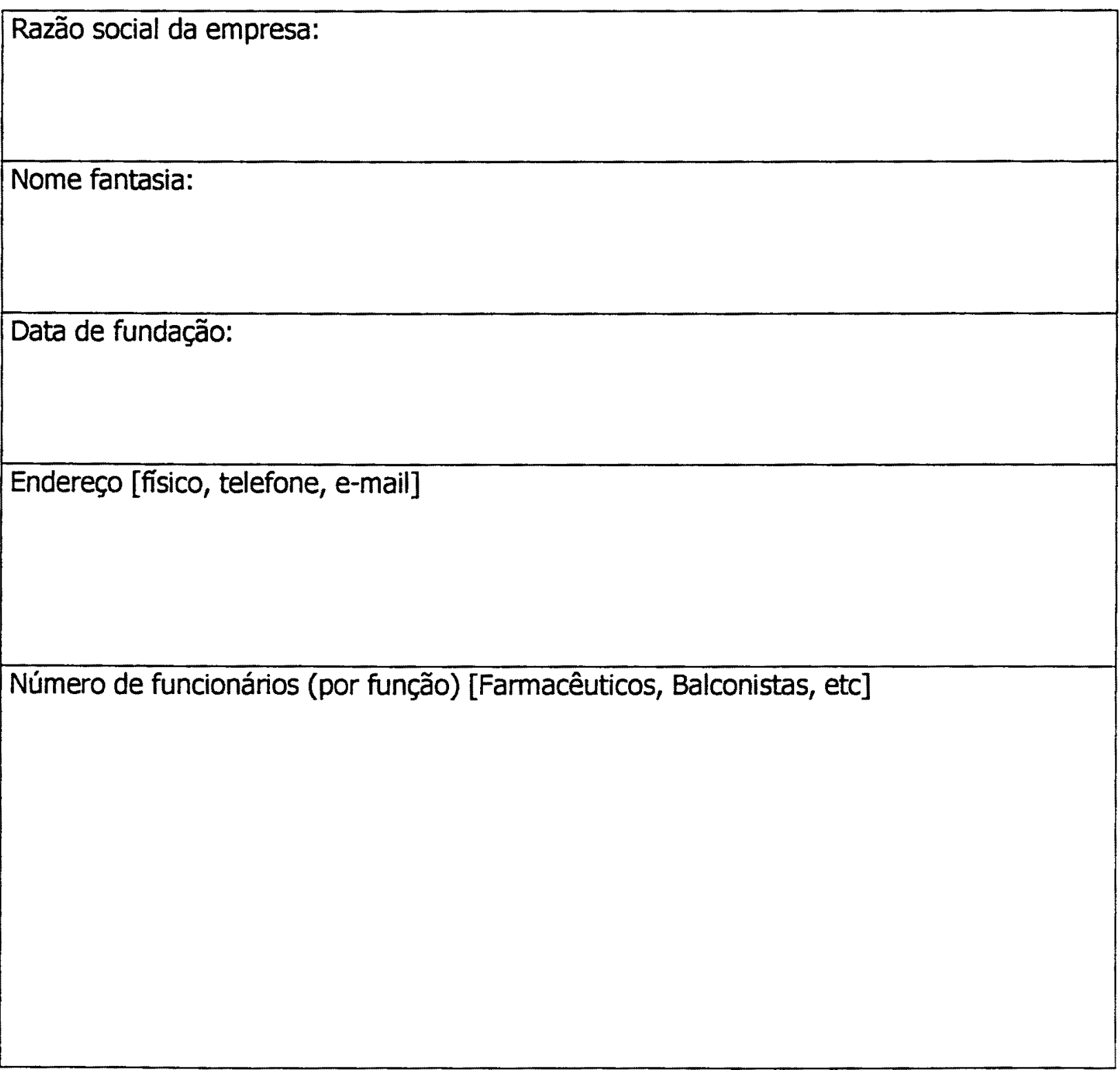




\section{Informações específicas}

2.1. Faturamento nos últimos três anos

\begin{tabular}{|l|l|l|l|}
\hline Período & 1999 & 2000 & 2001 \\
\hline PRIMEIRO TRIMESTRE & & & \\
\hline SEGUNDO TRIMESTRE & & & \\
\hline TERCEIRO TRIMESTRE & & & \\
\hline QUARTO TRIMESTRE & & & \\
\hline FATURAMENTO GLOBAL & & & \\
\hline
\end{tabular}

2.2. Composição do faturamento por linha de cliente:

\begin{tabular}{|l|c|c|c|}
\hline \multirow{2}{*}{ Cliente } & \multicolumn{3}{|c|}{ Percentual de faturamento } \\
\cline { 2 - 4 } & 1999 & 2000 & 2001 \\
\hline CONVÊNIOS & & & \\
\hline & & & \\
EXNDA & & & \\
\hline
\end{tabular}

2.3. Quais são os cinco concorrentes mais importantes da farmácia? (listar em grau de importância)

1.

2.

3.

4.

5.

2.4. Quais são as principais vantagens competitivas da farmácia em relação aos concorrentes? 
2.5. Quais são as principais vantagens competitivas dos concorrentes em relação a farmácia?

2.6. Existe um sistema (ou processo) de medir a satisfação dos clientes?

$\begin{array}{lll}\text { CONSUMIDORES } & \text { O SIM } & \text { O NÃO } \\ \text { PRESCRITORES } & \text { O SIM } & \text { O NÃO } \\ \text { EMPRESAS CONVENIADAS } & \text { O SIM } & \text { O NÃO }\end{array}$

\section{Dinâmica de trabalho}

3.1. Quais são os horários de funcionamento da farmácia?

3.2. Em que horários o farmacêutico está presente?

3.3. Quais são os horários de pico de consumidores (clientes) na farmácia? 
3.4. Quais serviços a farmácia oferece?

O VENDA DE MEDICAMENTOS EM SUAS EMBALAGENS ORIGINAIS.

O FRACIONAMENTO DE MEDICAMENTOS.

O VENDA DE MEDICAMENTOS MANIPULADOS.

O VENDA DE MEDICAMENTOS GENÉRICOS.

O CONTROLE DE PRESSÃO.

O CONTROLE DE TEMPERATURA.

O NEBULIZAÇÃO (INALOTERAPIA).

O REALIZAÇÃO DE PEQUENOS CURATIVOS.

O ADMINISTRAÇÃO DE MEDICAMENTOS INJETÁVEIS.

O CONTROLE DA GLICEMIA.

O VENDAS POR TELEFONE.

O ENTREGA EM DOMIĆLIO.

O VENDAS DE PRODUTOS NÃO FARMACÊUTICOS.

O SORVETES.

O REFRIGERANTES.

O DOCES E CHOCOLATES.

O COSMÉTICOS.

O EQUIPAMENTOS TERAPÊUTICOS.

3.5. Que ações a farmácia possui para se comunicar com clientes e outros interessados?

O PROPAGANDA NO RÁDIO (O FM O AM).

O PROPAGANDA EM TELEVISÃO (O TV ABERTA O TV FECHADA).

O PROPAGANDA EM REVISTAS DE CIRCULAÇÃO GERAL.

O PROPAGANDA EM JORNAIS.

O PROPAGANDA EM REVISTAS ESPECÍFICAS DA ÁREA MÉDICA.

O PATROCINIO DE EVENTOS, CONGRESSOS, ETC.

O VISTTAS A MÉDICOS.

O VISTTAS A EMPRESAS.

O MALA DIRETA PARA MÉDICOS.

O MALA DIRETA PARA EMPRESAS.

O MALA DIRETA PARA CONSUMIDORES.

O CARTÃO FIDELIDADE.

O DISTRIBUIÇÃO DE BRINDES.

O DISTRIBUIÇÃO DE FOLHETOS.

O MÍDIA EXTENSIVA (OUTDOORS, BUSTERS, FAIXAS, ETC.)

O MALA DIRETA PARA EMPRESAS. 


\section{Faculdade de Saúde Pública da Universidade de São Paulo}

\section{Departamento de Prática de Saúde Pública - Administração Hospitalar}

Projeto de Pesquisa para Doutorado em Saúde Pública

Acreditação de Farmácias: a construção de um modelo

\section{Questionário para Entrevista de Consumidores}

$n^{0}:$

\section{Prezado Senhor (a),}

Você está convidado(a) a responder um questionário de 9 perguntas. Este questionário é parte da pesquilsa de Doutorado realizada por Rogério Renato Silva, aluno da Faculdade de Saúde Pública da Universidade de São Paulo. Suas respostas serão tratadas com absoluto sigilo pelo pesquisador, e as informações aqui coletadas serão utilizadas com finalidade estritamente acadêmica. Nos próximos dias você poderá ser procurado por telefone para participar da próxima fase da pesquisa. Vocé entendeu esta explicação? O SIM O NÃO. Você está de acordo em participar? O SIM O NÂO Muito obrigado.

(1) Nome: (apenas primeiro nome e sobrenome)

(2) Idade:

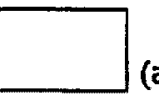
(anos completos até a data da entrevista)

(3) Telefones:

(4) Sexo:

(1) $O$ feminino

(2) O masculino

(5) Renda familiar aproximada:

(somar renda de todos os membros da familia que residem juntos)

(1) $O$ de 0 a 2 salários mínimos (até $R \$ 400,00$ )

(2) $O$ de 2 a 4 salários mínimos (de $R \$ 401,00$ a $R \$ 800,00$ )

(3) $O$ de 4 a 6 salários mínimos (de $R \$ 801,00$ a $R \$ 1200,00$ )

(4) $O$ de 6 a 10 salários mínimos (de $R \$ 1201,00$ a $R \$ 2000,00$ )

(5) $O$ de 10 a 14 salários mínimos (de $R \$ 2001,00$ a $R \$ 2800,00$ )

(6) $O$ de 14 a 18 salários mínimos (de $R \$ 2801,00$ a $R \$ 3600,00$ )

(7) $O$ acima de 18 salários mínimos (acima de $R \$ 3601,00$ )

(6) Escolaridade: (1) O nunca freqüentou a escola (nunca estudou / não é alfabetizado)

(2) $O$ ensino fundamental incompleto (parou entre a $1^{2}$ e a $4^{4}$ série)

(3) $O$ ensino fundamental incompleto (parou entre a $5^{\circ}$ e a $8^{\circ}$ série)

(4) $O$ ensino fundamental completo (concluiu a $8^{a}$ série)

(5) $O$ ensino médio incompleto (parou entre $\circ 1^{\circ}$ ano e $3^{\circ}$ ano)

(6) $O$ ensino médio completo (conduiu o $3^{\circ}$ ano)

(7) $\mathrm{O}$ ensino superior incompleto (está cursando ou interrompeu a faculdade)

(8) $O$ ensino superior completo (concluiu a faculdade ou faz pós-graduaçăo)

(7) Faz uso contínuo de algum medicamento?

(1) O sim

(2) $\bigcirc$ não (se não, vá para questão 9)

(8) Se sim, para qual finalidade? (1) O para a pressão ou coração

(2) O para o diabetes

(3) $O$ para não engravidar

(4) O para o sistema nervoso

(5) $O$ para o pulmão ou respiração

(6) $O$ outros

(9) Costuma vir a esta farmácia quantas vezes ao mês? (1) O uma vez

(2) $O$ duas vezes

(3) $O$ três vezes

(4) $O$ quatro vezes

Em caso de observações, use o verso do questionário.

(5) $O$ cinco vezes ou mais 


\section{Faculdade de Saúde Pública da Universidade de São Paulo Departamento de Prática de Saúde Pública - Administração Hospitalar Projeto de Pesquisa para Doutorado em Saúde Pública Acreditação de Farmácias: a construção de um modelo}

\section{Procedimentos do Trabalho de Campo}

\section{Princípios gerais}

Os princípios que regem a pesquisa no Brasil estão explicitados pela resolução 196/96 do Conselho Nacional de Saúde. Esta resolução explicita com bastante clareza a necessidade de se observar princípios éticos da pesquisa, implicando, entre outras coisas:

口 Consentimento livre e esclarecido dos indivíduos-alvo e a proteção de grupos vulneráveis e aos legalmente incapazes (autonomia). Neste sentido, a pesquisa envolvendo seres humanos deverá sempre tratá-los em sua dignidade, respeitá-los em sua autonomia e defendê-los em sua vulnerabilidade.

- A pesquisa, em qualquer área do conhecimento, envolvendo seres humanos deverá observar as seguintes exigências como contar com o consentimento livre e esclarecido do sujeito da pesquisa;

- Contar com os recursos humanos e materiais necessários que garantam o bemestar do sujeito da pesquisa;

- Prever procedimentos que assegurem a confidencialidade e a privacidade, a proteção da imagem e a não estigmatização, garantindo a não utilização das informações em prejuizo das pessoas e/ou das comunidades, inclusive em termos de auto-estima, de prestígio e/ou econômico-financeiro;

$\square$ Ser desenvolvidas preferencialmente em individuos com autonomia plena;

- Respeitar sempre os valores culturais, sociais, morais, religiosos e éticos, bem como os hábitos e costumes quando as pesquisas envolverem comunidades;

口 Garantir que as pesquisas em comunidades, sempre que possivel, traduzir-se-ão em benefícios cujos efeitos continuem a se fazer sentir após sua conclusão;

ㅁ Garantir o retorno dos benefícios obtidos através das pesquisas para as pessoas e as comunidades onde as mesmas foram realizadas; 
- Comunicar os resultados da pesquisa as autoridades sanitárias, sempre que os mesmos puderem contribuir para a melhoria das condições de saúde da coletividades;

\section{Orientações práticas}

\subsection{Entrevistas individuais com informantes chave}

As entrevistas individuais deverão ser realizada seguindo um conjunto de procediméntos que visam preservar a integridade do entrevistado bem como a qualidade da informação coletada.

a) deverão ser realizadas em ambiente particular, prioritariamente fora do espaço de trabalho, que reuna boas condições de trabalho como temperatura, silêncio e facilidades (água, café).

b) deverão ser realizadas em horário que não prejudique outras atividades profissionais e pessoais do entrevistado.

c) deverão ser antecedidas pela revisão do termo de consentimento informado (em 2 vias) (anteriormente apresentado aos entrevistados na data do agendamento da entrevista).

d) deverão ser gravadas e quaisquer outras notas de campo deverão ser registradas em um periodo máximo 12 horas da entrevista ou antes da próxima entrevista, prevalecendo o critério que primeiro se manifestar.

e) as entrevistas deverão ser transcritas por profissional que não possua qualquer relação com o entrevistado e seu entorno. Depois de transcritas as entrevistas poderão ser lidas pelos entrevistados se eles assim o desejarem, permitindo-lhes, inclusive, alterações em suas falas.

f) Alguns dos entrevistados (farmacêuticos e representante da Associação Profissional Local receberão o protocolo de acreditação antes da entrevista, a fim de que possam fazer a leitura do mesmo e virem para a entrevista com conhecimento (visão crítica) do material. 


\subsection{Entrevistas individuais com os consumidores das farmácias}

A abordagem dos consumidores é um processo extremamente delicado, e assim deve ser tratado pelos entrevistadores de campo. Em nenhuma medida a abordagem e o diálogo podem ser encarados como banais ou irrelevantes. Os entrevistadores devem estar cientes de que qualquer contato é uma intervenção, e que estão intervindo no curso natural da vida de cada entrevistado. Esta intervenção merece profundo respeito.

O respeito deve ser demonstrado para todos os entrevistados da mesma maneira, independente de suas aparentes diferenças físicas, psicológicas e sociais. Quaisquer tipos de "brincadeiras", "piadas" ou qualquer outra forma de "intimidade" devem ser evitadas a fim de que o procedimento não causa constrangimento aos entrevistados.

As entrevistas são extremamente curtas, desde que preservadas as condições normais de seu planejamento e os aspectos apreendidos na fase de pré-teste. $O$ roteiro deve estar sobre total domínio do entrevistador, a fim de que o contato seja objetivo, e que a relação entrevistador-entrevistado se dê de maneira agradável. À medida que o diálogo se dá de forma humanizada (com os olhos no entrevistado e não no papel), esta relação ganha qualidade. Alguns elementos importantes precisam ser observados:

口 OS pesquisadores receberão pranchetas, 3 lápis-borracha, apontador, cópias dos questionários, envelope para depósito dos questionários preenchidos e crachás. Este é o material básico de trabalho do entrevistador.

- todos os questionários devem ser preenchidos a lápis (com marcas fortes nos círculos correspondentes às respostas) e em caso de erro o material deve ser imediatamente corrigido.

口 OS entrevistadores não devem utilizar roupas demasiadamente curtas (no caso de mulheres) e bermudas ou camisetas regatas (no caso de homens), tendo em vista que haverá contato com diferentes pessoas, diferentes culturas e diferentes valores.

口 OS entrevistadores não devem utilizar "gírias" para se comunicar com os entrevistados, e a abordagem deve sempre ser iniciada pela palavra por favor, seguida de senhor, senhora (independente da idade) e finalizada pela expressão muito obrigado. 
- ao longo do diálogo sempre devem ser utilizadas as palavras senhor e senhora.

口 Todos os consumidores maiores de idade (idade maior a 18 anos) devem ser entrevistados.

- Para todos os entrevistados deve ser lido o termo de consentimento e deve ser obtida a confirmação verbal de entendimento e posterior autorização, que deve ser registrada em cada questionário.

口 é fundamental não perder consumidores que estão deixando o estabelecimento. A meta é uma perda igual a zero. Entende-se por perda aqueles consumidores que não são abordados pelos entrevistadores. Aqueles que se recusam em participar da entrevista não são considerados perdas. É fundamental que o pesquisador registre na Ficha de Registro de Neqativas os casos de consumidores que dizem não à entrevista ou que passam pelos pesquisadores sem a possibilidade de abordagem.

\subsection{Grupos focais}

Os grupos focais são espaços privilegiados para a coleta de informações qualitativas. Para que este espaço seja efetivamente utilizado, um conjunto de procedimentos precisa ser realizado.

$\square$ os grupos focais devem ser realizados em uma sala que reuna as melhores condições possiveis ao trabalho: ambiente agradável, ausência de mobiliários e demais equipamentos, presença de facilidades. Estas são: lavabo acessível, silêncio, água, café, refrigerante e pequenos sanduiches e biscoitos doces. Tendo em vista que não se trata de um programa realizado próximo ao local de residência dos participantes, bem como da inexistência de espaço adequado ao trabalho nas farmácias, sugere-se o uso de uma sala de reunião de um Hotel.

- Na sala deve haver 7 cadeiras para os participantes, 2 cadeiras para mediador e observador e 1 pequena mesa de canto onde devem ser servidos as bebidas e os alimentos.

- os participantes devem ser esclarecidos sobre sua participação no momento de sua convocação (por telefone). Além deste esclarecimento, cada participantes assinará um Termo de Consentimento (em 2 vias) antes do início do grupo focal. É fundamental que sejam realizadas 4 confirmações de presença: 7 dias antes, 3 dias antes, véspera, dia do trabalho ( 3 horas antes). 
口 cada participantes receberá uma recompensa de participação no valor de $R \$ 30,00$. Esta recompensa será entregue aos mesmos ao final da atividade de grupo focal, anexo a uma carta de agradecimento pela participação assinada pelo pesquisador. Este pequeno valor se destina a simbolizar o agradecimento pela participação na pesquisa, funcionando também como ajuda de custo de deslocamento e tempo disponivel dos participantes.

- os participantes que desejarem, devem ser buscados em casa, levados ao lugar do grupo focal e então levados em casa ao final do trabalho.

- os participantes devem ser orientados para não trazerem parentes (especialmente crianças) para o trabalho. Além do mediador e observador, apenas os entrevistados poderão ficar na sala.

os grupos focais não deverão durar mais do que 1,5 horas.

ㅁ o mediador deverá firmar os acordos ao início do trabalho, sendo fundamental que os participantes desliguem seus telefones celulares, não fumem, não conversem em paralelo e não deixem o grupo antes de seu final, saibam ouvir as opiniões dos outros, coloquem suas opiniões sobre os assuntos. Se possível, fora da sala deve estar uma pessoa que atenda os celulares e anote os recados.

- o mediador deverá ser previamente preparado para seguir o roteiro da entrevista, mas também preparado para intervenções fora do roteiro que se fizerem necessárias no curso da entrevista. É preciso que ele tenha claras habilidades de diálogo em grupo desenvolvidas, como habilidade de estimular pessoas a falar, habilidade para controlar pessoas que falem demais, habilidade para estimular debates entre o grupo, e habilidades para que as pessoas acessem as questões relevantes à pesquisa. $O$ grupo focal deve ser iniciado com questões gerais que façam os participantes ativarem sua memória sobre o foco da discussão, por exemplo: "quantas vezes você foi a uma farmácia nos últimos 15 dias para comprar um medicamento de uso contínuo?", depois "que pontos positivos viu no atendimento recebido na farmácia? , "que pontos negativos viu no atendimento recebido na farmácia", "o que poderia ser feito para o atendimento ser melhor" . Esta técnica de afunilamento da discussão é importante para que imagens mais claras e concretas surjam para a pesquisa. Os detalhes estão presentes no anexo que trata do roteiro do grupo focal. 
Faculdade de Saúde Pública da Universidade de São Paulo Departamento de Prática de Saúde Pública - Administração Hospitalar Projeto de Pesquisa para Doutorado em Saúde Pública Acreditação de Farmácias: a construção de um modelo

Ficha de Registro de Negativas

Pesquisador:

Assinale o dia da recusa (coluna branca) e marque um $X$ no espaço da recusa (coluna cinza_ $\mathrm{N}^{\circ}$ )

\begin{tabular}{|c|c|c|c|c|c|c|c|c|c|}
\hline dia & recusa & dia & recusa & dia & recusa & dia & recusa & dia & recusa \\
\hline & 1. & & 28. & & 55 & & 82 & & 109. \\
\hline & 2 & & 29. & & 56 & & 83 & & 110. \\
\hline & 3. & & 30. & & 57. & & 84. & & 111. \\
\hline & 4. & & 31. & & 58. & & 85 & & 112. \\
\hline & 5. & & 32. & & 59. & & 86. & & 113. \\
\hline & 6 & & 33. & & 60 & & 87. & & 1114. \\
\hline & 7 & & 34 & & 61 & & 88 & & 115: \\
\hline & 8. & & 35 & & $62 . \quad$ & & 89. & & 116: \\
\hline & 9. & & 36. & & 63. & & 90. & & 117. \\
\hline & 10. & & 37. & & 64. & & 91. & & 118. \\
\hline & 11. & & 38. & & 65 & & 92. & & 119. \\
\hline & 12. & & 39 & & 66. & & 93 & & 120. \\
\hline & 13. & & 40. & & 67. & & 94. & & 121. \\
\hline & 14. & & 41. & & 68. & & 95. & & 122. \\
\hline & 15. & & 42 & & 69 & & 96. & & 123. \\
\hline & 16. & & 43. & & 70. & & 97. & & 124. \\
\hline & 17. & & 44. & & 71. & & 98. & & 125. \\
\hline & $18:$ & & 45 & & 72. & & 99. & & 126. \\
\hline & 19. & & 46 & & 73. & & 100. & & 127. \\
\hline & 20. & & 47 & & 74. & & 101. & & 128. \\
\hline & 21: & & 48. & & 75. & & 102. & & 129. \\
\hline & 22. & & 49. & & 76. & & 103. & & 130. \\
\hline & 23. & & 50. & & 77. & & 104. & & 131. \\
\hline & 24. & & 51. & & 78. & & 105. & & 132. \\
\hline & 25. & & 52. & & 79. & & 106. & & 133. \\
\hline & 26. & & 53. & & 80. & & 107. & & 134. \\
\hline & 27. & & 54. & & 81. & & 108. & & 135. \\
\hline
\end{tabular}


Faculdade de Saúde Pública da Universidade de São Paulo Departamento de Prática de Saúde Pública - Administração Hospitalar Projeto de Pesquisa para Doutorado em Saúde Pública Acreditação de Farmácias: a construção de um modelo

\section{Consentimento Informado para as Entrevistas em Grupo Focal}

Eu, residente à

concordo em participar, em caráter voluntário, da pesquisa Acreditação de Farmácias: a construção de um modelo, de autoria do pesquisador Rogério Renato Silva, sob orientação do Professor Doutor Francisco Bernardini Tancredi, desenvolvida no Departamento de Prática de Saúde Pública da Universidade de São Paulo, com fins de outorgar ao pesquisador o título de Doutor em Saúde Pública.

Estou ciente de que minha participação na referida pesquisa implica em que serei entrevistado junto a outros 7 cidadãos (grupo focal) pelo pesquisador, que está autorizado a gravar a referida entrevista em fita cassete e utilizá-la, preservando quaisquer identificações pessoais, para estrita finalidade acadêmica.

Firmo o presente.

Londrina, de de 2003. 
Faculdade de Saúde Pública da Universidade de São Paulo Departamento de Prática de Saúde Pública - Administração Hospitalar Projeto de Pesquisa para Doutorado em Saúde Pública Acreditação de Farmácias: a construção de um modelo

\section{Roteiro de Entrevista com Balconistas}

\section{Apresentação do pesquisador}

- Deve incluir a apresentação da pesquisa, a leitura e assinatura em duas vias do termo de consentimento informado, o acordo de tempo da entrevista, acordo de gravação da entrevista, acordo da revisão da entrevista (se assim desejar o entrevistado), e ênfase no sigilo com as informações.

\section{Caracterização do entrevistado}

2.1. Qual é seu nome? Qual é sua idade?

2.2. Você está estudando atualmente? Até que ano você estudou?

2.3. Como e quando você começou sua carreira na área farmacêutica?

3. Exploração de aspectos do trabalho

3.1. Você poderia descrever suas atividades na farmácia?

_explorar o processo de venda de medicamentos.

3.2. Qual é seu regime de trabalho (carga horária, sistema de vínculo, comissão)?

\section{Exploração focal (papel da farmácia)}

4.1. Qual é a função da farmácia em que você trabalha? Qual sua importância?

5. Exploração dos aspectos da mudança

5.1. Capacitação profissional.

5.2. Venda controlada de medicamentos.

5.3. Fim da comissão por vendas.

5.4. Acompanhamento de usuários (registros em prontuários).

5.5. Outras mudanças desejadas (o que você mudaria na farmácia, se pudesse?)

6. Relação com o farmacêutico(a)

6.1. Como é sua relação com o farmacêutico(a)?

\section{Perspectiva de futuro profissional}

7.1. Você tem planos para se desenvolver nesta área profissional? Quais?

_Registrar os agradecimentos a participação do entrevistado. 


\section{Faculdade de Saúde Pública da Universidade de São Paulo Departamento de Prática de Saúde Pública - Administração Hospitalar Projeto de Pesquisa para Doutorado em Saúde Pública Acreditação de Farmácias: a construção de um modelo}

\section{Roteiro de Entrevista com Gerentes e Sub-gerentes}

\section{Apresentação do pesquisador}

- Deve incluir a apresentação da pesquisa, a leitura e assinatura em duas vias do termo de consentimento informado, o acordo de tempo da entrevista, acordo de gravação da entrevista, acordo da revisão da entrevista (se assim desejar o entrevistado), e ênfase no sigilo com as informações.

\section{Caracterização do entrevistado}

2.1. Qual é seu nome?

2.2. Você está estudando atualmente? Até que ano você estudou?

2.3. Como e quando você começou sua carreira na área farmacêutica?

\section{Exploração de aspectos do trabalho}

\subsection{Você poderia descrever suas atividades na farmácia?}

_explorar o processo de venda de medicamentos.

3.2. Qual é seu regime de trabalho (carga horária, sistema de vínculo, comissão)?

3.3. Quem são os concorrentes diretos?

\section{Exploração dos aspectos da mudança}

4.1. Elementos capazes de diferenciar uma farmácia das outras

4.2. O que Ihe parece um sistema externo que classifique e diferencie as farmácias?

\subsection{Atendimento aos usuários}

_processos (valorização do farmacêutico, realização de diversas atividades sanitárias)

_resultados (impacto real e conhecido na vida das pessoas)

\section{Exploração focal (papel da farmácia)}

5.1. Qual é a função da farmácia em que você trabalha? Qual sua importância?

\section{Perspectiva de futuro profissional}

6.1. Você tem planos para se desenvolver nesta área profissional? Quais? 


\section{Faculdade de Saúde Pública da Universidade de São Paulo Departamento de Prática de Saúde Pública - Administração Hospitalar Projeto de Pesquisa para Doutorado em Saúde Pública Acreditação de Farmácias: a construção de um modelo}

\section{Roteiro de Entrevista com Farmacêuticos}

\section{Apresentação do pesquisador}

- Deve incluir a apresentação da pesquisa, a leitura e assinatura em duas vias do termo de consentimento informado, o acordo de tempo da entrevista, acordo de gravação da entrevista, acordo da revisão da entrevista (se assim desejar o entrevistado), e ênfase no sigilo com as informações.

\section{Caracterização do entrevistado}

2.1. Qual é seu nome?

2.2. Em que universidade você se formou? Quando?

2.3. Como você começou sua carreira profissional na área? Como isso se deu?

2.4. Você realizou algum curso de pós-graduação?

\section{Exploração de aspectos do trabalho}

3.1. Você poderia descrever suas atividades na farmácia?

_explorar o processo de venda de medicamentos e atenção aos usuários

3.2. Qual é seu regime de trabalho (carga horária, sistema de vínculo, comissão)?

3.3. Como é a relação com os balconistas? E com os gerentes/subgerentes?

\section{Exploração focal (papel da farmácia)}

4.1. Qual é a função da farmácia em que você trabalha? Qual sua importância?

\section{Exploração dos aspectos da mudança}

5.1. Elementos capazes de diferenciar uma farmácia das outras

5.1. O que Ihe parece um sistema externo que classifique e diferencie as farmácias?

5.2. Explorar os pontos críticos do protocolo de acreditação lido pelo farmacêutico

_estrutura, processos e resultados (pontos negativos e positivos / atingíveis e inatingíveis)

6. Perspectiva de futuro profissional

6.1. Você tem planos para se desenvolver nesta área? Quais? 


\section{Faculdade de Saúde Pública da Universidade de São Paulo Departamento de Prática de Saúde Pública - Administração Hospitalar Projeto de Pesquisa para Doutorado em Saúde Pública Acreditação de Farmácias: a construção de um modelo}

\section{Roteiro de Entrevista com Associação dos Farmacêuticos de Londrina}

\section{Apresentação do pesquisador}

- Deve incluir a apresentação da pesquisa, a leitura e assinatura em duas vias do termo de consentimento informado, o acordo de tempo da entrevista, acordo de gravação da entrevista, acordo da revisão da entrevista (se assim desejar o entrevistado), e ênfase no sigilo com as informações.

2. Caracterização do entrevistado

2.1. Qual é seu nome?

2.2. Qual é seu cargo na Associação?

\section{Exploração focal (papel da farmácia)}

\subsection{Qual é a função da farmácia para a Associação?}

4. Exploração do contexto

4.1. Quais são as prioridades estratégicas da Associação?

\section{Exploração dos aspectos da mudança}

5.1. Elementos capazes de diferenciar uma farmácia das outras

5.2. Explorar o mérito do modelo.

5.3. Explorar o espaço político do modelo.

5.4. Explorar os pontos críticos do protocolo de acreditação lido pelo entrevistado

_estrutura (pontos negativos e positivos / atingiveis e inatingiveis)

_processos (pontos negativos e positivos / atingiveis e inatingiveis)

_resultados (pontos negativos e positivos / atingiveis e inatingiveis)

_Registrar os agradecimentos à participação. 


\section{Faculdade de Saúde Pública da Universidade de São Paulo \\ Departamento de Prática de Saúde Pública - Administração Hospitalar \\ Projeto de Pesquisa para Doutorado em Saúde Pública \\ Acreditação de Farmácias: a construção de um modelo}

\section{Roteiro de Grupo Focal com Consumidores}

\section{Recebimento dos participantes}

_Deve incluir a apresentação do pesquisador (moderador) e do observador, a leitura e assinatura em duas vias do termo de consentimento informado e distribuição do crachá.

\section{Apresentação da pesquisa e acordos de trabalho}

_Apresentação do foco da pesquisa (qualidade dos serviços realizados pelas farmácias), acordos de trabalho (tempo de duração, celulares, saber ouvir, se colocar, gravação da entrevista, uso de sanitário, alimentos e bebidas disponíveis, carta de agradecimento e incentivo, ênfase no sigilo com as informações); Comunicar o papel do pesquisador e do observador.

\section{Apresentação dos participantes}

\subsection{Quem sou eu?}

_dinâmica da apresentação com o palito de fósforo - enquanto ele queima, o participante se apresenta escolhendo as características que ele deseja mostrar ao grupo.

\section{Questão de abertura}

4.1. Quando foi a última vez que você foi à farmácia?

4.2. Você se lembra o que foi fazer lá?

4.3. Você poderia nos dizer o que foi fazer lá?

\section{Questões introdutórias}

_tente se lembrar das últimas vezes que você utilizou os serviços da farmácia.

5.1. Nestas lembranças, qual é a passagem mais agradável da qual você se lembra?

5.2. Nestas lembranças, qual é a passagem mais desagradável da qual você se lembra?

\section{Questões chave (expectativas - oportunidades de mudanças)}

6.1. O que uma farmácia precisa fazer para ganhar e manter sua confianca?

6.2. O que uma farmácia precisa fazer para não ganhar ou perder sua confianca?

6.3. O que você espera do farmacêutico da farmácia?

6.4. O que você espera do balconista da farmácia? 


\section{Questões de fechamento}

7.1. Se você fosse o proprietário da farmácia, o que você faria para melhorá-la?

7.2. O que você pode fazer para aproveitar melhor os serviços da farmácia?

\section{Questões de verificação}

8.1. De todas as coisas que discutimos, o que lhes parece mais importante (marcante)?

8.2. Nós deixamos de falar sobre algo muito importante para vocês?

\section{Encerramento}

_moderador faz breve resumo (5') verbal das questões apontadas pelo grupo.

_registrar os agradecimentos à participação.

_entregar o envelope com carta de agradecimento e recompensa.

\section{Habilidades importantes}

\section{Para o moderador}

_esteja mentalmente concentrado para o trabalho.

_conheça o roteiro e conheça, sobretudo, o ponto focal do grupo.

_use, propositadamente, intervenções verbais curtas como padrão.

_faça uma introdução agradável ao trabalho.

_utilize pausas para reflexão (o silêncio pode ser importante).

_esteja atento às reações dos participantes (enderece-as).

_evite utilizar questões com "porquê" e questões fechadas "sim ou não".

_use questões que acessem a memória: "nos últimos 15 dias", "na última vez que", etc.

_use questões que retomem o foco: "voltando à pergunta", "retomando o que fulano disse",

"considerando a pergunta inicial", etc. (às vezes é necessário repetir a pergunta).

\section{Para o observador}

_esteja atento aos comportamentos não verbais.

tente deixar de lado sua visão pessoal a respeito do tópico em debate.

_procure por padrões que se repitam na fala dos participantes.

_procure por similaridades e por diferenças.

_em algum tópico da discussão os participantes mostraram maior excitação?

_procure descrever durante o registro. A interpretação é o próximo passo.

_lembre-se que a diferença entre a interpretação e a descrição é que a descricão é aquilo que foi realmente dito, palavra a palavra, no grupo, enquanto a interpretacão é aquilo que você acredita que as pessoas queriam dizer com suas afirmações.

_elabore um breve relatório contendo um parágrafo síntese para cada pergunta. 


\section{Faculdade de Saúde Pública da Universidade de São Paulo Departamento de Prática de Saúde Pública - Administração Hospitalar Projeto de Pesquisa para Doutorado em Saúde Pública Acreditação de Farmácias: a construção de um modelo}

\section{Carta de Agradecimento}

\section{Aos participantes do grupo focal}

\section{Prezado Participante,}

Gostaria de registrar meu agradecimento por sua participação neste grupo focal. Como você sabe, ele é parte de minha pesquisa de doutorado e, portanto, é um momento de grande importância para minha vida acadêmica e pessoal.

Acredito também que as discussões que fizemos hoje, e as reflexões e análises que estarão presentes em minha tese doutorado, possam contribuir para o desenvolvimento do campo da farmácia no Brasil, o que torna sua colaboração ainda mais importante.

Como todos sabemos, cabe à Universidade brasileira um papel central na construção da sociedade em que queremos viver. A geração de tecnologias, a formação de profissionais, 0 fomento ao desenvolvimento científico e tecnológico, a preservação de nossa cultura, em fim, são papéis importantes que justificam a existência da Universidade Pública e seu uso de recursos também públicos. Espero, sinceramente, que minha tese cumpra um papel neste cenário e que cada um de vocês se reconheça nesta construção.

Por fim, e com grande destaque, espero que o espaço de reflexão que procurarmos criar na noite de hoje possa lhes ser objetivamente útil. É refletindo sobre nossas experiências que ampliamos o domínio sobre nossas ações e percebemos como nossos desejos e atitudes são relevantes para a organização da comunidade ao nosso redor e da nossa sociedade.

A recompensa que acompanha esta carta é também uma forma de the agradecer.

Londrina, de de 2003.

\section{Atenciosamente,}

Rogério Renato Silva

pesquisador 


\section{Faculdade de Saúde Pública da Universidade de São Paulo Departamento de Prática de Saúde Pública - Administração Hospitalar \\ Projeto de Pesquisa para Doutorado em Saúde Pública \\ Acreditação de Farmácias: a construção de um modelo}

Roteiro de Entrevista com Proprietário da Rede de Farmácias

\section{Apresentação do pesquisador}

- Deve incluir a apresentação da pesquisa, a leitura e assinatura em duas vias do termo de consentimento informado, o acordo de tempo da entrevista, acordo de gravação da entrevista, acordo da revisão da entrevista (se assim desejar o entrevistado), e ênfase no sigilo com as informaçôes.

\section{Caracterização do entrevistado}

2.1. Qual é seu nome?

\subsection{Qual sua função na Rede?}

\section{Exploração focal (papel da farmácia)}

3.1. Qual é a função da farmácia atualmente?

\section{Exploração dos aspectos da mudança}

4.1. O que diferencia atualmente as farmácias da Rede de outras?

- Explorar papéis profissionais, importância do farmacêutico, capacitação, organização e comunicação.

4.2. O que the parece um sistema externo que classifique e diferencie as farmácias?

4.3. A Rede tem feito investimentos em processos de mudanca? Quais?

4.4. Explorar os pontos críticos do protocolo de acreditação lido pelo proprietário.

_estrutura, processos e resultados (pontos negativos e positivos / atingíveis e inatingiveis)

\section{Perspectiva de futuro para a Rede}

\subsection{Onde a Rede quer estar em cinco ou dez anos?}

_Registrar os agradecimentos à participação. 


\section{Faculdade de Saúde Pública da Universidade de São Paulo \\ Departamento de Prática de Saúde Pública - Administração Hospitalar \\ Projeto de Pesquisa para Doutorado em Saúde Pública' \\ Acreditação de Farmácias: a construção de um modelo}

\section{PRIMEIRO DOCUMENTO DE TRABALHO}

Prezado colaborador,

Em primeiro lugar gostaria de agradecer por sua inestimável colaboração neste trabalho, afirmando que seu conhecimento, impressões e idéias a respeito das questões que aqui trataremos, tornar-se-ão um marco fundamental para o desenvolvimento deste trabalho de doutorado. Desde já afirmo que estou fortemente compromissado com esta pesquisa, e que os minutos que você depositar neste trabalho serão tratados com grande respeito e atenção, além de cuidadosamente transformados em um arcabouço conceitual importante sobre qualidade de serviços farmacêuticos no Brasil.

Este documento apresenta 03 questões relacionadas ao início do trabalho de elaboração de padrões (standards) de qualidade. A opção por esta metodologia (elaboração de consenso), cujos interessados poderão receber informações mais detalhadas no momento que desejarem, se deu principalmente pela necessidade de reunir especialistas em torno desta discussão, aliada a inexistência de recursos para a metodologias presenciais, como grupos nominais ou grupos focais, por exemplo.

A elaboração dos standards partirá deste documento, que cumprirá o papel de inaugurar as discussões e de investigar, através de perguntas não estruturadas, a visão que cada colaborador possui a respeito das premissas que fundamentam este trabalho, e por sua vez, a respeito da hipótese subjacente à pesquisa.

Serão utilizadas neste documento questões não-estruturadas, e todo o conjunto de respostas do grupo de especialistas será consolidado e analisado pelo pesquisador, a fim de que outras etapas da investigação sejam preparadas, outras informações recolhidas e analisadas, e avanços sejam alcançados na elaboração de um consenso. Lembre-se que você tem liberdade para responder ou não às perguntas aqui apresentadas, bem como para sugerir temas ou exprimir opiniões que a priori não estejam diretamente relacionadas às perguntas.

Mais uma vez, muito obrigado.

\footnotetext{
${ }^{1}$ Material de inteira responsabilidade do Pesquisador Rogério Renato Silva.
} 


\section{Premissas da pesquisa}

1. O modelo de acreditação será proposto para farmácias e drogarias do setor privado (excluem-se as farmácias hospitalares e os dispensários de medicamentos em unidades de saúde do SUS).

2. A utilização de um modelo de acreditação de serviços farmacêuticos, compreendendo a avaliação de aspectos da estrutura, processos e resultados da instituição, e que privilegie os conceitos, ações e instrumentos de atenção farmacêutica, pode provocar mudanças positivas nos padrões de qualidade das organizações acreditadas.

3. A acreditação é um processo voluntário, periódico, sigiloso, externo e gradual de avaliação. Sua dimensão gradual requer que padrões diferentes (gradualmente exigentes) sejam criados para serem perseguidos pelas organizações interessadas.

\section{Perguntas}

1. Quais aspectos (atributos / indicadores) relacionados às condições estruturais de uma farmácia ou drogaria deveriam ser levados em conta no momento de avaliar sua qualidade?

\section{Resposta:}

2. Quais aspectos (atributos / indicadores) relacionados às atividades de uma farmácia ou drogaria deveriam ser levados em conta no momento de avaliar sua qualidade?

\section{Resposta:}

3. Quais aspectos (atributos / indicadores) relacionados aos resultados atingidos por uma farmácia ou drogaria deveriam ser levados em conta no momento de avaliar sua qualidade?

Resposta:

Obs. Salve este arquivo com seu primeiro nome Q1.doc, por exemplo rogerioQ1.doc envie quando preenchido. Em caso de dúvidas, permaneço a sua disposição. 
Faculdade de Saúde Pública da Universidade de São Paulo Departamento de Prática de Saúde Pública - Administração Hospitalar

Projeto de Pesquisa para Doutorado em Saúde Pública ${ }^{1}$

Acreditação de Farmácias: a construção de um modelo

\section{SEGUNDO DOCUMENTO DE TRABALHO}

Prezado colaborador,

Gostaria de agradecer a você pelo interesse e compromisso em responder ao documento enviado anteriormente. Sua resposta ajudou a abrir uma importante discussão na confecção do consenso ao qual chegaremos. Como você perceberá, o volume de informações sistematizadas a partir do primeiro trabalho aponta para o sucesso de nossa interação neste momento.

A pesquisa prossegue agora assumindo um caráter mais específico. Nas próximas páginas, você encontrará uma breve descrição das áreas em que todos os padrões e indicadores de qualidade estarão distribuídos ao fim desta pesquisa. Digamos que este documento apresenta um esqueleto ao qual se agregará todo um conjunto de padrões mais específicos.

Gostaria de solicitar que você fizesse uma leitura desta proposta, acrescentando suas observações a respeito das áreas propostas e de suas definições. Reafirmo que ainda iremos mais fundo dentro de cada área definida, e o que precisamos agora é definir se as áreas listadas atendem as expectativas de um processo de avaliação de qualidade.

Gostaria de solicitar que suas observações fossem realizadas com letra maiúscula, colorida, com a inserção de comentários ou controle de alterações, a fim de diferenciá-las da forma que utilizei para escrever.

Mais uma vez muito obrigado!

\section{Rogério Silva}

Obs. Salve este arquivo com seu primeiro nome [nananaQ2.doc], e envie para rogerio_rs@uol.com.br.

\footnotetext{
${ }^{1}$ Material de inteira responsabilidade do Pesquisador Rogério Renato Silva.
} 


\section{Critérios para acreditação de farmácias - áreas de avaliação}

\section{Condições estruturais}

A avaliação das condições de estrutura comportará as características perenes de farmácias e drogarias, ou seja, instrumentos e recursos necessánios ao desenvolvimento do serviço.

\subsection{Documentação sanitária}

Compreende a avaliação do cumprimento - não cumprimento das características necessárias ao credenciamento do estabelecimento segundo a agência de vigilância sanitária local e o Conselho Profissional local.

\subsection{Condições da estrutura física}

Compreende a avaliação das condições estruturais de farmácias e drogarias, ou seja, acesso, higiene sanitária, facilidades para pacientes, área para tarefas administrativas e áreas para procedimentos técnicos.

\subsection{Condições dos equipamentos}

Compreende a avaliação da disponibilidade - não disponibilidade de equipamentos da área técnica para aferição de pressão arterial, aferição de temperatura, aferição de glicemia, realização de curativos, aplicação de injetáveis, nebulizador e refrigerador, bem como de equipamentos para área administrativa: mobília e microcomputadores.

\subsection{Condições de armazenamento de medicamentos}

Compreende a avaliação das condições de armazenamento de medicamentos e controle de estoque.

\subsection{Cumprimento da Portaria ANVISA $328 / 99$}

Compreende a avaliação do cumprimento - não cumprimento da legislação voltada aos medicamentos sujeitos a controle especial.

\subsection{Responsável técnico}

Compreende a avaliação da disponibilidade, formação, papel e remuneração do responsável técnico pela farmácia ou drogaria.

\subsection{Equipe técnica}

Compreende a avaliação das condições de formação, papel e remuneração dos demais componentes da equipe técnica da farmácia ou drogaria.

\subsection{Normas e Procedimentos}

Compreende a avaliação da existência - não existência e da utilização - não utilização de normas e procedimentos para as seguintes atividades: limpeza, armazenamento, descarte de materiais, dispensação, aplicação de injetáveis, nebulização, curativos, 
aferição de pressão arterial, determinação de glicemia, consulta farmacêutica, registro de informações de pacientes, notificação de reações adversas e contato com prescritores.

\subsection{Registros dos pacientes}

Compreende a avaliação da realização - não realização de registros dos procedimentos realizados junto aos pacientes.

\subsection{Material de pesquisa e atualização}

Compreende a avaliação da disponibilidade - não disponibilidade de materiais de pesquisa como livros, periódicos e acesso à Web.

\subsection{Dinâmica de atendimento}

Compreende a avaliação do volume e tipo de atendimento em relação ao farmacêutico e demais membros da equipe técnica.

\subsection{Responsabilidade ambiental}

Compreende a avaliação do cumprimento - não cumprimento de boas práticas de descarte de resíduos sanitários produzidos pela farmácia ou drogaria.

\section{Atividades}

As atividades, também denominadas processos, são os espaços em que se dá a interação entre os profissionais da farmácia ou drogaria e os pacientes e entre os profissionais da farmácia e os prescritores, cujo objetivo é alterar, de forma positiva, a condição de saúde dos pacientes.

\subsection{Dispensação de medicamentos}

Compreende a avaliação das condições em que se dá a dispensação de medicamentos para os pacientes.

\subsection{Aplicação de injetạveis}

Compreende a avaliação das condições em que se dá a aplicação de medicamentos para os pacientes.

\subsection{Realização de curativos}

Compreende a avaliação das condições em que se dá a realização de curativos para os pacientes.

\subsection{Realização de nebulização}

Compreende a avaliação das condições em que se dá a realização de nebulização para os pacientes. 


\subsection{Realização de controle de parâmetros bioquímicos e fisiológicos}

Compreende a avaliação das condições em que se dá a realização de parâmetros bioquímicos e fisiológicos, como a aferição de pressão arterial, aferição de temperatura e determinação da glicemia.

\subsection{Acompanhamento terapêutico}

Compreende a avaliação das condições em que se dá o acompanhamento terapêutico do paciente.

\subsection{Relacionamento com prescritores}

Compreende a avaliação das condições em que dá o contato dos profissionais da farmácia com prescritores de outros serviços de saúde, em especial, médicos e dentistas.

\subsection{Comunicação e Marketing}

Compreende a avaliação da forma de comunicação da farmácia com os pacientes, considerando a confecção de folhetos explicativos, a utilização de cartazes nos ambientes interno e externo à farmácia, a disposição de medicamentos em gôndolas de livre acesso, o comércio de produtos não medicamentosos sem finalidade terapêutica e a prestação de serviços caracterizados como não sanitários, como 0 pagamento de contas e taxas públicas.

\section{Resultados}

Os resultados das atividades desenvolvidas por farmácias e drogarias, assim como os resultados elementares a qualquer serviço de saúde, dizem respeito à produção de alterações nas condições de saúde de um paciente.

\subsection{Aderência terapêutica}

Compreende a avaliação de parâmetros de aderência de pacientes às prescrições dispensadas pela farmácia.

\subsection{Farmacovigilância}

Compreende a avaliação da identificação - não identificação e notificação - não notificação de reações adversas a medicamentos.

\subsection{Resultados em grupos de pacientes específicos}

Compreende a avaliação do controle - não controle de parâmetros fisiológicos e bioquímicos de grupos de pacientes específicos, em particular o grupo de pacientes hipertensos e o grupo de pacientes diabéticos. 


\subsection{Satisfação de pacientes}

Compreende a avaliação da satisfação - não satisfação dos pacientes com o serviço desenvolvido, considerando os seguintes critérios: aceitabilidade, relação profissionais de saúde - paciente, cumprimento de expectativas, conforto e custos.

\subsection{Ações de promoção da saúde}

Compreende a avaliação da realização de ações de promoção de saúde, como campanhas com foco em doenças crônico-degenerativas, imunização, alimentação, atividades físicas, tabagismo e automedicação. 


\section{Faculdade de Saúde Pública da Universidade de São Paulo}

\section{Departamento de Prática de Saúde Pública - Administração Hospitalar \\ Projeto de Pesquisa para Doutorado em Saúde Pública \\ Acreditação de Farmácias: a construção de um modelo}

\section{Convite aos Especialistas}

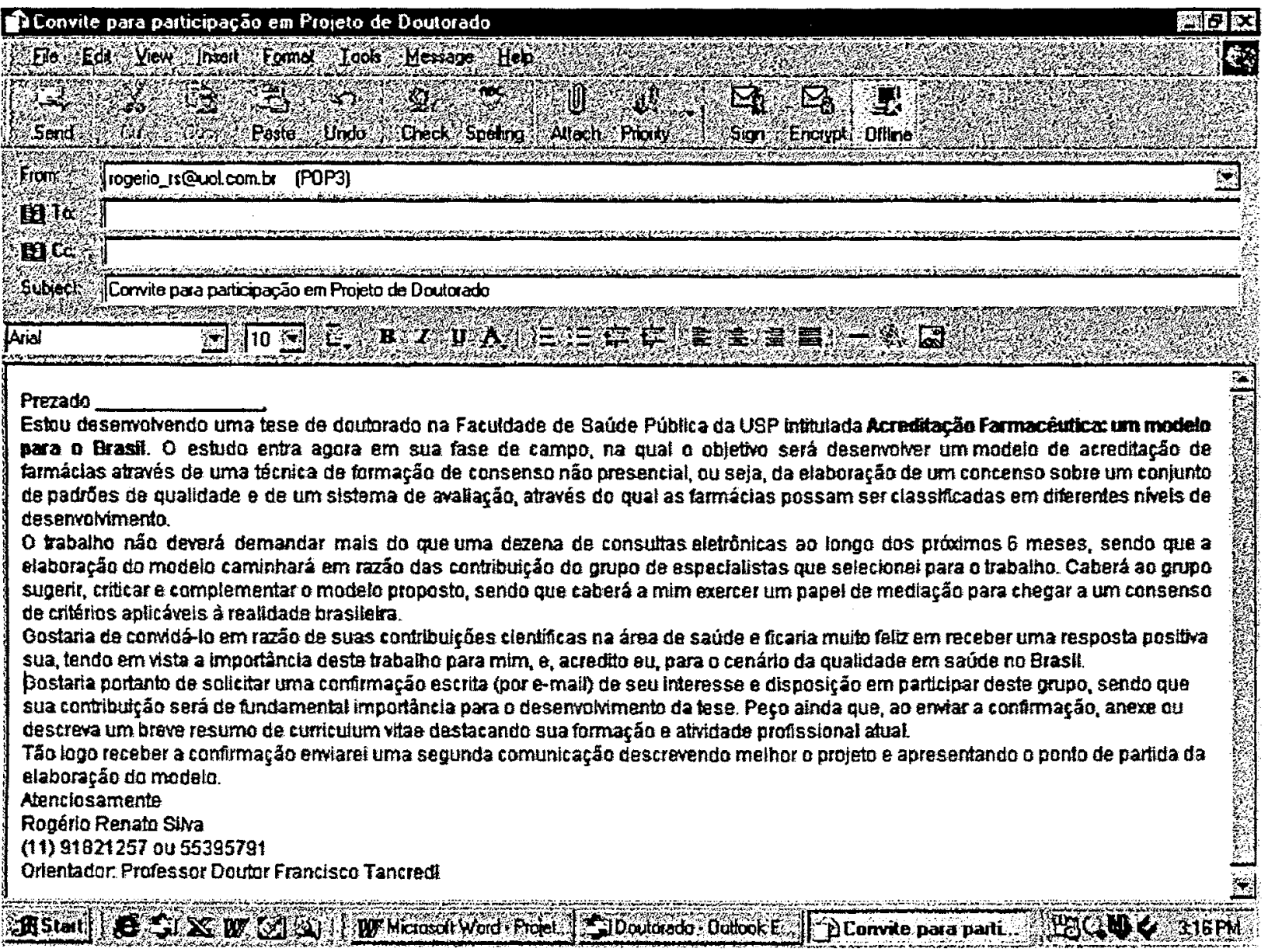

